Volker Wittke and Heidemarie Hanekop (Eds.)

New Forms of Collaborative Innovation and Production on the Internet

An Interdisciplinary Perspective
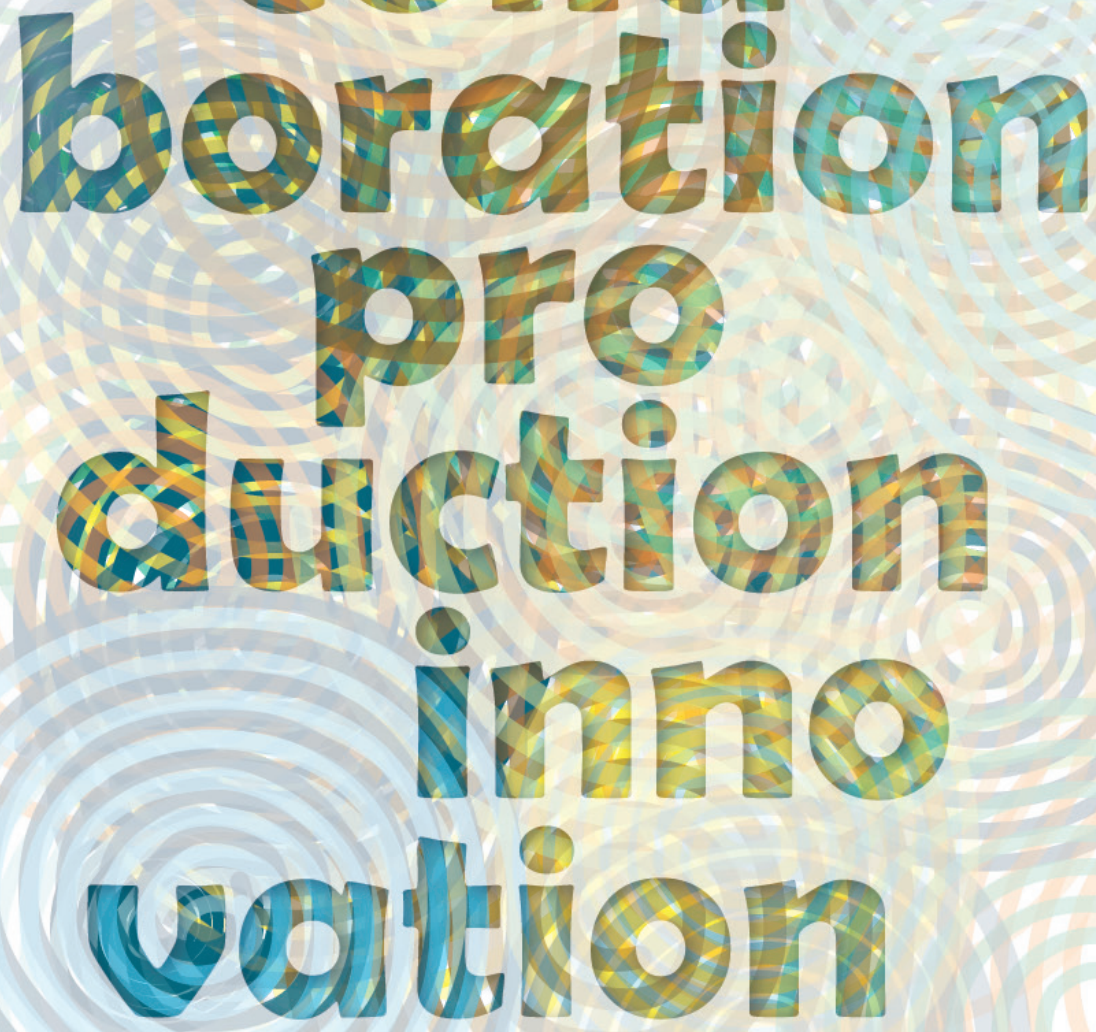

Volker Wittke, Heidemarie Hanekop (Eds.)

New Forms of Collaborative Innovation and Production on the Internet

This work is licensed under the Creative Commons License 3.0 "by-nd", allowing you to download, distribute and print the document in a few copies for private or educational use, given that the document stays unchanged and the creator is mentioned.

You are not allowed to sell printed copies of the free version.

$$
\text { (c) }
$$

SORIERIGHISRESERVED 
erschienen im Universitätsverlag Göttingen 2011 
Volker Wittke and

Heidemarie Hanekop (Eds.)

New Forms of

Collaborative Innovation and Production on the Internet

An Interdisciplinary Perspective

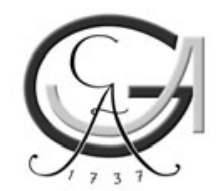

Universitätsverlag Göttingen 2011 


\section{Bibliographische Information der Deutschen Nationalbibliothek}

Die Deutsche Nationalbibliothek verzeichnet diese Publikation in der Deutschen Nationalbibliographie; detaillierte bibliographische Daten sind im Internet über $<$ http://dnb.ddb.de $>$ abrufbar.

\section{Address of the Editors}

Soziologisches Forschungsinstitut an der Universität Göttingen

Friedländer Weg 31

D-37085 Göttingen

heidi.hanekop@sofi.uni-goettingen.de

volker.wittke@sofi.uni-goettingen.de

This work is protected by German Intellectual Property Right Law.

It is also available as an Open Access version through the publisher's homepage and the Online Catalogue of the State and University Library of Goettingen

(http://www.sub.uni-goettingen.de). Users of the free online version are invited to read, download and distribute it. Users may also print a small number for educational or private use. However they may not sell print versions of the online book.

Satz und Layout: Jan Mielenhausen

Umschlaggestaltung: Margo Bargheer

(C) 2011 Universitätsverlag Göttingen http:/ / univerlag.uni-goettingen.de ISBN: 978-3-86395-020-0 


\section{Acknowledgements}

The origin of this book was a workshop on "New Forms of Collaborative Production and Innovation: Economic, Social, Legal and Technical Characteristics and Conditions" that was held in May 2010 at the Lichtenberg-Kolleg Institute for Advanced Studies at the University of Göttingen. The goal of the workshop was to provide an interdisciplinary perspective on the new innovation and production processes on the Internet, which are characterized by voluntary collaboration among numerous users and co-producers. The workshop was prepared and organized by a group of researchers at the University of Göttingen from the disciplines of multimedia law, sociology, economic policy, political science, computer science, microeconomics, e-business studies and international economic law. We are greatly indebted to Gerald Spindler, Kilian Bizer, Andreas Busch, Dieter Hogrefe, Claudia Keser, Matthias Schumann, and Peter-Tobias Stoll, who were deeply involved in the fruitful interdisciplinary cooperation and who helped to organize and contributed to the workshop without which the book would not have been written. We also appreciate the contributions of the speakers, many of whom are authors in this volume. The lively and inspiring discussion at the workshop has been very helpful, and the book chapters benefited from this input. We want to thank the Lichtenberg Kolleg for financing and hosting the workshop. We are most grateful to the director, Dagmar Coester-Waltjen for generous support and to Dominik Hünniger for professionell and friendly assistance in organizing the workshop. Thanks also go to Elizabeth Crawford for translation and revision and to Jan Mielenhausen for technical and organisational support. 



\section{Contents}

\section{Introduction}

1 New Forms of Collaborative Innovation and Production on the Internet

Volker Wittke and Heidemarie Hanekop

\section{Interdisciplinary Perspectives on Collaborative Innovation and Production: Conceptual Debates}

2 Customer Co-Creation: Open Innovation with Customers

Frank Piller, Christoph Ibl and Alexander Vossen

3 Governing Social Production

Niva Elkin-Koren

4 Trust Management in Online Communities Audun Josang

5 Building a Reputation System for Wikipedia

Christian Damsgaard Jensen

6 Cooperation in Wikipedia from a Network Perspective Christian Stegbauer

Firm Driven Collaborative Innovation and Production:

Case Studies

7 Managing a New Consumer Culture: "Working Consumers" in Web 2.0 as a Source of Corporate Feedback

Sabine Hornung, Frank Kleemann and G. Günter Voß

8 Prosuming, or when Customers Turn Collaborators:

Coordination and Motivation of Customer Contribution

Birgit Blättel-Mink, Raphael Mener, Dirk Dalichau, Daniel Kabnert

9 Role Confusion in Open Innovation Intermediary Arenas

Tobias Fredberg, Maria Elmquist, Susanne Ollila, Anna Yström 



\title{
New Forms of Collaborative Innovation and Production on the Internet
}

\author{
Volker Wittke and Heidemarie Hanekop
}

\section{Large-Scale Collaboration on the Internet: The Intriguing Phenomenon}

Enabled by Internet and Web 2.0 technologies, a growing number of products and services are being developed with large numbers of autonomous actors participating in the production process. The participating actors, many of whom are themselves users of the products they co-produce, make their contributions voluntarily, without contract or salary, and are free to decide which tasks to undertake. The organization of co-production is highly decentralized and collaboration is undertaken on a large scale. Although the contributors are autonomous and their activities are decentralized, they produce complex, sophisticated and competitive products and services, employing an elaborate division of labor in a highly efficient process. Many scholars take these phenomena as evidence for the emergence of new forms of production and innovation (Chesbrough, Vanhaverbeke and West 2006, von Hippel 2005, Tapscott 2006, Benkler 2002 and 2006, Weber 2004). The key distinguishing feature of these new forms of production and innovation is the governance mechanism that coordinates the contributions of numerous actors. Collaboration among co-producers is coordinated neither by markets nor by hierarchies. Evidently, the governance of collaborative production and innovation does not 
follow traditional mechanisms of market exchange. Contributions are made without recompense, and goods and services produced in joint efforts are freely accessible as public goods on the Internet (Bessen 2005). Nor does the way in which actors organize their contributions correspond to the hierarchical, planned production and assignment of tasks within firms.

The earliest, best-known and most studied examples of these new forms of production are open source software development and Wikipedia. Today, however, there is a much broader spectrum of collaboratively developed products and services. The wide variety of cases of collaborative production includes products and services such as YouTube, Spreadshirt, Crytec, Lego factory and MyParfuem as well as Facebook and other social networks. A closer look reveals considerable differences between these cases of collaborative production, in particular with respect to the roles that firms play. Generally speaking, collaborative production works without the participation of firms, as in the pure cases of Wikipedia and many OSS projects, which are the predominant sources of evidence for new forms production and innovation. But collaborative production also works when firms are involved (Reichwald and Piller 2006). In these cases firm-driven production and innovation processes are open to contributions from external actors, although the degree of openness to external participation varies significantly. In some cases, such as YouTube, social networks and other media platforms, the content is created entirely by external actors, while firms provide the platform, infrastructure or services. In other cases, firms open only some tasks to external actors, who are often users of the same products. Such tasks typically include product feedback, tests, design, or product development and innovations. In such firm-driven forms of collaborative production the governance is hybrid: value creation by firms is coordinated by markets and/or hierarchies, while the collaboration of external actors who are not members of the firms is governed by these actors' online community (West, J. and S. O'Mahony 2008).

Empirical case studies of OSS and Wikipedia have shown how collaborative production with large numbers of actors can work (Gosh 2002, O’Mahony 2006, Weber 2004, Pentzold 2007, Scacchi 2006, Prasarnphanich and Wagner 2008). Explanations of basic cooperation patterns and governance mechanisms are offered by approaches such as "commons-based peer production" (Benkler 2002 and 2006) and "community-managed" governance e.g. of OSS projects (O'Mahony 2006, 2007), alongside more sociological explanations based on social network theories and the emergence of a specific social order of production communities (Gläser 2007, Stegbauer 2009 and chapter 6 in this volume).

However, it is not yet clear whether these explanations apply to other cases, in particular to those in which firms play an important or even dominant role. On the one hand, firms are eager to involve large numbers of external actors whose willingness to contribute is stimulated by their own intrinsic motives and the success of collective action. This is because firms are considering the advantages of inte- 
grating external actors and customers, and the new business models of open innovation and customer co-creation (see also chapter 2 in this volume) are increasingly pushing firms to involve externals. On the other hand, production and business models of firms basically rely on hierarchical and market coordination. Therefore for firms, it is questionable whether it makes sense to adapt coordination mechanisms from the "pure" collaborative projects (i.e. Wikipedia and OSS). And if the adaptation seems advantageous, further questions arise about the impact on firm's business strategies and production models. How does the insertion of elements of collaborative production and innovation work, and how does it affect firm's established strategies and practices? The interpenetration of different forms of production is less understood than the "pure cases", although it is gaining importance.

In our introduction to this book, which is based on an interdisciplinary workshop in Göttingen in 2010, we aim to specify the challenges that collaborative production and innovation provide for the further interdisciplinary research. We will argue in three steps to emphasize the issues that we think are critical to understand the new phenomenon of large-scale collaboration and its varieties. We start with the less controversial issue and end up with the less analyzed and more controversial. The first question is about the motivation of actors. What motivates large numbers of autonomous actors to voluntarily contribute to the development of products and services, and is it possible to foster sustained motivation for external actors to voluntarily contribute to this development? It has received great attention in the scholarly debate, and a large body of literature exists. The second issue is about the governance of collaborative production. How can autonomous, highly decentralized activities of large numbers of actors be coordinated and integrated into the highly divided production of sophisticated products and services? The critical point here is that collaborative production is a new kind of collective action that is socially embedded in Internet communities. The specifics of this social embeddedness have received less attention in the debate. The third issue, finally, is about firm-driven collaborative models of production and innovation. The critical question here is how can collective action of autonomous actors be successfully combined with the value-creation activities of companies? This is a controversial issue in the current debate.

This is also reflected in the following chapters of this volume, four of which specifically address firm-driven collaborative production and innovation models. There is a wide range of examples in which collaborative production intertwines with company activities. Still, the relationship between the companies involved and the external actors and their community is rife with conflicts and demands, which is another point addressed in various chapters of this book. In the following three sections we will take a closer look at each of these three questions. In the final section of this introduction we give an overview of the subsequent chapters in the volume, where these questions are also referred to. 


\section{Why Do Autonomous Actors Participate in Collaborative Production and Innovation?}

New forms of collaborative production and innovation are based on voluntary and uncompensated participation of autonomous actors rather than on contracts. The specifics of participation differ fundamentally from the way employees participate in intra-firm production or innovation processes, even when the external actors take on tasks that previously had been handled by employees (Voss and Rieder 2005). Autonomous actors that contribute to collaborative production processes are outside companies' hierarchies, and they are not subject to their instructions or assignment of tasks, nor are they under any obligation to perform or provide a particular service. In fact it is assumed to be unlikely that they would voluntarily subject themselves to hierarchical controls or central coordination. Rather, the actors themselves choose what contribution to make, based on their own interests and intrinsic motives (Lakhani and Wolf 2005).

Contributions to collaborative production processes are not driven by market exchange either. Usually the products created from the voluntary contributions of external actors are public goods, available free of charge over the Web, rather than commodities. Contributions to the production of these products are not stimulated by financial rewards, neither by sharing of product sales, nor by direct payments for the underlying work or reciprocal contributions by others.

In new forms of collaborative production, in cases such as Wikipedia, open source software, YouTube, and social media, large numbers of actors are involved. Thus voluntary contributions here are not on a small scale, nor sporadic or exceptional, but on a very large scale, systematic, and with lasting returns. Moreover, they produce core components of highly knowledge-intensive products that originate in sophisticated, innovative and creative activities of professional quality. The fact that products compete successfully with products from leading commercial firms is emphasizing the high professional standard of the volunteers.

But who are these actors and why do they make voluntary contributions? As empirical studies show, motives include fun, gratification, self-fulfillment, an interest in the specific issue or activity, and the enhancement of knowledge and abilities (Ghosh and Glott 2002, Glott et. al. 2010, Lakhany and Wolf 2005, Bitzer, Schrettl and Schröder 2007). Such motives are most likely to be answered by creative, innovative and challenging activities; in other words, tasks with these characteristics are most likely to stimulate contributions of this kind. If the aim is to attract as many participants as possible and gain a large number of contributions, providing a wide selection of possible activities would be an advantage, especially as the interests and abilities of the contributors are quite heterogeneous. 
Furthermore, as Benkler notes (Benkler 2006:8), it is the Internet that has enabled individuals to do more for and by themselves ${ }^{1}$. The means of production required for innovations and knowledge-based production processes (computers, Internet access, software) are widely available today. Many tasks that formerly required a lot of cost-intensive equipment - generally only available within companies - can now be carried out easily by individuals thanks to the Internet and inexpensive information technology. As a result, distributed production and extensive division of labor are no longer restricted to bureaucratic organizations.

In many cases, independent producers are simultaneously users of the products and vice versa. Open source software production is a typical and frequently cited example. Here, the initiators and main producers are generally developers who feel the need of a particular software product that does not yet exist, or to which they have no access (Raymond 1998, Weber 2004). They first develop an idea for a product, and then begin with the initial programming steps. If other developers find the idea useful, a project emerges and eventually leads to a software product that is available free of charge; one that specifically targets the need of the users, who are simultaneously the producers. Eric von Hippel has generalized this model of "user-centered" or "user-driven" innovation and production processes (von Hippel 2005). He argues that users' roles are unique because they "expect to benefit from using a product or service, while manufacturers, by contrast, expect to benefit from selling it" (von Hippel 2005:3). Users are thus to a certain extent the "better", more competent product developers because they know from their own experience exactly what features the product should have. Returning to our initial question as to why these external actors are voluntarily involved in production, in these cases the answer is: Because they want to use the products. Von Hippel expands this argument further by pointing out that mass products do not satisfy individual needs. Their manufacturers, he states, "tend to follow a strategy of developing products that are designed to meet the needs of a large market segment. But users' needs for products are highly heterogeneous in many fields" (von Hippel 2005: 5). That is why users often do not get exactly what they want and, according to von Hippel, why they are so willing to develop, modify or otherwise customize products for their own use. In this respect the active participation in the manufacture of products can be seen as rational, purposeful behavior on the part of these actors. According to this view, the incentive for participation is that users want a certain product that serves their individual needs, and their specific competence to make such contributions is based on their knowledge of the required

\footnotetext{
${ }^{1}$ Benkler 2006, p 6: "The networked information economy improves the practical capacities of individuals along three dimensions: (1) it improves their capacity to do more for and by themselves; (2) it enhances their capacity to do more in loose commonality with others, without being constrained to organize their relationship through a price system or in traditional hierarchical models of social and economic organization; and (3) it improves the capacity of individuals to do more in formal organizations that operate outside the market sphere."
} 
product features ("stickiness of need information;" this topic is dealt with in detail in chapter 2).

However, in all these cases co-producers work for the benefit of others. The products are for direct use (as opposed to production for the market), not only by the producers, but are also intended for the use of others. Unlike the typical "do-ityourself" cases, these goods are produced and used by large numbers of people (Hanekop/ Wittke 2010). Just as single contributions to knowledge-intensive digital goods typically are not made toward one's own use, but for the use of others, the converse applies as well: Meeting one's own needs is at most only a partial incentive for contributing. Thus even when one wishes to use a particular product, the question of why one should contribute remains unanswered. In point of fact, in widely-observed projects such as open source software development or in Wikipedia it is evident that most users make only small contributions or none at all, while just a few users create large portions of the product (Hanekop/ Wittke 2008). Since individuals are making contributions for others without ensuring that they will gain any reciprocal benefit from corresponding contributions made by those others, rational benefit calculations apparently cannot satisfactorily explain the motive for action. Efficient collective action and steadily growing products seem to be necessary to stimulate these contributions. But how are these collective action problems solved? And how can the activities of so many autonomous actors be coordinated so that large-scale, sophisticated, competitive products are created? Production models that are based on voluntary contributions from autonomous actors must mobilize individual interests, and at the same time promote collective behaviors and enable coordination of highly divided work processes without hierarchical planning and control.

\section{Collective Action by Large Numbers of Actors in Highly Distributed Production}

While the autonomous actors participating in the production of Wikipedia, the development of open source software, in user-generated media, or in social networks are pursuing their own interests, their actions are embedded in a process of collective action. Large numbers of contributors are successfully integrated in global, highly divided production and innovation processes. Weak ties and a broad base of participants facilitate highly efficient production and innovation processes. This new way of organizing production includes self-selected individual action as part of collective self-organization - this is what we call collaborative production. But what kinds of mechanisms are used to coordinate these activities? How are these activities embedded and governed by the community?

As a starting point for the discussion we would like to refer to Ostrom's influential work on "Governing the Commons" (Ostrom 1990). This reference can clarify similarities as well as differences of the way in which collective action prob- 
lems are solved. Very much in line with Ostrom's argument, one could assume collaborative production as a form of collective self-organization. Ostrom's examples 3 the sustainable preservation of common pool resources? [leal with a specific kind of collective self-organization and a specific way in which self-organization is enabled. Although common pool resources can be better managed through collective action, opportunistic behavior and free riding are common problems threatening the sustainability of these resources. In the communities studied by Ostrom, these problems are solved and the commons are governed by institutionalizing rules and norms for sustainable use of resources, to restrict individual overuse of the limited natural resources and define obligations for preserving and regenerating collective resources (Ostrom 1990). It is essential that the ensuing usage rights and obligations are to be accepted by and applied equally to all members. Collective self-organization is possible, as Ostrom argues, when rules for governance of the commons are institutionalized and collective self-control and sanctions ensure that these rules are followed. Mechanisms of social control are based on the fact that physical proximity, personal relationships and shared everyday experience make the behavior of community members transparent for the others, and thus controllable. Institutionalized rules can also curtail opportunistic behavior and free riding.

But collective action on the Internet also differs from collective action as studied by Ostrom. Ostrom analyzed natural common pool resources, where the main problem is to avoid overuse and to preserve the commons. By contrast, digital information products are non-rival goods. There is no problem of over-usage and no need to restrict the use of the (digital) products. The potential for use by those who actively participate in production is not reduced through use by noncontributors. Large groups of users are not a disadvantage with digital goods, but an advantage due to network effects.

However, the products or services must first be collectively produced before they can be used. Thus the collective action aims not at governing the commons, but at producing the commons. The collective action problem here is that people can use it without any contribution in reverse, but these public goods are not feasible without any producer.

In spite of the difference of the collective action problem, there are similarities in the way in which this problem can be solved by the social embeddedness of actors. As Ostrom argues, action necessary to preserve common pool resources is ensured by socially constituted rules and norms. New forms of collaborative production and innovation on the Internet, as has been argued frequently, rely on shared goals, norms and institutionalized rules of behavior, too. (Benkler 2002 and 2006, Gläser 2007, Pentzold 2010, Reagle 2010). These goals, norms and rules are accepted within the communities. Shared goals are mainly related to the product, its usefulness, design and functionality. A shared vision of the product (which Lepsius 1995 calls "Leitidee") stimulates people to invest time and collective effort. In 
the case of open source software, the goal is to develop free and open software and in many cases to provide an alternative to Microsoft; or with Wikipedia, to create a free encyclopedia that makes the world's knowledge available to all.

Rules and guidelines for participation that correspond to the goals and behavioral norms of the community are defined and institutionalized within the collaborative processes. Such norms also include that behavior has to be fair and participants have to take care of each other. Furthermore, decision rules have to be meritocratic. Finally, the openness of products and contributions on web platforms makes the collaboration process transparent for everybody, enables selfcoordination by the contributors and social self-control of adherence to those rules and norms by the community. Shared goals, norms and institutionalized rules can be seen as common principles of collective action in both cases - Ostrom's common pool resources as well as collaborative production on the Internet.

However, Internet communities are not of the same breed as communities governing the commons or embedding other forms of economic action (Granovetter 1985; Powell 1990; Hollingsworth/Boyer 1997). Traditionally, communities are based on long-term relationships of a comparatively small number of members with strong ties of relationship and personal trust. The emergence of common goals and the establishing of norms and rules are typically based on physical proximity that allows for co-presence of action and face-to-face interaction. Noncompliance with norms, rules and obligations is strictly sanctioned. Furthermore, conventional communities establish defined obligations and strong norms of reciprocity within the boundaries of a defined membership. Access to and use of collective goods is restricted to members of the community only.

In this, Internet communities differ basically from conventional communities (Brint 2001, Gläser 2007b). Here, short term or often one time contacts, weak ties, the absence of proximity, face-to-face co-presence and defined memberships with clear external boundaries are characteristic for collaborative production communities on the Internet. These are large, globally distributed communities without defined rights and obligations of members. Anyone can participate, but no-one is obligated to do so - contributions are indeed voluntary. Finally, social control is hard to imagine with large numbers of frequently changing actors. In such volatile, globally distributed Internet communities the production of the commons must operate without all these conventional means of social embeddedness.

The question therefore is, how producing the commons can be ensured. Benkler (Benkler 2006) and many others (e.g. Raymond 1999, von Hippel 2005, Weber 2004, Gläser 2007, Tapscott 2006, Pentzold 2007, Osterloh and Rota 2007) argue that the Internet offers radically new options for collective production and innovation. The economic effects of the digital "networked information economy" enable the spread of non-market production, a broad culture of "sharing" and the involvement of very large numbers of contributors (Benkler 2006:29, see also above). The Internet facilitates necessary collective action and makes it much easier 
to produce common goods in a joint effort. New opportunities for collective action grow out of the fact that "the networked environment makes possible a new modality of organizing production: radically decentralized, collaborative, and nonproprietary; based on sharing resources and outputs among widely distributed, loosely connected individuals who cooperate with each other without relying on either market signals or managerial commands. This is what I call 'commons-based peer production'." (Benkler 2006:60). And a broad base of participants facilitate highly efficient production and innovation processes. Previous limitations on largescale collective action are eliminated and the means of production (PC + Internet access) are widely available. Furthermore, the specifics of the products developed collaboratively on the Internet allow a very high and global division of tasks due to a very granular task structure, the aggregation of many small-scale contributions and easy-to-change product releases (Weber 2004, Raymond 1999).

The openness and transparency of the product is a central prerequisite for the ability of these actors to self-coordinate their actions. They integrate their contributions in a common product, by "mutual adjustment of individual actions. OSS communities solve this problem by mediated adjustment, that is, by all producers adjusting to the common subject matter of work, which they observe and from which they derive their tasks. ... Thus, the shared subject matter of work mediates the adjustment of producers' actions by providing them with a common point of reference" (Gläser 2007:171). Transparency of the product and the rules for contributing are implemented on web platforms, as well as in collaboration tools such as Wikis or CMS, that provide a workspace in which numerous, widely distributed actors can coordinate their tasks as if they were watching each other work. While all information relevant for participation is available to everyone at any time on the Web, cooperation and self-coordination among actors is possible without physical proximity and without the actors knowing one another personally.

The shared Internet workspace not only offers enhanced options for ubiquitous interaction and virtual co-presence of the participants; transparent rules and standardized routines of participation also facilitate frequent changes of participants. It is not necessary to rely on a stable community in order to progress in collaborative work. By contrast, capable Internet communities can evolve even if the volatility of contributors is high and direct personal relations are lacking. Although such communities create only weak ties they can ensure a steady flow of contributions. The lack of obligations can be compensated by a large base of motivated users and co-producers who can join collaboration easily. The possibilities of compensation are facilitated by the specifics of the workspace. This can explain why weakly tied communities can ensure producing the commons. However, how can it be explained that some participants contribute substantially more than others?

The starting point might be once again the transparency of the collaborative production process itself. Transparency not only allows for self-coordination but also for easy monitoring of the contributions of others. Thus, differences in scale 
and relevance of contributions are widely visible inside the community. Based on this visibility a social structure can emerge in the process of ongoing collaboration and interaction that defines roles and positions within communities. Stegbauer describes this emerging social structure in Wikipedia (chapter 6 in this volume and Stegbauer 2009). The same process is described for open source projects (O’Mahony 2006, Scacchi 2006, Gläser 2007, Weber 2004). Roles and positions within collaborative production communities on the Internet are primarily based on contributions. They differ heavily between core contributors or even leaders on the one side and occasional - frequently anonymous - contributors on the other side (Hanekop/Wittke 2008). Core contributors attain several non-monetary rewards, such reputation, influential positions and influence on decisions. Individual actions and motives in such communities are socially embedded and shaped by the positions, roles and relationships in the social order of the network. Membership is not formalized, but based on the commitment to the community by contribution. The volatility of membership is compensated by the openness of those communities and the large number of users and contributors. Trust and reputation are important mechanisms within Internet communities, too, though not based on personal face-to-face relations. Recognition of one's own work by peers, reputation, and positions in the social order of the community are organized by web applications. IT-based trust and reputation systems facilitate trust building even without personal relationships or face-to-face contact (see chapter 4).

The answer to the question of how "production of the commons" can work without reciprocal obligations and strong ties therefore is multidimensional. First, contributions can be easily made and in many cases it is fun to do. As there are many contributors, tasks are distributed over many shoulders. Second, the high volatility of contributors can be compensated by the large base of potential contributors, the openness of those communities and the attractiveness of the shard goals. Third, collective action is embedded in a social structure that evolves in the process of collaboration and interaction. The social structure is established in spite of weak ties, where the core contributors can expect non-monetary rewards, influential positions and reputation within the community. It-based applications facilitate the emergence of such a social structure.

However, social embeddedness and ease of collective production through the Internet works well, if there is a critical mass of the product and of actors that participate. As the number of participants grows, so does the probability that the product will be successfully created and continuously improved. Thus the success of collective action stimulates more contributions, in particular during phases of rapid dynamic diffusion and after a critical mass of the product and number of participants is reached. The growing number of participants also strengthens the expectation that one's own needs will be met.

This explains how the specific collective action problem of "producing the commons" can be solved when there already is a usable common good. However, 
before this critical point is reached, it is doubtful whether a usable product will ever be produced. Looking at the large number of projects started (see the OSS projects registered with SourceForge), it is striking how few attain a critical mass. If the project fails, the efforts that were invested in it will have been in vain. In its initial stages, the new product is often no more than a vision. If the critical mass is not reached, it remains in a rudimentary state, because the product idea did not spark sufficient interest. In short, collective action problems on the Internet are typically problems of producing a critical mass of the product (Cominoa, Manenti and Parisi 2007). However, the issue of how to gain critical mass is still underresearched. Very little is known about the factors that are decisive for the initial and sufficiently sustaining attraction of participants by successful projects in contrast to others. In order to discuss the perspective of a further diffusion of collaborative production and innovation seriously this knowledge gap has to be addressed.

In this context it might be of interest to look at new ways of mixing selforganized collaborative production with firm-based activities. Firms may provide, for instance, critical infrastructure that enable collaborative production of autonomous co-producers. YouTube and most of the social networks are such cases in which companies operate infrastructure platforms. While operating a web platform is less complex than building a factory, large collaborative projects do require large global infrastructures, which often is expensive and difficult to organize (as seen in Wikimedia). Therefore, firms may play a critical role in particular for the emergence of forms of collaborative production that need complex and costly platforms. However, although firms can afford to continue providing an expensive infrastructure even if it is under-utilized, providing an enabling infrastructure is no guarantee for its usage by voluntary co-producers.

\section{Collaborative Production and Value Creation by Firms}

Collaborative production is possible with and without companies, as the wide range of successful cases from Wikipedia and open source software to YouTube and Facebook, Spreadshirt and Crytec (see chapter 8) shows. In the previous sections we discussed how autonomous actors work together without firms, making voluntary contributions to the development of large public goods. In this final section we look at constellations with companies. As has been argued frequently, firms are interested in integrating external actors into production and innovation processes for many reasons (von Hippel 2005; Reichwald and Piller 2006; Voß and Rieder 2006; Hanekop and Wittke 2010). The critical question here is how are firms able to attract voluntary contributions from a large number of external actors. Or to put it in our line of argumentation more specifically: Can collaborative production mechanisms as we have described above be made consistent with firms' value creation strategies? This question calls for further research. In the 
following we start with the discussion of these questions, while the subsequent chapters in this book address various aspects in more detail.

As a starting point we will address the most likely inconsistencies between firms business models as well as their production and innovation strategies on the one hand and mechanisms of collaborative production as described in the previous section on the other hand. (1) Value creation strategies might conflict with the provision of public goods. (2) Firm-driven hierarchically organized production strategies might conflict with the principles of autonomously defined tasks. And (3) firms strategies to control production and innovation processes might conflict with the principles of community-based collective self-organization.

First, there are good reasons for external actors to expect that their contributions are freely available for the use of others even if they collaborate within firmdriven constellations. As voluntary co-producers they intend their contributions to be used without restrictions by others within the community and not for the profit of the company. Furthermore, the transparency of the collaborative product, which is necessary for collective self-coordination, demands open access to the contributions made by all others. The external actors see themselves as part of a community in which the product is created through collective action. The shared goals that keep the community together are focused on the collective product, and the social structure evolves from contributions. So, without public and open goods, social embedding of the productive activities in a community could fail and uncompensated contributions from large numbers of external actors become unlikely.

Second, interests and motives of external actors may be neglected or suppressed when possible tasks are predetermined and planned by the firm. As autonomous actors voluntary co-producers are used to self-selecting the tasks they address and the contributions they make. They presumably would not wish to follow companies' instructions. However, firms' strategies for organizing production and innovation processes rely at least to some extent on firm-centered planning and predefinition of tasks. If the company does not allow the externals sufficient room to maneuver in implementing their own interests and self-organizing their voluntary activities, the company may find that no voluntary contributions are made.

Third, firms' hierarchically planned production and innovation processes with their inherent rules of decision-making conflict with basic principles of community based collective self-organization. Communities of external actors are the locus of decision in the way we have described collaborative production and innovation. Here, rules for contributions and the basic design of the collaborative product are discussed in the community according to their rules and the structure. Decisions about the selection of contributions must be widely accepted in the community and are strictly observed.

To come back to the question of how firms are able to attract voluntary contributions from a large number of external actors, one possible answer is, by miti- 
gating those inconsistencies. However, as far as conventional business models of firms are assumed, it may be difficult to cope with this challenge (see Chesbrough 2006). And if we look at some of the best known cases of firm-driven collaborative production far-reaching changes in conventional business strategies and production models are made in order to attract voluntary contributions on a large scale. These adjustments can be seen as specific answers to challenges that result from inconsistencies between conventional business strategies on the one hand and the preconditions for collaboration of external actors we described above.

The perhaps most elaborated approach firms follow to combine collaborative production patterns with value creation strategies is to search for new business models and new strategies to co-create value (Chesbrough et al, 2006, Reichwald and Piller 2006, Piller et al. chapter 2). A typical model in the software industry is to create value not by selling (OS-)software, but by offering open-soure-softwarebased services (West 2007, Chesbrough and Appleyard 2007, West and O'Mahony 2008). In the media sector firms typically draw on advertising as a common business model that deal in public or free products. It can easily be combined with the collaborative production of free and open content on a web platform. But, in contrast to the conventional advertising models, the content here is provided by voluntary contributions of external actors (user-generated-content), while the company organizes the infrastructure services. From the perspective of the company this approach requires a (new) strategy. The offered product or service is split into two parts one remains firm-organized, but the other is self-organized by a community of external actors. Although the firms' commercial service provision relies entirely on the contributions of externals, the firm has no control over the communitymanaged part of the production. Therefore risks and uncertainties in this model are high, in particular in its initial stage, when there is no critical mass of content. On the other hand the initial investment of firms may be low, as long as the service is not used on a large-scale.

Furthermore, new forms of intellectual property rights (IPR) are necessary to deal with collectively created products from private acquisition (open source software licenses and Creative Commons licenses; see also chapter 3). Although the protagonists of the new IPRs are not often found in companies, companies have to make use of such regulations when they seek a relationship with external coproducers.

A slightly different strategy for combining commercial value generation with the collaborative production of public goods is to have the companies produce the core product, while external actors - primarily users of the product - collaboratively create additional services. Online recommendation services are an example of this model. The advice given by other users, based on their real experience with the firm's product, constitute a new kind of recommendation service, that cannot be given by the firm. The unique quality of the service relies on the autonomy of externals. So this specific service might better be produced collaboratively by exter- 
nals - from the perspective of both, firms and users. But again, the question of how to gain contributions is still open. And additonally, from the firms' perspective, how to deal with negative assessments and excessive demands of users that are publicly available on the web (see chapter 7).

The fragmentation of the whole production process into one firm-organized part and another part that is (self-) organized by a community of external actors is discussed in the literature as hybrid form of production (von Hippel and von Krogh 2006; Lessing, L. 2008, Harhoff and Mayrhofer 2010). In such hybrid models, firms offer external co-producers those kinds of activities that correspond to their interests. They do this by removing these activities from the company's internal process in order to create the space for the actors' self-organization and collaboration. Examples are also Webplatforms, such as YouTube or other forms of user-generated content, where externals take on creative tasks, in which they experience enjoyment and self-expression, and in which at the same time there is a potential for gaining attention and recognition from others. Companies allow extensive latitude in these areas, since as a rule they are not involved in the production of content, but rather allow it to be created entirely by volunteers. In other cases, too, external actors are offered creative and innovative activities that are fun to do; for example, innovative production ideas, design, feedback, field reports, tests and requests for improvements. There are various possibilities, attractive to both the external actors and the companies. But, the challenge here is, how to design an appropriate division of labor, that attracts a critical mass of contributions.

To attract contributors might be easier in cases in which these actors are at the same time customers of the company, because users of products or services usually are interested in their performance. Motives for voluntary participation thus include possible improvements in the product, which the company may implement based on the feedback and suggestions from users. In conventional customer relationships, the customer can only wait and hope for the company to react, for example to a customer complaint. In the collaborative environment, however, criticism and suggestions are in the public eye. It is no longer a dyadic relationship between the customer and the company; in fact, the situation is different in many aspects (see also chapter 7). On the one hand, public criticism can put the company under pressure to make improvements; on the other, the interaction concerning individual experiences increases the motivation of customers to provide feedback and make suggestions. Each user has access to the information shared by others, and the exchange of knowledge and experience becomes an important impetus for participation by the customer; the public discussion changes the relationship between customer and company.

Those firm-driven strategies of collaborative production and innovation usually means partly to give up control in order to arrange their internal processes in accordance with rules that are accepted by the external actors and the community. 
One model is - as the above-mentioned examples show - to clearly divide tasks and responsibilities between the company and the community. To avoid conflicts and promote the success of such interactions, it is apparently important that roles and the expectations on each side are clearly defined and consistently maintained, to prevent complicated and lengthy negotiation processes and mistrust of the company by the externals. A company that implements decisions that were not accepted in the community would risk a surge in public criticism and a drop in participation by external actors. A widespread expectation on the part of external participants is that important decisions are made transparently and serve the shared goals and values of the community (rather than unilaterally serving the economic interests of the company). Experience has shown that web platforms' "Terms of Use," usually laid out by the platform operator, are a common point of conflict (see chapter 3, the conflicts at Facebook).

To conclude, firm-driven collaborative production and innovation models may work best if firms act as far as possible in accordance with community-based norms and rules. Firms have to give leeway for principles of self-organized collaborative production by autonomous actors. The main direction firms follow in order to avoid inconsistencies between firm-driven strategies and the practices and principles of self-organized collaborative production seems to be the fragmentation of realms. By establishing and respecting a realm for the self-organization of autonomous actors firms can facilitate producing the commons even within a value-creation dominated context. However, so far the number of successful real-life examples of this approach is very limited. This indicates that its hard to define proper lines of fragmentation in order to attract contributions and to be able at the same time to reduce risks and uncertainty to allow value generation by firms. More generally speaking, it is an open question how far the fragmentation approach can help to mitigate the basic inconsistencies between firm driven strategies and selforganized collaborative production. The limited number of real-life cases indicates that so far there is no "golden road" for firm-driven collaborative production and innovation. The question of what are the prospects of collaborative production with firms, therefore is still open. Examining firm-driven collaborative production from various (inter-)disciplinary perspectives is a major focus of this book and an ongoing challenge for further research.

\section{The Structure of this Book}

Large scale collaboration of autonomous actors, collectively producing freely accessible goods, is an intriguing phenomenon for a variety of scientific disciplines. So, in many disciplines new approaches and models are discussed, but are still widely discipline-specific. In order to meet the requirements to further research it seems to be fruitful to apply an interdisciplinary approach to address the scientific challenges posed by the new phenomenon (Lessing 2010). This was the idea be- 
hind the international workshop held in May 2010 at the Lichtenberg Kolleg of Göttingen University which led to this book. The chapters of this book are from the fields of economics, sociology, legal and political sciences and computer sciences. The chapters are organized as follows.

In chapter 2 Frank Piller, Christoph Ihl and Alexander give an overview on the concept of customer co-creation in innovation processes. They present a typology of methods of co-creation along the three dimensions, "degrees of freedom" (customers' autonomy in the task), "degrees of collaboration" among customers (dyadic firm-customer interaction vs. communities) and the "stage of the innovation process" (early vs. late stage). All methods of customer co-creation involves customers actively in a company's innovation process. But companies intending to profit from co-creation need to know which of the different methods are most suited for themselves and how to use these tools best. The authors conclude, that modeling the effect of customer co-creation and the scare resource of "innovative users" could become a fascinating field for future research in economics and strategy.

In chapter 3, entitled 'Governing Social Production,' Niva Elkin-Koren examines the social dimension of content production from a legal perspective, and analyzes the consequences for the governance of content in the social web. While copyright law is primarily designed to regulate the relationships of a single owner with other non-owners and is focused on the sovereignty of the author, social production, by contrast, requires a matrix of relationships between the individual, the facilitating platform and the communities and crowds involved in social production. She claims, that a legal strategy is needed, preserves incentives for social motivation, and protects the community assets so that community members who have already made use of content shared by others can continue to use it. The interdependency between platforms and users, and the fact that social media platforms depend on the enduring livelihood of the community, makes these platforms a good candidate for implementing a "social contract" for collaborative online communities.

Chapters 4 and 5 deal with trust and reputation systems for collaborative production on the Web from the perspective of computer sciences. As trust in onlinecommunities cannot evolve from personal relations, IT-based trust and reputation management systems are implemented as a substitute. Trust management in online communities aims at making trust reasoning more powerful and reliable by collecting, analyzing and disseminating information that is relevant for trust and trustbased decision making. In chapter 4 Audun Jøsang gives an overview of trust management concepts and methods in online communities. He describes semantic aspects of trust as well as principles and methods for building online trust and reputation systems. The problems and challenges for designing and implementing reliable trust and reputation systems are invoked and some potential solutions are 
mentioned. Finally, he articulates a vision for trust management in online communities.

In chapter 5 Christian Damsgaard Jensen analyzes how a reputation system can be built, using Wikipedia as an example. The Wikipedia Recommender System (WRS) helps users determine the credibility of articles based on feedback from other Wikipedia users. A generic architecture for integrating a reputation system into existing legacy systems is developed. Both the generic architecture and the design of the WRS are outlined in the chapter. The author elucidates both the capabilities of such systems and the potential problems involved in their implementation.

In chapter 6 Christian Stegbauer presents a social network approach to explain "the mystery of participation" in Wikipedia. While neither the classic individualistic nor the collectivist approach can explain participation in Wikipedia, he presents an alternative, empirically-based rationale for this participation. Based on an empirical study Stegbauer analyzes the evolution of the positional structure in Wikipedia at the meso level, where positional allocations are negotiated. He demonstrates how social order evolves from the allocation of responsibilities, roles and positions, where positions and roles are formed dynamically during the interaction.

Sabine Hornung, Frank Kleemann and Günter Voß present findings from a sociological study on the "working consumers in Web 2.0" as a source of corporate feedback (chapter 7). Customer feedback on a collaborative web platform leads to far-reaching effects and potential loss of organizational control from a firm's perspective: a new level of communicating and negotiating with consumers is necessary and all domains of the value chain have to be reconceptualized in terms of their role for customer service. If companies disregard these challenges, new risks are entailed in using Web 2.0 for gaining feedback from customers. Further research is needed to understand how to combine organizational control with the new demands of collaborating customers in Web 2.0 constellations - or, as the authors put it, how to "manage the new consumer culture."

In chapter 8 Birgit Blättel-Mink, Raphael Menez, Dirk Dalichau and Daniel Kahnert present case studies on customer co-production, or prosuming. Their main questions are: Why do customers participate and how are these processes coordinated by the firms? The results show a considerable range of motives and forms of coordination. Whether motives are extrinsic or intrinsic in nature apparently depends on the type of co-production involved. With regard to the organizational models the authors identify a range of different strategies: from rationalization, to prosuming as a basic business model, up to interactive value creation between the company and the web community. The authors conclude that collaborative practices provide a rich field for future research. Theoretical approaches are needed that allow for a better understanding of the reciprocity of the relationship between customers and companies. 
In some of the firm-driven collaborative models the collaborating users or customers are employees of the firm. In the case of OSS, the developers are frequently at the same time employees of a firm in which the OSS software is used (Henkel 2008 and Sojer and Henkel 2010). In chapter 9 an open innovation intermediary arena is analyzed by Tobias Fredberg, Maria Elmquist, Susanne Ollila, and Anna Yström. Here, the collaborating actors are employees of a firm that is a partner in the network of the intermedia arena. The authors provide insight into the tensions that these actors experience in their work in the intermediary arena. As they are embedded in two organizational structures, they constantly need to renegotiate their positions both within their firm and in the intermediary arena. Role confusions occur in four dimensions: trust, loyalty, knowledge sharing and career. To enable these actors to bring their full potential into the collaborative process, both the partner firms and the intermediary organization have to deal with these tensions.

\section{References}

Balka, K., Raasch, C. and Herstatt, C. (2010). "How open is Open Source? Software and beyond." In: Creativity and Innovation Management, 19(3), 248-256.

Benkler, Y. (2002). "Coase's Penguin, or Linux and the nature of the firm." In: The Yale Law Journal, 112, 371-446.

Benkler, Y. (2006). The wealth of networks. How social production transforms markets and freedom. New Haven: Yale University Press.

Bessen, J. (2005). Open Source Software: Free provision of complex public goods. Available at SSRN: http://ssrn.com/abstract $=588763$ or doi:10.2139/ssrn.588763.

Bitzer, J., Schrettl, W. and Schröder, P. (2007). "Intrinsic motivation in Open Source Software development.” In: Journal of Comparative Economics, 35(1), $160-$ 169.

Brint, S. (2001). "Gemeinschaft Revisited: A Critique and Reconstruction of the Community Concept”. In: Sociological Theory, 19(1), 1-23.

Bruns, A. (2008). Blogs, Wikipedia, Second Life, and beyond: from production to produsage. New York: Peter Lang Publishing.

Chesbrough, H., Vanhaverbeke, W. and West, J. (2006). Open innovation: Researching a new paradigm. Oxford, Oxford University Press.

Chesbrough, H. and Appleyard, M. (2007). “Open Innovation and Strategy.” In: California Management Review, 50(1), 57-76.

Cominoa, S., Manenti, F. and Parisi, M. L. (2007). "From planning to mature: On the success of open source projects.” In: Research Policy 36, 1575-1586. 
Elkin-Koren, N. (2011). "Tailoring copyright to social production.” In: Theoretical Inquiries in Law, 12.

Frost, I. (2006). Zivilgesellschaftliches Engagement in virtuellen Gemeinschaften? Eine systemwissenschaftliche Analyse des deutschschprachigen Wikipedia-Projektes. München: Herbert Utz Verlag GmbH.

Fueller, J. and von Hippel, E. (2008). "Costless creation of strong brands by user communities: Implications for producer-owned brands." In: MIT Sloan School of Management Working Paper 4718-08. Available at SSRN: http:/ / ssrn.com/abstract $=1275838$.

Gläser, J. (2007). "The social order of Open Source software production.” In: Amant, K. and Still, B.: Handbook of research on open source software: technological, economic and social perspectives.(pp. 168-182). Hershe, PA: Idea Group Inc.

Gläser, J. (2007b). “Gemeinschaft.” In: Benz, A., Lutz, S., Schimank, U., Simonis, G. (ed.): Handbuch Governance. Theoretische Grundlagen und empirische Anwendungsfelder, (pp. 82-92). Wiesbaden: VS-Verlag für Sozialwissenschaften.

Ghosh, R.A. and Glott, R. (2002): Free/Libre and Open Source Software: Survey and Study (FLOSS final report). Merit, Infonomics: Maastricht

Glott, R., Schmidt, P, and Rishab, G. (2010). Wikipedia Survey - Overview of Results. http:/ /www.wikipediastudy.org.( last visited 06.10.2011).

Glott, R. (2010). Making Wikipedia - Results of the 1st Global Wikipedia Survey. Presentation on the Workshop "New Forms of Collaborative Production and Innovation” May 2010, http://www.sofi-goettingen.de/index.php?id=947.

Harhoff, D. and Mayrhofer, P. (2010). "Managing User Communities and Hybrid Innovation Processes: Concepts and Design Implications." In: Organizational Dynamics, 39(2), 137-144.

Hanekop, H. and Wittke, V. (2010): "Kollaboration der Prosumenten. Die vernachlässigte Dimension des Prosuming-Konzepts.“ In: Birgit Blättel-Mink, B., Hellmann, K-U. (eds.): Prosumer Revisited. Zur Aktualität einer Debatte. (pp. 96113). Wiesbaden: VS Verlag für Sozialwissenschaften.

Hanekop, H. and Wittke, V. (2008): „Die neue Rolle der Anwender in internetbasier-ten Innovationsprozessen.“ In: AIS-Studien, 1, H. 1, S. 7-28. (engl. „The Role of Users in Internet-based Innovation Processes“ available at http://www.sofi-goettingen.de/index.php?id=132)

Henkel, J. (2008). Champions of revealing - the role of Open Source developers in commercial firms. Available at SSRN: http://ssrn.com/abstract=946929.

Hollingsworth, J. R. and Boyer, R. (1998). "Coordination of economic actors and social systems of production.” In: Hollingsworth, J. R. and Boyer, R. (ed.): Contemporary capitalism. The embeddedness of institutions. (pp. 1-47). Cambridge University Press. 
Kleemann, F., Voß G. G. and Rieder, K. (2008). "Crowdsourcing und der Arbeitende Konsument." In: Arbeits- und Industriesoziologische Studien 1(1), 29-44.

Kleemann, F., G. G. Voß, Rieder, K. (2008). "Un(der)paid Innovators: The Commercial Utilization of Consumer Work through Crowdsourcing." In: Science, Technology \& Innovation Studies 4(1), 5-26.

O’Mahony, S. (2003). "Guarding the commons. How community managed software projects protect their work." In: Research Policy 32, 1179-1198.

O’Mahony, S. (2006). "Developing community software in a commodity world." In: Fisher, M. S. and Downey, G.: Frontiers of capital: Ethnographic reflections on the New Economy. Durham: Duke University Press.

O'Mahony, S. (2007). "The governance of open source initiatives: what does it mean to be community managed?” In: Journal of Management \& Governance, 11, 139-150.

Reichwald, R. and Piller, F. (2006). Interaktive Wertschöpfung: Open Innovation, Individualisierung und neue Formen der Arbeitsteilung. Wiesbaden, Gabler.

Lakhani, K. R. and Wolf, R.G. (2005). "Why Hackers Do What They Do: Understanding Motivation and Effort in Free/Open Source Software Projects." In: Feller, J., Fitzgerald, Hissam, B.S. and Lakhani, K.: Perspectives on Free and Open Source Software, Cambridge, MA: MIT Press.

Lepsius, R. M. (1995). "Institutionenanalyse und Institutionenpolitik.“ In: Kölner Zeitscbrift für Soziologie und Sorialpsychologie - Sonderheft 35, 392-403.

Lessing, L. (2010). "Foreword". In: Reagle, J. M.: Good faith collaboration: the culture of Wikipedia. Cambridge: MIT Press.

Lessing, L. (2008). Remix. New York: Penguin Press.

Osterloh, M. and S. Rota (2007). "Open source software development - Just another case of collective invention?” In: Research Policy 36, 157-171.

Ostrom, E. (1990): Governing the commons. The evolution of institutions for collective action. Cambridge: Cambridge University Press.

Pentzold, C. (2010). Imagining the Wikipedia community: What do Wikipedia authors mean when they write about their "community"? In: New Media Society published online 6 December 2010.

Pentzold, C. (2007). Wikipedia. Diskussionsraum und Informationsspeicher im neuen Net: München: Reinhard Fischer Verlag.

Prasarnphanich, P. and Wagner, C. (2008). "Creating Critical Mass in Collaboration Systems: Insights from Wikipedia.” In: Second IEEE International Conference on Digital Ecosystems and Technologies (IEEE DEST 2008).

Raymond, E. (1999). The cathedral and the bazaar. Sebastopo, CA:O'Reilly.

Reagle, J. M. (2010). Good faith collaboration: the culture of Wikipedia. Cambridge: MIT Press. 
Tapscott, D. and Williams, A. D. (2006). Wikinomics: How mass collaboration changes everything. New York, Penguin Group.

Stegbauer, C. (2009). Wikipedia: Das Rätsel der Kooperation. Wiesbaden, VS Verlag für Sozialwissenschaften.

Sojer, M. and Henkel, J. (2010). "Code reuse in Open Source Software development: Quantitative evidence, drivers, and impediments.” In: Journal of the Association for Information Systems 11(12), 868-901.

Voß, G.G. and Rieder, K. (2006): Der arbeitende Kunde. Frankfurt/M: Campus Verlag.

Scacchi, W. (2006). "Free/Open Source Software development: Recent research results and methods." In: Advances in Computers 69, 243-269.

Von Hippel, E. (2005). Democratizing innovation. Cambridge, The MIT Press.

Von Hippel, E. and von Krogh, G. (2006). "Free revealing and the privatecollective model for innovation incentives." In: R\&D Management 36(3), 295306.

Von Hippel, E. and von Krogh, G. (2003). "Open Source Software and the "private-collective" innovation model: Issues for organization science." In: Organization Science, 14(2), 209-223.

West, J. and Lakhani, K. (2008). "Getting Clear About the Role of Communities in Open Innovation.” In: Industry and Innovation, 15(2), 223-231.

West, J. and S. O'Mahony (2008). "The role of participation architecture in growing sponsored Open Source communities.” In: Industry \& Innovation 15(2): 145-168.

Weber, S. (2004). The success of Open Source. Cambridge, MA and London, England: Harvard University Press.

Wiesenthal, H. (2006). "Selbstorganisation und Selbststeuerung." In: H.

Wiesenthal: Gesellschaftssteuerung und gesellschaftliche Selbststeuerung: Eine Einführung. (pp. 79-142).Wiesbaden, VS Verlag für Sozialwissenschaften. 



\title{
Customer Co-Creation:
}

Open Innovation with Customers

\section{A typology of methods for customer co-creation in the innovation process}

Frank Piller, Christoph Ihl and Alexander Vossen

\begin{abstract}
Customer co-creation denotes an active, creative and social collaboration process between producers (retailers) and customers (users), facilitated by the company. Customers become active participants in an innovation process of a firm and take part in the development of new products or services. In this paper, we provide a review of the evolution of customer co-creation and related forms of customer participation and suggest a typology of recent methods of co-creation. Our typology is based on three dimensions, addressing (i) the customers' autonomy in the process, (ii) the nature of the firm-customer collaboration (dyadic versus community based), and (iii) the stage of the innovation process when the customer integration takes place. Along these dimensions, we then present specific methods of customer co-creation. We conclude with a number of suggestions for further research.
\end{abstract}

\section{Introduction: The Idea of Open Innovation}

Managing uncertainty can be regarded as a core practice of successful innovation management. Firms face various sources of uncertainty with regard to their technological and managerial capabilities and the target markets. Thomke (2003) diffe- 
rentiates the uncertainties of an innovation project into technical, production, need, and market uncertainty. To reduce these uncertainties, firms need to access and transfer different types of information (Cassiman and Veugelers 2006). In a generic framework, this information can be divided into two groups (von Hippel 1998):

- Information on customer and market needs ("need information"), i.e. information about the preferences, needs, desires, satisfaction, motives, etc. of the customers and users of a new product or new service offering. Better access to sufficient need-related information from customers increases the effectiveness of the innovation activities. It reduces the risk of failure. Need information builds on an in-depth understanding and appreciation of the customers' requirements, operations and systems. This information is typically transferred by means of market research techniques from customers to manufacturers.

- Information on (technological) solution possibilities ("solution information"), i.e. information about how best to apply a technology to transform customer needs into new products and services. Access to solution information primarily addresses the efficiency of the innovation process. Better solution information enables product developers to engage in more directed problem-solving activities in the innovation process. The more complex and radical an innovation is, the larger in general the need to access solution information from different domains.

All innovations are characterized by both types of knowledge, although their relative proportions may vary (Nambisan, Agarwal and Tanniru 1999). Need and solution information may be located physically in different places, which are often external to the firm's innovation process (Nonaka and Takeutchi 1995). It is necessary to transfer at least a certain amount of each type of information from one place to another, as successful innovation requires a combination of the two. Caloghirou, Kastelli and Tsakanikas (2004) conclude after a study of information exchange in new product development projects that " $[. .$.$] both internal capabilities$ and openness towards knowledge sharing are important for upgrading innovative performance." The innovation process thus can be seen as a continuous interaction between internal actors in a firm and external actors on its periphery (Allen 1983; Berthon et al. 2007; Blazevic and Lievens 2008; Brown and Eisenhardt 1995; Chesbrough 2003; Freeman and Soete 1997; Reichwald and Piller 2009; Szulanski 1996). Along all stages of this process, need and solution information has to be transferred from various external actors into the innovation function of the firm. One of the fundamental sources of information for innovation is the customer.

Today, the common understanding of the innovation process builds on the observation that firms rarely innovate alone and that the innovation process can be seen as an interactive relationships among producers, users and many other different institutions (Laursen and Salter 2006). Mansfield (1986) showed that innova- 
tion projects which are based to a large extent on external developments have shorter development times and require less investment than similar projects based solely on internal research and development. As a result, the early Schumpeterian model of the lone entrepreneur bringing innovations to markets (Schumpeter 1942) has been superseded by a richer picture of different actors in networks and communities (Laursen and Salter 2006). These actors are seen to work together in an interactive process of discovery, realization and exploitation of a new idea. Innovative performance today is seen to a large extent as the ability of an innovative organization to establish networks with external entities.

Recently, the term open innovation has been used to characterize such a system where innovation is not solely performed internally within a firm, but in a cooperative mode with other external actors (Fredberg et al. 2008; Reichwald and Piller 2009). Open innovation is the opposite of closed innovation, in which companies use only ideas generated within their boundaries, characterized by big corporate research labs and closely managed networks of vertically integrated partners (Chesbrough 2003). Open innovation is characterized by cooperation for innovation within wide horizontal and vertical networks of universities, start-ups, suppliers, and competitors. Companies can and should use external ideas as well as those from their own RandD departments, and both internal and external paths to the market, in order to advance their technology. Sources of external information for the innovation process are plentiful, including market actors like customers, suppliers, competitors; the scientific system of university labs and research institutions; public authorities like patent agents and public funding agencies; and mediating parties like technology consultants, media, and conference organizers (Knudsen 2007; Tether and Tajar 2008).

Against this background, we define open innovation as the formal discipline and practice of leveraging the discoveries of others as input for the innovation process through formal and informal relationships. ${ }^{1}$ The objective is to access external information to reduce uncertainties in an innovation project with regard to need and solution information. In our opinion, especially the informal relationships define the "innovativeness" of open innovation. Open innovation goes beyond conventional contractual arrangements of organizing collaborative value creation. It especially includes new forms of value creation which are based on informal, non-contractual, flexible and often short-term relationships. Threadless, for example, is a company that has "outsourced" almost all of activities to its peri-

\footnotetext{
1 Our understanding of open innovation here is focused on "inbound open innovation," i.e. "the practice of leveraging the discoveries of others" (Chesbrough and Crowther 2006: 229) to support sourcing and acquisition of external ideas and knowledge to the innovative process. Inbound open innovation is supplemented by "outbound open innovation," i.e. "the commercialization of technological knowledge exclusively or in addition to its internal application" (Lichtenthaler 2009: 318).
} 
phery of customers. But with none of them does it have any contract, or even know their identity.

In the remainder of this chapter, we will focus on customers and users as external participants in the innovation process of a firm. We will introduce the term "customer co-creation" to define strategies of open innovation with customers. Our objective is to investigate the different roles customers and users take in cocreation processes and the methods and tools facilitating these roles. In the next section, we will review important stages of the conceptual development of customer co-creation and define some key terms. We then will present a typology of different forms of customer co-creation and discuss the different modes and approaches along this typology. Our chapter ends with conclusions and some ideas for future research.

\section{The Path from Market Orientation via Customer Orientation towards Customer Centricity}

The conventional view of customers in the innovation process is that they are either passive or "speaking only when spoken to" (von Hippel 1978) in the course of market research or concept testing. This view has recently been challenged by various researchers who note that there is also a more active role of customers in innovation (von Hippel 2005). But the recent notion of "lead user innovators" and "customer co-creators" as the central entity of the value chain (Seybold 2006; Prahalad and Krishnan 2008) has been the result of a long intellectual debate in the literature and discussion in management practice. A short review of this literature development may serve as a good introduction into the development of today's school of thought on customer innovation. It is important to note that the following concepts are presented in the chronological order of their appearance. This order does not imply that all value creation at one time follows the most recent pattern. No perspective has been or is at one time the only appropriate approach. It is the context of the task that determines which orientation seems most suitable for a given context.

\section{Market orientation}

Before mass production was brought about by the industrial revolution, products were customized with craftsmanship. Craftsmanship often presented high-quality products that were only available to selected groups of individuals (with appropriate purchasing power). Every customer was a market segment of one, and "marketing" was individualized and personal, but performed implicitly and as part of the interaction process. The advent of mass production standardized the products and operations to leverage economy of scales and division of labor. This reduced the cost of production drastically. As a consequence, a mass population could now 
afford the goods and services that were only available to pockets of society before. A new generation of mass consumers was created to enjoy the products that were designed to meet the demands of a segment of population large enough to justify the fixed cost of production, including set up cost and capital outlays. The "mass consumption society" (Sheth, Sisodia and Sharma 2000: 55) arose as a sellersmarket, leading firms to adopt organizational forms centered on products. Groups of related products were seen during this period as the primary basis for structuring the organization (Homburg et al. 2000; Sloan 1963).

With the resulting increase in product variety and increasing competition at the end of the 1950s, firms started to pay more attention to markets rather than to products. Market orientation as an organizational pattern of firms came up, following Drucker's (1954) argument that creating a satisfied customer is the only valid definition of business purpose. Market orientation places as first objective to uncover and satisfy customer needs at a profit. The market orientated perspective was popularized by Kotler (1991 [1967]) and soon widely adopted. Market orientation implies seeing the total market not as a homogenous mass market but to divide it into market segments of consumers. Segmentation started with the notion of sociodemographic division with variables such as age, sex, and income. This resulted in a limited number of focused product variants (Smith 1956). Later, segmentation became more refined. More subtly defined niches based on lifestyles and previous buying behavior resulted in an increasing number of product variants to cater for individual, specific needs. Market segmentation demands information on consumers' needs (Narver and Slater 1990). Today's instruments of market research were created as tools to satisfy exactly this set of demands by applying better understanding with information about customers.

\section{Customer orientation}

With a continuous refinement of segmentation, market orientation was replaced by the notion of customer orientation. Its principal features are (i) a set of beliefs that puts the customer's interest first; (ii) the ability of the organization to generate, disseminate, and use superior information about customers and competitors; and (iii) the coordinated application of interfunctional resources to the creation of superior customer value (we refer the reader to Day 1994, for a review of the literature). Especially the strong emphasis on providing "customer value" in all functions of the organization can be regarded as the differentiation of customer orientation to the previous stage of market orientation. The customer came closer into the focus of the firm. During this time, the notion of the marketing function as the central entity to deal with and think about a firm's customers developed. Relationship management reinforced this perspective. It "emphasizes understanding and satisfying the needs, wants, and resources of individual consumers and customers rather than those of mass markets and mass segments" (Sheth, Sisodia and Sharma 2000). Instead of segments of customers, individual customers were seen as the target of 
the marketing mix, resulting in the term "one-to-one marketing" (McKenna 1991; Peppers and Rogers 1993). The members of one market segment are now no longer regarded as being heterogeneous in relation to their profit contribution for the firm; rather, each customer is assessed individually. Based on an individual outputto-input ratio of the marketing function for individual customers ("share of wallet"), customers are either addressed by a standardized offering or, if it pays off, by a customized offering (Day 1996; Parasuraman and Grewal 2000). As a result, product-based strategies are being replaced with a competitive strategy approach based on growing the long-term customer equity of the firm.

\section{Customer centricity}

Today, the ability to manage the value chain from the customers' point of view, and not from the perspective of the provider, determines the competitiveness of many organizations. The idea of a customer centric enterprise is to focus all company operations on serving customers and deliver unique value by considering customers as individuals (Tseng and Piller 2003; Piller, Reichwald and Tseng 2006). Customers are becoming more and more empowered and are using this power to "vote" with their payment individually, not as a group or a block. They make their own judgment based on the value assessed from their own perspectives at the moment of transaction. For firms, the advent of computing and communication technology enables pervasive connectivity and direct interaction possibilities among individual customers and between customers and suppliers. This connectivity offers an enormous amount of additional flexibility. Beyond "listening into the customer domain" (Dahan and Hauser 2002) to address specific needs better and with shorter response time, manufacturers are enabled to connect capabilities of different suppliers to give customers the best economic value. Looking at customers as individuals and proactively developing products to cater to them at the price they are willing to pay and the schedules that they are willing to wait is by no means a straightforward task.

Customer centricity means that the organization as a whole is committed to meet the needs of all relevant customers. At the strategic level, this translates to the orientation and mindset of a firm to share interdependencies and values with customers over the long term. At the tactical level, companies have to align their processes with the customers' convenience as the utmost importance, instead of focusing on the convenience of operations. Of course, sufficient infrastructural systems and mechanisms have to be implemented to reach this state. These changes include a customer-centric organizational structure. Traditionally separated functions like sales, marketing (communications), and customer service shall become integrated into one customer-centered activity (Sheth, Sisodia and Sharma 2000). At the operational level, mass customization and personalization have emerged as leading ideas in the last decade to reach exactly this objective (Pine 1993; Salvador et al. 2009). 
As a result, customer-centricity is turning the marketing perspective from the demand to the supply side. Marketing management has traditionally been viewed as demand management. The focus has been on the product or the market, and marketing had to stabilize demand for an offering through promotional activities such as incentives or pricing policies. The customer centric enterprise is turning its focus to the individual customer as the starting point for all activities. Instead of creating and stabilizing demand, i.e. trying to influence people in terms of what to buy, when to buy, and how much to buy, firms should try to adjust their capabilities, including product designs, production, and supply chains to respond to customer demand. In the customer centric firm, it is the customer who drives the business. In the next section we will discuss how this perspective can be applied to innovation management.

\section{Three Modes of Interacting with Customers in the Innovation Process}

Access to customer information is one of the basic requirements for any successful innovation (Cooper 1993). Two conventional approaches exist to get this information. Customer input can be either accessed explicitly, that is by asking customers about their basic needs and preferences via market research like surveys or focus groups, or by listening in to the customer domain, for example by analyzing sales data, internet log files, or surveying sales personnel. In the past decade, there has been a growing stream of research on the contributions of customers towards a firm's innovation process. This research also has identified some contributions of customers that seem to go beyond their traditional role of being a mere respondent to a company's activities (see for an overview Danneels 2002; Fredberg and Piller 2008; Fang 2008; Carbonell et al 2009). These studies demonstrate a general consensus on the benefit of customer (user) integration for innovative performance. But they also identified rather different roles customers can take in an innovation process. Some studies propose that contributing customers should have special characteristics (Gruner and Homburg 2000; Urban and von Hippel 1988), implying that not all customers are equally suited to contribute to the innovation process. Other studies, however, stress the need for a broad interaction with customers for successful innovation (Gales and Mansour-Cole 1995; Joshi and Sharma 2004; Magnusson 2009). In general, however, this research indicates that customers can take different roles in the innovation process. While some customers provide important information about future trends and possible solution technologies, other customers may be more suited to evaluate innovative concepts or to participate in the refinement of a prototype.

Expanding a framework by Dahan and Hauser (2002), these roles can be structures around three different modes of using and generating customer information in new product development: (1) "Listen into" the customer domain, (2) "ask" customers, 
and (3) "build" with customers. These three modes differ in their degree respectively extent of the customer activities:

Mode 1 - "Listen into".

In the first approach, products are designed on behalf of the customers. This has been one of the typical understandings of the "market orientation" paradigm as presented above. Firms use existing customer information from diverse input channels like feedback from sales people, analyzing the sales data from the last season, internet $\log$ files, or research reports by third parties to identify customer needs (Dahan and Hauser 2002). Another important input in this mode is reviews of the performance of existing products (the firm's and competitors'). This approach also includes methods to study customer by observation, such as netnography (Kozinets 1998; 2002; Bartl and Ivanovic 2010) or empathic design (LeonardBarton and Rayport 1997), and engineering-based methods like Quality Function Deployment (Akao 1990) which integrates customer data with a design methodology.

Mode 2 - "Ask".

In addition to observed data on customer preferences, a second strategy explicitly asks customers for input for a company's innovation process. In the early stages of an innovation project, customer preferences or unmet needs are identified via surveys, qualitative interviews, or focus groups ("voice of the customer" methods, Griffin and Hauser 1993; Green, Carroll and Goldberg 1981). An advanced and proven method here is the "outcome driven innovation" approach that combines a number of survey and evaluation methods into a coherent framework (Ulwick 2002). In the later stages of an innovation project, different solutions or concepts are presented to customers so they can react to proposed design solutions (Acito and Hustad 1981; Page and Rosenbaum 1992; Dahan and Hauser 2002). For example, a manufacturer may recruit so called "pilot customers" or "beta users." These customers are observed and regularly surveyed to use their experiences and ideas for improvements of the pilot product to make it suit the majority of customers (Dolan and Matthews 1993). In the consumer goods field, concept testing in focus groups or the invitation to customers to join "product clinics" are examples of this approach. In addition, the systematic analysis of feedback or complaints from existing customers provides important input for the innovation process (Brockhoff 2003; Kendall and Russ 1975; Füller, Matzler and Hoppe 2008). In general, the approaches of customer interaction in the innovation process according to this Mode 2 can be seen as practices within the paradigm of "customer orientation," as presented above. 


\section{Mode 3 - "Build".}

In the previous modes, customers remain isolated from the firm. The alternative approach of Mode 3 is to actively involve customers in the design or development of future offerings, often with the help of tools that are provided by the firm. Hence, this mode refers to an active integration of customer participation in innovation (Ramirez 1999; von Hippel 2005), building on the understanding of "customer centricity" according to the definition in the previous section (Kaulio 1998; Piller 2004; Tseng, Kjellberg and Lu 2003, for extended reviews refer to von Hippel 2005; O'Hern and Rindfleisch 2009; Piller and Ihl 2009). The manufacturer is either empowering its customers to design a solution by themselves or is implementing methodologies to efficiently transfer an innovative solution from the customer into the company domain. This mode 3 is the genus of customer co-creation - open innovation with customers - and the focus of this chapter. The term customer cocreation denotes a product development approach where customers are actively involved and take part in the design of a new offering (Kaulio 1998; Piller 2004; Tseng, Kjellberg and Lu 2003, for extended reviews of the active role of customers in the innovation process refer to von Hippel 2005; O’Hern and Rindfleisch 2009; Piller and Ihl 2009). More specifically, customer co-creation has been defined as an active, creative and social process, based on collaboration between producers (retailers) and customers (users) (Piller and Ihl 2009). Customers are actively involved and take part in the design of new products or services. Their co-creation activities are performed in an act of company-to-customer interaction which is facilitated by the company. Customer co-creation can be seen as the application of customer centric management in the innovation process. Its objective is to utilize the information and capabilities of customers and users for the innovation process.

The main benefit is to enlarge the base of information about needs, applications, and solution technologies that resides in the domain of the customers and users of a product or service. Examples for methods to achieve this objective include user idea contests (Ebner et al. 2008; Piller and Walcher 2006; Sawhney, Verona and Prandelli 2005; Terwiesch and $\mathrm{Xu}$ 2008), consumer opinion platforms (Hennig-Thurau et al. 2004; Sawhney, Verona and Prandelli 2005), toolkits for user innovation (Thomke and von Hippel 2002; von Hippel and Katz 2002; Franke and Schreier 2002; Franke and von Hippel 2003), mass customization toolkits (Franke, Keinz and Schreier 2008; Franke and Piller 2004), and communities for customer co-creation (Franke and Shah 2003; Sawhney and Prandelli 2000; Henkel and Sander 2003; Benkler 2002; Howe 2006, 2008; Füller, Matzler and Hoppe 2008).

At this stage, we have to make an important differentiation between customer co-creation and the lead user concept von Hippel 1988, 1994 (for a review of the lead user research refer to von Hippel 2005). Research has shown that many commercially important products or processes are initially thought of by innovative users rather than by manufactures. Especially when markets are fast-paced or turbulent, so called lead users face specific needs ahead of the general market participants. Lead 
users are characterized as users who (1) face needs that will become general in a marketplace much earlier before the bulk of that marketplace encounters them; and (2) are positioned to benefit significantly by obtaining a solution for those needs. In situations when need information can be converted into a final solution or prototype directly at the locus of the users, customers are taking over the role the innovator entirely.

The lead user concept has dominated the perspective of the earlier research on user innovation. Lead users are seen are being motivated intrinsically to innovate, performing the innovation process autonomously and without an interaction with a manufacturer. It then is the task of the firm "just" to identify and capture the resulting inventions. Our understanding of customer co-creation, bowever, is built on a firmdriven strategy that facilitates the interaction with its customers and users. Instead of just screening the user base to detect any existing prototypes created by lead users, here the firm provides instruments and tools to its users to actively co-create a solution together.

\section{A Typology of Methods for Customer Co-Creation}

Our literature review suggests different modes and intensities in the ways customers can contribute to innovative activities of the firm. Customer co-creation is a multifaceted phenomenon. In order to better understand the relationships and ties between firms and customers in the innovation process, we will present a conceptual typology of customer co-creation in the following (based on Piller and Ihl 2009). Note that this typology (and the remaining discussion) is focused on strategies that are based on a collaborative mode of participation of customers in the innovation process, facilitated and initiated by an explicit firm strategy towards open innovation (representing the "Mode 3" in the previous section). Our perspective is that firms are organizing the process of customer innovation. Firms are building capabilities and infrastructures that allow customers to perform activities in their innovation process. This perspective represents the new understanding of open innovation with customers (as also presented, e.g., in Reichwald and Piller 2009; Tapscott and Williams 2006; Seybold 2006).

Building on our previous research in the field (Diener and Piller 2010), we propose three characteristics that form the conceptual dimensions of a typology of possible settings for co-creation with customers:

- The stage in the innovation process refers to the time when customer input from co-creation activities enters the new product development process; i.e. whether customer input enters early in the front end stages of the process (idea generation and concept development) or whether it enters later in the back-end (product design and testing). 
- The degree of collaboration refers to the structure of the underlying relationships in an open innovation setting; i.e. whether there is a dyadic collaboration between a firm and one customer at a time or whether there exist networks of customers who collaborate among themselves more or less independent from the firm.

- The degrees of freedom refers to the nature of the task that has been assigned to customers; i.e. whether it is a narrow and predefined task with only a few degrees of freedom or whether it is an open and creative task for which a solution is hardly foreseeable because of many degrees of freedom.

According to these three dimensions, one can think of altogether eight ideal types of co-creation with customers. In the following, we describe and give examples for these eight types in a systematic manner by classifying them according to the typology.

\section{Dyadic (1:1) co-creation at the front end}

We begin with customer innovation in the front end of the innovation process (see Figure 1). The front end of the innovation process centers on two essential activities: (1) generating novel concepts and ideas, and (2) selecting specific concepts and ideas to be pursued further (O'Hern and Rindfleisch 2009). Regarding degrees of freedom, generating ideas is a task which is more open and creative than selecting from a predefined set of ideas. Both of these tasks have been suggested to be handed over to customers by means of idea contests (Piller and Walcher 2006; Terwiesch and $\mathrm{Xu}$ 2008) and idea screening (Toubia and Florès 2007) respectively. In both of these settings, the task is carried out in a dyadic interaction between a firm and individual customers, each of them submitting and/or evaluating ideas without collaborating with other customers.

In an idea contest, a firm seeking innovation-related information posts a request to a population of independent (competing) agents, e.g. customers, to submit solutions to a given task within a given timeframe. The firm then provides an award to the agent that generated the best solution (Piller and Walcher 2006). Thus, idea contests overcome a core challenge for firms when opening the innovation process: how to incentivize customers to transfer their innovative ideas. This is important in the early stages of the innovation process because customers are unlikely to benefit from their contributions through new products within a short time frame, as in later stages of the innovation process. 


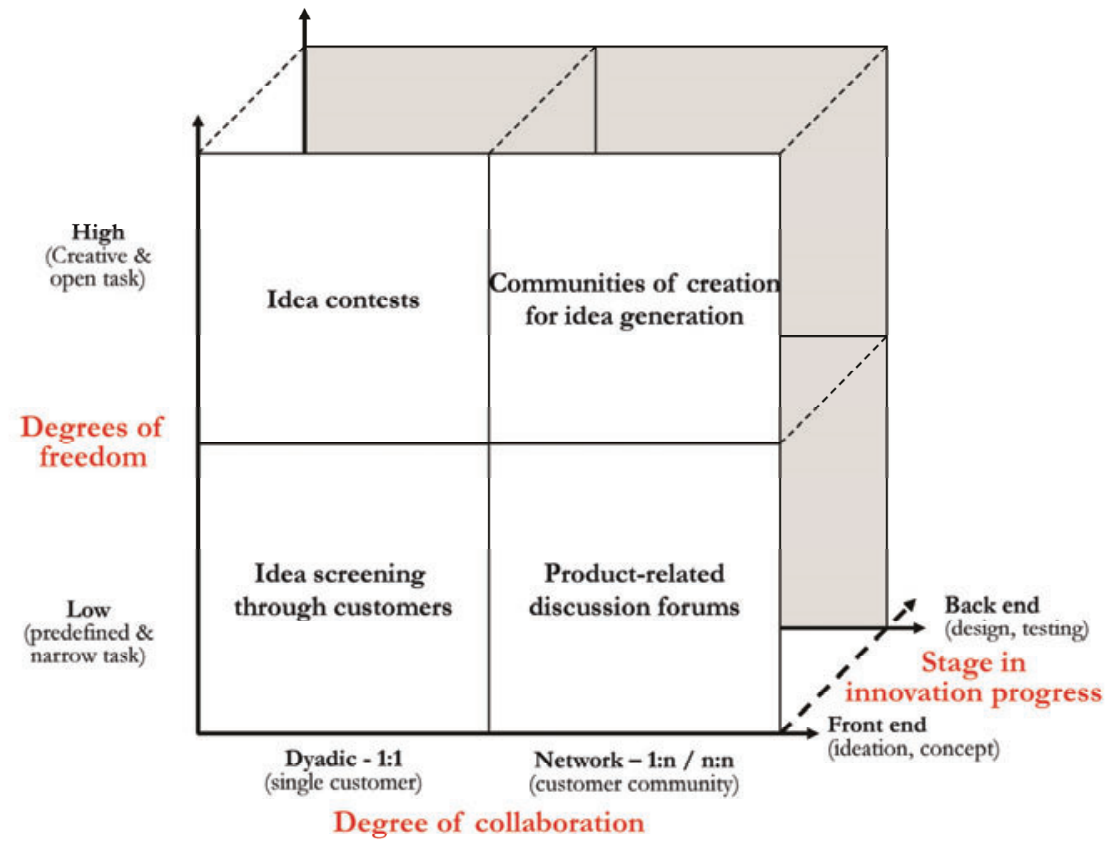

Figure 1: Typology of customer innovation at the front end of the innovation process

Some companies thus promise cash rewards or licensing contracts for innovative ideas, other build on non-monetary acknowledgments promising peer or company (brand) recognition and facilitating a pride-of-authorship effect. Obviously, these rewards or recognitions are not given to everyone submitting an idea, but only for the "best" of these submissions. This competitive mechanism is an explicit measure to foster customer innovation. It should encourage more or better customers to participate, should inspire their creativity and increase the quality of the submissions. Box 1 describes an innovation contest conducted by Fujitsu Siemens Computers in 2008 in greater detail.

\section{Box 1: Co-Creation at Fujitsu Siemens Computers}

(Source: From a post to mass-customization.blogs.com by Frank Piller on April 24, 2008)

Fujitsu Siemens Computers (FSC), a large IT infrastructure provider, just started their first community-based innovation contest this week. The contest asks everyone with a clever idea to develop ideas around the Data Center of the future. They ask the questions how data centers will work in the future, what services will be required by users, and which topics will be of strategic importance for their business. The contest has been created by a business team within FSC with the help of HYVE AG, a Munich based open innovation accelerator. On the platform, users not just become a source of 
ideas, but a member of an Innovation Community. This shall enhance their ideas with the help of other contest participants and the internal experts from Fujitsu Siemens Computers.

Every idea can be evaluated and commented by every contestant. As a consequence, ideas become vital elements which can be formed and developed by many spirits and thereby have the chance to gain excellence. While the original spin doctor competes for one of the prizes for one specific idea, the contestant's activity within the community is rewarded as well. In order to enable the contestants to actively interact beside the discussions on ideas, several additional functions are available to the participants. Weekly chats with other participants and Fujitsu Siemens Computers Professionals are dedicated to specific topics which are defined according to eminent issues within the pool of ideas. Not to mention the forum and other features. Every contestant can contribute several ideas. The essence of the ideas is described through a handful of uniform parameters such as target group and basic functionality. The idea can also be enriched by any attachment such as diagrams or mind maps. In order to compare and rank the ideas, the contributions are evaluated along some criteria such as market potential, value to the customer or novelty to the market. Contestants evaluate their own as well as any other idea by these criteria.

The contest consists of different phases: First, ideas are contributed and evaluated by the community. After two weeks the contest went on, FSC experts will come into play and start the expert evaluation phase were ideas are evaluated along similar criteria as the community evaluated the ideas. A tag cloud helps to explore the pool of ideas intuitively and your favorite ideas can be added to your personal list in order to keep an eye on their progress. And in the end, the winning idea gets 5000 Euro, plus there are several of the latest FSC laptops to win (http://innovation-contest.fujitsusiemens.com).

The results of the contest are held private, but according to company voices, the firm was "more than satisfied" with this initiative and considers to repeat the contest in the future (note: due to the change in the ownership structure of FSC at the end of 2008, this initiative has been placed on hold).

Piller and Walcher (2006) present a broad range of examples for idea contests in practice. These are differentiated according to the degree of problem specification, i.e. does the problem clearly specify the requirements for the sought solution or is it more or less an open call for solutions to a vaguely specified problem (see also Terwiesch and Xu 2008). Consider the example of Threadless.com, a company entirely based on a continuous user contest where winning designs (for t-shirts) are transferred into mass products (Ogawa and Piller 2006). Threadless demands some degree of elaboration for the submissions by requesting the usage of specific software that allows for an easy transfer of the chosen designs to manufacturing. The theme of the designs (problem specification) however is not defined at all.

Following a successful idea generation exercise by means of contest, firms might easily end up with several hundreds of ideas generated by customers. The next step is idea screening and evaluation, i.e. to select these ideas and identify those 
with the highest potential. Submitted ideas might be evaluated by a panel of experts from the solution seeking firm, and ranked according to a set of evaluation criteria. However, Toubia and Flores (2007) suggest that even this task may be successfully carried out by customers by means of adaptive idea screening. They propose that in light of a potentially very large number of ideas it would be unreasonable to ask each consumer to evaluate more than a few ideas. This raises the challenge of efficiently selecting the ideas to be evaluated by each consumer. Toubia and Flores (2007) describe several idea-screening algorithms that perform this selection adaptively based on the evaluations made by previous consumers. A good example for idea screening in practice again is Threadless.com. Here, customers not only create and submit many T-shirt designs. By means of a poll they also determine the winning designs that will later on be transferred into mass products (Ogawa and Piller 2006).

\section{Network (community) based (n:n) co-creation at front end}

Customer communities have been shown to be an important locus of innovations. These communities may be operating entirely independent of firms or even dealing with firms' products in an unauthorized manner (see for the notion of outlaw communities Flowers 2008). For example, Franke and Shah (2003) analyze four firm-independent sports communities and show that on average one third of the community members improved or even designed their own product innovations for sports equipment. It is important to note that these innovations do not emerge solely from individual efforts, but are also driven to a significant extent by collaborations with other community members (Franke and Shah 2003). This effect also holds in customer communities that are initiated and run by firms (Jeppesen and Frederiksen 2006).

Internet-based customer communities differ in structure and extensity of social ties and are often termed online or virtual communities, communities of interest, communities of consumption, virtual settlements or brand communities. They are mainly based upon shared enthusiasm and knowledge concerning specific product domains and are often virtual meeting places for users that discuss their usage experiences with certain products and ideas for new products and their improvement. Customer communities differ, however, in their objective and hence their devotion to open and creative tasks that produce novelties. Along this line, we want to differentiate general product-related discussion forums on the one hand and communities of creation on the other hand.

In product-related discussion forums, customers primarily exchange their usage experiences and support each other in using the product. Generating novel ideas or concepts is not a central objective in such communities. Henkel and Sander (2003) investigate the product-related forum smart-club.de which is not primarily devoted to innovative activities. They find that posts that are relevant for innovation activities 
occur, but are rather rare. Customer posts build on each other and sometimes argue along an innovative thought, but the verbal input by consumers primarily is of moderate creativity and elaboration.

On the other hand, communities of creation are primarily concerned with generating novel ideas and concepts (Sawhney and Prandelli 2000). Hence, their innovation productivity is rather high and not restricted to the verbal output, but may also include the virtual exchange of more elaborated contributions such as technical drawings (Füller et al. 2006). A popular example of a highly innovative online community is the "Harley-Owners-Group" (bttp://www.hog.com). Concepts of individualized motorbikes and accessories demonstrated and discussed within this community were later included in the development process of the producer Harley-Davidson. There are also examples that communities of creation can emerge from an ordinary discussion forum. At Outdoorseiten.de, a nucleus of customers devoted several threads to the creation of a new tent. Starting out from several vague ideas, they reached a degree of elaboration that convinced a manufacturer to actually produce this tent on a larger scale. Box 2 denotes a further strategy for profiting from customer input at the front end of innovation.

\section{Box 2: Muji.com: An example of customer input at the front end from Japan (Source: Updated extract from Ogawa and Piller 2006)}

Muji is a Japanese specialty retail chain with 2004 sales topping 117,100 million Yen. Muji is a household name in Japan for all kind of consumer commodities, and highly acclaimed in Europe for its industrial design and product esthetics. Its major product categories are apparel (38\% of total sales), household goods and stationary (52\%), and food $(10 \%)$. While the company is famous for its powerful internal design practice, it has a very strong method to incorporate customer input into the new product development process.

In its Japanese home market, the company receives more than 8000 suggestions for product improvements or new product ideas each month. Suggestions are sent as postcards attached to catalogues, as e-mails or via feedback forms on the company's website. On the sales floor, sales associates are encouraged to collect notes on customer behavior and short quotes from sales dialogues. More than 1000 of these memos are processed each month. The company even organizes a vacation club, Muji Camp, where customers can experience a summer vacation with Muji products. The camp provides Muji with the opportunity to observe customers during the camp and to develop relationships with the vacationers that go beyond the summer.

But the most important means of interaction with its customers is its online community, Muji.net, with approximately 410,000 members. This dazzling array of customer input is motivated by the customers' high involvement with the brand. In return, Muji acknowledges the customer input by marking products triggered by suggestions of customers clearly in its catalog. Notwithstanding this openness to external input, product planning and product development remains a closed, internally managed process. Customer input is collected, categorized and evaluated in a structured process, resulting in an internal short-list of top ideas which are discussed in a "business improvement 
meeting" by a management board, including the company president. This board has also the sole decision how to proceed with a submitted idea.

Dyadic (1:1) co-creation at the back end

Next we turn to customer innovation types in the back end of the innovation process (see Figure 2). Here, customer inputs have to be more concrete and elaborated in order to be valuable for firms. A higher degree of elaboration often requires a more structured approach for the interaction with customers. In order to obtain an adequate solution for an innovation problem, firms needs to combine need information from the customer domain with their own solution information. As first solutions are not always best, firms usually repeat this process several times and evaluate possible solutions for an innovation problem in an iterative process.

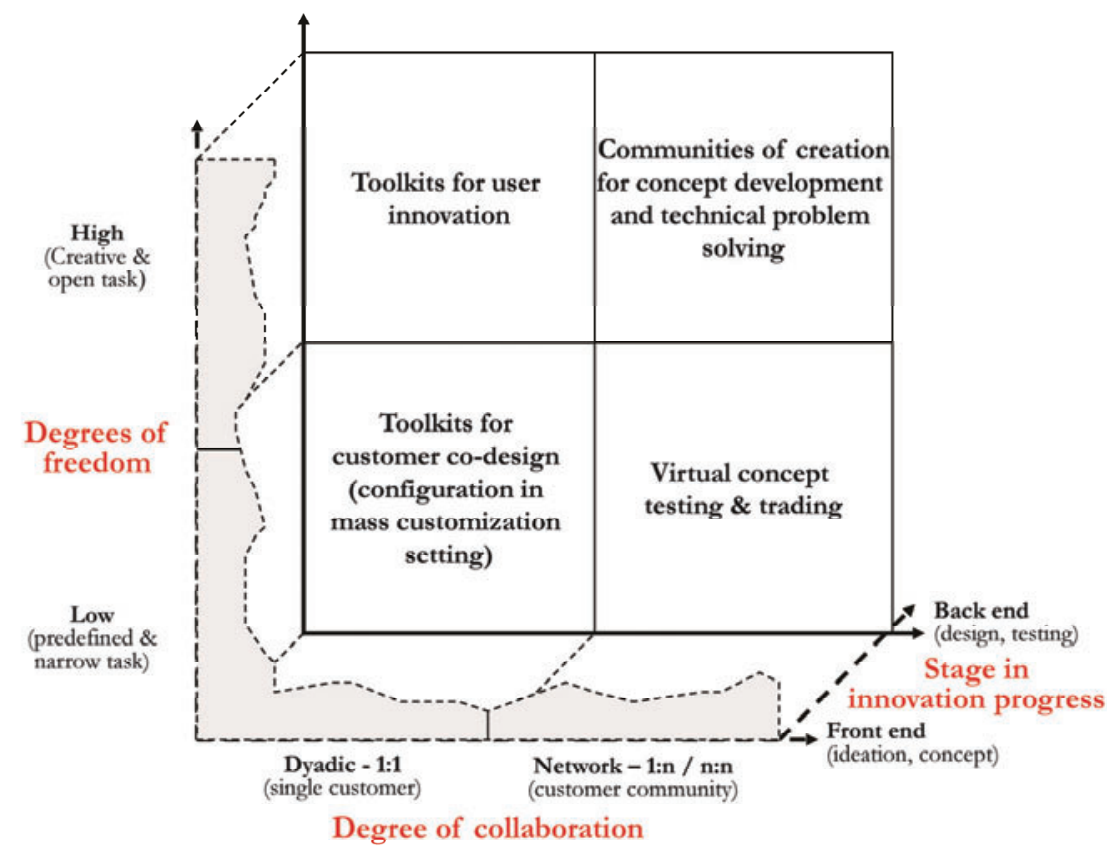

Figure 2: Typology of customer innovation at the back end of the innovation process

This process of trial and error is very expensive, because it fosters a steady flow of iteration and communication between the user and manufacturer. Because of the "stickiness" of (location-dependent) needs and solution information, the exchange between both parties is often tedious and accompanied by high transaction costs (von Hippel 1998). 
Toolkits in general are based upon the idea of handing over the trial and error process to customers (Franke and Piller 2003, 2004; von Hippel and Katz 2002; Thomke and von Hippel 2002). A toolkit is a development environment which enables customers to transfer their needs iteratively to a concrete solution - often without coming into personal contact with the manufacturer. The manufacturer provides users with an interaction platform, where they can make a solution according to their needs using the toolkit's available solution space.

In order to operate efficiently, toolkits should fulfill five basic requirements (von Hippel and Katz 2002): (1) Trial and error learning: Toolkit users should receive simulated feedback on their solution in order to evaluate it and to improve on it in an iterative process. In this way, learning-by-doing processes are facilitated. (2) Solution space: A toolkit's solution space defines all variations and combinations of allowed possible solutions. Basically, the solution space only permits those solutions which take specific technical restrictions into account and are producible from the manufacturer's perspective. (3) User friendliness: User friendliness describes how users perceive the quality of interaction with the toolkit. Expenses influence the user's perception of quality, (time, intellectual effort), as well as the perceived benefit (satisfaction with the developed solution, fun), of interacting with the toolkit. (4) Modules and components library: Modules and components libraries allow users to choose from predefined solution chunks for their convenience. Such libraries may also contain additional functionalities such as programming languages, visualization tools, help menus, drawing software, etc. (5) Transferring customer solutions: After users have developed the best possible solution for their needs, it should be transferred to the manufacturer. A transfer over toolkits allows for perfect communication of the customer's solution, which is conveniently translated into the manufacturer's "language". Following Franke and Schreier (2002), we distinguish two types of toolkits according to the degrees of freedom that the underlying solution space provides to customers: toolkits for user innovation and toolkits for customer codesign and customization.

Toolkits for user innovation resemble, in principle, a chemistry set. Their solution space or, at least some of the product's design parameters, is boundless. Toolkit users not only combine the manufacturer's standard modules and components to create the best possible product for themselves, but they also expend a tremendous amount of effort in experimenting through trial and error processes on new and previously unknown solutions for their needs. The manufacturer's toolkit provides the necessary solution information in the form of, for example, programming languages or drawing software. A good example comes from the semiconductor industry where firms equipped customers with toolkits for custom development of integrated circuits and computer chips (von Hippel and Katz 2002).

On the other hand, toolkits for customer co-design are used for product customization and the development of variants, rather than developing new goods and services. It can be compared to a set of Lego bricks. Toolkits for user co-design offer 
users more or less a large choice of individual building blocks (modules, components, parameters), which can be configured to make a product according to the user's individual requirements. Therefore, the toolkit's solution space is limited and can be modified only according to its predefined "building blocks." These building blocks lie within the range of a manufacturer's economic and technological capability. They are often integrated into a mass customization strategy (Salvador et al 2009). Well-known examples of these types of toolkits are Dell's product configurator and configurators found, for example, in the automobile industry. Another well-known example is the strategy of toy-maker LEGO and its LEGO Factory, an advanced toolkit for user innovation targeting the children's market. Box 3 describes this example in more detail.

Box 3: LEGO Factory: Moving from mass customization toolkits towards open innovation (Source: Post: "Lego Factory hacked by users - and the company loves it" by Frank Piller on masscustomization.blogs.com, 12 Dec 2005)

Lego, a toy maker based in Billund, Denmark, provides an interesting case of a company combining mass customization toolkits and open innovation. Originally acclaimed for its modular product architecture, the company has provided users since its foundation the possibility to create almost unlimited designs. However, the relationship between the company and its users was following the conventional, disconnected transaction marketing approach. Also, all parts and logo kits were produced in a builtto-stock model. In recent years, Lego faced serious difficulties in forecasting its products. Also, it had a need to differentiate itself to more "modern" educational toys like children computers etc. To get inspiration for new products and connect closer with its users, the company had a great source of inspiration: Totally independent of the company, a Lego user community called LUGNET has been built by fanatic adult users of Lego. Lugnet is one of the best examples of a community where users co-create and co-design based around a manufacturer's products. Its members not only swap parts or share pictures of their individual models, but also developed collaboratively a design software (open source) to create expert constructions. Also, a large number of small user shops sell unique models and designs. When Lego introduced its Mindstorms Robotic toys, after several years of development, some users "hacked" the robotic kit and improved the performance of the construction kit and its processing capabilities by several dimensions in just a few weeks (this is one of the best documented and fascinating case of user innovation). All these user activities, however, were not facilitated or really utilized by Lego.

But finally, the Lego Company introduced a similar offering combining mass customization and open innovation: In August 2005, Lego announced the opening of LEGO Factory, a very advanced toolkit for user (children) innovation and co-design. The Lego Factory combines several trends and developments which were before invented in the user domain, and which are now incorporated into a business model of the company. At Lego Factory, users can create their own unique Lego models - using interactive software that helps them to overcome the engineering problem of combining basic modular elements (Lego bricks) into a new creation. Then, the company manufactures the bricks necessary for the model and ships them to users so they can assem- 
ble their models. Customers can also buy the bricks necessary to build from other people's designs, which are posted on the site. Lego Factory is based on a toolkit for user co-design, called Lego Designer, a free, downloadable, 3D modeling program that lets users choose from digital collections of bricks to compose their own unique models. In addition, the site finally features real open innovation at Lego: It highlights the fact that the company is now selling Lego sets which are designed by other Lego users. Children can not only create their own unique designs, and order the corresponding bricks in a customized set with the help of their father's credit card, but can also submit these designs to the company. Lego may then produce an extraordinary design as a mass product for other children as well. This idea has been also tested before (in the German Lego catalog, some user designed Lego sets have been included since 2003), but never utilized on a large scale.

\section{Network (community)-based (n: n) co-creation at the back end}

Collaborations among users in a community bear the potential that otherwise isolated (chunks of) customer solutions are more likely to be complementary, rather than redundant, or that they may even get integrated into a single product. This in turn might allow for more complex problems that can be handed over to and solved by customers. For this innovative institution where many individuals together produce a rather complex common good, Benkler (2002) has coined the term "peer production" within communities of creation for problem solving.

While communities of creation are often focused on the front end activities of idea generation and concept development, commons-based peer production may also cover early stages of the innovation process but usually extends to activities in the back end of the innovation process where products reach final states. Peer production describes the fact that there are a great number of internet-based projects where many users are working on the collective production and further development of knowledge and information products. One can speak of crowdsourcing (Howe 2006, 2008) if firms are able to utilize this trend.

Probably the most popular movement of this kind is the development of open source software (e.g. Lerner and Tirole 2002; Lakhani and von Hippel 2003) where users define problems, announce them to the community, provide solutions to problems, test and debug solutions and finally take care of distribution and documentation. Many of today's most successful computer applications, including Apache, Linux, and Firefox are open source projects that are managed by selforganizing communities of volunteer programmers.

Transferring and combining need and solution information is vital to solve complex innovation problems like software development, but costly in case of information "stickiness". This stickiness actually suggests that further division of labor among very many customers would not be a wise thing to do because of the increased costs of information transfer between actors. Nevertheless, organizing 
this division of labor between networks of customer and the firm in an efficient manner is what peer production is about.

Commons-based peer production does not rely on organizational principles like property rights, price mechanisms, contracts or formal managerial structures. It has thus a potential transaction cost advantage over traditional, hierarchical, hybrid or market forms. A central characteristic of peer production is that customers self-select into their respective sub-tasks rather than being assigned by a central authority. The self-selection mechanism is suggested to be more efficient for two reasons:

(1) It is better at identifying and allocating exactly those human capacities (special abilities of single individuals), suitable for single tasks within the information production process. The peer production model "loses less information about who the best person for a given job might be than do [...] other [...] organizational modes" (Benkler 2002: 1). A manager, who assigns a task to one of his many employees, often is not able to use all possible information about abilities and motivation to decide whether a certain employee is best for a given job. If a task is not assigned, but broadcasted, actors can then compare it with their knowledge and motivation levels themselves in order to decide about their participation.

(2) Through the effects of specialization, the efficiency of assigning tasks through self-selection is subject to substantial economies of scale. If large groups of potential participants face a large number of sub-tasks and sources of information, then it is more than likely that an actor will be found for a certain assignment who is truly qualified (specialized) and/or motivated. In addition, if no property rights and contracts are needed as a basis for cooperation, transaction costs can be lowered substantially by peer production. Actors decide for themselves which problem to solve, and whom they wish to work with together on the task. This means the more potential available actors exist in relation to a large amount of sub-tasks related in context, the higher the efficiency of this organizational form in comparison to conventional organizational forms (Benkler 2002).

As with any organizational approach, peer production has to solve the motivation problem and the coordination problem among customers; i.e. customers must be willing to bear the effort and able to fulfill their tasks in a compatible manner that can be integrated as a whole. The following four conditions favor self-selection as key principle of peer production in this regard: (1) an adequate large number of actors; (2) modularity of sub-tasks which can be worked on independently; (3) granular sub-tasks which are heterogeneous and small in size to attract a wide audience; (4) low transaction costs for assigning and integrating sub-tasks.

The possibility to digitalize a substantial number of value creation tasks dramatically increases the applicability of peer production principles. Digitalization reduces up-front costs for the necessary means of production. Capital investments 
like computers and communication devices are broadly distributed and not concentrated at one place (as with, for example, a steel factory). Digitalization also simplifies the modularization of tasks and the Internet creates the transparency necessary for the allocation of sub-tasks to external actors through self-selection according to their motivation and abilities. In addition, interaction can take place on a social level, for example, by the emergence of social identification within customer communities.

Beyond information products like software, customers are also becoming actively involved in peer production of traditional manufactured products; partly through digitalization. For instance, over 120,000 individuals around the world served as voluntary members of Boeing's World Design Team and contributed ideas and input regarding the design of its new 787 Dreamliner airplane (www.newairplane.com). Another example is the OSCar project (www.theoscarproject.org). The name OSCar stands for an ambitious project in which a car is developed after the principles of open source like peer production. Instead of the secrecy found within the automobile industry, ideas, designs and development plans are a public good. Since June 2000, motivated volunteers, creative hobby inventors, amateurs, and committed specialists debate in various forums about, among other things: design suggestions, impulsion, engineering, electronics, and safety for the OSCar.

While peer production has its primary strength in the creation of products, its principles may also be applied in the test and launch stage of the innovation process. A prominent example would be the bug fixing activities of many programmers in open source projects. In the automotive industry, consider the example of Volvo. The company presented different concept cars on an internet-based platform, e.g. in the adventure or performance sector, as possible future offerings (conceptlabvolvo.com). The visitors playfully familiarize themselves with these car concepts and give their feedback after virtual presentations and test simulations. Another method for open innovation with customers in the test and launch stage is a virtual concept market to test the appeal of different concepts in a customer segment by trading concepts like stocks on the Internet (Spann and Skiera 2003).

We want to conclude this section with the example of Quirky.com, a company that made community-based innovation the core of its business model. Similar to Threadless, the community suggests new concepts, votes on the best ideas, and collectively commits on the products that go into production. However, Quirky goes much further than Threadless and engages the community in many more activities along the entire span of the innovation process, as Box 4 describes.

Box 4: Quirky.com: Social product development in a community

(Source: Post: "Quirky.com" by Rob Walker on bttp:/ / www.murketing.com/journal/ ? $p=3962$, Sept 2009)

[In Summer 2009], Ben Kaufman, who is 22 and lives in New York, started a business aimed squarely at the armchair inventors among us. Quirky.com is meant to bring 
"community developed" products to the marketplace. For example: Marc Julian Zech, an advertising copywriter in Hamburg, Germany, had an idea for a double-sided mini hard drive (one USB plug might hold personal data, the other work data). He submitted his notion to Quirky.com, and now, a few weeks later, the Split Stick is being manufactured. This was actually the first Quirky product to cross over from the virtual drawing board to physical reality, but Kaufman's dream is to make the dreams of many Marc Julian Zechs come true - and of course to profit from them. The idea is to convert the creativity of quasi-mass audiences into an alternative to a formal researchand-development lab for a wide variety of objects.

Joining the Quirky community is free: after a registration process that involves a demographic questionnaire, anybody can weigh in on product ideas. Actually submitting an idea involves a $\$ 99$ fee, which Quirky keeps even if your dream flops. Zech, who read about the company on a tech blog, figured that was a price worth paying. "I like to invent things," he says, though until now he had been limited to dreaming up promotional products for ad clients. A double-sided USB drive was something he mulled in the past, so he wrote a descriptive pitch and drew some sketches. Every week the crowd of about 10,000 registered Quirky users votes to choose one pitch to go into development. Zech's won. Quirky members then chime in about the final design, the product's name and so on. "It gets better from step to step," Zech says. Quirky's small staff works out production details with manufacturers and suppliers. Then comes the final hurdle: the finished idea is offered to the general public in Quirky's online store, and if it receives enough (discounted) preorders, it goes into production. From that point on, Quirky forks over 30 percent of the profits to its community: the originator gets the lion's share, and those who offered helpful suggestions earn "influence" points that translate into some sliver of the pie. (In this case, Zech gets $\$ 2.87$ for every $\$ 24.99$ Split Stick sold; others will get anywhere from a penny to 43 cents.) Participants can also earn influence by ginning up presales from their online social networks. This extension of the communal idea into the sales process seems essential to the idea taking off. "The community," Kaufman says, "was particularly passionate about" the Split Stick, with members stoking presales through social-networking tools on Quirky.com, crossing the 200-sales production threshold in about five days. Kaufman notes that Quirky received another 100 or so orders for the device in the days after the presale ended. Buyers should start getting their Split Sticks later this month.

Quirky.com adds a new fleshed-out product concept to its online store every week: a multicolor sling, a melon-cutter, a combination key ring and mini-tripod called the DigiDude. More look poised to meet their presales goals and go into production. Surely part of what its customers are buying isn't just a doodad but also the crowdpleasing notion of tapping into the creativity of the many: a nonexpert with an interesting concept that is sharpened to perfection by the input of an engaged, online peanut gallery. There is none of the cautious focus-grouping of a traditional manufacturer. If things go well for Quirky, Kaufman says he hopes to have a temporary physical store in Manhattan in time for the holiday season, selling Quirky goods as well as drawing in more aspiring inventors.

(Update: Since publishing the article, Quirky has secured more than $\$ 7$ million in VC funding and its community has launched about one new product every week). 


\section{Conclusions and Outlook}

The typology developed in this paper demonstrates different methods and ways in which firms can benefit from open innovation with customers. Our objective was to offer a more systematic approach to the different methods of customer cocreation. We organized the methods among the three dimensions, "degrees of freedom" (customers' autonomy in the task), "degrees of collaboration" among customers (dyadic firm-customer interaction vs. communities) and the "stage of the innovation process" (early vs. late stage). Despite all the different approaches outlined in this paper, we conclude that all methods of customer co-creation follow a common principle. The underlying idea is that of an active, creative and social collaboration process between producers (retailers) and customers (users). Cocreation involves customers actively in a company's innovation process. But despite this common ground, companies intending to profit from co-creation need to know which of the different methods are most suited for themselves and how to use these tools best (Diener and Piller 2010). In order to answer these questions, more detailed research is needed.

First, firms need information and better guidance on how to assess whether their organization and branch is suited for customer co-creation. This information is crucial in order to build specific competences that aid firms in identifying opportunities and ultimately in using the right method. Managers need a clear picture of their own organizational settings and capabilities before being able to answer important questions during the implementation of one's own customer integration initiative. This could include answers to questions like how do innovation projects have to be reorganized, which kinds of projects are suited for customer integration and how do the internal development processes have to be adjusted in order to allow optimal customer integration.

Second, previous research mostly focused on showing the application of customer integration, mostly in terms of successful examples. These examples are valuable for creating evidence and generating attention for the phenomena, but often lack a differentiated perspective on the chosen method of customer integration. To take the discussion on customer integration methods to the next level, more research on specific design components of these methods are mandatory in order to provide information on how the method is used in the best way. For example, while the motives of customers participating in firm-hosted open innovation activities have recently been the subject of a considerable amount of research (see e.g. Füller 2010; Füller, Matzler and Hoppe 2008), the ways to design a specific method remains relatively vague. Future contributions to these aspects need to give an answer to questions like how to design the methods in order to attract the desired participants, or in order to evoke the preferred behavior, as well as how can the firm influence the output of the open innovation activities by adjusting these specific design factors. 
Finally, research is needed on the long-term effects of customer co-creation on competition. Today, open innovation with customers is booming. The number of firms and even governments implementing open innovation activities is steadily growing. This growth in numbers generates lots of opportunities for researchers to acquire empirical data from these activities, which may be used to answer some of the proposed questions above. But this growth also has its downsides. With more and more firms hosting co-creation activities, customers could become a scarce good, for which companies have to compete for in order to get them into "their" activities. Ultimately, this could result in a shortage of the formerly infinite resource, the "customer crowd", adding a new facet to firms' competition among customers. Modeling the effect of customer co-creation and the scare resource of "innovative users" could become a fascinating field for future research in economics and strategy.

\section{References}

Acito, F. and Hustad, T. P. (1981). "Industrial product concept testing.” In: Industrial Marketing Management, 10(3), 157-164.

Akao, Y. (1990). Quality function deployment: Integrating customer requirements into product design. Cambridge, MA: Productivity Press.

Allen, R. C. (1983). "Collective invention.” In: Journal of Economic Behavior and Organization, 4(1), 1-24.

Anderson-Connell, L. J., Ulrich, P. V., and Brannon, E. L. (2002). "A consumerdriven model for mass customization in the apparel market." In: Journal of Fashion Marketing and Management, 6(3), 240- 258.

Bartl, M., and Ivanovic, I. (2010). "Netnography - Finding the right balance between automated and manual research." In: Web-Monitoring, ed. Patrick Brauckmann. UVK Publishing, Konstanz 2010, 157-174.

Bendapudi, N., and Leone, R. (2003). "Psychological implications of customer participation in co-production." In: Journal of Marketing, 67(1), 14-28.

Benkler, Y. (2001). "Coase's Penguin, or: Linux and the Nature of the Firm.” In: The Yale Law Journal 112, 369-446.

Berthon, P. R., Pitt, L. F., McCarthy, I. and Kates, S. M. (2007). "When customers get clever: Managerial approaches to dealing with creative consumers." In: Business Horizons, 50(1), 39-47.

Blazevic, V. and Lievens, A. (2008). "Managing innovation through customer coproduced knowledge in electronic services: An exploratory study." In: Journal of the Academy of Marketing Science, 36(1), 138-151. 
Brockhoff, K. (2003). “Customers' perspectives of involvement in new product development." In: International Journal of Technology Management, 26(5/6), 464481.

Brown, J. S. and Eisenhardt, K. M. (1995). "Product Development: Past Research, Present Findings, and Future Directions." In: The Academy of Management Review, 20(2), 343-378.

Caloghirou, Y., Kastelli, I. and Tsakanikas, A. (2004). "Internal capabilities and external knowledge sources: Complements or substitutes for innovative performance?" In: Technovation, 24(1), 29-39.

Carbonell, P., Rodriguez-Escudero, A. and Pujari, D. (2009). "Customer involvement in new service development: An examination of antecedents and outcomes." In: Journal of Product Innovation Management, 26(5), 536-550.

Cassiman, B. and Veugelers, R. (2006). "In search of complementarity in innovation strategy: internal r\&d and external knowledge acquisition." In: Management Science, 52(1), 68-82.

Chesbrough, H. W. (2003). Open Innovation: The New Imperative for Creating and Profiting from Technology. Boston, MA: Harvard Business School Press.

Chesbrough, H. W. and Crowther, A. K. (2006). "Beyond high tech: Early adopters of open innovation in other industries." In: R\&D Management, 36(3), 229-236.

Cooper, R. G. (1993). Winning at New Products: Accelerating the Process from Idea to Launch. Boston, MA.: Perseus Books.

Dahan, E. and Hauser, J. R. (2002). “'The virtual customer." In: Journal of Product Innovation Management, 19(5), 332-353.

Dahan, E. and Srinivasan, V. (2000). "The Predictive Power of Internet-Based Product Concept Testing Using Visual Depiction and Animation." In: Journal of Product Innovation Management, 17(2), 99-109.

Danneels, E. (2002). "The dynamics of product innovation and firm competences." In: Strategic Management Journal, 23(12), 1095-1121.

Day, G. S. (1994). "The Capabilities of Market-Driven Organizations.” In: The Journal of Marketing, 58(5), 37-52.

Day, G. S. (1996). "Using the Past as a Guide to the Future: Reflections on the History of the Journal of Marketing." In: The Journal of Marketing, 60(1), 14-16.

Diener, K. and Piller, F. (2010). The Market for Open Innovation. Raleigh, NC: Lulu 2010.

Dolan, R. J. and Matthews, J. M. (1993). "Maximizing the utility of customer product testing: Beta test design and management." In: Journal of Product Innovation Management, 10(4), 318-330.

Drucker, P. (1954). The Practice of Management. New York, NY: Harper and Row. 
Ebner, W., Leimeister, M., Bretschneider, U. and Krcmar, H. (2008). "Leveraging the Wisdom of Crowds: Designing an IT-Supported Ideas Competition for an ERP Software Company" In: Proceedings of the 41st Annual Hawaii International Conference on System Sciences (HICSS 2008) (pp.417).

Fang, E. (2008). "Customer participation and the trade-off between new product innovativeness and speed to market." In: Journal of Marketing, 72(4), 90-104.

Flowers, S. (2008). "Harnessing the hackers: The emergence and exploitation of Outlaw Innovation.” In: Research Policy, 37(2), 177-193.

Franke, N. and von Hippel, E. (2003). "Satisfying heterogeneous user needs via innovation toolkits: the case of Apache security software." In: Research Policy, 32(7), 1199-1215.

Franke, N., Keinz, P. and Schreier, M. (2008). "Complementing Mass

Customization Toolkits with User Communities: How Peer Input Improves Customer Self-Design.” In: Journal of Product Innovation Management, 25(6), 546559.

Franke, N. and Piller, F. T. (2003). "Key research issues in user interaction with user toolkits in a mass customisation system.” In: International Journal of Technology Management, 26(5), 578-599.

Franke, N. and Piller, F. T. (2004). "Toolkits for user innovation and design: An exploration of user interaction and value creation." In: Journal of Product Innovation Management, 21(6), 401-415.

Franke, N. and Schreier, M. (2002). "Entrepreneurial opportunities with toolkits for user innovation and design.” In: International Journal on Media Management, 4(4), $225-234$.

Franke, N. and Shah, S. (2003). "How communities support innovative activities: An exploration of assistance and sharing among end-users." In: Research Policy, 32(1), 157-178.

Fredberg, T., Elmquist, M. and Ollila, S. (2008). Managing Open Innovation: Present Findings and Future Directions. Stockholm, Sweden: VINNOVA Swedish Governmental Agency for Innovation Systems.

Fredberg, T. and Piller, F. T. (2008). "The paradox of strong and weak customer ties." Paper presented at the 2008 Meeting of the SMS. Cologne, Germany.

Freeman, C. and Soete, L. (1997). The Economics of Industrial Innovation. London: Printer.

Füller, J., Jawecki, G. and Mühlbacher, H. (2006). "Innovation creation by online basketball communities.” In: Journal of Business Research, 60(1), 60-71.

Füller, J., Matzler, K. and Hoppe, M. (2008). "Brand community members as a source of innovation.” In: Journal of Product Innovation Management, 25(6), 608619. 
Füller, J. (2010). "Refining virtual co-creation from a consumer perspective." In: California Management Review, 52(2), 98-122.

Gales, L. and Mansour-Cole, D. (1995). "User involvement in innovation projects: Toward an information processing model." In: Journal of Engineering and Technology Management, 12(1-2), 77-109.

Green, P. E., Carroll, J. D. and Goldberg, S. M. (1981). “A general approach to product design optimization via conjoint analysis." In: The Journal of Marketing, 45(3), 17-37.

Griffin, A. and Hauser, J.R. (1993). "The voice of the customer." In: Marketing Science, 12(1), -27 .

Gruner, K. E. and Homburg, C. (2000). "Does customer interaction enhance new product success?” In: Journal of Business Research, 49(1), 1-14.

Henkel, J. and Sander, J. G. (2003). "Identifikation innovativer Nutzer in virtuellen Communities." In: C. Herstatt and B. Verworn (Eds.). Management der frühen Innovationsphasen. Wiesbaden: Gabler, 73-102.

Hennig-Thurau, T., Gwinner, K. P., Walsh, G. and Gremler, D. D. (2004). "Electronic word-of-mouth via consumer-opinion platforms: What motivates consumers to articulate themselves on the Internet?" In: Journal of Interactive Marketing, 18(1), 38-52.

Homburg, C., Workman, J. and Jensen, O. (2000). "Fundamental changes in marketing organization: The movement toward a customer-focused organizational structure." In: Journal of the Academy of Marketing Science, 28(4), $459-478$.

Howe, J. (2006). "The rise of crowdsourcing." In: Wired, 14(6).

Howe, J. (2008). Crowdsourcing: Why the Power of the Crowd Is Driving the Future of Business. New York, NY: Crown Business.

Jeppesen, L. B. and Frederiksen, L. (2006). "Why do users contribute to firmhosted user communities? The case of computer-controlled music instruments.” In: Organization Science, 17(1), 45-63.

Joshi, A. W. and Sharma, S. (2004). "Customer knowledge development: Antecedents and impact on new product performance." In: The Journal of Marketing, 68(4), 47-59.

Kaulio, M. A. (1998). "Customer, consumer and user involvement in product development: A framework and a review of selected methods." In: Total Quality Management, 9(1), 141-149.

Kendall, C. L. and Russ, F. A. (1975). "Warranty and complaint policies: an opportunity for marketing management." In: The Journal of Marketing, 39(2), 3643. 
Knudsen, M.P. (2007). "The relative importance of interfirm relationships and knowledge transfer for new product development success." In: The Journal of Product Innovation Management, 24(2), 117-138.

Kozinets, R.V. (1998). “The field behind the screen: using netnography for marketing research in online communities." In: Joumal of Marketing Research, 39(1), 61-72.

Kozinets, R.V. (2002). "On netnography: Initial reflections on consumer research investigations of cyberculture.” In: Advances in Consumer Research, 25, eds. Joseph W. Alba and J. Wesley Hutchinson. Provo, UT: Association for Consumer Research, 366-371.

Kotler, P. (1991). Marketing Management (7th Ed.). Englewood Cliffs, NJ: PrenticeHall.

Lakhani, K. and von Hippel, E. (2003). "How open source software works: "free" user-to-user assistance." In: Research Policy, 32(6), 923-943.

Laursen, K. and Salter, A. (2006). "Open for innovation: The role of openness in explaining innovation performance among UK manufacturing firms." In: Strategic Management Journal, 27(2), 131-150.

Leonard-Barton, D., and Rayport, J. F. (1997). "Spark innovation through empathic design.” In: Harvard Business Review, 75(6), 102-113.

Lerner, J. and Tirole, J. (2002). "Some simple economics of open source." In: The Journal of industrial Economics, 50(2), 197-234.

Lichtenthaler, U. (2009). "Outbound open innovation and its effect on firm performance: examining environmental influences." In: R\&D Management, 39(4), 317-330.

Magnusson, P. (2009). "Exploring the contributions of involving ordinary users in ideation of technology-based services." In: Journal of Product Innovation Management, 26(5), 578-593.

Mansfield, E. (1986). "Patents and innovation: An empirical study." In: Management Science, 32 (2), 173-181.

Matthing, J., Sandén, B. and Edvardsson, B. (2004). "New service development: learning from and with customers." In: International Journal of Service Industry Management, 15(5), 479-498.

McKenna, R. (1991). Relationship Marketing: Successful Strategies for the Age of the Customer. Reading, MA: Addison-Wesley.

Nambisan, S., Agarwal, R. and Tanniru, M. (1999). "Organizational mechanisms for enhancing user innovation in information technology.” In: MIS Quarterly, 23(3), 365-395.

Narver, J. C. and Slater, S. F. (1990). "The effect of a market orientation on business profitability.” In: The Journal of Marketing, 54(4), 20-35. 
Nonaka, I. and Takeuchi, H. (1995). The Knowledge-Creating Company: How Japanese Companies Create the Dynamics of Innovation. New York, NY: Oxford University Press.

O’Hern, M.S. and Rindfleisch, A. (2009). "Customer co-creation: a typology and research agenda." In: Review of Marketing Research, Volume 6. Ed. Naresh K. Malhotra, Armonk, NY: Sharpe, 84-106.

Ogawa, S. and Piller, F. T. (2006). "Reducing the risks of new product development." In: Sloan Management Review, 47, 65-72.

Page, A. L. and Rosenbaum, H. F. (1992). "Developing an effective concept testing program for consumer durables." In: Journal of Product Innovation Management, 9(4), 267-277.

Parasuraman, A. and Grewal, D. (2000). "Serving customers and consumers effectively in the twenty-first century: A conceptual framework and overview." In: Journal of the Academy of Marketing Science, 28(1), 9-16.

Peppers, D. and Rogers, M. (1993). "A new marketing paradigm: Share of customer, not market share.” In: Strategy and Leadership, 23(2), 14-18.

Piller, F.T. (2004). Innovation and V alue Co-Creation. Habilitationsschrift an der Fakultät für Wirtschaftswissenschaften der Technischen Universität München.

Piller, F.T. and Ihl, C. (2009). "Open Innovation with Customers - Foundations, Competences and International Trends." In: Expert Study commissioned by the European Union, The German Federal Ministry of Research, and Europäischer Sozialfond ESF. Published as part of the project "International Monitoring”. Aachen: RWTH ZLW-IMA 2009.

Piller, F.T. and Walcher, D. (2006). "Toolkits for idea competitions: A novel method to integrate users in new product development." In: R \&D Management, 36(3), 307-318.

Piller, F.T., Reichwald, R. and Tseng, M. (2006). "Competitive advantage through customer centric enterprises." In: International Journal of Mass Customization, 1(23), 157-165.

Pine, J. B. (1993). Mass Customization. Boston, MA: Harvard Buisness School Press.

Prahalad, C.K. and Krishnan, M. S. (2008). The New Age of Innovation: Driving Cocreated V alue Through Global Networks. New York, NY: McGraw Hill.

Ramírez, R. (1999). "Value co-production: Intellectual origins and implications for practice and research.” In: Strategic Management Journal, 20(1), 49-65.

Reichwald, R. and Piller, F.T. (2009). Interaktive Wertschöpfung: Open Innovation, Individualisierung und neue Formen der Arbeitsteilung. 2nd. Edition, Wiesbaden: Gabler.

Salvador, F., de Holan, M. and Piller, F. T. (2009). "Cracking the Code of Mass Customization.” In: MIT Sloan Management Review, 50(3), 71-78. 
Sawhney, M. and Prandelli, E. (2000). "Communities of Creation: Managing distributed innovation in turbulent markets." In: California Management Review, 42(4), 24-54.

Sawhney, M., Verona, G. and Prandelli, E. (2005). "Collaborating to create: The Internet as a platform for customer engagement in product innovation.” In: Journal of Interactive Marketing, 19(4), 4-17.

Schumpeter, J. A. (1942). Capitalism, socialism and democracy. New York, NY: Harper.

Seybold, P. (2006). Outside Innovation. Crown Business: New York.

Sheth, J., Sisodia, R. and Sharma, A. (2000). "The antecedents and consequences of customer-centric marketing." In: Journal of the Academy of Marketing Science, 28(1), 55-66.

Sloan, A. P. (1963). My years with General Motors. New York, NY: Doubleday.

Smith, W. R. (1956). "Product differentiation and market segmentation as alternative marketing strategies." In: The Journal of Marketing, 21(1), 3-8.

Spann, M. and Skiera, B. (2003). "Internet-based virtual stock markets for business forecasting." In: Management Science, 49(10), 1310-1326.

Stuart, T. E. and Podolny, J. M. (1996). "Local search and the evolution of technological capabilities.” In: Strategic Management Journal, 17(S1), 21-38.

Szulanski, G. (1996). "Exploring internal stickiness: Impediments to the transfer of best practice within the firm." In: Strategic Management Journal, 17, 27-43.

Tapscott, D. and Williams, A. D. (2006). Wikinomics: How Mass Collaboration Changes Everything. New York, NY: Portfolio.

Tether, B.S. and Tajar, A. (2008). "Beyond industry-university links: Sourcing knowledge for innovation from consultants, private research organisations and the public science base." In: Research Policy, 37 (9), 1079-1095.

Terwiesch, C. and Loch, C. H. (2004). "Collaborative prototyping and the pricing of custom-designed products." In: Management Science, 50(2), 145-158.

Terwiesch, C. and Xu, Y. (2008). "Innovation contests, open innovation, and multiagent problem solving." In: Management Science, 54(9), 1529-1543.

Thomke, S. (2003). Experimentation matters: Unlocking the potential of new technologies for innovation. Boston, MA: Harvard Business School Press.

Thomke, S. and von Hippel, E. (2002). "Customers as innovators: a new way to create value.” In: Harvard Business Review, 80(4), 74-81.

Toubia, O. and Florès, L. (2007). “Adaptive idea screening using consumers.” In: Marketing Science, 26(3), 342-360.

Tseng, M. M., Kjellberg, T. and Lu, S. C. Y. (2003). "Design in the new ecommerce era." In: CIRP Annals - Manufacturing Technology, 52(2), 509-519. 
Tseng, M. M. and Piller, F. T. (2003). “The customer centric enterprise.” In: M. M. Tseng and F. T. Piller (Eds.). The customer centric enterprise: Advances in mass customization and personalization (pp. 1-18). New York, NY Springer.

Ulwick, A.W. (2002). "Turn customer input into innovation.” In: Harvard Business Review, 80(1), 91-97.

Ulrich, P., Anderson-Connell, L. J. and Wu, W. (2003). "Consumer co-design of apparel for mass customization." In: Journal of Fashion Marketing and Management, 7(4), 398-412.

Urban, G. L. and von Hippel, E. (1988). "Lead user analysis for the development of new industrial products.” In: Management Science, 34(5), 569-582.

von Hippel, E. (1978). “A customer-active paradigm for industrial product idea generation.” In: Research Policy, 7(3), 240-266.

von Hippel, E. (1988). The Sources of Innovation. New York, NY: Oxford University Press.

von Hippel, E. (1994). "Sticky information and the locus of problem solving: Implications for innovation” In: Management Science, 40(4), 429-439.

von Hippel, E. (1998). "Economics of product development by users: The impact of “sticky” local information.” In: Management Science, 44(5), 629-644.

von Hippel, E. (2005). Democratizing Innovation. Cambridge, MA: MIT Press.

von Hippel, E., and Katz, R. (2002). "Shifting innovation to users via toolkits." In: Management Science, 48(7), 821-833. 



\title{
3
}

\section{Governing Social Production}

\author{
Niva Elkin-Koren
}

\begin{abstract}
The rise of social production and the increase in User Generated Content (UGC) destabilize some of the fundamental premises of our current copyright law. Copyright law is primarily designed to regulate the relationships of a single owner with other non-owners and is focused on the sovereignty of the author. Social production, by contrast, requires us to articulate a matrix of relationships between the individual, the facilitating platform and the communities and crowds involved in social production. This Article examines the social dimension of content production and analyzes the consequences for the governance of content in the social web. Part I describes social production and analyzes the implications for the stakeholders involved. Part II explains why social production might be incompatible with the current copyright regime. In particular, I argue that copyright law mainly defines rights against strangers and fails to provide a framework for managing the rights and interests within a gigantic group of collaborators. Furthermore, the exclusivity offered by copyright law may undermine social motivation and collaborative production. In Part III, I outline some of the challenges for legal policy.
\end{abstract}




\section{Introduction}

In this chapter I will focus on law and social production. Lawyers often tend to overrate the role of law in regulating the behavior of people. They tend to believe that by simply providing a legal framework one can change the behavior of the players in any given market. Indeed, there are serious doubts regarding the role of law in the information environment. This might be due to the global nature of the Internet that is disconnected from any particular legal regime. It may also arise from the virtual nature of the information environment and the enforcement challenges which contribute to a general disregard for the law in this environment. At the same time, however, the law shapes the behavior of many players, especially market players and governmental actors and, therefore, legal policy should be taken seriously when considering the future of social production.

The rise of social production has been widely discussed by the literature. The title of Clay Shirky's book, Here Comes Everybody: The Power of Organizing Without Organizations, suggests that social production occurs without any organizational structure. The seminal work of Yochai Benkler, The Wealth of Networks: How Social Production Transforms Markets and Freedom, describes the shift from industrial production of content to social production, which allows users to coordinate and collaborate outside the organizational structure of firms and the state.

This view may overlook some of the organizational structures that are in place in this type of production, which are shaping the behavior of players and the relationships among them. One needs to bear in mind that social production does not take place in a vacuum. There are different normative systems which affect our behavior online, and are shaping social production: not simply statutes and court decisions, but also licenses, Terms of Use (ToU), as well as social norms, DRMs, default settings of platforms such as Facebook, and the architecture of the network. In this chapter, I would like to take a look at the ways in which social production is shaped by legal norms, and offer some thoughts on how it should be regulated.

Copyright law is a legal regime which regulates the production of content, with the purpose of promoting creative activities. The shift from the industrial production of content to a more diverse environment, where content is also generated by individual users (User-Generated-Content, or UGC) and by social production, marks a significant moment for copyright law. Copyright law was tailored to serve the special needs of mass production of content, which dominated the content industry during the twentieth century. This traditional production structure is now displaced, as social production grow alongside the old model. The rationale of copyright law assumes that corporations require some economic incentives in order to make the large financial investments necessary for mass production and 
distribution of content. Copyright law provides these incentives by designing a set of exclusive rights, which allow the investors to recoup their investments. The content industry (book publishers, record companies, mass media) invested in producing a master copy of the work (a novel, a movie) and recouped their investment by selling copies at a monopoly price or by licensing exclusive broadcast rights. It was therefore essential for the content industry to exercise exclusivity over the economic exploitation of the works it produced. As we move to social production, we need to ask: Is copyright law still useful in facilitating creativity? And moreover, what type of new governing structures can facilitate the emerging model of social production?

I will begin by briefly describing social production and then highlight some drawbacks of the current copyright regime in facilitating this emerging mode of content production. Finally, I will offer some thoughts on how legal institutions can facilitate social production.

\section{What is Social Production?}

What is social production? One answer to this question is: "You know it when you see it." Wikipedia and Free Software are of course classic examples of social production. The question is: what makes them social? Some of the literature on social production has focused on the rise of user-generated content, emphasizing how individuals are now able to create what only corporations were able to produce until quite recently. Scholars were describing, for instance, how bloggers are replacing newspapers and how UGC might be politically empowering as it enables what Manuel Castells calls mass self-communication. Mass self-communication, as well as new opportunities for individuals to engage in generating culture, may enhance freedom and autonomy.

My focus here, however, is slightly different. I would like to focus on social production which reflects the cumulative effort of a group. Let me suggest three features that make social production significantly different from the mass production of content which characterized the content industry. These features relate to the following questions: Why we create? how we create? and, finally, what outcome of the creation process do we seek to induce? These features will help us identify the implicit assumptions of copyright law, and its discrepancy with the new environment.

A key feature of social production is social motivation. Monetary incentives were essential to the content industry and the business model of profit maximizing companies in the industrial era. Social production makes room for individuals and takes advantage of the wide variety of motivations which drives them, such as selfexpression, creative satisfaction, a desire to establish online reputation or a wish to strengthen one's self-esteem. Social production enables us to take advantage of 
these different motivations as individual creators are pushed to the forefront of creative processes.

But social motivation is not simply a type of non-monetary motivation, such as self-satisfaction and creative passion. To further understand social production we need to gain a better understanding of what is sometimes referred to as "othersoriented motivations," the motivations that acquire their meanings from interacting with others. While self-oriented motives focus on the individual creator, in other-oriented motives the social context plays a key role. This includes, for instance, the desire to gain recognition within a particular community. Selfexpression can sometimes be intrinsic, as we sometimes wish to express our individual voice simply for the sake of asserting our autonomy. In other cases, however, we are seeking a conversation: we are not simply looking for self-expression, but also want to be heard - often by a particular audience, to be approved by our listeners, to get feedback from our readers, to engage in dialogue. Another set of social motivations are linked to affiliation and identity: the need to feel part of a group, the contribution to others based on reciprocity, and also the commitment to others, to a particular social setting, to a special cause, or to a particular community.

All these motivations play a role when we talk about social production and as we move away from industrial production to a hybrid structure which incorporates also social production. From the perspective of policy, social motivation requires us to shift our focus from the individual or the corporation to the community of users who engage in creative processes. Facilitating social motivation may therefore require securing the social features which keep this motivation thriving.

Another aspect of social production is the social nature of the process of creation through interaction and collaboration. The collaboration with others is often what drives someone to join a creative initiative and the prospects of engaging with others may often enhance social motivation. One of the advantages of the Internet is the dramatic cut in the cost of communicating and coordinating with others. By reducing these costs, the web facilitates coordination among many actors. This enables large groups of individual users to synchronize their actions with other users and to coordinate their efforts to reach a particular outcome. Coordination could be achieved at the level of planning a joint project, preparing the design of a project or managing the division of labor. Coordination in the production of content may be achieved through online platforms which enable a massive number of users to accumulate their individual contributions into a unified outcome. Wikipedia is again a good example, where each editor may work on her original contribution, but also take part in constantly editing and revising the contributions of others. These micro-efforts of all contributors are merged into an outcome that is greater than the sum of its parts.

There are different kinds of collaborations emerging in this context, each of which may require a different regulatory approach. Collaboration might be ongo- 
ing and last over long periods of time, but it can sometimes be ad hoc, where it would be easier for users to opt in and out. Collaborative initiatives may involve different type of investments of time and resources, and may establish different bonds among the contributors. Some communities are very intimate and close together, and some are massive large-scale collaborations; some initiatives are focused on an immediate goal and some involve long-term interests and greater dependency among the participants. From a legal perspective, attention should be given to the special characteristics of each collaborative community.

A third feature of social production is the creation of social institutions. In this sense, social production is a community-building tool. The absence of central management and the lack of organization hierarchy do not entail that the coordinating parties are working in a normative vacuum. Relationships among the collaborating users are often shaped by the design, economic models and legal strategies of the social media platforms which facilitate collaboration among users. Social production involves many choices regarding the production of content, and therefore coordinating efforts requires some shared standards on how to make these mutual choices and on how to resolve conflicts. During the process of collaboration, the participants are generating shared norms and decision-making mechanisms regarding their joint efforts. In this sense, the potential benefits of social production go way beyond economic efficiency. Social production may generate a public good, the value of which could sometimes be greater than the content itself.

One of the hardest challenges for social production is to resolve the issue of collective action. The lack of a formal organizational structure makes it difficult to agree on a set of binding decisions related to the exploitation of the outcome of large-scale collaborations. Collaborative production can create tensions among individuals and between individuals and the group, regarding the exploitation of the output: How should the outcome generated by micro-efforts of many contributors be managed? Who will get credit for it? Who shall have the right to use it? What rights will users have in the general output? The right to simply access the output or also the right to commercially exploit it? Collaboration in making binding decisions regarding the future use of content requires that some voice be given to the individual users who are involved in the joint effort. At the same time, however, as a joint project, some weight should be given to the shared expectations and the interests of the community of collaborators as a whole.

\section{Social Production and Copyright Law}

All these aspects of social production are relevant for legal policy. From a legal perspective the question is how to design policies that would nurture social motivation, facilitate collaboration and strengthen community building.

Copyright law, which was designed to promote the production and distribution of creative works, does not promote social production. There are several reasons 
for that. One reason is that the basic tenet of copyright is exclusivity. Exclusivity is the tool by which copyright law provides incentives to create - authors are granted a set of exclusive rights and therefore every potential user is required to acquire a license to use. This enables owners to charge a fee for each and every use that falls under the bundle of rights. These monetary incentives were essential for the sustainability of the content industry. They may no longer offer a useful incentives matrix where individual users are motivated by a mixture of monetary and nonmonetary motivations.

Moreover, exclusivity may become an obstacle for collaborative efforts, which requires coordination of efforts, free flow of information, and mutual accountability. Copyright makes it more difficult to coordinate efforts and share content, since it requires prior license for each and every use. By default, collaborating users own their original contributions (i.e., photos, texts, video clips). A use by any other member may require a license. The need to acquire a license prior to the use becomes a serious obstacle, especially for amateur users who do not intend to exploit the work commercially and therefore often lack the organizational support and financial funds which are necessary for clearing rights. Amateur users may find it difficult to identify who the owner is, negotiate a license, and fund the license fees for the works they want to use.

Moreover, copyright law is a framing of the relationship among the collaborators as a transaction between a licensor (the owner of content) and a licensee (the user). This may undermine the social cohesion and the sense of community among collaborators that is one of the driving forces which keeps social production alive. Social production often reflects a different type of setting: not a market exchange among calculated individual actors, but instead engagement with a community, a conversation, a communicative act. The transactional framing shaped by copyright strengthens an individualistic perspective, which may insert distrust and strategic behavior in collaborative communities.

Another reason why copyright law does not serve social production is that at least in the United States, it fails to protect one of the most important forces that drive social motivation: the right to attribution. Credit is one of the major motivations driving authors to engage in social production and even waive in some cases the monetary rewards.

Yet, the most serious drawback of copyright law in facilitating social production is the lack of a legal framework for governing the relationships among collaborators. Copyright law governs the relationship between owners and strangers. It defines a set of exclusive rights which requires every potential user to acquire a license prior to the use, or otherwise risk liability. Copyright law does not define, however, the rights and duties among collaborators, such as the rights of each user in the outcome as a whole, the rights contributors may retain in each of their contributions and the privileges users may enjoy in the contributions of other collaborators. 
If Wikipedia, for instance, which is the output of large-scale collaboration, can now offer printed versions of derivatives of Wikipedia, what shall be the mechanism by which such an exploitation of the joint effort is decided? How do we decide whether this is permitted or not? Do we need to ask each contributor? Is it sufficient to rely on the Terms of Use which govern the use of the platform? What if the original license did not predict such new exploitation of the joint work? And, more importantly, how do we make sure people will continue to contribute to the collaborative enterprise? Copyright law does not provide any answers to these questions. It does not offer any rules or decision-making mechanisms for addressing these rights and duties among collaborators.

Copyright law rests on the notion of a single author and concentrates the power to authorize use in the hands of a single owner: the individual author, employer, exploiting firm or even partners who share ownership. The legal toolkit, which assumes collaboration under copyright law, is rather limited. The legal rules which pertain to joint ownership are not applicable to large scale groups. Some online collaborative initiatives may lack a common intention by all participants to contribute to a unitary whole as contributions are separate and independent. But even in cases, such as that of Wikipedia, where it is arguable that users intend to contribute to a unitary whole, the work might be treated under copyright law as jointly authored, and therefore joint ownership would apply. The problem is, however, that joint ownership under copyright does not offer a useful framework for governing the output of large-scale collaboration. Joint owners share equally the ownership of copyright, unless a contrary agreement is made. The rules related to co-ownership in copyright derive from co-ownership in tangible property. Each owner can act unilaterally and independently of the other co-owners. But this rule does reflect the shared interest of the community of collaborators to use each other's microcontributions.

Large-scale collaboration on content requires a mechanism of collective action that would enable participants to reach decisions regarding the exploitation of the work in a way that would bind the entire group.

The bottom line here is that the Internet has significantly reduced the cost of coordinating labor but not the cost of collective action; that is, the process involved in negotiating norms and reaching an agreement regarding the norms that would apply to the outcome of social production.

\section{Legal Strategies}

What legal institutions could promote social production where current copyright law fails to do so? We need a legal strategy that is capable of maintaining a lively community of contributors. A regime which preserves incentives for social motivation, and protects the community assets so that community members who have already made use of content shared by others can continue to use it. 
Two legal strategies may come into play: Public ordering and private ordering. Public ordering refers to rule-making processes, which are designed by the State and its apparatus. Its norms reflect the outcome of collective action mechanisms, which are formulated and applied from the top down by public institutions. Private ordering, by contrast, concerns bottom-up processes, where each party voluntarily chooses to undertake the norms that will govern its behavior.

One way to address the problems raised by social production is through public ordering: amend copyright law by introducing new legal arrangements which are tailored for collaborative works. The downside of such strategy is that different communities may have different needs and it is difficult to come up with one standard that fits all.

Another option is to address some of these issues via private ordering; that is, contracts among the parties involved. The private ordering approach assumes that different communities may have different needs and that no single standard would fit all. As the community is playing an important role in fueling social motivation, it may also be prudent to enable communities to decide their own rules.

There are several private ordering models that are already facilitating social production: One model leaves the power to decide how to use the content with the individual owner. This licensing option is actually based on the power of the owner to license the work and define the scope of the authorized use. This model was applied by Creative Commons.

Another model surrenders the power of individual owners in the form of a "social contact," in which each participant undertakes the shared standardized terms provided by the Terms of Use (ToU) or the End User License Agreement (EULA) which governs the content, such as the license governing Free Software, the GPL.

Can social media platforms facilitate a social contract among participants through the ToU? This model of private ordering may reflect the community dimension of social production. Social media platforms are facilitators of content generated by users. Can we rely on social media platforms as facilitators for negotiating a social contract among the users? Is there any reason to believe that ToU of social media platforms, such as Facebook, would facilitate social production?

There are several reasons why I believe social media platforms might be a good fora for negotiating such a social contract. But before I move to discuss this, let me first start with an example. Facebook used to have a provision in its ToU which authorized Facebook, and its users, to use any content which was uploaded by other users of the social media network. The license was set so that it would expire when a user successfully quitted Facebook. The provision provided as follows: 
"You may remove your User Content from the Site at any time. If you choose to remove your User Content, the license granted above will automatically expire, however you acknowledge that the Company may retain archived copies of your User Content."1

Accordingly, any contributor to Facebook that uploaded any content like a clip or a picture retained the copyright in their contribution and granted the platform and its users a license to use it as long as they remain on Facebook. Once the user/author quit, however, the license would expire.

In the spring of 2009 Facebook made an attempt to change this legal situation by deleting that provision from its ToU, so that Facebook, and its users, could continue to use any content even after a user had decided to terminate membership. On February 15, 2009, The Consumerist, a consumer rights advocacy blog, reported that Facebook had revised its ToU. The news traveled swiftly and provoked an online flame which quickly ran out of control. Users were outraged, describing Facebook actions as a "rip off" and accusing it of sneakily gaining a perpetual ownership in Users Generated Content (UGC). Many have joined the "People Against the New Terms of Service" group to protest against the alleged change in the ToU. Following a three-day vocally public campaign, Facebook decided to abandon the initiative to amend its ToU. Instead it initiated a vote for a new Bill of Rights and Responsibilities among its hundreds of millions of users.

This incident actually demonstrates the special character of social media platforms and their relationship with their users.

One way to understand this story is of course to think of Facebook as trying to exploit the free labor of users and deprive them of their rights. From this perspective the ToU proposed by Facebook should be treated as a type of unconscionable contract or, in the European framework, as a standard form contract that is subject to some scrutiny by the courts.

Another way to understand the actions taken by Facebook is as representing the interests of its users as a whole. Users of social networks often make use of content provided by others and incorporate it into their own content: pictures, songs or clips. A photo I distributed on Facebook may become part of someone else's collage. Some friends on Facebook may also create together - drafting a text, editing a clip, or creating a shared album of pictures. The deletion of the said provision from the ToU, was actually serving the mutual interests of all users. Each user that contributes to Facebook may want to keep control over the content they have contributed. At the same time, however, users are using each others' copyrighted content, and may wish to continue to use it indefinitely Users who incorporated a photo which was uploaded to Facebook into their online albums, or those who incorporated some music clips into their own works, have relied on the license which was originally granted by the contributing user. If this license would

\footnotetext{
${ }^{1}$ www.facebook.com/terms
} 
expire every time someone is quitting Facebook, the ability to use any content on a social network would be seriously compromised. Facebook actually protected the users who relied on the content which was provided by their peers. From this perspective, Facebook's ToU might be viewed as a social contract. It is multidimensional: It governs the rights of users vis-à-vis Facebook, but it also protects some social dimension. It governs the relationships among users.

The reason that social media platforms, such as Facebook, could facilitate a social contract, is that their sustainability depends on the ongoing engagement of all of its users. Users of social media platforms are not simply consumers of content produced by others. They are also producers who generate original content or mashup original content in new creative ways. Without their creative engagement, and their yearning to be part of the social network, the social media platform is left without its main assets. This dependency on users active engagement requires social media platforms to be very attentive to the needs and interests of the unorganized crowd who interacts and collaborates via the platform.

At the same time, however, a social contract for a community of users, which is defined by ToU of a social media platform, may suffer several limits. One set of issues arises from users' vulnerabilities in social media platforms and the type of activities they engage in. The nature of the bargain between users and social media platforms is that platforms provide access for free and users are "paying" with a special type of "currency" - a social currency: social graphs, personal interactions, social engagements, and creative works. This type of "currency" is related to some sensitive aspects of the human condition, such as labor, identity, personal interactions, intimacy and social engagements. Consequently, this bargain between users and platforms raise new interests which require special legal protection.

Another reason we might raise concerns regarding ToU facilitated by platforms relates to the dual nature of social media platforms. On the one hand, a social media platform forms a community of users and cultivates social production. At the same time, however, for the platform the community is simply a corporate asset, which is intended to maximize profits. Platforms are increasingly torn in between these two roles. These new vulnerabilities of users and communities create concerns that may not be sufficiently addressed by the crowd or by the social media platform.

A third set of issues relates to the tyranny of the crowd. In recent years many writers have been praising the "wisdom of the crowd", especially in the online environment. The story of Facebook bylaws demonstrates, however, that the crowd may sometimes act in non-efficient manners, and in fact may not necessarily represent all the constituencies and may not lead to a rational choice for the benefit of all participants. This suggests that the pressure on platforms created by the crowd of users may act as a mitigating force to the power of platforms, but cannot entirely safeguard the interests of the community of users. 
These concerns suggest that some intervention of regulators might be necessary in these private ordering arrangements and ToU. Regulation should set limits on private ordering by platforms to safeguard the civil liberties of participants against abuse by the social media platform and also against the crowd that may put pressure on the platform to disregard the interests of individual users and serve the needs of the community as a whole.

How to secure the rights of individual users, and, at the same time, protect the interests of the community of users? Such checks and balances should be based on the principles of Public Law. One mechanism for securing the rights of individual participants is voice. Rules adapted by social media platforms should explicitly enable participants to select the norms which apply to their works and shape them as circumstances change. Voice would require the transparency of the terms of use that apply to content, so that each user could clearly understand the type of rules which apply to the content she generates and shares. It further requires that participants be given notice prior to any legal change in the ToU intended by the platform. Voice also requires an opportunity for an ongoing deliberation and negotiation of the terms by the community of users, where users are given an opportunity to express their opinion over the proposed changes.

Another issue is exit: The ability to leave a platform and transfer content and data. Participants should be able to opt out, to make sure that their choice to stay in a particular social media and to participate is sufficiently voluntary. To secure the right to exit it is necessary to identify the necessary conditions that would make exit a viable option.

\section{Summary}

The challenges for the law are to enable online communities to devise social contracts with respect to the access and use of the output of social production.

The interdependency between platforms and users, and the fact that social media platforms depend on the enduring livelihood of the community, makes these platforms a good candidate for implementing a "social contract" for collaborative online communities. They can facilitate the large-scale negotiation of norms related to the sharing and use of creative content by drafting ToU and facilitating deliberation and voting.

Public ordering may still be necessary for safeguarding the rights of individual users against the platform and against the tyranny of the crowd, by requiring voice and exit in such contractual arrangements. 


\section{References}

Benkler, Y. (2006). The Wealth of Networks: How Social Production Transforms Markets and Freedom. New Haven: Yale University Press.

Castells, M. (2009). Communication Power. New York, Oxford University Press.

Elkin-Koren, N. (2011). Copyright and Its limits in the Age of Social Production. 12 (1) Theoretical Inquires in Law.

Elkin-Koren, N. (2010). "User-Generated Platforms.” In: Dreyfuss, R., Zimmerman, D.L. and First, H. (eds.) Working Within the Boundaries of Intellectual Property. Oxford University Press.

Shirky, C. (2008). Here Comes Everybody: The Power of Organizing Without Organizations. New York: The Penguin Press HC. 


\title{
4 \\ Trust Management in Online Communities
}

\author{
Audun Jøsang
}

\begin{abstract}
Our perception of trust works as a compass for safe navigation through a world of uncertainty. On the one hand it helps us find peers with whom interaction and collaboration is most likely to be fruitful. On the other hand it helps us steer away from unacceptable risks and potential deceptions. While human intuition about trust often fails, it seems to provide us with guidance very quickly in most situations, which has the effect of significantly saving cognitive effort. Online communities represent a new environment for human interaction, and we often find that our capability to reason about trust is not well adapted to online environments. The reason for this can be the limitation of current digital interfaces which thereby reduces the richness of information we receive about others, and also the fact that people actually encounter misrepresentation or deceptive online services and behaviour relatively often. Trust management in online communities aims at making trust reasoning more powerful and reliable by collecting, analyzing and disseminating information that is relevant for trust and trust based decision making. This article describes semantic aspects of trust as well as principles and methods for building online trust and reputation systems. The problems and challenges for designing and implementing reliable trust and reputation systems are invoked and some potential solutions are mentioned. Finally, the article articulates our vision for trust management in online communities.
\end{abstract}




\section{Introduction}

Trust is a fundamental consideration for the growth and stability of markets and communities because trust guides decisions about interactions between humans and organizations. Large-scale online environments with participants from diverse geographical and cultural groups are primary arenas for human interaction, but the very nature of online environments makes trust management challenging. For example, it is common to request services from a website we have never heard of before, and from which we might never request a service again in the future.

The relative difficulty of assessing trust in online environments leads to security problems on many levels. On the technology level, the exploitation of global network mechanisms can enable attackers to disrupt services on a massive scale. On the psychological level, cleverly designed deceptions can dupe a significant percentage of online users into divulging sensitive information. On the commercial level, automated agents can exploit market platforms to commit fraud and gain unfair advantages. On the social and political levels, online media and communities can be manipulated to create unnatural opinion biases and to hijack democratic processes. There are currently very few practical methods for assessing the reliability or good faith of entities and the quality of resources in the online environment. It is challenging to enforce policies or to sanction non-compliance, and in many cases it is even difficult to know which policies apply in specific online environments. This uncertainty makes it difficult to know which resources can be relied upon and which entities it is safe to interact with, which thereby represents a serious obstacle to the creation and cultivation of quality online markets and communities. However, it is in this environment of risk and uncertainty that online communities and markets must grow.

Innovation in traditional security technologies is an important and a necessary factor for creating reliable online environments, but it is certainly not enough. The traditional definition of information security is the preservation of confidentiality, integrity and availability. Traditional information security assumes that the information resources have an owner who wants to protect their confidentiality, integrity and availability. The owner then defines policies and implements security controls to enforce them and to prevent misuse of the resources or keep misuse to a minimum. Unfortunately this model does not fit well with reality on the open Internet. We can be harmed simply by accessing low-quality, misrepresented or deceptive resources. Even if deceptive resources do not affect our information systems directly, they can have a negative effect on our knowledge and our business processes. This type of harm is not addressed by the traditional interpretation of information security. In fact, traditional information security mechanisms are not designed to protect against this type of harm because the classic security paradigm is reversed. Security is not only about controlling who can access information assets that we own or control. We also need methods to identify which agents and third party information assets and services can be safely accessed and which should 
be avoided. Trust management, sometimes called soft security, can provide the type of security required for this purpose and is a crucial complement to traditional information security. Trust management makes our approach to solving security problems more general.

Trust management is the activity of assisting participants in online markets and communities to assess the quality, reliability and good faith of online services and of each other in order to make better decisions about which parties it is safe to transact with, and which services are correctly represented. Trust management also allows providers of quality services to market themselves as such; so that it serves parties on both sides of a trust relationship. The combination of providing an incentive for quality services and good-faith behaviour, and of providing a mechanism for sanctioning low-quality services and deceptive behaviour is the primary effect that trust management brings to online communities. The secondary effect is that this stimulates the emergence of quality markets and communities. The challenge is not only to design effective models, but also to design robust methods and mechanisms for trust management.

\section{TRUst Concepts}

Trust allows people to interact spontaneously and helps the economic system to run smoothly. Lack of trust, on the other hand, is like sand in our social and economic systems, it makes us spend inordinate amounts of time and resources on protecting ourselves against possible harm and thus slows transactions considerably. Fukuyama (Fukuyama 1995) describes the role mutual trust plays in the formation of social structures, and it is natural to assume that this also applies to the creation of quality online communities and markets. However, distrust can also serve as a useful state of mind, as it helps us to avoid harm when confronted with unreliable systems or dishonest people and organizations. The question of whom to trust online is, according to Craig Newmark, the biggest challenge for the Internet in the next decade (Ingram 2010). To face this challenge, he believes that the Web needs a "distributed trust network" that allows us to manage our online relationships and reputations.

Trust is a directional relationship between a relying party and a trusted party. One must assume the relying party to be a "thinking entity" in some form, meaning that it has the ability to make assessments and decisions based on received information and past experience. The trusted party can be anything from a person, organisation or physical entity to an abstract notion such as information or a cryptographic key. A trust relationship has a scope, meaning that it applies to a specific purpose or domain of action, such as "being authentic" in the case of an agent's trust in a cryptographic key, or "providing reliable information" as in the case of a person's trust in the correctness of an entry in Wikipedia. Mutual trust is when both parties trust each other within the same scope, but this is obviously only 
possible when both parties are thinking entities. Trust can be seen as a state of mind of the relying party, but can also have effects on the trusted party and other elements in the environment; for example, by stimulating reciprocal trust. The term "trust" is used in the literature with a variety of meanings; we will focus on just two types of trust. On the one hand, we shall look at trust as a subjective evaluation of the reliability or quality of something or somebody (i.e. the trusted party), which we will call "evaluation trust."1 On the other hand, we have the view of trust as a decision to enter into a situation of dependence on the trusted party, which we call "decision trust."

As the name suggests, evaluation trust can be interpreted as the evaluation of something or somebody independently of any actual commitment. Decision trust, on the other hand, indicates that the relying party has actually made a commitment to depend on the trusted party. To illustrate the difference between evaluation trust and decision trust with a practical example, consider a fire drill where participants are asked to escape from the third floor window of a house using a rope that looks old and appears to be in a state of deterioration. In this situation, the participants would assess the probability that the rope will hold their weight. A person who thinks that the rope could rupture would distrust the rope and refuse to use it. This is illustrated on the left-hand side of Fig. 1.

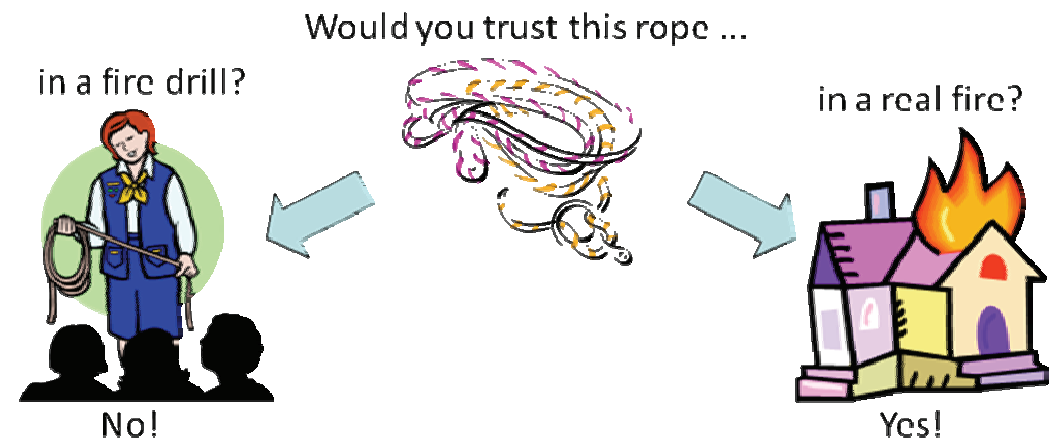

Figure 1. Same evaluation trust, but different decision trust

Imagine now that the same person is trapped in a real fire, and that the only escape is to descend from the third floor window using the same ragged-looking rope. In this situation, illustrated on the right-hand side of Fig. 1, it is likely that the person would trust the rope, even if he thinks it might break. "This change in trust decision is perfectly rational because the likelihood of injury or death while descending is weighed against the hazards of smoke suffocation and death by fire. Although the evaluation trust in the rope is the same in both situations, the decision trust

\footnotetext{
1 Also called "reliability trust."
} 
changes as a function of the different utility values associated with the different courses of action in the two situations.

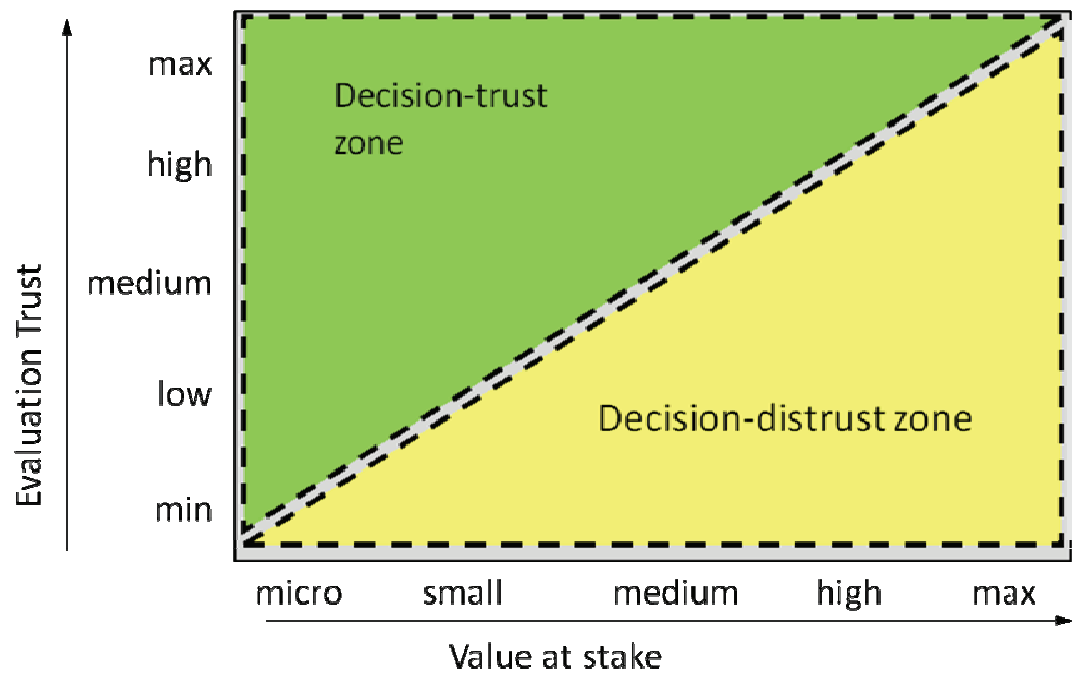

Figure 2. Relationship between evaluation trust and decision trust

This difference shows that decision trust depends on many factors, as illustrated in Fig. 2. If the value at stake is very high, then a relying party normally requires higher evaluation trust before making a trust decision. On the other hand, buying a 1 Euro lottery ticket puts little value at stake and does not require much evaluation trust. In addition to these factors, one must also consider subjective risk attitudes among many other factors. This simple analysis shows that decision trust can be a complex measure whereas evaluation trust is simply an evaluation of the trusted entity in isolation.

Trust and reputation systems, abbreviated as TRS hereafter, are mechanisms for the computation of trust/reputation measures. Different types of TRSs have different properties, so it is interesting to identify typical categories. One way to classify them is according to whether they utilize aspects of trust transitivity and whether the computed trust/reputation scores are private or public. This classification results in 4 different categories, as illustrated in Table 1. 
Table 1. Trust and reputation system (TRS) categories

\begin{tabular}{|l|l|}
\hline 1) Trust Systems & \multicolumn{1}{|c|}{ 2) Public Trust Systems } \\
Private Scores and Transitivity & Public Scores and Transitivity \\
Examples: & Examples: \\
Rummble.com, LinkedIn & PageRank, Slashdot moderation \\
\hline 3) Private Reputation Systems & 4) Reputation Systems \\
Private Scores, No Transitivity & Public Scores, No Transitivity \\
Example: & Examples: \\
Customer feedback analysis & eBay Feedback Forum, epinions.com \\
\hline
\end{tabular}

Category 1 contains pure trust systems with transitive trust and private scores, and category 4 contains pure reputation systems with public scores and without transitivity. It can be argued that pure reputation systems do use transitivity in the sense that the computed scores are derived from ratings in a transitive way. However, the transitivity goes no further than that, and these systems do not explicitly take the relying party's trust in the reputation system into account. There are systems that are neither pure trust systems nor pure reputation systems. For example, Category 2 systems, where scores are public and where transitivity is a significant factor, can be called public trust systems; one example is the Google PageRank algorithm and model. Another example is Category 3 systems, in which community participants provide ratings but the computed scores are private. This can be called a private reputation system; e.g., a customer feedback analysis performed by an organisation. The abbreviation TRS is used below to indicate any type of trust and reputation system.

Trust transitivity merits a closer look, as it relies on specific semantic constraints in order to be operable. This is illustrated in Fig. 3 below. 


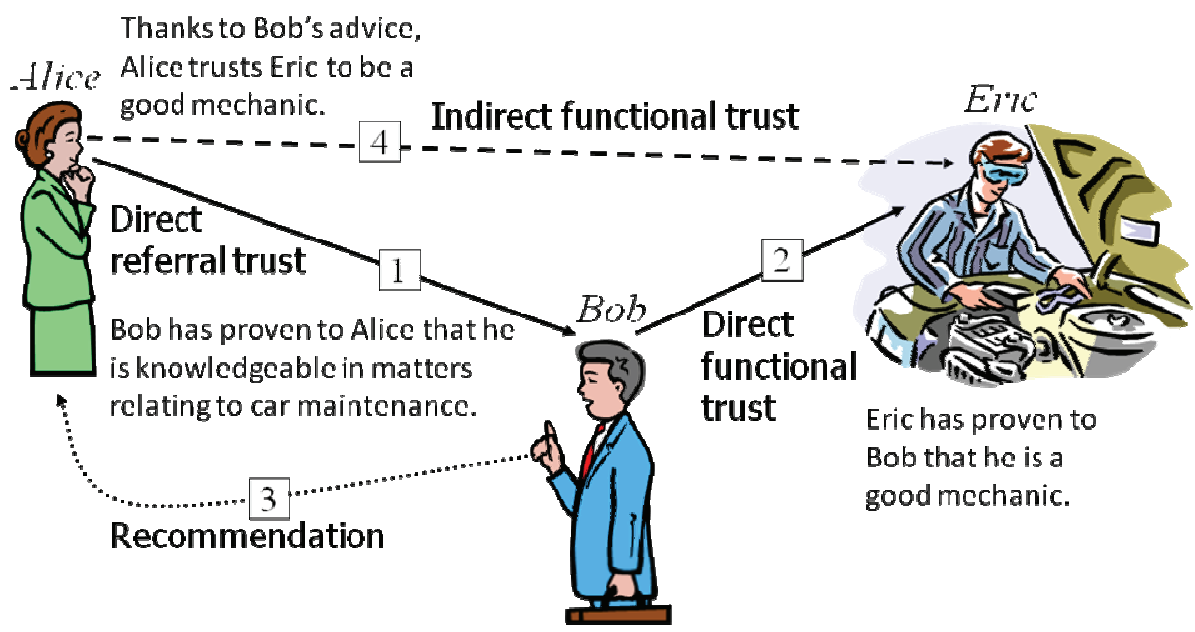

Figure 3. Trust transitivity

Assume that Alice needs to get her car fixed, but she has just arrived in town and does not know any mechanics. She asks her colleague Bob for his recommendation, because she has seen that Bob's car is always well maintained. She has direct trust in Bob on matters of car maintenance, but she would not trust Bob to actually service her car, so this is only referral trust. Assume further that Bob has had his car serviced by Eric many times and is very satisfied with Eric's work. As a result Bob's trust is both direct and functional, because Eric actually does the job. Assume now that Bob provides a recommendation to Alice about Eric. Alice can then derive functional trust in Eric because he is going to fix the car, but this trust is indirect because Alice has not had any direct experience with this mechanic. However, once Eric has serviced Alice's car she will have direct experience, so her functional trust in Eric will be based on both recommendation and direct experience. Studies show that direct experience carries more weight than indirect recommendations; as the amount of direct experience increases, the influence of indirect recommendation decreases.

One important observation from this example is that edges of referral trust make transitivity and recommendations operable, whereas the final edge of functional trust enables derivation of functional trust. A transitive trust path must thus consist of one or several consecutive referral trust edges followed by a final functional trust edge.

Another important observation is that all the trust edges have the same scope - in this example, that of car repair. Although Alice does not trust Bob to fix her car, she trusts him to recommend somebody who can do so. Trust transitivity thus requires that each edge have the same trust scope. If that were not the case, e.g. if Alice trusts Bob to look after her children, and Bob trusts Eric to fix cars, this 
would not enable Alice to derive trust in Eric, neither for fixing cars nor for looking after her children.

The level of detail in the representation and analysis of trust described above is not normally considered in practical TRSs, i.e. such systems do not distinguish between functional and referral trust, nor between direct and indirect trust.

An aspect of trust not mentioned so far is the trust or reputation values which can be binary, discrete or continuous. Humans prefer discrete verbal categories such as "low trust", "medium trust" or "bigh trust", but such measures must often be mapped to numerical values to facilitate computational analysis. Expressing trust directly as numerical values can simplify the analysis, but the derived values must often be mapped to discrete categories to facilitate human cognition.

\section{Trust and Reputation Models}

There are a large number of proposed and implemented TRSs; we will only describe some general principles here. It is worth comparing the physical and the online world in terms of their potential for trust management. Table 2 illustrates some general aspects.

Table 2. Potential for trust management in the physical world and online world

\begin{tabular}{l|l|l|} 
& $\begin{array}{l}\text { Availability and richness } \\
\text { of trust evidence }\end{array}$ & $\begin{array}{l}\text { Efficiency of communication } \\
\text { and processing }\end{array}$ \\
\hline Brick \& mortar world & Good & Poor \\
\hline Online world & Poor & Good \\
\hline
\end{tabular}

In general, the physical world provides rich and varied input evidence, but does not support highly efficient communication and analysis of this evidence. The online world, on the other hand, offers a rather limited variety of evidence, but consists of powerful networks and computers that enable extremely efficient communication and analysis of evidence.

In the case of reputation systems, for example, members of a community typically provide ratings to a reputation center as illustrated in Fig. 4 below. 


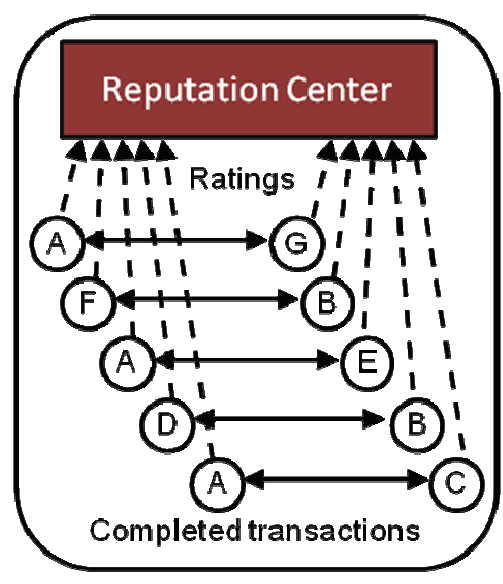

a) Past

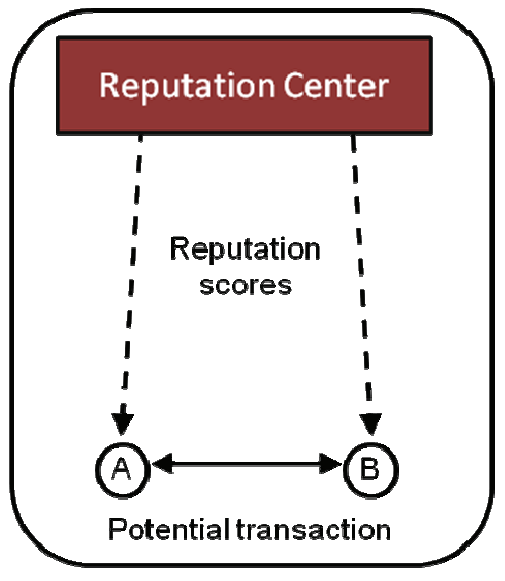

b) Present

Figure 4. Centralised Reputation System

As depicted in Fig. 4.a, the reputation system receives ratings that reflect the direct experience of community members. From these ratings, the reputation center computes reputation scores that are published online. When participants contemplate transacting with one another, they can use the reputation scores as a basis for making their decisions, as illustrated in Fig. 4.b. A reputation score thus represents a degree of evaluation trust, whereas a decision to transact represents binary decision trust, where the former supports the latter.

A simple trust network is illustrated in Fig. 5 where levels of trust are expressed as a subjective opinion visually represented by a dot within an opinion triangle. The closer the dot is to the right hand side of the triangle, the greater the trust. Conversely, proximity to the left-hand side indicates distrust. The height of the dot within the triangle indicates the level of uncertainty in the trust value. Subjective logic defines operators and methods for modeling and analyzing this type of trust networks where trust edges are represented as subjective opinions. 


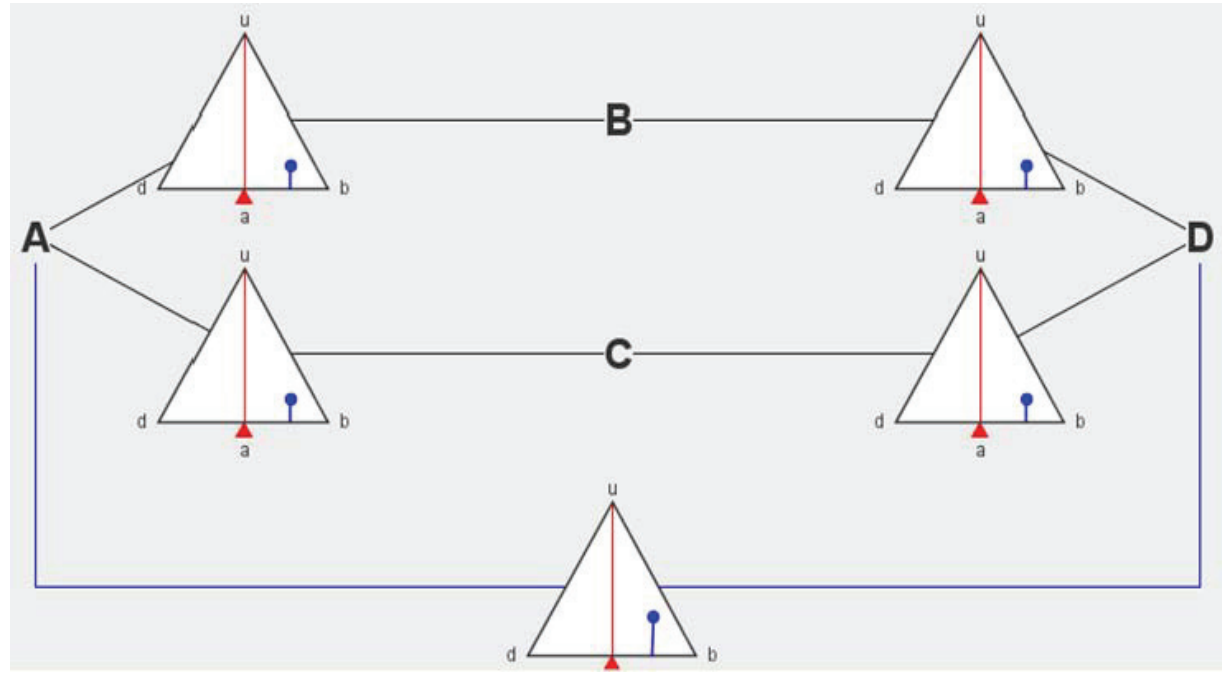

Figure 5. Simple trust network with trust values represented as subjective opinions

The two parallel trust paths $A \rightarrow B \rightarrow D$ and $A \rightarrow C \rightarrow D$ in the upper part of Fig. 2 represent input arguments for deriving agent $A$ 's trust in agent $D$, which is illustrated at the bottom of the diagram. More specifically, the input arguments are the opinions for the trust edges $[A, B],[B, D],[A, C]$ and $[C, D]$. It must be assumed that agent $A$ has already formed opinions for the trust edges $[A, B]$ and $[A, C$. Agent $B$ must then inform agent $A$ of its opinion concerning $[B, D]$, and agent $C$ must inform agent $A$ of its opinion concerning $[C, D]$. Agent $A$ can then analyse the entire trust network, expressed as $[A, D]=([A, B]:[B, D]) \vee([A, C]:[C, D])$.

The theoretical models illustrated in Figs. 4 and 5 give little detail about how a TRS should be implemented in practice. It seems that there are no general architectures that fit in all situations, so that each community or market requires a specially designed architecture in order for the TRS to function well. One of the more advanced architectures for a trust system is the moderation system used on Slashdot, the general architecture of which is illustrated in Fig. 6. 


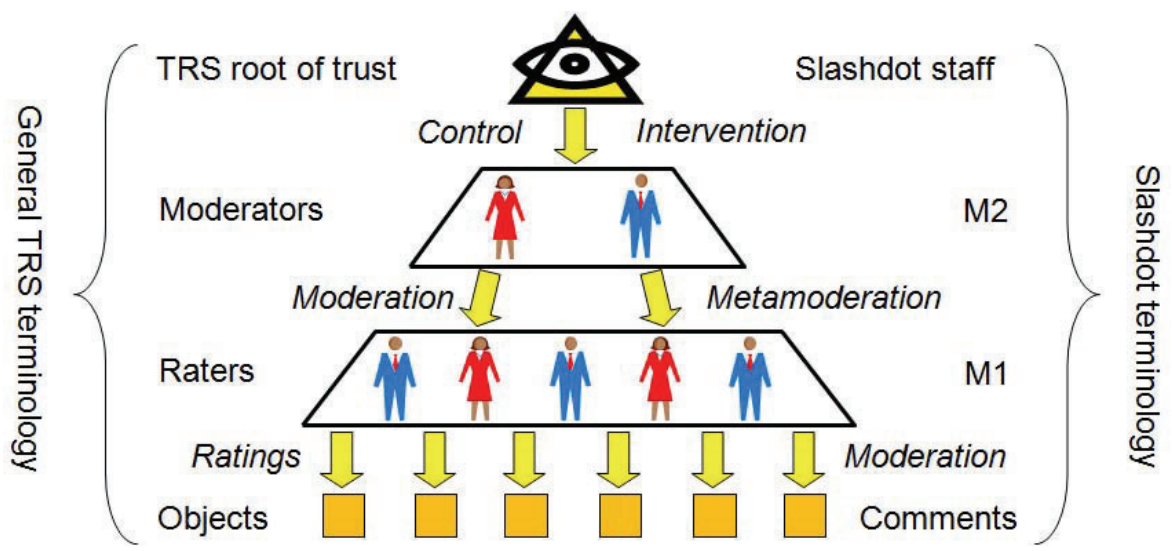

Figure 6. Slashdot moderation system architecture

Articles are posted on the Slashdot website by Slashdot staff. Once an article has been posted, anyone can comment on that article. The purpose of the Slashdot moderation system is to allow readers to filter the comments as a function of their quality. The moderation scheme actually consists of two moderation layers, where M1 is for moderating comments to articles, and M2 is for moderating M1 moderators. Users can rate comments; thus each comment gets a score. A user who only wants to read the best comments can set the threshold to only read high-scoring comments. To reduce the likelihood of unfair moderations, Slashdot implements the metamoderation layer M2 to moderate the M1 moderators. A user who wants to metamoderate will be asked to moderate the M1 ratings on 10 randomly selected comments. The metamoderator decides if a moderator's rating was fair, unfair, or neither. This moderation affects the Karma of the M1 moderators which in turn influences their eligibility for being M1 moderators in the future. The Slashdot TRS directs and stimulates the mass-collaborative effort of moderating thousands of postings every day. The system is constantly being tuned and modified and can be described as an ongoing experiment in the pursuit of the best practical way to promote quality postings, discourage noise and to make Slashdot as readable and useful as possible for a large community.

\section{Challenges for Trust and Reputation Systems}

The primary purpose of TRSs is to provide decision support for users. The value of this decision support function depends on the reliability and accuracy of the trust and reputation scores produced. Unfortunately, it seems that TRSs have many types of vulnerabilities which make them relatively easy targets for attacks and manipulation. Vulnerabilities and attacks mentioned in the literature are e.g.: 
- Ad hoc computation

- Playbooks

- Unfair ratings

- Discrimination

- Collusion

- Proliferation

- Reputation lag
-Re-entry/Change of identity

-Value imbalance

- The Sybil Attack

- No incentive to provide ratings

- Hard to elicit negative feedback

- Notorious attackers

Ad hoc computation means that the algorithm or model for deriving trust and reputation scores is unsound; i.e., that they simply produce erratic scores. A playbook consists of a sequence of actions that maximises profit or fitness of a participant according to certain criteria. There is an infinite set of possible playbook sequences, and the actual profit resulting from any particular sequence will be influenced by the actions (and playbooks) of other participants in the community. Unfair rating attacks consist in providing ratings that do not reflect the genuine opinion of the rater. Discrimination means that a service entity provides high-quality services to one group of relying parties, and low-quality services to another group of relying parties. Collusion means that a group of agents coordinate their behaviour, which e.g. can consist in running playbooks, of providing unfair recommendations, or practicing discrimination. Proliferation means that an agent offers the same service through many different channels, thereby increasing the probability of being chosen by a relying party. The reputation lag attack means that the attacker uses the time lag between an instance of a service provision and corresponding rating's effect on the service entity's score, e.g. to offer and provide a large number of low-quality services over a short period before the rating suffers any significant degradation. Re-entry means that an agent with a low score leaves a community and subsequently reenters the community under a different identity. The effect is that the agent can start from fresh, and thereby avoiding the consequences of the low score associated with the previous identity. The value imbalance attack is possible when the weight of a rating is not related to the value of the transaction. The effect of providing a large number of high-quality, low-value services and a small number of deceptive high-value services would then result in a high profit resulting from high value deception without any significant loss in scores. The Sybil attack is when a single entity establishes multiple pseudonym identities within a TRS domain to provide multiple ratings on the same service object. The name Sybil attack comes from a book of the same name by Flora Rheta Schreibe (1973) about a woman suffering from multiple personality disorder.

A TRS needs ratings to function properly. However, participants have little incentive to provide ratings after direct experiences because the ratings are only beneficial to others, not to themselves. It therefore seems that altruism plays a 
certain role in providing ratings, but reliance on altruism could potentially be considered as a weakness of TRSs. In some situations it can be especially challenging to obtain feedback about negative experiences because of people's reluctance to offend and because some might fear some form of retaliation from the rated party.

Finally, there will always be participants whose sole purpose it is to disrupt the order in a community or market, and for whom incentives for good behavior or the sanctioning of bad behavior will have no effect. While there is little a TRS can do to moderate the behavior of such participants, the community or the TRS itself should at least not risk breaking down when confronted with such participants.

Evaluation is an obvious approach to determine the strength and improve the robustness of TRSs, but TRS evaluation seems particularly challenging. A few approaches have been proposed:

- TRS evaluations can be conducted from a theoretical perspective, e.g. through simulation. However, this would only provide a partial exposure to potential threats.

- A comprehensive set of robustness evaluation methods and criteria can be defined. This would make it possible for TRS designers to produce comparable evaluations. However, the great variety in types of TRS makes it difficult to apply the same criteria to different TRSs.

- TRS robustness can be evaluated by implementing the TRS in a real environment where a certain proportion of participants have an interest in manipulating the TRS. However, establishing a real online community with a representative population of participants can be difficult.

When we see that TRSs often cannot be considered robust, it seems surprising that they still can provide significant value and that they have become so widespread. One might therefore say that TRSs follow the paradoxical "Yhprum's Law," which is the inverse of Murphy's Law, expressed by: "Something that shouldn't work sometimes does work."

One possible explanation of why TRSs are useful despite their weaknesses is that in many situations, a TRS does not necessarily need to be robust. Resnick \& Zeckhauser (Resnick and Zeckhauser 2002) consider two explanations in relation to eBay's reputation system: (a) Even though a reputation system is not robust it might serve its purpose of providing an incentive for good behaviour if the participants think it works, and (b) even though the system might not work well in the statistical normative sense, it may function successfully if it reacts swiftly to bad behavior and imposes costs for a participant to get established.

Finally, it could be argued that the TRS in an online community serves as a kind of social glue. A TRS provides an interface through which participants can communicate and relate to each other, which in itself is valuable. Any TRS with user participation will depend on how people can use it to better connect to other 
participants and to the community as a whole, and must be designed with that perspective in mind.

\section{Conclusion and Vision for Online Trust Management}

We are witnessing the emergence of new forms of cultures in which human and automated agents interact, and where it is often impossible to distinguish between the two. Cultural and biological evolution has resulted in our current set of civilized communities, despite continuous failures and setbacks along the way. When considering our options for cultivating the best possible online communities that are beneficial for local or global communities, we must remember that we have the power to make certain design choices and to implement constraints - at both the technological and behavioural levels of human and automated agents and platforms - in the way they interact in online environments. Trust management is an important element of such a culture-by-design. Trust management can enable service consumers to reliably assess the quality of services and the reliability of entities before they decide to use a particular service, or to interact with or depend on a given entity. Trust management will also enable serious service providers and online players to correctly represent their own reliability and the quality of their services, so that in effect it becomes a marketing tool as well as a compass for safe navigation of online environments.

\section{References}

Fukuyama, F. (1995). Trust: The Social Virtues and the Creation of Prosperity. New York: The Free Press.

Ingram, M. (2010). “Craig Newmark on the Web’s Next Big Problem”. Online Article featuring an interview with Craig Newmark, founder of www.craigslist.org. http://gigaom.com/2010/03/18/craig-newmark-on-thewebs-next-big-problem/, accessed on 31.03.2010.

Resnick, P. and Zeckhauser, R.. (2002). "Trust Among Strangers in Internet Transactions: Empirical Analysis of eBay's Reputation System.” In: M.R. Baye (Ed.). The Economics of the Internet and E-Commerce 11 of Advances in Applied Microeconomics. Elsevier Science. 


\title{
5
}

\section{Building a Reputation System for Wikipedia}

\author{
Christian Damsgaard Jensen
}

\begin{abstract}
Wikipedia is a web-based encyclopedia, written and edited collaboratively by Internet users. Wikipedia has an extremely open editorial policy that allows anybody to create or modify articles. This has promoted a broad and detailed coverage of subjects, but also introduced problems relating to the quality of articles. The Wikipedia Recommender System (WRS) was developed to help users determine the credibility of articles based on feedback from other Wikipedia users. The WRS provides a rating which emphasizes feedback from recommenders that the user has agreed with in the past.

This paper presents some of the work that has gone into the development of the Wikipedia Recommender System. We first developed a generic architecture for integrating a reputation system into existing legacy systems and based our design of the WRS on this architecture. Both the generic architecture and our design of the WRS are outlined in this paper. Finally, we present ongoing work to improve the reputation rating of the WRS by determining the areas of expertise for the different feedback providers in the WRS. This will allow more accurate recommendations because the system can assign a higher weight to feedback from recommenders that have previously demonstrated competence in the area of the article. In order to determine the areas of expertise of recommenders, however, we first need to identify a way to classify content in Wikipedia. We outline current efforts to evaluate different classification schemes and illustrate how knowing the expertise of recommenders may help us when we calculate the rating for a Wikipedia article.
\end{abstract}




\section{Introduction}

Wikipedia is a web-based encyclopedia, written and edited collaboratively by ordinary unpaid users of the Internet. Wikipedia has an extremely open editorial policy that allows anybody to create or modify articles. This has promoted a broad and detailed coverage of subjects, but there are plenty of examples of erroneous information that has been propagated through Wikipedia (Seigenthaler 2005; Orlowski 2006). Despite these problems, however, Wikipedia has experienced a dramatic growth in popularity over the past decade and is by many considered the first source of information on the Internet. This appears quite surprising from the perspective of economical theory, and we suspect that if the question of the longterm success of Wikipedia compared to other online references, such as Microsoft's Encarta which is edited and meticulously verified by experts, was given to economists or investors 10 -15 years ago, most of them would have predicted the success of the verified resources over Wikipedia. The strength of the crowd ensures that Wikipedia has up-to-date information on current topics that may not be considered worthy of inclusion by the editorial standards of traditional encyclopedias. Moreover, the fact that everybody can contribute to Wikipedia secures a broad coverage of topics compared to similar efforts with more restrictive editorial policies. In 2006 Larry Sanger, one of the co-founders of Wikipedia, announced the introduction of the Citizendium ${ }^{1}$ (Sanger 2004), which is a collaboratively edited encyclopedia with better verification of the content and the intentions to guarantee a higher degree of responsibility among the authors; at the time of writing (October, 2010), the Citizendium has fewer than 15000 articles (of which 148 are expert-approved $)^{2}$, while the English-language version of Wikipedia alone has more than 3.4 million articles ${ }^{3}$. It therefore appears that the open editorial policy of Wikipedia guarantees a better coverage of topics. The problem, however, remains that malicious or incompetent authors may edit articles so that they misinform the readers (Orlowski 2006) and Wikipedia articles are sometimes subject to frequent conflicting updates, so called edit wars ${ }^{45}$. It is therefore important to develop ways for ordinary Wikipedia users to determine the quality of Wikipedia articles that they read, i.e., after they have been written and published on Wikipedia. This will combine the benefits of the broad and detailed coverage of the open editing policy of Wikipedia with a higher degree of confidence in the correctness of the articles. We acknowledge the contributions of millions of Wikipedia users over the past decade, so instead of changing Wikipedia or starting from scratch, we propose the Wikipedia Recommender System (WRS) as a means to assess the qual-

\footnotetext{
1 http://en.citizendium.org/wiki/Citizendium (October 2010)

2 http://en.citizendium.org/wiki/Welcome_to_Citizendium (October 2010)

${ }^{3}$ http://en.wikipedia.org/wiki/Size_of_wikipedia (October 2010)

${ }^{4}$ http://www.webpronews.com/topnews/2006/01/30/wikipedia-bans-congress

5 http://www.podcastingnews.com/archives/2005/12/wikipedia_caugh_1.html
} 
ity of Wikipedia articles, which we believe is vitally important for the users to build trust in Wikipedia and ensure the continued success and growth of the system.

We have identified two different ways to assess the quality and establish trust in content of uncertain provenance, such as articles on Wikipedia where author may be anonymous: content-based filtering and collaborative filtering; in both cases, the term filtering embodies an assessment of the quality of an article and a ranking of an article based on its quality. Content-based filtering estimates the quality of Wikipedia articles based on textual properties and edit revision histories of the article (Vegas 2004; Suh et al. 2008; Seigneur et al. 2006, Adler and de Alfaro 2007; Adler et al. 2008), i.e., articles that contain neutral language and have not been updated for a long time are considered better than articles that contain colourful language or are still in the process of being written as can be inferred from frequent recent updates. Collaborative filtering is a filtering technique based on the subjective evaluations, generally called annotations in the literature but we prefer the less formal term feedback, of other readers (Goldberg et al. 1992), i.e., it uses feedback from other users who have read the article to determine the quality of the article. Modern collaborative filtering systems often implement a trust metric where the weight given to feedback from a particular user depends on the similarity between feedback about previously read articles and the reader's own opinion about those articles. We discuss the respective merits of these two filtering techniques in more detail in Section 2.2. The Wikipedia Recommender System (Korsgaard 2007; Korsgaard 2009; Lefevre and Korsgaard 2009), discussed in this paper, is to the best of our knowledge the only collaborative filtering system for Wikipedia. The Wikipedia Recommender System (WRS) was developed to help human users of Wikipedia to determine the credibility of an article based on feedback from other Wikipedia users. In order to preserve both the large investment that authors have made in terms of time and effort and the familiarity of the user interface for occasional users, the collaborative authoring system must be considered a legacy system that cannot be modified. Moreover, the broad established user base of Wikipedia means that the WRS should only be offered to users who opt in and must be transparent to everyone else.

The WRS allows users to calculate a personalized rating for any article based on feedback (recommendations) provided by other Wikipedia users. As part of this process, WRS users are themselves expected to provide feedback about the quality of Wikipedia articles that they have read, so the WRS implements what may be characterised as a rating-based collaborative filtering system. The recommendations consist of a simple numerical rating that encodes all relevant quality attributes, i.e., a single number is used to describe all quality attributes including accuracy, completeness, focus and lack of bias ${ }^{6}$, but it also includes "soft issues,"

${ }^{6}$ This is similar to the way that a single number, the exam mark, is used to summarize all of a student's achievements in a complete course 
such as language, structure and style. This means that it is relevant for all users to provide feedback on all articles that they read, because they may provide useful feedback about the soft issues even if they know little about the subject of the article. Not all recommenders are expected to agree on these attributes, so the WRS implements a trust metric to determine the weight that should be given to the feedback from each individual recommender, i.e., ratings from recommenders that have provided ratings that were similar to the user's own ratings in the past will carry more weight in the calculation of the overall rating for the article. The scope of Wikipedia is very broad and recommenders cannot be assumed to be equally knowledgeable in all areas, e.g., some recommenders may provide useful feedback about military history, but may know little about psychology or philosophy. It is therefore important to extend the trust metric, so that it incorporates an assessment of the recommender's expertise in the area of the article. Establishing the areas of expertise for each recommender allows more accurate use of their recommendations when rating the article, because the weight of their rating will depend on whether the article is within their area of expertise (we discuss this topic further in Section 3.4).

This paper is based on a presentation made at the workshop on "New forms of collaborative production and innovation" held in May 2010 at the LichtenbergKolleg for Advanced Studies in Göttingen. The presentation described work on the development of a reputation system for Wikipedia (the WRS) that is currently ongoing at the Technical University of Denmark. We present a brief outline of Wikipedia and the Wikipedia Recommender System that is based on previously published material (Korsgaard 2007; Korsgaard 2009). The paper also examines how an assessment of the expertise of recommenders may help improve the WRS's reputation ratings of Wikipedia articles (Lefevre 2009; Lefevre et al. 2009). We do not generally expect recommenders to be known to other users and we do not wish to violate privacy by requiring all recommenders to certify their qualifications, so the assessment of expertise must rely on existing evidence, i.e., the existing recommendations which contain the ratings that the recommender has provided for other articles. In order to assess the areas of expertise for a recommender, we need to know the areas of the articles that they have previously rated, i.e., we first need to define a way to classify content on Wikipedia. This allows us to identify recommenders who have previously provided ratings that are similar to the user's own ratings within the content class of the current article. Wikipedia contains articles about all areas of human knowledge, so the classification of Wikipedia content must be broad, but at the same time intuitive, or at the least easy to learn and understand. This means that the classification scheme must have a small number of clearly distinct classes. We discuss the classification of Wikipedia content further in Section 4. Finally, we present some initial experiments that we made to explore the feasibility of these ideas. The rest of this paper is organized in the following way: We provide a brief overview of the Wikipedia architecture in Section 2 and an outline of the Wikipedia Recommender System in Section 3. The problem 
of classifying Wikipedia content is examined in Section 4, where we also present the solution that has been implemented in the WRS. Our preliminary evaluation of the proposed classification scheme is presented in Section 5 and our preliminary conclusions and some directions for future work are presented in Section 6.

\section{Wikipedia}

The basic philosophy behind Wikipedia is that everyone should be allowed to edit everything, but that it should be easy to restore the document to its prior state if the modifications are considered undesirable. Detection is left to the users and the only means of response is to restore the previous page.

\section{Wikipedia architecture}

Wikipedia is accessed through an ordinary web browser and the Wikipedia appears to the user, as an ordinary website. The Wikipedia HTML pages are dynamically created by the MediaWiki software. MediaWiki is written in the PHP programming language, and can use a relational database management system to store the articles.

An article in Wikipedia has several sub-pages which are useful in the WRS. The structure of these sub-pages is shown in Figure 1.

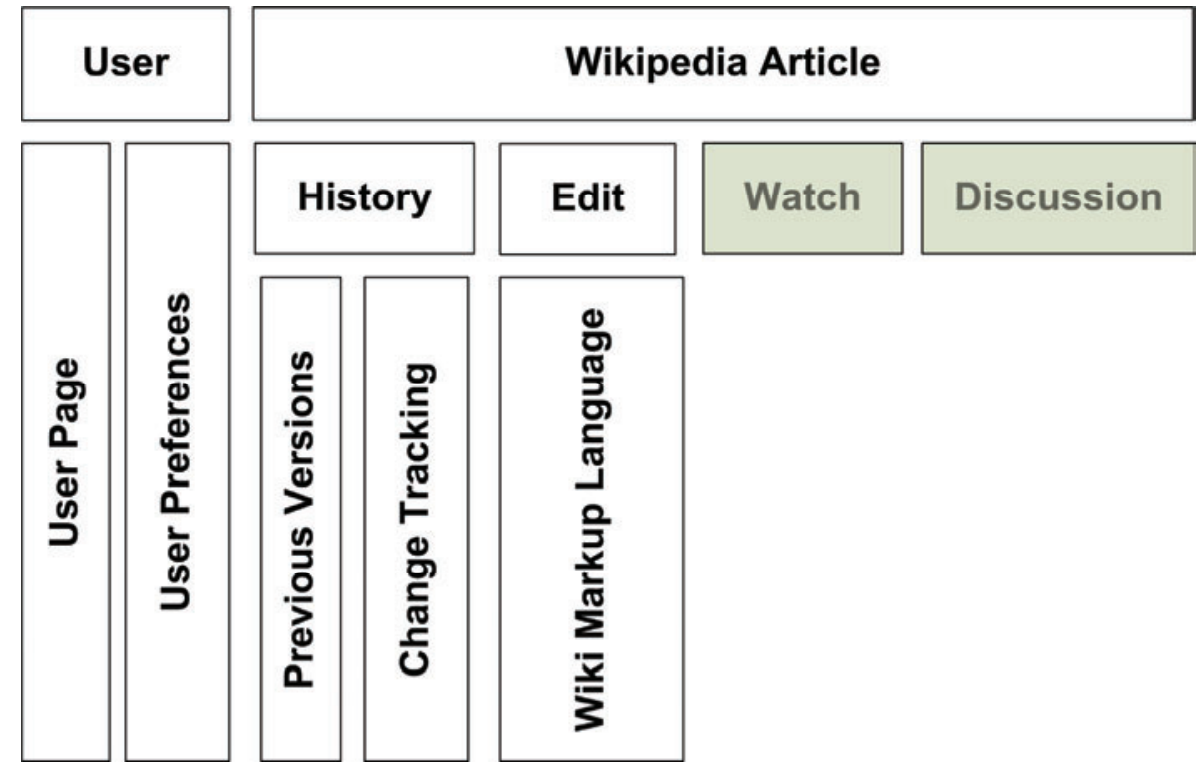

Fig.1. Simplified structure of the Wikipedia articles 
Each article has the main article presented to the viewer. Furthermore there are 4 pages that are related to each article: the history page, the edit page, the watch page, and the discussion page. The watch page is not visible unless the user is logged in. The edit page allows an active user to alter the content of the article without these modifications being visible to everyone before the page is saved. The history page provides access to previous versions of the page. Every prior version of an article, up to the existing version of the article, can be found on the history page. The history page also offers the functionality of reverting the page to a previous version if the current version has been vandalized, and of showing the difference between two versions. Furthermore, there is a user page available to users who are logged in. The user page allows the user to set preferences for Wikipedia and to keep a personal homepage. In accordance with the Wikipedia philosophy other users may still edit the content of the user page.

\section{Trust in Wikipedia}

Trust in Wikipedia is ultimately a question of the quality of the articles that it contains. The quality of a Wikipedia article is determined by a few simple properties, e.g., the article should be complete, correct and unbiased. We have previously identified two ways to establish these qualities; either by content-based filtering or by collaborative filtering (cf. Section 1). In the solutions proposed so far (Viegas et al. 2004; Suh et al. 2008; Seigneur et al. 2006, Adler and de Alfaro 2007, Adler et al. 2008), work on content-based filtering has primarily focused on identifying negative indicators, e.g., WikiTrust rates text that has remained unaltered for a long time higher than text that is frequently changed or has recently been added to the system. WikiTrust uses the background colour of the individual words in an article to indicate how long each word has remained unaltered in the article. New words will be shown on a coloured background, which will slowly fade to white if the word remains unaltered for a long time, i.e., texts that are very stable will have the same black text on white background as current Wikipedia articles. WikiTrust also implements a trust metric, so that the background colour of contributions from authors of content that has survived unaltered for long period in the past, i.e., that have a high reputation in the WikiTrust terminology, will be less intense than the background colour of contributions from authors with lower reputation. One problem with this approach is that stability does not necessarily imply quality. In the case of WikiTrust, black text on a white background can be interpreted as "nobody has seen the need to modify this text," but it may equally well be interpreted as "nobody has read this text since it was last updated long ago" or even "nobody has cared enough about this topic to correct the mistake." The fundamental problem with content-based filtering in the context of Wikipedia is that there is currently no way to explicitly endorse the content of an article, especially regarding the "soft issues," so we propose to rely on feedback from the users, i.e., to implement a collaborative filtering system. The advantage of using a collaborative filtering 
system is that articles can only have a high rating if many Wikipedia users have read and endorsed the article. Moreover, if the collaborative filtering system implements a trust metric, it ensures that feedback from users that the Wikipedia reader has agreed with in the past will carry more weight than feedback from strangers. A collaborative filtering system cannot prevent incorrect or undesirable content from entering Wikipedia, but it may help readers assess the quality of Wikipedia articles and allow them to decide whether to believe the article or look for more reliable information elsewhere. Moreover, the introduction of a reputation system is in line with the Wiki philosophy, where we find few mechanisms to prevent malicious or accidental modification of a Wiki page; detection is left to the users and the only means of response is to restore the previous page.

\section{Reputation in Wikipedia}

The number of articles in Wikipedia is growing rapidly. There are currently more than 3.4 million articles in the English Wikipedia alone and around 1,000 new articles emerge every day ${ }^{7}$. It appears obvious that modifying such a large and dynamic system is difficult and should therefore not be attempted unless absolutely necessary, so the existing Wikipedia software base should be considered as a legacy system that cannot be modified. Fortunately, the functions of a reputation system are orthogonal to the basic functions of Wikipedia, so it is possible to provide these functions, i.e., management of feedback and calculation of reputation values, from external servers.

\section{The Wikipedia Recommender System}

The Wikipedia Recommender System (WRS) has been designed to integrate with the existing Wikipedia without requiring modifications to the MediaWiki installation or the underlying Wiki engine. The design is based on a generic architecture for reputation systems which was previously published (Korsgaard and Jensen 2009). Before describing how the WRS works and how this generic architecture is implemented in the WRS, we provide a brief discussion of the application of reputation systems in the context of Wikipedia.

In the following, we describe the design of the WRS and discuss the extensions that are necessary support an assessment or recommender expertise based on the categories of articles.

\footnotetext{
7 http://en.wikipedia.org/wiki/Size_of_wikipedia (October 2010)
} 


\section{WRS overview}

The WRS is mostly implemented in a web-proxy, which mediates all communication between the user's browser and Wikipedia. Recommendations are stored in Wikipedia itself, but the recovery and distribution of recommendations, calculation of reputation ratings and formation and evolution of the user's trust in recommenders are managed by the web-proxy. This is illustrated in Figure 2, where the proxy executes on the user's own computer along with the browser.

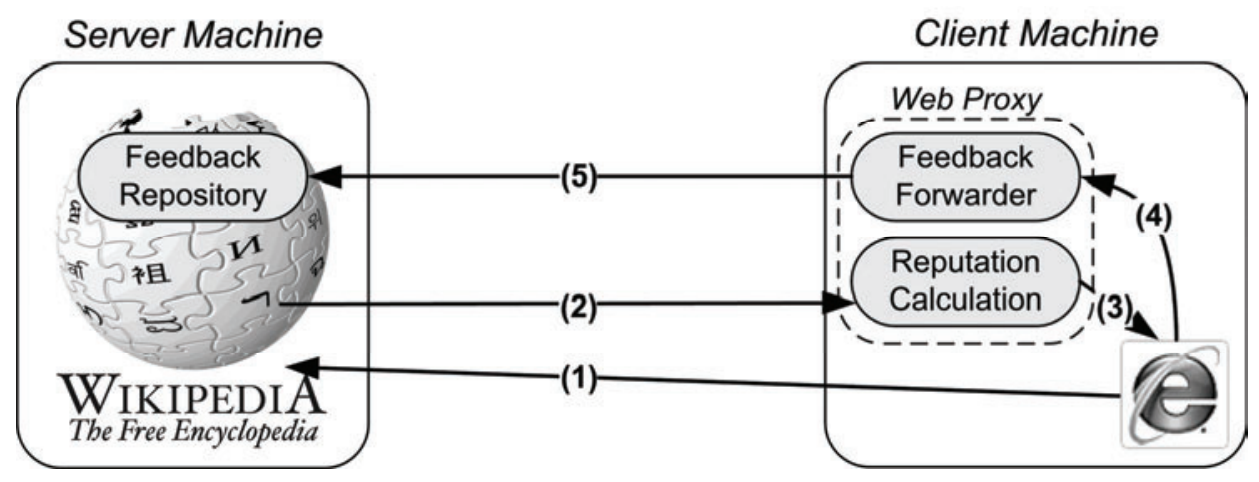

Fig.2. Overview of Wikipedia Recommender System

The browser must be configured to use the local web proxy (this is how users opt in), which intercepts requests to Wikipedia (1). The proxy retrieves the article from Wikipedia (2) along with any feedback stored about the article, which is then used to calculate the reputation score for the article. The page ${ }^{8}$ is rewritten to include the reputation score and forwarded to the browser (3).

The user now has an indication of the quality of the article and may decide to provide feedback regarding the quality of the article and the utility of the reputation rating (4). The user's indication of the utility of the score is used by the proxy to build trust in the recommenders who recommended this article and the user's own rating is stored in the feedback repository in the Wikipedia (5).

\section{WRS architecture}

The WRS is based on our general architecture for integrating reputation systems with legacy applications, which identifies the following main components: a Feedback Repository which stores user feedback, a Reputation Calculation component which calculates reputation ratings based on data from the Feedback Repository, an Identity Management component which verifies the(, possibly virtual,) identities of feed-

\footnotetext{
8 Articles in Wikipedia are contained in web pages, so we generally use the term article to refer to the logical content and page to refer to the physical data structure.
} 
back providers ${ }^{9}$ and, finally, an Interception Mechanism which mediates communication between clients and servers and makes reputation ratings and reputation data available where they are needed.

Feedback Repository The implementation of the Feedback Repository is based on the observation that everyone can edit Wikipedia, so we can store user feedback in Wikipedia itself. We have therefore created a special Wikipedia user and maintain the Feedback Repository on the user page of that user. The feedback consists of a recommendation which includes all the information relating to the recommender's rating of the article and the recommender's signature.

Identity Management The Identity Management component is used to verify recommendations, by downloading the recommender's public-key from his Wikipedia user page and validating his signature on the recommendation. When downloading the public-key, the WRS must ensure that the key has been added by the owner of the user page, i.e., that the Wikipedia user name included in the recommendation is equal to the Wikipedia name of the user who uploaded the public-key. Using Wikipedia for key distribution means that we support the same degree of anonymity as Wikipedia.

Interception Mechanism The Interception Mechanism in the WRS requires the ability to rewrite the content read from Wikipedia (to insert recommendations for the user) and to capture and store the feedback from the clients. A simple way to do this is therefore to insert a web-proxy between the user and Wikipedia.

Reputation Calculation The proxy also implements the Reputation Calculation module, which calculates the rating for a given article based on all the recommendations for the current version of that article. The rating is calculated as an average of the ratings in the recommendations weighted by the user's trust in the recommender. The rating calculator inserts an applet in the Wikipedia page, which displays the overall rating for the article and solicits feedback from the user. When the proxy receives the feedback from the user, it updates the trust values for all the recommenders who rated the article, which are then stored locally, and creates a recommendation for the article which is uploaded to the relevant location in Wikipedia. The update of trust values calculates both the trust value for the recommender that will be used in the next interaction and the user's dispositional trust (the trust dynamics) for each recommender. Both of these values are calculated as a function of the difference between the number of positive and negative expe-

\footnotetext{
9 Identity Management is only relevant for reputation systems that implement trust metrics, i.e., it is not required for a simple summation-based system, such as the one used on eBay.
} 
riences with that recommender (an interaction where the user agrees with the recommender's rating count as a positive experience; if they disagree it counts as a negative experience) (Korsgaard 2007; Jensen and Korsgaard 2008).

\section{Reputation and ratings in the WRS}

Many reputation systems provide users with a single rating, generally in the form of a numerical value or a number of stars. The interpretation of these ratings is often implicitly given by the range to which they belong, e.g., a rating of 2 on a scale 1-10 is poor but 4 out of 5 stars is good. Reputation ratings are based on the feedback from other users of the reputation system, which often include several attributes, e.g., the detailed seller information on eBay consists of the following four attributes: "Item as described", "Communication", "Shipping time" and "Shipping and handling charges". Users providing feedback may not be equally competent to evaluate the feedback attributes or they may simply have different expectations, e.g., a buyer on eBay may expect fast "Shipping time" despite ordering items from an overseas seller. It is therefore necessary to evaluate the experience of the user providing the feedback in order to properly calibrate the inclusion of the feedback in the calculation of the aggregated reputation value.

In the context of the Wikipedia Recommender System, an evaluation of the experience of a recommender aims to determine whether she is knowledgeable in the domain of the article and whether she is able to write an accurate, complete and concise article. The ratings provided by the first version of the WRS (Korsgaard 2007; Korsgaard and Jensen 2009; Lefevre et al. 2009) capture the second set of qualifications, but the system does not consider the domain of the article for which feedback is given. This means that the ratings from WRS users who have provided good feedback in one domain may carry more weight in all other domains, e.g., a WRS user who has provided good feedback about drag racing is automatically believed when she provides feedback about painters from the Italian Renaissance; this is not necessarily a good idea.

We have identified two ways to establish the expertise of recommenders, either through certification or through an evaluation of the recommenders past performance within each individual domain, but in either case we need to know the domains of all Wikipedia articles rated.

Establishing expertise based on certification requires all recommenders to document their qualifications, e.g., by making certified copies of their diplomas available on their Wikipedia user page. However, this violates both the Wikipedia's policy of allowing anonymous modifications and the privacy of recommenders. Moreover, it introduces the problem of interpreting the value of the different types of qualifications, such as establishing a universal ranking of all the different accredited and non-accredited universities. Finally, it does not allow the incorporation of recommendations from autodidacts. We therefore believe that it is better to 
base the ratings on an evaluation of the expertise demonstrated by the authors past performance. We propose to do this by classifying rated Wikipedia articles into different categories and apply the existing reputation system to the articles within each class.

\section{Extending the WRS to include categories}

In order to include the expertise of recommenders in the calculation of the rating for an article, we have implemented a new version of our prototype (Lefevre 2009; Lefevre et al. 2009) which extends the WRS to include an assessment of the expertise of recommenders according to the classification defined in Section 4. As suggested above, users are now expected to provide both a rating and a category for the article, when they return feedback to the WRS. This means that there are now two separate types of feedback that must be considered by the WRS and the trust metric must, in some way, reflect the recommender's ability to provide reliable feedback of both types. It seems obvious, however, that it is more important that a recommender is able to determine that the article is accurate, complete and well written, so we consider the rating metric the primary parameter and the category rating the secondary parameter when the WRS updates the trust value.

The introduction of the second type of feedback means that there are now four separate cases that must be considered when the user and recommender ratings are compared, because they may agree or disagree about both ratings and categories; this is illustrated in Figure 3.

\begin{tabular}{c|c} 
Rating & Category \\
\hline Agree & Agree \\
Agree & Disagree \\
Disagree & Agree \\
Disagree & Disagree
\end{tabular}

Fig. 3. Outcome of interactions.

The two cases where the user and the recommender agree on the category are covered by the trust dynamics implemented in the first WRS prototype, so we only need to define appropriate trust dynamics for the two other cases. This is an intriguing problem, because both the rating and the category are subjective values. We therefore propose to examine all the other recommendations for the article in order to determine if there is a majority among the other recommenders who support either category (if there is no clear majority, the user carries the deciding vote). We wish to define a decision function that corresponds to human intuitions. We 
therefore believe that it is reasonable to say that if the majority agrees with the user, this is clear evidence that the recommender is considered to be wrong, but if the majority agrees with the recommender, it must be considered that she could be right. We examine the two cases in greater detail in the following.

Agreement on rating, disagreement on category. Both user and recommender agree on the quality of the article, but at least one of them is wrong about the category, which suggests some problem with the comprehension of the article. However, they both agree on the apparent qualities of the article, which we consider the primary parameter, so the overall interaction is considered positive. In order to reflect the problem with comprehension of the article in the updated trust value, we introduce the notion of semi-successful interactions for which a value of $-1 / 2$ positive interaction seems appropriate.

Disagreement on rating and category. When the user and the recommender disagree about everything, we need to consider the majority of the other recommenders regarding the category of the article (in short, the majority). If the majority agrees with the user, the recommender has severely misunderstood the article, so it seems appropriate to penalize him more severely. We therefore consider the recommendation as evidence for $\mathrm{a}-3 / 2$ "positive" interaction. If the majority agrees with the recommender, the recommendation is obviously provided in a different context and should be considered on its own merit, i.e., the rating might have been right if the they had agreed on the category. It does not, however, change the fact that the rating is wrong in the user's opinion, so we consider the recommendation as evidence for $a-1 / 2$ "positive" interaction. It is important to determine what constitutes a majority. In the mathematical sense it means more than $50 \%$, but that seems inconclusive and unconvincing when deciding on the severity of penalties. We have performed a survey of Wikipedia users ability to categorize articles according to our classification scheme (cf. Section 5.1), which indicates that a majority of more than $80 \%$ appears to be safe, even for articles that have a small element of ambiguity about the category.

\begin{tabular}{c|l|r} 
Rating & \multicolumn{1}{|c|}{ Category } & Impact \\
\hline Agree & Agree & 1 \\
Agree & Disagree & $1 / 2$ \\
Disagree & Agree & -1 \\
Disagree & Disagree without majority & $-1 / 2$ \\
Disagree & Disagree with majority & $-3 / 2$
\end{tabular}

Fig. 4. Impact of categorization on trust dynamics. 
Summary The evaluation of the expertise of recommenders should have the following impact on the number of "positive" interactions used in the trust evolution function. The first and the third line in the table above correspond to the first prototype of the WRS. The second line displays the effect when the user agrees with the recommender on the rating but disagrees on the category. The two last lines show the impact of the interaction when the user and the recommender disagree on both rating and category. Line 4 shows the case where the majority agrees with the category of the recommender and line 5 shows the case where the majority agrees with the user.

\section{Classification of Wikipedia Articles}

As mentioned in Section 3.3, we need to identify a way to categorise Wikipedia articles, so that we can classify feedback according to these categories in order to assess the experience of each recommender within each of the categories that she has contributed to. We have identified two different ways to classify Wikipedia articles. We may either rely on the information that is already available in the Wikipedia, such as Portals or Wikipedia Categories, or we may define a new classification scheme and then rely on the feedback from WRS users to categorize the article; this means that recommendation ratings must be interpreted in the context that the recommender specifies.

\section{Portals}

A portal, or Wikiportal, on the Wikipedia serves as an entry-point to Wikipedia content within a topic area. Portals vary from very broad coverage, such as the "History" portal, down to very specific topics, such as the "Led Zeppelin" portal. They are hierarchically structured, so it is possible to enter a portal and find a selection of articles and sub-portals, but it is generally impossible to enter an article and find out which portal it belongs to. Moreover, articles may be reachable from several portals, which introduce problems if we wish to assign a unique category to each article. Finally, a portal is not a complete enumeration of articles belonging to the category, or topic, of the portal. This severely limits the use of portals as a means to determine the category of an article, because we cannot be sure to find an article even if we traverse all links on all pages and sub pages reachable from the main portals. Using the portals to determine the category of an article is therefore going to be computationally difficult, perhaps even impossible, and from an overall perspective will yield incomplete results. 


\section{Wikipedia categories}

A hierarchical scheme of categories has been introduced to allow authors to classify articles in the Wikipedia. The Wikipedia rules state that each article should belong to at least one category, so it is fair to assume that all articles have at least one category, but most articles will have more than one category, e.g., the "London" article belongs to 8 categories. This means that categories cannot be used directly to classify articles, but each article has a set of categories and it is possible to traverse bi-directional links in the article all the way to the root categories (and back down again). It should therefore be possible to follow all the category links to their root category and use these to define a classification of the article. There is, however, one major problem with this solution, which is that categories are socially annotated, i.e., they are all created and maintained by Wikipedia users. While the initial idea behind the categories was that they should be shaped into a tree-like structure, the actual structure has mutated into a more general graph structure, e.g., each leaf may have several parents and there may even be cycles, so some categories are their own grandparents. Finally, the set of categories is not fixed, so new categories are created as the Wikipedia expands. These new categories may have a significant overlap with existing categories, which means that an evaluation of recommender expertise would have to transfer (some of) the expertise demonstrated in the context of older categories to each of the new, overlapping categories. It is not clear to us how this may be achieved in practice and, when added to the other difficulties outlined above, it is difficult to see how categories may be used to provide a simple unambiguous classification of the articles in the Wikipedia.

\section{User-maintained categories}

As mentioned above, social annotations are often dynamic, which makes them unsuitable for the definition of a classification scheme for a dynamically growing set of articles. However, once the classification scheme has been defined, social annotations may be used to assign categories to articles. We examine the problem of defining a simple and intuitive classification scheme for the Wikipedia, which is intended to cover all areas of human knowledge.

Wikipedia Portals and Categories We briefly revisit the idea of using the existing set of Portals or Root Categories to define the classification scheme. As mentioned above, both of these schemes are dynamically growing, i.e., new Portals and new Root Categories maybe introduced into the system. This means that neither provide the stable reference structure that we need to support our evaluation of re- 
commender expertise. Similar problems exist in the Citizendium ${ }^{10}$, which defines 6 "general areas" and a number of work groups within each of these areas.

We have therefore decided to focus on existing classification schemes used in libraries, which have been designed to classify all areas of human knowledge. In particular, we examine: the "Library of Congress Classification", the "Universal Decimal Classification" and the "Dewey Decimal Classification". It is important to remember that a classification system used in this context has different requirements than it has in a library. We need a system that covers the entire spectrum of knowledge, in a simple and unambiguous way.

Library of Congress Classification The Library of Congress Classification ${ }^{11}$ (LCC) is developed by one specific library, the US Library of Congress. It is in widespread use among research and academic libraries and thus qualifies for consideration. The system contains 21 classes and new classes have been added as needed, which has led to much criticism because of a lack of a sound theoretical basis, e.g., some unusual sciences have their own categories, such as Military and Naval sciences. Another problem is that it is regionally specific to the US, which can be seen by the fact that there are separate categories for "world history" and the "history of the Americas." The size and peculiarity of the classification scheme means that the LCC is not considered sufficiently intuitive for the WRS.

Universal and Dewey Decimal Classification The Universal Decimal Classification ${ }^{12}$ (UDC) is derived from the Dewey Decimal Classification (DDC), so we discuss both here. The UDC uses a complex system of additional symbols to indicate special aspects or relationships of a subject. Both systems have 10 well defined base classes ${ }^{13}$ which makes them interesting from a usability perspective and neither have the regional bias of the LCC. While either of these systems satisfy our requirement for a classification scheme, we believe that the DDC is more descriptive, so we have decided to use this scheme in the WRS. The DDC class table is as follows:

\footnotetext{
10 http://en.citizendium.org/wiki/Welcome_to_Citizendium (October 2010)

$11 \mathrm{http}: / /$ www.loc.gov/catdir/cpso/lcco/, visited 4 January 2010

12 http://www.udcc.org/udcsummary/php/index.php, visited 4 January 2010

13 The UDC only use 9 of the 10 , classes leaving category "4" vacant.
} 
Table 1. The Dewey Decimal Classification

\begin{tabular}{l|l} 
Class & Description \\
\hline 000 & Computer science, information, and general works \\
100 & Philosophy and psychology \\
200 & Religion \\
300 & Social sciences \\
400 & Languages \\
500 & Science and mathematics \\
600 & Technology and applied science \\
700 & Arts and recreation \\
800 & Literature \\
900 & History, geography and biography
\end{tabular}

Using a complete classification scheme, such as the DCC, means that WRS users may consult the reference definition in case of uncertainty.

\section{Evaluation}

In the following we present a few preliminary experiments that we have done to evaluate the categorization of recommendations implemented in the current prototype of the WRS.

\section{Classification scheme in the WRS}

The evaluation of expertise depends on the concurrence among recommenders regarding the categories of articles. In order to determine whether users would consistently categorize articles, we conducted a small survey of 32 users $^{14}$ who were asked to categorize 5 different articles: "Perfect Competition," "Fermat's Last Theorem," "Power Drill," "Patagonia" and "Punic Wars". The articles were chosen so that they have varying degrees of ambiguity. The first article on „Perfect Competition" is primarily about economy (not everybody knows that this belongs to the social sciences), but there are also elements of mathematics so there are multiple sources of uncertainty. The two next articles on "Fermat's Last Theorem"

\footnotetext{
14 The survey was sent by email to family, friends and an Internet forum, so the respondents correspond to a broad selection of Internet users.
} 
and "Power Drill" have strong elements of a single domain but there is some element of another domain in the article - the first article is primarily about mathematics, but contains elements of history while the second article is primarily about technology \& applied science, but the topic is so ordinary that it may be classified as general. Finally, the two last articles should belong clearly to the "History, Geography and Biography" category. The result of this survey is shown in Table 2 below ${ }^{15}$.

Table 2. Result of categorization survey

WRS Categories

\begin{tabular}{l|c|c|c|c|c|c|c}
\cline { 2 - 8 } & 000 & 100 & 300 & 400 & 500 & 600 & 900 \\
\hline Patagonia & & & & & & & $100 \%$ \\
\hline Punic Wars & $8 \%$ & & & & & & $92 \%$ \\
\hline Fermat`s Last Theorem & & & & & $90 \%$ & & $10 \%$ \\
\hline Power Drill & $13 \%$ & & & & & $87 \%$ & \\
\hline Perfect Competition & $9 \%$ & $3 \%$ & $57 \%$ & $3 \%$ & $28 \%$ & &
\end{tabular}

The survey shows that almost all users agreed on the classification of the two unambiguous articles that were selected to belong to category 900 (History, geography and biography). There was generally high agreement among the respondents concerning the two articles that were selected to be ambiguous - both got more than $85 \%$ replies in one category and the remaining replies fell in just one other category. Finally, there was lower agreement on the categorisation of the article on "Perfect Competition," but $85 \%$ of the respondents classified it in one of just two categories. 57\% classified it as category 300 (Social sciences) and 28\% classified it as category 5 (Science, including mathematics). These results confirm our hypothesis that users can consistently categorize existing Wikipedia articles according to the DDC scheme. We may therefore expect a benefit when we calculate the trust level of recommenders according to their past benefit within different article categories.

\footnotetext{
15 The survey was conducted twice with two disjoint groups of users. The two categories that are supposed to be unambiguous, i.e., "Patagonia" and "PunicWars", were only included in the second survey, so the result for these categories are only based on 13 replies.
} 


\section{Expertise evaluation in the WRS}

In order to determine the impact of the proposed categorization scheme on the calculation of trust values, we have performed a simulation based on a sample scenario. In the seminal paper on the strategies for evaluating collaborative filtering systems, Herlocker et al. (Herlocker 2004) indicates that the norm should be to use a standardized data set to test algorithms. Some of the most popular of these standard data sets are shown in Table 3. These data sets can be used to deter mine the general similarity of preferences between users, but they do not include data where both users categorize data.

Table 3. The most popular data sets for collaborative filtering accuracy tests.

\begin{tabular}{l|l}
\hline Data set & Characteristics \\
\hline MovieLens & $\begin{array}{l}100,000 \text { ratings for } 1682 \text { movies by } 943 \text { users } \\
1 \text { million ratings for } 3900 \text { movies by } 6040 \text { users } \\
10 \text { million ratings, } 100,000 \text { tags for } 10681 \text { movies by } 71567 \text { users }\end{array}$ \\
\hline Book-Crossing & $1,149,780$ ratings for 271,379 books by 278,858 users \\
\hline Jester Joke & 4.1 million ratings for 100 jokes by 73,496 users
\end{tabular}

Unfortunately, we have been unable to identify any standard data sets that allow us to evaluate the performance of categorization in a collaborative filtering system with more than one annotation, i.e., the WRS, so, until the user base of the WRS becomes big enough to provide this data, we must rely on a few scenarios that we believe will be typical for the application of the WRS.

In order to illustrate how the evaluation of recommender expertise is calculated, we consider a scenario where a trustor rates the article on the Wheel, an article that Alice has already rated. Alice classified the article as "History" and gave the article a low score, but the trustor rates it as a "Technology \& Applied Science" article with a high score. Based on the trust metrics, Alice will be penalized in the "History" category and, because the majority of trustees have also rated this article as "Technology \& Applied Science", she will be further penalized by half a point, to a total of $-3 / 2$ interaction. Because Alice disagreed with the majority, and the user agreed with the majority, we can now state that according to the user there is no uncertainty that Alice was wrong in categorizing the article as History. Furthermore, the low score distanced Alice from the trustor even more. The next time an article is visited which Alice has rated it as "History", Alice's opinion will matter 
less both in determining the score of the category and the score of the article; this amplifies the result over the previous prototype of the WRS.

Let us consider a similar scenario, but where Alice rates the "Wheel" article as "Technology \& Applied Science" with a high score. This time, the trustor rates it as "History", but also with a high score. The system will recognize the similarity in their score and determine that the overall interaction is good, both agree that the article is well written and structured. However, there is a difference of opinion in determining the category. The trustor's trust pro le has determined that the majority supports the "Technology \& Applied Science" category, which means that Alice might have been correct. Because of this the system determines that Alice should have $1 / 2$ an interaction recorded for "Technology \& Applied Science" to signify that the interaction even though not perfect was in her favor. The most important aspect of determining whether the trust dynamics make sense, is to evaluate their intuitiveness. That is the purpose of the above two examples, to illustrate the intuitiveness of these conclusions through scenarios.

Comparing the trust evolution between the previous and current prototype, the current version will build trust for a user at a slower rate because trust is now specific to a single category, so there will be fewer recommendations and thus less evidence on which to build trust in each category. A simple example is shown in Figure 5 below.

The figure illustrates a scenario where a user encounters recommendations from Alice for the first time. Both Alice and the user agrees on the rating for the first three articles, but they disagree on the categories - Alice agree with the majority of recommenders that the articles belong to the category "History." In the fourth article, the user disagrees with Alice on both score and category. In the previous version of the WRS (Old WRS, shown in red), this set of interactions would result in a slight reduction in the trust in Alice, but in the current WRS, which includes categorization (shown in blue), the disagreement is amplified and there will be no trust in Alice in the category of "History" after the fourth recommendation. The following interactions concern various authors and novels (clearly belonging to the category "Literature"), where both Alice and the user agrees on both rating and category. In this case, both the previous and the current trust dynamics evolve trust at the same rate ${ }^{16}$. The scenario shows that, after the four articles in "Literature" where both agreed on rating and category, the user's trust in Alice will be $50 \%$ higher in the previous prototype, because of the first set of interactions where Alice and the user disagreed on the domain of the article. Finally, the user now browses to an article about the Chevrolet Corvette, which Alice has rated. Alice is not very good with cars, but she has correctly categorized the article as Technology \& Applied Science.

16 The two trust evolution functions are identical when recommenders agree on the category. 


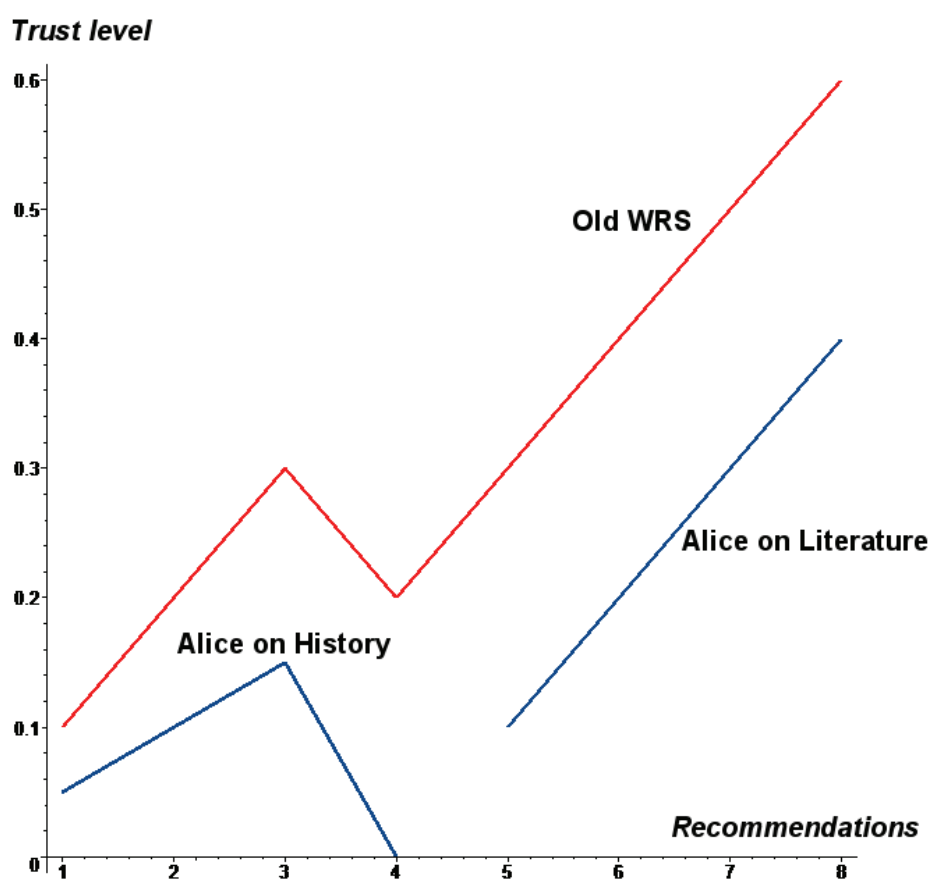

Fig. 5. A sequence of actions and their effects demonstrated before and after.

In the previous prototype, Alice's rating on this article would carry large weight, but in the current prototype, the user has no reason to trust Alice in the category “Technology \& Applied Science", so Alice's recommendation would carry little weight in the calculation of the rating of the article. In the first prototype, the WRS had built up high trust in Alice and the article would receive a high rating, so if Alice is wrong about the Corvette, this would lead to a bad experience for the user who would potentially lose faith in the WRS.

Without an empirical data set, the best we can do is to construct simple scenarios, as the ones above, to illustrate the intuitive nature of the proposed trust model and how the results differ from the previous model. The above examples should hopefully have demonstrated why it is important to rate articles by category and how the proposed trust model achieves this goal.

\section{Conclusions and Future Work}

In this paper we have presented a reputation system that has been developed at the technical University of Denmark to help Wikipedia users assess the credibility of Wikipedia articles. The Wikipedia Recommender System relies on feedback from 
other Wikipedia users, which makes it a collaborative filtering system. Not all feedback providers are equally knowledgeable and most feedback providers are not equally knowledgeable in all subjects, so the WRS implements trust metrics that aim to assess the expertise of feedback providers and assign a higher weight to feedback from those recommenders who have previously provided valuable feedback on a particular class of articles. We have presented the design of a mechanism that allows evaluation of recommender expertise and shown how this mechanism can be integrated into the existing WRS infrastructure. The mechanism has been implemented and our preliminary evaluation of this extension to the WRS indicates that most people are able to consistently categorize Wikipedia articles, which is a prerequisite for the proposed mechanism, which accepts user feedback about the category of articles. This indicates that the system is feasible. Finally, we presented a scenario-based simulation of the WRS extension, which demonstrated that the system provides ratings that better correspond to human intuition; this shows that the extension is useful.

The first version of the WRS only had the weights 1 and -1, which means that given an equal distribution of agreement and disagreement in the interactions, the average trust value would remain constant. The introduction of our new weights of $1 / 2,-1 / 2$ and $-3 / 2$, however, upsets this stability of the trust dynamics, but it is difficult to hypothesize on the precise effects without actual live data sets. We are about to make the WRS generally available on the web and hope that this will help us build a sufficiently large user base to acquire this data set.

\section{References:}

Adler, B.T., Chatterjee, K., de Alfaro, L., Faella, M., Pye, I. and Raman, V. (2008). "Assigning trust to wikipedia content." In: Proceedings of the 4th International Symposium on Wikis (WikiSym'08). Porto, Portugal (September 2008).

Adler, B.T. and de Alfaro, L. (2007). "A content-driven reputation system for the wikipedia." In: Proceedings of the 16th International World Wide Web Conference. Ban, Alberta, Canada (May 2007), pp. 261-270.

Dondio, P., Barrett, S., Weber, S.and Seigneur, J.M. (2006). "Extracting trust from domain analysis: A case study on the wikipedia project." In: ATC, pp. 362-373.

Goldberg, D., Nichols, D., Oki, B.M. and Terry, D.(1992). "Using collaborative filtering to weave an information tapestry." In: Communications of the ACM 35(12), pp. 61-70.

Herlocker, J.L., Konstan, J.A., Terveen, L.G. and Riedl, J.T.(2004). "Evaluating collaborative filtering recommender systems." In: ACM Transactions on Information Systems 22(1), pp. 5-53. 
Howe, J.(2006). "The rise of crowdsourcing." In: The Wired Magazine (14.06), accessed 10 October 2010.

Jensen, C.D. and Korsgaard, T.R. (2008). "Dynamics of trust evolution: Autoconfiguration of dispositional trust dynamics." In: Proceedings of the International Conference on Security and Cryptography (SECRYPT 2008). Porto, Portugal (July 2008), pp. 509 -517.

Jones, M.B. (1999). "Interposition agents: Transparently interposing user code at the system interface." In: Secure Internet Programming, Lecture Notes in Computer science, 1603, pp. 339-369.

Jøsang, A., Ismail, R. and Boyd, C.(2007). "A survey of trust and reputation systems for online service provision.” In: Decision Support Systems 43(2), pp.68644.

Kiczales, G., Lamping, J., Mendhekar, A., Maeda, C., Lopes, C.V., Loingtier, J.M. and Irwin, J. (1997). "Aspect-oriented programming." In: Proceedings of the European Conference on Object-Oriented Programming (ECOOP). Jyväskylä, Finland (June 1997), pp. 220-242.

Korsgaard, T.R. (2007). “Improving Trust in the Wikipedia.” Master's thesis, Technical University of Denmark.

Korsgaard, T.R. and Jensen, C.D.(2009). "Reengineering the Wikipedia for reputation." In: Electronic Notes in Theoretical Computer Science 244, pp. 81-94.

Lefevre, T. (2009). "Extending the Wikipedia Recommender System." Master's thesis, M.Sc. Thesis, Department of Informatics \& Mathematical Modelling, Technical University of Denmark.

Lefevre, T., Jensen, C.D. and Korsgaard, T.R. (2009). "WRS: the Wikipedia Recommender System.” In: Proceedings of the 3rd IFIP WG 11.11 International Conference (IFIPTM). Purdue University, West Lafayette, Indiana, U.S.A., pp. 298-302.

Orlowski, A. (2006). "Avoid wikipedia, warns wikipedia chief, it can seriously damage your grades.” In: The Register (15th June 2006).

Sanger, L. (2005). "Why Wikipedia must jettison its anti-elitism.” Kuro5hin.org: Op-Ed (31 December 2004), http://www.kuro5hin.org/story/2004/12/30/142458/25.

Seigenthaler, J. (2005). "A false Wikipedia 'biography”." In: Editorial USA TODAY (29 November 2005).

Seigneur, J.M., Farrell, S., Jensen, C., Gray, E. and Chen, Y. (2003). "End-to-end trust in pervasive computing starts with recognition." In: Proceedings of the First International Conference on Security in Pervasive Computing. Boppard, Germany (March 2003). 
Suh, B., Chi, E.H., Kittur, A. and Pendleton, B.A. (2008). "Lifting the veil: Improving accountability and social transparency in wikipedia with wikidashboard.” In: Proceedings of CHI 2008. Florence, Italy (April 2008), pp. 1037-1040.

Viegas, F.B.,Wattenberg, M. and Dave, K. (2004). "Studying cooperation and conflict between authors with history flow visualizations." In: Proceedings of CHI 2004. Vienna, Austria (April 2004), pp. 575-582.

Wot: Against intuition inc. http://www.mywot.com (2010), accessed 4 October 2010. 



\title{
6 \\ Cooperation in Wikipedia from a Network Perspective
}

\author{
Christian Stegbauer
}

\begin{abstract}
Neither the classic individualistic nor the collectivist approach can explain participation in Wikipedia. The following article presents an alternative, empirically-based rationale for this participation.

The explanations presented here, which grew out of a long-term research project, are in alignment with relational sociology. The modern approach we used is flexible and positional, unlike earlier role models, and demonstrates how an order arises through the allocation and acceptance of responsibilities. The most important social level here is the meso level, where positional allocations are negotiated. An example is provided to demonstrate the functioning and consequences of this allocation process. The result is a social context with integration mechanisms that present a precondition for long-term participation.
\end{abstract}




\section{Introduction}

Mass collaboration in an encyclopedia such as Wikipedia is somewhat of a mystery, from a traditional socio-scientific perspective. How is "knowledge"1 produced in Wikipedia? And why do people cooperate in its production? With regard to Wikipedia, the on-line encyclopedia, answering these questions is special challenge. Wikipedia has been called an "impossible public good" (Ciffolilli 2005) and a mystery (Viégas et al. 2007) precisely because the classic approaches cannot explain why this collaborative project works.

Wikipedia is the market leader in on-line encyclopedias and is among the 20 most frequently visited websites in the USA (Hitwise 2010). Anyone can edit the content and all are encouraged to contribute, from their own knowledge, to the creation of the largest encyclopedia in the world. The articles, accessed by large numbers of people both privately and professionally, now number in the millions. Thanks to the widespread availability of Internet access, it is a nearly ubiquitous public good. But how does this good come into being?

To understand developments in Wikipedia, it is essential to examine the type and manner of cooperation that takes place in that particular environment. The motives conventionally thought to explain a willingness to participate in creating public goods are not always applicable in the case of Wikipedia. Furthermore, collaboratively produced knowledge is a special form of public good. Even sociology has failed to supply a convincing explanation for the success of Wikipedia. In this article $^{2}$ we address this puzzle and suggest an approach for analysis and explication that is based on methodical and theoretical principles of network research, and modelled on the principles of position and role theory as formulated in the modernized social-constructive version of modern American structuralism (in particular Harrison White 1992; 2008).

\section{The Mystery of Participation and the Limits of Conventional Approaches}

Classic sociology offers two theories on the production of collective goods: one is centered around the benefit to the individual, and the other around a phenomenon known as "collective consciousness." The former approach is referred to as methodological individualism. As a methodological individualist, James Coleman (1991) tries to explain dynamics on the macro level, i.e., based on individual behavior. In

\footnotetext{
1 The term "knowledge" as used here refers to information that has been pronounced relevant; for information to become knowledge, however, an act of acquisition must be interposed.

2 This article is part of the results achieved in a project financed by the German Research Foundation (DFG). The project began in July 2006 and ended in April 2009.
} 
this model, every individual behaves rationally in the sense that he or she pursues her own best interests under cost/benefit considerations. This approach does not, however, account for the intercession of actions beyond rational choice, within sociality. Coleman's view is limited to the individual considerations that precede action.

The second approach assumes deep bonds: a collective consciousness (Durkheim 1893; 1895). This fits well with Tönnies's classic community theory, in which ties based on region, blood or religion play a major role (Tönnies 1898).

Neither of these sociologies offers a satisfactory explanation of the Wikipedia phenomenon. Rational choice, for example, is said to drive participation in scientific communications forums (Matzat 2001). In the case reported, individual participants are motivated by a gain in reputation, or the hope of such a gain. This may hold true for conventional encyclopedias, as the authors receive either monetary compensation or name attribution (or both). They probably add the contributions to their publication lists as well. Being the author of an article in a conventional encyclopedia carries a certain amount of prestige.

In Wikipedia, however, authors are not in the public eye. Contributors can hardly hope to gain reputation in the form of name recognition through participation in Wikipedia. There are indeed instances in which an article is written almost entirely by a single author, and this authorship can be traced, but most participants operate under a pseudonym, and determining who is behind a given "login name" is not a simple matter.

The idea that participation is motivated by individual cost/benefit considerations seems sufficiently disproved by these facts alone. But there is another aspect of methodological individualism that is subject to severe criticism, based on a diametrically opposed concept of society: Individualism assumes that the individual has an unchanging constitution, endowed with a fixed system of values and preferences (Coleman and Kreutz 1997). Thus this approach cannot explain voluntary participation in the production of Wikipedia articles.

But what of the "collective consciousness" approach? In a nutshell: It is no more able to explain the Wikipedia phenomenon than is the individualist approach, because the strong bonds that are prerequisite for a collective consciousness do not exist in Wikipedia.

Wikipedia does have its ideologies, however, and ideologies are an excellent means of evoking cohesive forces. In general, an ideology presents a worldview which may well be seen as a motivator for "joining up." However, it is difficult to imagine real cohesion forming from such ideologies as "Anyone can join," "Knowledge should belong to everyone in the whole world," "Knowledge and commercial exploitation are contradictory," "When everybody contributes, the result is greater than anything a single company could conceive of," "The argument is more important than the person who states it," "Access to knowledge 
should not be dependent on the wealth (nor the cultural capital) of the one who seeks it," etc. They might just be enough - or so we assume - to spark an interest in collaboration, from which a motivation to participant in Wikipedia might emerge.

\section{Positions, Roles and Cooperation in Producing Public Goods}

If neither of the sociologies outlined above can explain the phenomenon of participation and the production of knowledge, what can? Does sociology have anything to offer toward interpreting cooperation in Wikipedia? Why are there so many people involved in Wikipedia, and why have they put so much time into making Wikipedia what it is today?

Our approach attempts to explain the behavior of participants on the basis of their positions within the structure. We have chosen a relational approach in which actions are understood not in terms of individual preferences, maximization of interests, or similar considerations, but rather in terms of the dynamics that emerge from the relationship structure. The structural-relational perspective sees the structure of relationships as a structure of positions, and the persons involved as acting in accordance with the positions they hold. The typical actions concomitant to the positions are called "role behaviors." Motivation and enforcement arise within the relationship structure. There is no fixed goal; rather, preferences are formed only in the context of interaction with others. This interaction engenders a reasonably reliable relationship structure with two primary components: social integration on the one hand, and competition on the other. Kreutz argued for this in a fictitious conversation with Coleman, who at the time was recently deceased (Coleman and Kreutz 1997). Not only preferences, but also identities are formed during interaction with others, with the effect that people's behavior is dependent on their membership in (or exclusion from) a group, and on their concomitant position. Identities are flexible and change with social context, which in turn changes the impetus for actions and - returning to our study of Wikipedia - the motives for participation.

In methodological individualism, the network of relationships represents first and foremost an infrastructure for individual action. Our reasoning is exactly the converse: interaction within the relational network determines the position, and the behavior patterns and views concomitant to the position appear as "motives" - we do not interpret these as individual motives, however, but rather as actions that result from the position. Thus motives and actions result from interaction with others; in other words, the individual actor, with his or her identity, is socially constituted and must be perceived as such, rather than as a "lone warrior" guided solely by intrinsic motives. This does not rule out competition; on the contrary, competition is an explicit component of this view. Competition does not occur in just any random context; rather, it results directly from the position taken and 
arises primarily in a context with others who are perceived as structurally equivalent (White 1992).

\section{The Intermediate Level: Positions and Roles}

The two approaches outlined above, methodological individualism on the micro level and collectivism on the macro level, are clearly not adequate to solve the mystery of Wikipedia's distributed production.

Thus we present a different rationale. We maintain that the explanation can be found on an intermediate level: the meso level. Our theory assumes that motives form on this level; we could in fact take it much further and say the individual is constituted on this level. The arguments for this idea are presented below, followed by a sampling of our empirical evidence.

When we observe the meso level, we investigate actions in dependence on the sociality in which they take place. The claim could be made that the individual is constituted on this level, in dependence on the relationship structure.

The middle level can thus be termed the positional level. To better understand what happens on this level, we call to mind the definitions of "position" and "role." Role theory has a long history in the field of sociology; prominent proponents include Ralph Linton (1967) and Siegfried Nadel (1957), among others. Ralf Dahrendorf's book, "Homo Sociologicus" (1959) was well known in Germany and is still in print today, and essays by Popitz (2006) on this topic have been recently reprinted.

From this perspective, the individual is immersed in his or her position; actions are not determined by individual preferences, but rather by the demands of the role. Positions are arranged in systems: It is difficult to imagine a position existing without the reference positions that are necessary for its constitution. Examples include father/son, teacher/pupil, and doctor/patient relationships. Nadel (1957) in particular made reference to such role systems.

Today, these concepts of role theory are largely outdated. Why? The answer is simple: they are too rigid. Harrison White addresses this topic in numerous publications (White 1992; White et al. 1976; etc.). We can single out two explicit points of criticism to understand the arguments against role theory. First, new positions are constantly being created. Thus positions, with their concomitant role behaviors, can be considered - one might say must be considered - to be socially constituted. Human beings are subject to so many influences and so much incoming information, confronted with so many decisions, changing environments and memberships in different social circles that we simply could not function if we were limited to rigid role behaviors. Behavior patterns and relationships are open to negotiation (see also Harrison White 1992). There are limitations, of course; for example, behavior patterns tie in to habits long practiced in other contexts, as be- 
havior is generally transferred from one context to another (Kieserling 1999). Once positions have been defined, they do not remain static; they are liable to adaptation and various dynamics, even while the position structure itself affords a certain level of security and stability. Harrison White would say that this describes the attempt to control contingencies, where negotiations are not so much negotiations per se; rather, the allocation of positions is a by-product of normal interaction.

The second major criticism of classic role theory concerns identity construction. An identity or that which is considered the most basic sociologically relevant unit, does not necessarily refer to a single person. Larger social units also form identities. White refers to such entities as "disciplines."

There are two other points that must be noted here. The first was alluded to above: role behavior is not necessarily rooted in the individual's own interests, but rather on the requirements of his or her position (see Tenbruck 1956; Gerhard 1976; Stegbauer 2001). The second point is more important for the constitution of a modern role theory, and specifically relates to the criticisms of classic role theory: Up to now, we have focused primarily on the action behaviors associated with positions. This is not incorrect, but it highlights only one side of the story. On the other side, we have the demands imposed on the position, which are developed only through interaction with others. In this respect, there can be no rigidity; coping with the many-faceted and often unpredictable demands of the various relationships and networks of relationships requires flexibility. Also, societal dynamics require that role behaviors be variable ${ }^{3}$ on the one hand, and on the other hand open to adaptation to changing environments. It should be clear by now that roles in this sense are not limited to the traditional examples cited so frequently, i.e., father/mother-child, couple relationships, doctor-patient, etc. There is no area in which relationships do not form behaviors and expectations of behaviors. This is a basic social principle, and is essential in restricting the complexity of the almost endless possibilities for action. ${ }^{4}$

Although this is a social-constructivist view, a conservative momentum always comes into play, as mutual expectations limit the range of possible variation. In this sense, all social interaction is bounded by the expectations that others have on us, which limit the range of possible development.

Nevertheless, this means that the classic, relatively rigid role theory can be replaced by something more dynamic that allows for social negotiations. Such negotiations, and the allocation of positions, all take place on the meso level.

\footnotetext{
${ }^{3}$ Habermas made this criticism as early as 1963 . Here, the old criticism of the ahistoricity of structuralism also applies to role theory, which can - certainly in Nadel's view (1957) - be interpreted as structure theory.

${ }^{4}$ In this context, we relate this argument to the idea that we need some way to control imponderables, i.e. contingencies. For H. White (1992) this is one of the most important principles. In this aspect he agrees with Luhmann, who also asks why a particular selection is made from the virtually unlimited number of possibilities (Luhmann 1997).
} 
But how exactly does the meso level have affect human behavior? We take a closer look at this in the following section.

\section{How Important is the Positional Level in Wikipedia?}

In Wikipedia, as in other networks, a process of positioning takes place through negotiation. But how and under what conditions does this happen in Wikipedia? And what do we mean meant by "negotiations"?

Negotiations occur wherever people come into contact with one another. In Wikipedia, a person may initiate contact by writing their first contribution. Others react, and the positioning process that begins with this reaction can play a decisive role in defining the subsequent "Wikipedia career" of the new contributor. If the reaction consists in deleting the article, there will likely be no further positioning of that person within the Wikipedia context (although there are rare cases in which a newcomer asserted his or her position). If the contribution is accepted and the contributor is "adopted" by a "wikimentor," a different situation develops - one in which the new participant is assigned to (one might say "placed under") a mentor for "socialization" in Wikipedia. While this is not entirely a one-sided process, those who have the institution of Wikipedia at their backs undeniably have greater power of definition than the newcomer has.

The power structure within Wikipedia has several different levels. There are a number of positions that are in contact with one another; in discussing Wikipedia itself, these positions play a stronger role than others in shaping the organizational development of Wikipedia. One example of such a process is seen in the development of Wikipedia's ideologies. Initially, the Wikipedia ideology was one of freedom and production, with emphasis on the accessibility of "knowledge" outside of copyright; a guiding principle that actively encouraged "everyone" to participate. This changed over time. Today, the ideology is more product-oriented; the focus has shifted to the accuracy of content as well as competition with conventional encyclopedias. However, not all Wikipedians are involved to the same extent in the development of ideologies. Contact with other participants is prerequisite for joining this discussion, and the most common and most frequent contacts take place between administrators. The least contact involves participants known as "IPs," who write or edit articles without logging in and thus are identified only by an IP address. Somewhere in between these two extremes is the heterogeneous mass of registered Wikipedians, where the spectrum ranges from the numerous editors who participate in just one article, to the very few expert authors in specialized areas or those who have taken on a special position, such as fielding questions about Wikipedia.

Each category of participants has a specific level of opportunity for participation in the development of Wikipedia as an organization and its ideologies, and each has a different realm of experience. Administrators have broad experience in 
dealing with conflicts; they make decisions on whether and when to block or delete articles or ban users. Most have experience with vandalism and endless, usually fruitless, discussions. It is relatively easy for them to reach agreement among themselves, as they all have similar experience in the same position. This is the framework of the discussions that are most likely to result in organizational developments or changes in ideologies. Such changes are usually decided by consensus among the circle of administrators and certain other active users. It is difficult to reach consensus on changes with other users, many of whom yearn for the original ideologies which emphasized liberation and production - particularly as these principles are hauled out and dusted off practically every year during fundraising campaigns. Thus ideologies of "normal" users often differ from, and even contradict, those of the leadership level that has since become established. This can lead to confrontations, and the importance of position within Wikipedia is clearly manifested in these areas.

But there are other areas of conflict as well; for example, in competition between those positions that can be defined strictly in terms of content (for example, article authors or vandalism fighters).

As mentioned above, positional structures are found in all social spaces, and positions play a major role in determining people's actions and behavior. As the Wikipedia project is a form of social space, it naturally has its positions as well. Even without an empirical approach, several positions can be easily distinguished from their degree of embeddedness.

The least embedded are the most basic users of the encyclopedia: the readers. Their contact with the positional level is tangential at most, as it lies solely in the fact that the articles they read are developed within the social structure. This can be termed a one-sided and indirect relationship with Wikipedia, as the reader receives without giving, and is not involved in the underlying production of knowledge.

\section{Knowledge Production and Positional Structure: An Example}

How are positions negotiated in Wikipedia? We investigated positional structuring in discussions relating to 30 Wikipedia articles. In the following we present a fairly typical example of these, illustrating how the positional structure is established. The discussion is evaluated using network analysis techniques. The example we have chosen is the discussion of the German Wikipedia article, "Logik." The positional structuring observed in here can be examined from a number of perspectives. Quantifiable dimensions are found within the Wikipedia article itself, such as the number of contributions or the quantity of text that came from each editor. For our study, however, the content of the discussion page is more important, as it provides indicators of participants' positions. This is where negotiations take place; where the participants must hold their own in discourse. In addition to quantifiable 
relationship data, this area yields text sequences that permit insight into the relationships.

Let us turn to our example. The analysis is based on the status of the "Logik" article at the time of our investigation (February 2007). The first thing we notice is that a relatively small number of participants are involved (see Fig. 1). More than half of the text comes from a single editor (Ma), one-quarter from another (Go), and a little over 10\% from a third editor (To). The other participants made considerably smaller contributions: five of them are responsible for some $1-2 \%$ of the text, and the other 24 participants' together account for less than one percent. In fact, only a single word remains of the contributions from many of the last group. This statistic is somewhat skewed, however, as the article had to be rewritten at one point due to a copyright issue. This revision was carried out by Ma.

In our view, however, analyzing the structure and content of the discussion is more to the purpose than quantifying the volume of contributions, since the aim is to evaluate the relationships between producers of content. Some might raise the objection that the majority of Wikipedia articles come about with no discussion at all. This is true. In fact, at the time of this study only $30 \%$ of the articles had any discussion recorded on their "talk page." 5

In spite of their low quantitative significance, the discussions are meaningful because they are a context in which content is explicitly negotiated. Moreover, the significance of a discussion grows with continued development of the article. Once an article has been in place for a long period, further changes are rarely made without some preceding discussion. When the content of an article has been fully discussed, it is difficult to make changes without making reference to existing discussion points. In this sense, discussion contents themselves become structuring elements. This is seen on two levels: both in the content of the article and in the positional structure around that article. The participants' positions within the system determine the extent to which they can influence article content.

How can we visualize the positional system that arises in the production of an article? This is illustrated in Figure 1 below. The participants (nodes) are represented by circles, and their relationships within the discussion by arrows (directed edges). The direction in which the arrow points indicates who is addressing their remarks to whom. The thicker the arrow's shaft, the more discussion sequences took place. Participants Go and Ro, for example, share 6 sequences. The more central the participant's position in the discussion, the larger the node. In this context, "centrality" means "degree-centrality." The degree-centrality value corresponds to the proportion of incoming and outgoing relationships in the total num-

\footnotetext{
5 To estimate the quantitative significance of these pages, we took a sample at the end of 2006. Of the 2754 articles in our sample, $28 \%$ had active discussion pages, of which the vast majority contained only one contribution. Clearly, discussions are very unevenly distributed over articles. In our sample the mode was 1, the median 3 and the arithmetic mean 9.6. It should be noted that the sample also contains articles that have almost 500 discussion contributions.
} 
ber of coded relationships in the entire discussion. The isolated nodes on the far left have the least centrality, and participant Go has the highest centrality value.

There is more information than this to be gleaned from this diagram, as a positional analysis was also performed: a cluster analysis with a hierarchical algorithm (Concor) in which clusters are formed by similarities in relationship patterns. These clusters are also called blocks; thus we refer to a block model analysis. ${ }^{6}$ Ideally the analysis will group participants by structural similarity. ${ }^{7}$ Structurally similar actors are not in a strict sense structurally equivalent, but here they are treated as such. Structurally equivalent actors are interchangeable. Thus in the context of positions and block models, when we speak of an individual person we are referring to the position that person has.

Figure 1 displays participants in accordance with their block affiliation. It can be seen at a glance that some nodes have very high centrality, in particular Go, who is in contact with most of the participants in the discussion. The isolated participants, relegated to the upper left-hand corner of the diagram, form the opposite extreme. The relationships that develop in the discussion are stronger between some participants than others, due to the exchange of multiple sequences.

Another distinct feature of the diagram is its division into two parts, with one cluster on the right and one on the left. This is typical of a center-periphery structure. In the cluster on the right, most of those who are connected with Go refer only to Go and for the most part are not connected to one another. Next to this cohesive structure, the block on the left is not structurally connected to the relationships on the right. To put it succinctly, the diagram clearly shows that Go is in a singular position.

\footnotetext{
${ }^{6}$ For details on the procedure, see White et al. (1976).

${ }^{7}$ For more on the significance of structural similarity, and for structural equivalence terminology, see Kappelhoff (1992). For a detailed discussion of these terms, see Stegbauer (2001).
} 


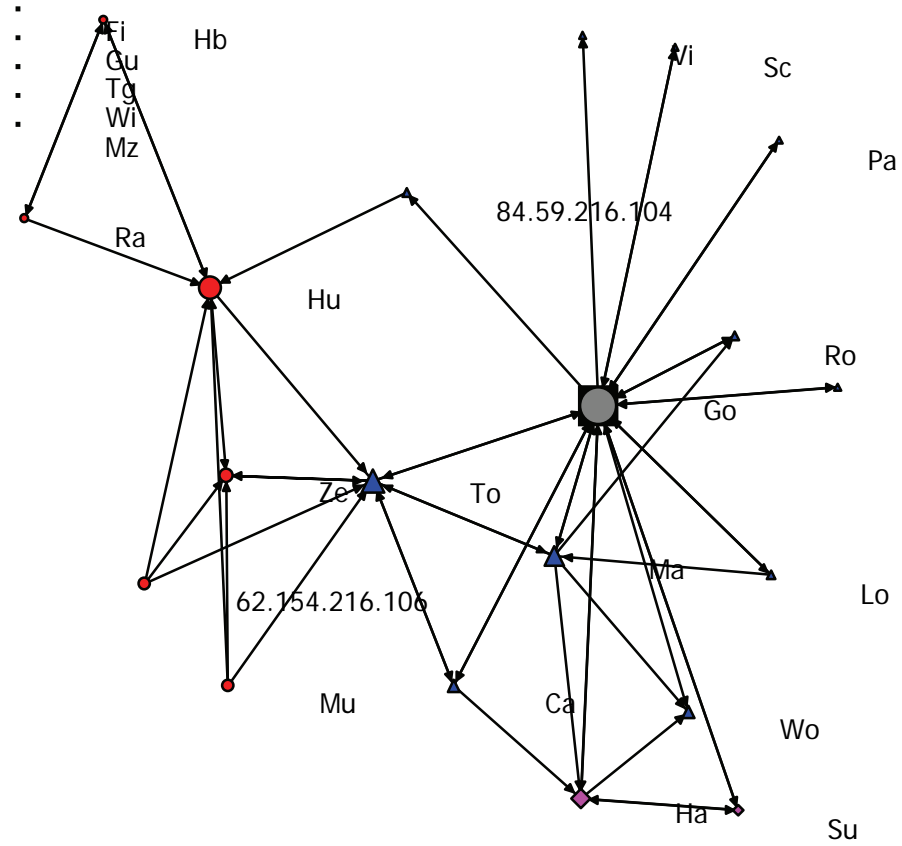

129.247 .247 .238

Diagram of the discussion around the "Logik" article

Node size: Degree centrality (the larger, the more central)

Blocks: Concor 5-block solution

Node shape:

Circle in square

1100

Rhombus

11000

Triangle

10000

Circle

00010

Square

00000

Edge thickness: Number of discussion sequences exchanged; arrow: direction of remarks

Ma's position is unique in that $\mathrm{Ma}$ is the only one who frequently calls on others to act (5 times). In this Ma differs significantly from the 25 other participants in the discussion, which is easily understood in the light of pertinent background information: $\mathrm{Ma}$ is an Admin and the coordinator of the German Wikipedia's "Philosophie" portal, and thus has a formal position as administrator, an informal position as coordinator, and the position of being the main author of the article under discussion. 
Go's position is highly central. Since our purpose is to examine how positioning takes place and what effects it has, it is important to find out how Go came to be in this key position. To this end, we analyze elements of the discussion (Table 1) and find that Go was co-opted, or recruited into this position, by Ma.

- At the time of joining the "Logik" article discussion Go is already known, to some extent, for other activities within the "Philosophie" portal.

- Go's first contribution to the "Logik" discussion: 19 May 2005, "I would like to put the structure of this chapter up for discussion"

- Support: 19 May 2005, Pa, a known Wikipedian (and later an Admin), responds to Go’s suggestion: "Good idea; I agree."

- Jockeying for position: In the subsequent days, Go has to defend the proposal and provide specific reasons for it (particularly in response to Ro)

- Recruiting: 19 May 2005, Ma to Go: “...Don’t be intimidated. :-) Just give it a try - remember: [WP:BB (Be bold)]. ${ }^{8}$ I think it would be good if you were to overhaul this section."

- Support of the position: In a later exchange, Ma supports Go's position.

Tabelle 1: Recruiting Go as article coordinator

In reading these sequences, we are witness to a recruitment: we can retrace exactly how Go is assigned a position, most of all by Ma. As a result of the assignment to, and subsequent acceptance of, this singular position Go subsequently invests more work in the "Philosophie" portal. In general, the main actors are well known to each other. This is evident in the next diagram, Figure 2, which depicts the embedding of the parties involved in the area surrounding the "Logik" article. This area includes all discussions of all articles that are referenced by hyperlinks in the "Logik" article. The network in this diagram is bimodal, in the sense that it maps both the articles and the persons involved in the discussions. The main participants in the "Logik" discussion are additionally in contact with one another through involvement in other article discussions. Figure 2 also shows that Ro, who challenged Go early on in the "Logik" discussion (see Tab. 1 above), is involved in other articles in the same topic area. Thus their interactions can plainly be interpreted as competition for the position of coordinator.

8 Wikipedia has a number of editing guidelines, which are often referenced in short form in discussions. One of them is "Be bold" (http://en.wikipedia.org/wiki/Wikipedia:Be_bold; 2 October 2010). 


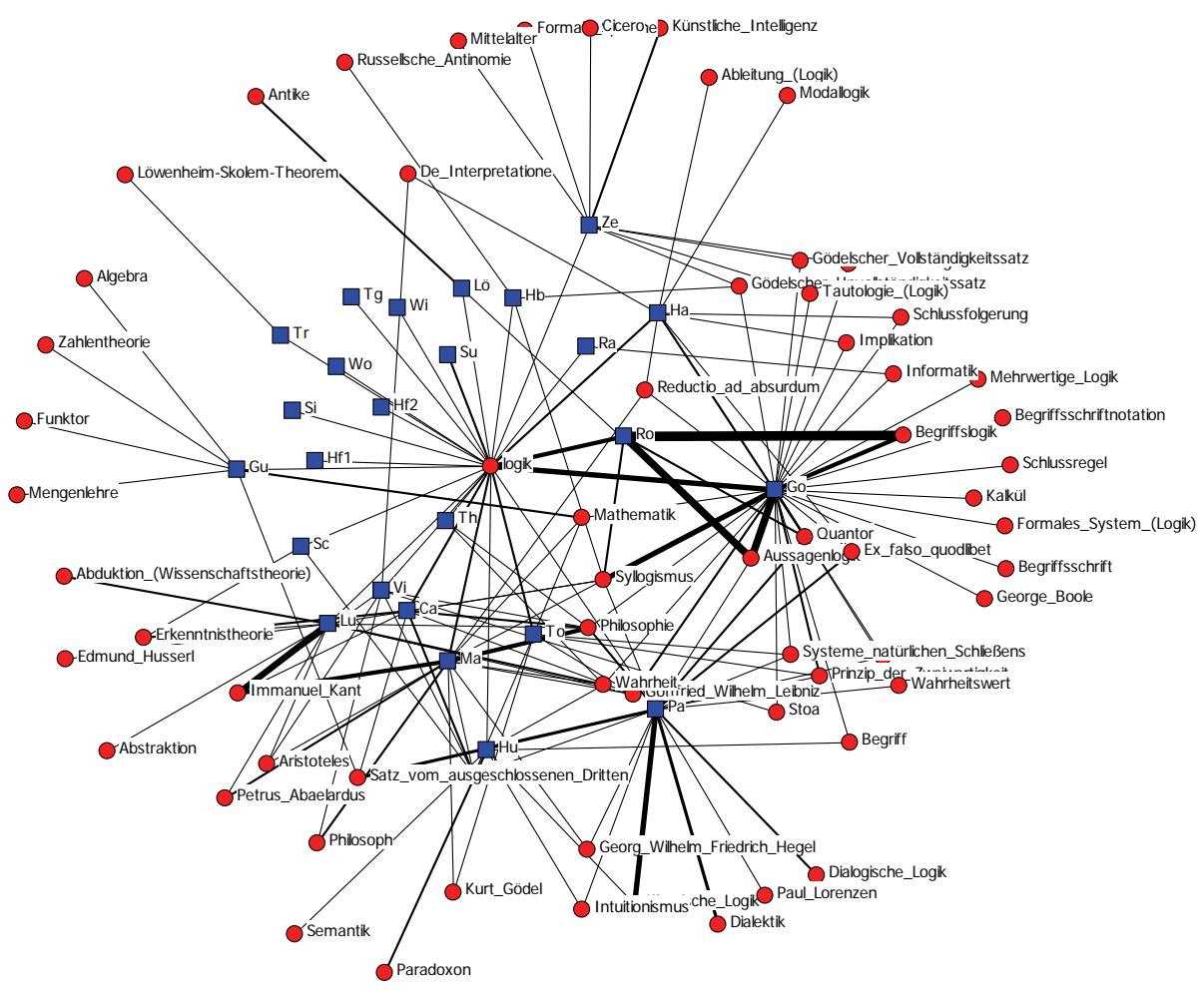

Actors' embeddedness: Discussion network around the "Logik" article

Bimodal network

Squares: Actors

Circles: Articles

Edge thickness: Relationship density

Further analyses involving the entire "Philosophie" portal show the same tendency: A small number of people repeatedly turn up in central positions, and are in contact with one another over a large number of connections. We interpret this as an indicator that distinctive positions are found within the social spaces created around articles and the concomitant discussions. There are no anonymous masses (Larnier 2006) who are responsible for the articles; rather, there is a social context in which major players clearly perceive one another. The question of who can carry out central functions is a matter determined to a great extent, if not entirely, by established participants. 
We carried out similar studies on another 30 article discussions ${ }^{9}$. In most cases we found very similar structures, although the connections between participants are often only temporary, as some of the parties involved gradually stop appearing, after which a new structure forms. The relationship structure is not always clearly tailored to one or a few participants, but the participation, measured by number of contributions, is always unevenly distributed.

\section{Conclusions}

We began by stating that the motives for collaboration in Wikipedia are not well understood. Neither of the classic explanations for participation in producing a collective good - individualism and collectivism - are able to tell us how and why Wikipedia actually works. This is because both of these sociological perspectives fail to take the meso level, where social attribution takes place, into account. We maintain that motivations for participation arise on the meso level, beyond individualist and collectivist rationales. There are essentially two forces in effect here: One is situational, as, for example, when a traffic accident occurs and the assignment of positions by the situation can cause a person to switch from the position of an observer to that of a helper. The other force, independent of the first, has its basis in the social demands contingent upon a person's position.

In the context of Wikipedia, situational factors clearly play a role. In this weakly structured environment, the structure formed initially may later develop in one of two directions: it may dissolve, due to the ephemeral nature of contact in the discussion pages. Or, if contact is maintained, the structure may be reinforced. In the latter case, the responsibilities for further activity are derived from the positions that emerge; i.e., once a participant has been integrated, obligations arise. The responsibilities and obligations mentioned here refer to the social compulsions concomitant to the position taken, which in turn entail certain role behaviors; for example, the activities expected of a person in the position of article coordinator.

This process is complicated in Wikipedia, because in this environment roles are developed ad hoc; there are no models that can simply be adopted. Roles are developed during the process of discussion; are apparently transferable from one area of Wikipedia to another, and are accepted by some of the other actors. The more distinctive positions carry the potential for conflict; for example, when a given actor has the ability to delete the contributions of others. Some conflicts are productive in the sense that they bring role boundaries and patterns into sharper focus, making them more easily distinguishable for all participants. All of this takes place on an intermediate level, beyond individual ambition.

\footnotetext{
${ }^{9}$ and many further analyses as well (Stegbauer 2008).
} 


\section{References}

Burt, R. S. (1992). Structural Holes: The Social Structure of Competition. Cambridge, MA: Harvard University Press.

Ciffolilli, A, (2003). "Phantom authority, self-selective recruitment and retention. of members in virtual communities: The case of Wikipedia." First Monday Peer-reviewed journal on the internet, http://www.firstmonday.dk/issues/issue8_12/ciffolilli (10.03.2005).

Coleman, J. S. (1991). Grundlagen der Sozialtheorie. München: Oldenbourg.

Coleman, J. S. and Kreutz, H. (1997). "Begründet oder zerstört das Eigeninteresse jenes wechselseitige Vertrauen, das Gesellschaft überhaupt erst ermöglicht?" In: Kreutz, H., Leben und Leben lassen. Die Fundierung der Marktwirtschaft durch symbolischen Tausch und Reziprozität. Opladen: Leske und Budrich, pp. 13-22.

Conrad, W. and Streeck, W. (1976). Elementare Soziologie. Opladen: Westdeutscher Verlag.

Dahrendorf, R. (1959). Homo Sociologicus. Ein Versuch zur Geschichte, Bedeutung und Kritik der Kategorie der sozialen Rolle. Köln und Opladen: Westdeutscher Verlag.

Döring, N. (2000). "Romantische Beziehungen im Netz.” In: Caja T., Soziales im Netz. Sprache, soziale Beziehungen und Identität im Internet. Opladen, Wiesbaden: Westdeutscher Verlag, pp. 39-70.

Durkheim, E. (1977). Über die Teilung der sozialen Arbeit. Frankfurt: Suhrkamp.

Durkheim, E. (1984). Die Regeln der soziologischen Methode. Frankfurt: Suhrkamp.

Friebe, H. and Lobo, S. (2006). Wir nennen es Arbeit. Die digitale Bohème oder intelligentes Leben jenseits der Festanstellung. München: Heyne.

Gerhard, U. (1976). "Georg Simmels Bedeutung für die Geschichte des Rollenbegriffs in der Soziologie.” In: Böhringer, H. and Gründer, K., Ästhetik und Soziologie um die Jahrhundertwende: Georg Simmel. Frankfurt: Klostermann. pp. 71-83.

Goffman, E. (1973). Interaktion: Spaß am Spiel, Rollendistanz: München: Piper.

Habermas, J. (1963). Theorie und Praxis. Neuwied: Luchterhand.

Hitwise (2010). Top 20 Sites and Engines.

http://www.hitwise.com/us/datacenter/main/dashboard-10133.html (29.07.2010).

Homans, G. C. (1960). Theorie der sozialen Gruppe. Köln, Opladen: Westdeutscher Verlag.

Hondrich, K. O. (2002). Weltgesellschaft zwischen Disharmonie und Chancen zur Harmonie.

http://www.calw.de/hessejahr2002/dokumentation/beiträge/020606/hondric h.pdf (13.02.2007). 
Kadushin, C. (2002). "The motivational foundation of social networks." In: Social Networks 24, 77-91.

Kappelhoff, P. (1992). "Strukturmodelle von Position und Rolle." In: Andreß, H. J. et al., Theorie, Daten, Methoden - Neue Modelle und Verfahrensweisen in den Sozialwissenschaften. München: Oldenbourg, pp. 243-268.

Kieserling, A. (1999). Kommunikation unter Anwesenden. Studien über Interaktionssysteme. Frankfurt: Suhrkamp.

LaPière, R. T. (1934). “Attitudes vs. Action.” In: Social Forces 13, 230-237.

Larnier, J. (2006). "Digital Maoism: The Hazards of the New Online Collectivism." Edge -The Third Culture.

http//www.edge.org/3rd_culture/larnier06/larnier06_index.html (02.01.2007).

Linton, R. (1967). "Rolle und Status.” In: Hartmann, H.. Moderne amerikanische Soziologie. Stuttgart: Enke, pp. 251-254.

Lorenzer, A. (1981). Das Konzil der Buchbalter. Die Zerstörung der Sinnlichkeit. Eine Religionskritik. Frankfurt: EVA.

Luhmann, N. (1993). Soziale Systeme. Grundriss einer allgemeinen Theorie. Frankfurt: Suhrkamp.

Luhmann, N. (1997). Die Gesellschaft der Gesellschaft. Frankfurt: Suhrkamp.

Macaulay, J. R. and Berkowitz, L. (1970). Altruismus and Helping Behavior. New York: Academic Press.

Matzat, U. (2001). Social Networks and cooperation in electronic communities: a theoretical-empirical analysis of academic communication and internet discussion groups. Amsterdam: Thela Publishers. http://dissertations.ub.rug.nl/ppsw/2001/u.matzat/ (13.03.2007).

Möltgen, T. ( 2003). Engagiert für Gotteslohn? Impulse für das Ehrenamt. Reader zu Sommeruniversität Ehrenamt 2003. Köln, Kevelaer: Butzon \& Bercker.

Nadel, S. F. (1957). The Theory of Social Structure. London: Cohen \& West.

O’Reilly, T. (2005). What Is Web 2.0? Design Patterns and Business Models for the Next Generation of Software. http:/ / oreilly.com/web2/archive/what-is-web20.html (28.07.2010).

Picot, S. (2000). Freiwilliges Engagement in Deutschland. Frauen und Männer, Jugend, Senioren, Sport. Stuttgart: Kohlhammer.

Popitz, H. (2006). Soziale Normen. Frankfurt: Suhrkamp.

Raymond, E. S. (1998). "The Cathedral and the Bazaar." First Monday 3, 3, March 1998. http://www.firstmonday.org/issues/issue3_3/raymond/index.html (10.11.2006). 
Schroer, J. and Hertel, G. (2006). Wikipedia: Motivation für die freiwillige Mitarbeit an einer offenen webbasierten Enzyklopädie. Oder: Wikipedians, and Why They Do it. Foliensatz. http://wy2x05.psychologie.uniwuerzburg.de/ao/research/wikipedia/wikipedia_praesentation_2006_07.pdf (12.02.2007).

Simmel, G. (1992). Soziologie. Untersuchungen über die Formen der Vergesellschaftung. Frankfurt: Suhrkamp.

Spitz, R. (1967). Vom Säugling zum Kleinkind. Naturgeschichte der Mutter-Kind Beziebung im ersten Lebensjahr. Stuttgart: Klett.

Sproull, L. and, Kiesler, S. (1991). "Computers, Networks and Work. Electronic interactions differ significantly from face-to-face exchanges. As a result, computer networks will profoundly affect the structure of organizations and the conduct of work." In: Scientific American. September 1991, Special Issue, 8491

Stegbauer, C. (2001). Grenzen virtueller Gemeinschaft. Strukturen internetbasierter Kommunikationsforen. Wiesbaden: Westdeutscher Verlag.

Stegbauer, C. (2009). Wikipedia. Das Rätsel der Kooperation. Wiesbaden: VS Verlag.

Stegbauer, C., Schönberger, K. and Schmidt, J. (2007). "Editorial: Wikis Diskurse, Theorien und Anwendungen.” In: Stegbauer, C., Schmidt, J. and Schönberger, K., Wikis: Diskurse, Theorien und Anwendungen. http://www.soz.uni-frankfurt.de/K.G/B2_2007_Stegbauer_Schoenberger_ Schmidt.pdf

Tenbruck, F. H. (1965). "Formal Sociology.” In: Lewis A. Coser. Georg Simmel. Englewood Cliffs: Pretence Hall, pp. 77-96.

Tönnies, F. (1963). Gemeinschaft und Gesellschaft. Darmstadt: Wissenschaftliche Buchgesellschaft. Fortdruck der 8. Auflage von 1935

Turkle, S. (1995). Life on the Screen. Simon and Schuster, New York.

Viégas, F. B., Wattenberg, M., Kriss, Jesse and Ham, F. van (2007). “Talk before you type: Coordination in Wikipedia." In: Proceedings of the 40th Hawaii International Conference on System Sciences 2007.

White, H. C., Boorman, S. A. and Breiger, R. L. (1976). "Social Structure from Multiple Networks I. Blockmodels of Roles and Positions." In: American Journal of Sociology 81, 73-780.

White, H. C. (1992). Identity and Control. A Structural Theory of Social Action. Princeton: Princeton University Press.

White, H. C. (1995). "Network Switchings and Bayesian Forks: Reconstructing the Social and Behavioral Sciences." In: Social Research 62, pp1035-1063. http://www.ssc.wisc.edu/theory@madison/papers/white02.pdf (10.08.2010) 
White, H. C. (2008). Identity and Control. How social formations emerge. Princeton: Princeton University Press.

Wiese, L. von. (1967). Soziologie. Gescbichte und Hauptprobleme. Berlin: Walter de Gruyter. 


\title{
Managing a New Consumer Culture: "Working Consumers" in Web 2.0 as a Source of Corporate Feedback
}

\author{
Sabine Hornung, Frank Kleemann and G. Günter Voß
}

\begin{abstract}
Our paper, based on interviews and web-page analyses, investigates 28 companies that use web-2.0 applications to activate internet users as a source of corporate feedback. Company activities are illustrated using prototypical Facebook "like pages" and corporate blog applications. Using the web for corporate feedback, we find, often has unintended consequences for the structure of company-consumer interactions. Companies struggle to communicate with internet users because they continue to treat users as conventional customers or consumers, i.e., as the passive "working customers" of conventional self-service contexts. Users are not treated as part of an emerging new culture defined by different standards of participation and communication, and this can lead to conflicts and difficulties within the organization. Through these mechanisms, the new internet culture may lead to a shift of customer-company relationships generally. In short, open innovation calls for more open company structures. The paper draws on the "working customer" concept (Voß and Rieder 2005), through which various forms of self-service are understood as a means by which companies try to integrate consumers' productive labor power into production processes. We suggest that a broader interpretation of this theoretical approach is useful for analyzing the even more comprehensive modes of user integration common to web-2.0 applications, including the new
\end{abstract}


forms of interaction with the company and among users that we observe in the cases presented here.

Generating and managing consumer feedback is, and has always been, a task of critical importance for corporate success. The main sources of conventional feedback are customers' complaints as filtered by corporate complaint management systems (Ramsey 2010; Zairi 2000) and feedback deliberately solicited by the company through conventional market research methods such as the focus groups developed in Calder 1977 (see also Bruseberg and McDonagh-Philp 2002; McQuarrie and McIntyre 1986 ). Today, however, the emergence of new information and communication technologies is changing the way companies generate and manage feedback. The use of the internet for these purposes is now very common. Of course, conventional feedback-generation techniques such as surveys can be administrated via the internet, but this kind of non-interactive feedback is not the focus of this paper. Instead, we examine innovative techniques that make use of the characteristics of "web 2.0," i.e., the new opportunities internet users have not just to browse alone in the internet but to interact with other users by leaving messages, participating in various forums, voting, or uploading pictures (Knorr 2003). In Kaplan and Haenlein's (2010, p. 61) summary, "content and applications are no longer created and published by individuals, but instead are continuously modified by all users in a participatory and collaborative fashion." The same authors consider web 2.0 to be the native biotope for the evolution of social media, which exploit web-based technologies to allow interaction between users for activities such as long-term collaborations, blogs, content communities, and social networking (Alby 2008; Ebersbach, Glaser and Weigl 2008; Münker 2009; Stegbauer and Jäckel 2008). The new transparency of persons, content, and relationships made possible with new web technologies allows companies to interact with customers in new and more direct ways. Consequently, two innovative forms of feedback have become possible. First, a company can actively provide new communication channels for feedback such as corporate blogs (Zerfaß 2006) or branded communities in which consumers can chat about or comment on products and services. Second, indirect feedback can be generated once internet users start discussing suggestions for improvement of company products or processes among each other independently of corporate cues on external sites such as social networks, consumer platforms, review sites, external blogs, and forums. Customer-created content can be "generated" by the affected company simply by gleaning these sites for desired information.

From a sociology of work perspective, these new ways of integrating customers as feedback sources represent a new dimension of the concept of the "working customer" (Voß and Rieder 2005; Voß 2005, 2006). The main thrust of this set of hypotheses is that enterprises are under constant pressure to integrate consumer's productive labor power into production processes in order to reduce costs. The use of self-service by department stores, grocery stores, mail-order firms, and 
vending companies was the start of a broader shift away from the customer as "king," whose only role is to be waited upon passively, to practices of relying on consumers to play an active role as co-workers at some point in the production or delivery process. Thenceforward, the domains of customer involvement extended rapidly. Participation in the end-production of furniture and fast-food and even the systematic utilization of customers as vehicles for advertising are now accepted practices. The emergence of the internet in the 1990s intensified this trend. Directbanking, e-government, travel, and tourism are only some of the many new fields in which elements of self-service are commonplace. Customer participation is mainly done without financial compensation, and, often, prospective customers are given no choice but to participate actively. As a consequence, a new quality of the consumption-production relationship has emerged in which a new type of active consumer, called the "working consumer," increasingly becomes an important economic factor to be controlled by the commercial enterprise.

The emergence of web 2.0 allows profit-oriented firms to enhance their utilization of private labor power (Hanekop and Wittke 2008; Kleemann et al. 2008; Papsdorf 2009; Voß and Kleemann 2009; Voß and Rieder 2010). The general internet public can be harnessed for several functions. The predominant functions of consumer work are those of product configuration (e.g. Dell), rating (e.g. Amazon), incentivized tasks (e.g. Amazon Mechanical Turk) as well as product development, design innovation and idea finding in various innovation contests or on permanent platforms. But integrating internet users in the value chain process via web 2.0 affects all aspects of company activity and thus tends to expose more aspects of the company's production process to outside scrutiny than perhaps intended. The "working consumer" is no longer solely involved in just one limited function of the company; internet users start to participate in several domains by giving feedback concerning, for example, the company's customer friendliness, website design and usage, or even production process using web 2.0 applications. In addition, companies start to proactively ask for suggestions for improvements using these new channels. Therefore, over and beyond the obvious and clearly definable areas of customer integration in web 2.0 already encompassed by the "working customer" concept, we consider it necessary to extend the "working consumer" approach to include users' efforts to give multifaceted forms of feedback via internet channels. In conventional feedback, customers proactively provide information about a concrete negative aspect of product performance or service delivery related to a specific situation (a "complaint"). But feedback via interactive channels in web 2.0 applications leads to a new quality of customer input. It allows both positive and negative inputs in a permanent and general structure that is not limited to a specific consumption context. In addition, because new software technology makes it easy for users to generate content, anyone and everyone can provide input to companies, not just the persons who actually consume a product or service. Interestingly, a new customer-company relationship is emerging in which customers as co-workers have a systematically greater effect on actual inter- 
nal operating procedures. The explicit elaboration of this thesis makes an extended model of "working consumers" necessary.

Recent studies emphasize the undeniable potential of social media for generating new forms of feedback on products, services, and corporate behavior. Thus, theoretically we would expect social media to transform corporate feedback strategy, but such transformations are rare in organizational practice. We assume that this is because the new role of consumers has not been noticed fully or accepted by enterprises. Unlike most existing empirical studies, we do not seek to offer practical recommendations regarding how to take advantage of social media for integrating customers. Instead, we aim to identify the potential risks and problems of exploiting social media for generating feedback. Therefore, situations shall be identified in which companies had to deal with some problematic consequences of using web 2.0 in their marketing and communication strategies. Our illustrations are taken from public Facebook entries published on two real corporate "like pages." Furthermore, we discuss the kinds of consequences that opening the company to inputs from social media can have for formal organizational structures. For doing so, we make use of illustrations garnered from publicly accessible corporate blogs. Each illustration ends with the discussion of the potentially problematic consequences of utilizing internet users as a feedback resource. Our general hypothesis regarding why companies find it difficult to utilize new forms of consumer feedback in practice is that, until now, companies have not completely realized that they face a completely new consumer culture in the web 2.0 environment. The new structure of the "working customer" setting and novel motives of participation require a different understanding of consumer-company relations. We assume that integrating internet users as co-workers can never be a fully controlled, compelled, and uncompensated way of exploiting the private work force. This means that the opportunities of web 2.0 bring not only advantages of customer integration; they also bring risks caused mainly by the loss of control when operating in the virtual public sphere of web 2.0. In order to arrive at a more comprehensive characterization of the role of internet users as "working consumers," we will broaden the theoretical approach of the "working customer" in the conclusion of this paper.

\section{Methodology}

The following analysis builds on data from the research project "Consumer Work: The Integration of Labor Power of Consumers into Internal Business Processes" funded by the German Research Foundation (Deutsche Forschungsgemeinschaft / DFG) (cf. http:/ / www.konsumentenarbeit.de). From a sociology of work perspective, we focus on the integration of consumers' productive activities into the company's production process on the basis of interactive ("web 2.0") internet applications. This includes the consumers' participation in product development and design, idea finding, rating, and the execution of incentivized tasks. We focus on compa- 
nies with websites consisting of user-generated content only (e.g. sites where users can upload tips or where users can ask and answer various questions). Moreover, we focus on the ways consumers make use of the companies' sites, on consumers' perception of the activities in which they are involved, and on the motivations of consumers to participate. The project started in November, 2009 and runs for two years.

In this paper, we utilize data from the first empirical wave of the project, in which we conducted 28 case studies of German companies and projects. The case studies comprised a total of 47 personal interviews with managers and staff members. The empirical waves to follow will deepen the analysis by including interviews with consumers and additional staff. We will also broaden the sample by including additional companies and consumers.

This paper refers to only a few case studies in order to illustrate key findings. However, the general findings are based on activities observable across the entire sample. Inducing from analyses of personal interviews and customer-created content on websites, we identify problematic aspects of gaining feedback via social media. We make no claim that these findings describe exhaustively the entire range of possible risks. Public user quotes and interview passages are translated from German. For easier tracing of quotes obtained from social networks, we include the time and date of posting. Those interview partners and companies who asked to remain anonymous are not mentioned by name.

\section{Empirical Findings}

In our case studies, we looked for various types of problematic impacts of customer feedback via social media. Two major issues stood out in this analysis: how companies react to feedback and how feedback is "heard" or becomes implemented within the company. The distinction is between a company's external public reaction to feedback and the internal reactions it creates. First, we illustrate problematic ways of external communication with social media users. Second, we discuss the difficult balancing act between opening new feedback channels and being able to implement the resulting feedback internally. Thereafter, we speculate on the causes of these difficulties, based on our empirical findings.

\section{External issues - The public reaction to consumer feedback}

Our case studies of companies and projects based on web 2.0 platforms showed new ways of feedback collection, but an entirely new quality of consumer feedback can also be identified that originates in the "community spirit" principle of web 2.0 communication. A new company-customer relationship arises because of internetusers' wish to communicate in an open, informal, and rapid way. Receiving a quick response to comments and questions is a fundamental expectation of web 2.0 us- 
ers (Thiele et al. 2010). Obviously, companies have problems in meeting this and other new expectations, as can be seen in the following illustrations from two company "like pages" on Facebook.

The social networking website Facebook allows people to set up a user profile with personal information (pictures, contact details, interests, etc.) and to connect with other users. One can send private and public messages or chat with friends. In addition, users can link their personal sites to "like pages," a function that is often exploited by companies. If they have set up their own like page, companies can communicate with internet users directly. They share company-related information, carry out contests, or launch discussions on different subjects. Facebook users can also generate content on such pages. They can leave public posts, comment on others' entries, and upload pictures on the "wall" section of the like page. The feedback companies get on their "walls" consists mainly of compliments, suggestions for improvement, or complaints about the product, service, delivery, or technical problems with the company's website. The like pages referred to in this paper are public and can be accessed also by unregistered Facebook users. In our case studies, we found three types of communication errors made with (potential) customers on Facebook like pages: (1) delayed responses, (2) reactions that were not anticipated or requested by the user, and (3) no response whatsoever. ${ }^{1}$ Examples for all three can be found on the "like page" of two different companies that rely on mass customization strategies (Piller 2000; Piller and Müller 2004; Piller et al. 2004; Salvador et al. 2009). On the websites of "MyParfuem" and "chocri," customers can configure an individual perfume or chocolate bar by choosing certain product features with a special online tool. ${ }^{2}$ While the basic product components remain fixed, users can tailor the end-product to their own personal tastes to a much greater extent than is typically possible in normal production processes. Customers "create" perfumes with customized combinations of olfactory notes or chocolate bars with a unique combination of ingredients and toppings.

On one Saturday evening, a customer addressed MyParfuem on its "like page" with this problem: "The designer tool is freezing up time and time again. What can I do? Please send me a pm." 3 This message has two components. First of all, the user is asking for support because he or she had technical problems with ordering the product, possibly indicating that other customers also could not complete the online ordering process. Second, the user is asking the company to respond by private message. In this message, the customer uses the informal communication

\footnotetext{
${ }^{1}$ We also identified two additional but less common types of problematic company reactions. First, companies sometimes answered at a later time without responding to the actual entry. Second, companies sometimes asked users to refer to answers given to similar questions received via the same communication platform.

2 http://www.myparfuem.com/

${ }^{3}$ http://www.facebook.com/pages/MyParfuem/152990889868 (17/04/2010, 10:53; accessed: $08 / 07 / 2010)$
} 
style common to social networks (Crystal 2006; for chat technologies see Harnoncourt et al. 2005). In the original German message, the user referred to the designer as the "disinger," used no punctuation, and abbreviated "private message" to "pm." The user seems to expect that the recipient is familiar with Facebook features and knows what "pm" means. Furthermore, in his request, the user assumes that writing a private message is no particular problem for the host of the "like page." The company's response can be tracked easily on Facebook. It responded almost two days later using the comment function, which creates a publicly viewable comment on the "like page" beneath an entry. A company representative wrote, "Hello Florian..., please be so kind as to write an email to: mail@myparfuem.de in which you inform us about the type of browser you have, then we can have a closer look at the problem. Thank you and kind regards." 4 The Facebook like page user was asked to contact the regular customer support service via email and to provide additional information. In doing so, the company could have a closer look at the problem. The answer has a formal and "educating" tone.

The behavioral standards applied here by MyParfuem are conventional company-customer interactions, although the company is interacting in an online context. The reaction of the company combines the first two types of problematic behavior noted above. First, two days' waiting time for an answer in Facebook is much too slow by social media standards. Social media users are accustomed to receiving immediate answers from friends at all hours and expect this from companies using online forums as well (Thiele et al. 2010). Even if the question was raised on a Saturday evening, the company must ensure that someone reacts within a short time. Obviously, the user wanted to configure his own product on the company's website in that instant and expected immediate support. The second error was the style of the company's reaction. They did not respond in the way the customer requested. The company representative did not write a private message, he or she answered rather using the public message feature of Facebook. Most importantly, a constructive suggestion about how to solve the problem raised by the customer was waived completely at this stage. The company failed to meet the user's needs and expectations in every way. It is likely that the user did not resend the question to the standard support service, as this is time-consuming and represents additional work for the customer. Whether the user will try to use the production toolkit again later is also an open question. Moreover, note the unusual communication style used by the company. Users of social networking websites are accustomed to informal communication. It can be assumed that "like page" users also frame their interaction with the company in this informal mode, in contrast to conventional frames of commercial interaction. Therefore, the friendly but somewhat authoritative tone taken by the enterprise to rebuke "undisciplined" communicative behavior can put off users, many of whom would feel snubbed by the

${ }^{4}$ http://www.facebook.com/pages/MyParfuem/152990889868 (19/04/2010, 05:02; accessed: $08 / 07 / 2010)$ 
instruction to send an email to the company's customer service address. It is easy to predict what that user will tell his friends in real life and on Facebook about the quality of the company's customer service.

On the same company's "like page," many similar examples can be found. ${ }^{5}$ Apparently, other customers also assume that this channel can be used as a help center. But every time, users seeking help were referred to the conventional support service. Again and again, individuals were disappointed, and this is bound to have an impact on customer satisfaction. However, the crucial factor of these exchanges is not related to the handful of customers who are disappointed but rather to the public character of communication on Facebook. Every internet user, including those not registered at Facebook, can follow the online movements of the company in this public and virtual sphere. Problematic communication not only disappoints customers seeking help, the behavior is also visible to the whole virtual sphere. When an unfriendly communication style or customer service problems become a topic on the virtual circuit, the potentially beneficial opportunities of viral marketing (Rayport 1996; Ferguson 2008; Morrissey 2009; Breazeale 2009) can become potentially destructive risks. Potential negative consequences include not only direct attacks on the company image through various kinds of comments but also include more subtle and indirect damage such as that caused by users too infrequently recommending company products.

As mentioned, another type of communication problem in social media is ignoring comments. Not only Facebook but social media in general allows almost everyone to contribute to discussions online. If the company does not intervene, customer satisfaction can be affected negatively in two ways. First, individuals who do not receive satisfactory answers after giving feedback are disappointed. There is a high likelihood that they will not (re)purchase or recommend company products. Second, the statements of internet users have a public character and often remain visible for a long time, thus an unfriendly communication style can be seen by all internet users. Again, negative viral effects can arise. A bad image and, in consequence, the loss of actual and potential customers are possible results. Above all, ignoring critique can also lead to uncontrollable, self-intensifying emergence effects because communication in web 2.0 is public and users typically are able to crossreference each other's entries in their own comments (generating indirect feedback). Given these two simple conditions, public discussion in virtual forums can become chaotic and non-linear, with the level of input sometimes increasing rapidly. With such swing effects, it is hard to predict and control the flow of communication. The top executive of a mass customization company summarized the problem succinctly: "Even if usually no one comments on the company blog, as soon as a negative post like 'I didn't receive my order' is made, its as if an avalanche gets

\footnotetext{
5 http://www.facebook.com/pages/MyParfuem/152990889868 (e. g. 28/04/2010, 00:33; 07/06/2010,02:30; 25/06/2010,02:53; accessed: 08/07/2010)
} 
set off. Suddenly everybody feels like they have to put in their two cents' worth and write 'Yeah, I didn't receive my order either' and so on." The interviewee illustrated how even on the corporate blog, where customers normally contribute only by commenting on company posts and do so rarely, users carry out intense discussions. Another support employee confirmed this impression: "Once that gets going and somebody starts saying 'hey, that's advertising and I don't like that,' others join in, and then of course you have to decide how to deal with it and how to reply." Interesting is the interviewee's explicit mention of the necessity of deciding how to react in this situation.

All three examples of problematic communication behavior show that the companies we studied experience difficulties using social media. Although research and consulting companies often strongly recommend the use of social media to their clients as a new and innovative communication channel, we discovered that the supposed benefits of such interaction might well turn into long-term and irreversible customer disappointment, decreased repurchasing and recommendation behavior, and finally, image damage both online and offline. At first glance, we might assume that the recommendations to participate in social media are meant to apply only to well-established companies who can afford to meet the requirements of social media. It would not be surprising then, that small and medium-sized businesses have problems. However, well-established firms such as Deutsche Bahn or the telecommunications companies $\mathrm{O} 2$ and $1 \& 1$ make similar mistakes in social media environments, as one can readily observe on their respective Facebook "like pages." Thus, these are common problems that need to be addressed in further literature. Enterprises need to consider that customers joining "like pages" do not necessarily "like" the company and do not communicate positive messages only.

\section{Internal issues - The implementation of feedback}

Becoming part of social networks as well as setting up new feedback channels lead to a massive increase of customer feedback. Identifying feedback sources and reacting where appropriate is just one point, the other is that one can assume that users giving feedback expect their feedback to cause the company to change its behaviors so as to improve its product or services in some way. This leads to a balancing act between proactively stimulating feedback and adopting the changes that customers want. New feedback management and customer communication efforts are required. As already indicated, the great wave of feedback input must be followed up on by company action. If not, communication with customers appears unreliable and could discourage and annoy customers. On the one hand, enterprises increasingly need to decide which suggestions for improvement are realizable in

\footnotetext{
${ }^{6}$ http://www.facebook.com/pages/Berlin/Deutsche-Bahn-AG/52305069034,http://dede.facebook.com/pages/Deutsche-Bahn/109716302387436, http://www.facebook.com/o2\#!/o2?v=wall, http://www.facebook.com/1und1
} 
the light of available human and financial resources. This is a new kind of selection problem, and it requires new criteria for choosing which feedback is relevant. Furthermore, it becomes important to the overall process of customer-relation management to give convincing reasons why some customer feedback is not implemented. Aside from the new management of communication problems, an additional problematic effect of feedback in web 2.0 is that an effective company response may require company representatives to enter into a collective negotiation process involving many users of the website. Joint requests of customers can become so explicit and strong that companies are more or less forced to implement changes that they originally had no intention of making. The fact that it is easy for customers to buy from another supplier, to refrain from buying, or quit using websites gives customers this power.

In one case, users gave feedback regarding new but inefficient formal rules of the website Designenlassen.de. On this platform, users can announce a competition for design projects (for logos, business cards, web sites, banners, etc.). After publishing a briefing with the amount of money the user is willing to pay and setting a deadline, an international designer community uploads suggestions or drafts. Designs can be evaluated by the person who initiated the project with the help of a rating function. In the end, the initiator chooses a winner, who is then vested with the copyright. ${ }^{7}$ The principle of a 'one-winner' contest had been criticized for a long time internally by designers as well as externally by other users. In response to these critical statements, the platform operators decided to amend the formal rules and did so without asking for user input. Amending the existing rule, they did not use social media to connect their decision-making procedure with designers' wishes. The hosts simply announced a revision of the reimbursement system in their blog, writing that the amount of prize money is now to be shared, with one part going to the winner and another part divided up equally among all designers whose designs received a rating of at least three stars by the person who set up the contest. After the announcement of the new rule, an enormous number of community members commented on the blog. Many designers criticized the three-stars rule. ${ }^{8}$ One designer wrote: "...only designs/drafts with at least four stars should be taken into account...FLAMINGFLOW." Another comment makes reference to this: "I have...to agree with Flammingflow that only drafts with at least four stars should be taken into account...PicctureVisions." At some point, the host responds: "OK, this thing with the four stars seems to be a real issue. Thanks for the suggestion." An additional cross-referencing example is as follows: "On top of that, this cuts the profit of the winner, which usually much too low anyway...smik." To this, another member added: "I agree with smik totally... if you have a contest, you have to have a winner." Two criticisms are central to the whole discussion. Some users

\footnotetext{
${ }^{7}$ http://www.designenlassen.de

8 http://www.designenlassen.de/blog/2010/05/07/groses-update-vorkasse-projektenutzungsvertrag-neue-vergutungsregeln/\#comments (accessed: 15/07/2010)
} 
want to have four stars as the threshold, others want a complete abolition of the new rule. But all in all, many designers and users are unsatisfied, and this could have been avoided if the companies had communicated their plans before publishing the new rules. The collective pressure of criticism forced the host to make an amendment after just a few days: "The threshold for sharing the bonus for favorites has been raised to four stars. This simply makes more sense, thanks for the good comments on that topic." Yet, website users still complained about the new rules. As the host posted in the corporate blog: "It is still surprising to us that the $75 \%-25 \%$ split is so disliked. Our aim with this rule, actually, was to make the platform more fair..." In fact, the opposite appears to have occurred. Users felt that the rules were still unfair. An interesting development in this process was the sudden flip-flop of the company: they abolished the original rule change that mandated the sharing of 100 percent of the prize money. ${ }^{9}$ In sum, within just a few weeks after this change was announced, site users managed collectively to get the host to amend the basic rules by providing critical feedback. Thus, users do not just provide classic feedback. They also force negotiations over the essential basics of the site they use. These are not in the rule one-time events. Users "stay on the ball," because having good rules is of central importance for their own usage of the site. In some cases, this makes necessary a new type of meta-communication with the customer. More than ever before, companies have to consider very carefully how to explain to the customer their decisions about what feedback gets implemented and what feedback is not implemented. A new type of justification is needed. Companies have to explain their actions more extensively in order to ensure that customers will continue to give constructive feedback.

In sum, there are two sides to collaborative feedback. On the one hand, it can lead to better website usage. This creates satisfied customers and a possible increase of additional registrations. In this case, users' feedback, including helpful suggestions for improvement and even explicit proposals for problem solutions, becomes necessary for the site's advancement. On the other hand, opening up to social media can result in a certain loss of control over which feedback gets implemented. In the past, the company made significant strategic decisions autonomously from its customers. The logic of web 2.0, however, can undermine this authority. Companies are forced to implement at least some suggestions in order to avoid discouraging its customers. They have to take users' ideas seriously and thus need a more elaborate style of communication with website users. In addition, they have to decide which elements of the avalanche of input are really important. Are ideas being expressed by mainstream users or by freaks? How many users wish to have a certain rule change? In answering these kinds of questions, it must be clarified whether particular suggestions are really useful for the project and for the company and whether the suggested changes are feasible. An additional new chal-

9 http://www.designenlassen.de/blog/2010/06/21/ergebnis-umfrage-vorkasse-projekte/ (accessed: $15 / 07 / 2010)$ 
lenge is the communication of why some ideas cannot be implemented. Of course, in the end it is the company that decides what amendments are made to the business, but still the customer obtains more power. The user gains the opportunity to address the company through the internet directly, no matter when and no matter which communication channels the company prefers. This means that providing too many channels for allowing users to negotiate company rules coupled with continuous efforts to bolster user feedback can lead to a new kind of "boundaryless organization" (cf. Ashkenas et al. 1995; Picot et al. 1996; Schreyögg and Sydow 1997; Voß 1998). The user receives new rights, and the company must manage more "employees" than in a business with classic structures.

One of the major challenges for company employees is managing imbalances and instabilities in web 2.0 feedback. As shown, organizations not only take advantage of users' informative and constructive input. Users' feedback can lead to conflicts. Especially when hosts have to explain convincingly why particular suggestions or ideas will not be realized in the near future. Risk arises from the fact that in this age of an increased number of suppliers in every sector, dissatisfied users always have the option to flock to another supplier, decreasing the number of registered users and quieting the internet buzz surrounding one's product. In addition, fewer recommendation and the signaling of negative opinions and experiences with the company in the web 2.0 universe can keep potential new users away. Therefore, corporate policy justification has to become a main part of customer management. Phenomena similar to those illustrated in the case studies presented here can also be found in bigger companies. Recently, the biggest German social network for students ("StudiVZ") was confronted with strong critique after amending its starting page. A group called "Bring the old starting page back !!!" was established by users on the 6th of July, 2010. One week later, 116,706 users had joined the protest action demanding changes.

\section{Discussion}

Effective utilization of web 2.0 as a channel for feedback seems still to be a problem for companies. In terms of external reaction to feedback, some companies demonstrated quite problematic online-communication behavior. Reacting late, poor quality of answers, ignoring customers' expectations, and even ignoring feedback altogether were to be observed. In terms of the internal reaction to feedback, it was shown that setting up feedback channels and identifying company-related entries on channels not controlled by the company in web 2.0 lead to a large inflation of the volume of suggestions for improvement. Since users expect their suggestions to be implemented, companies have to develop a new quality of customer communication and feedback management. They have to decide which ideas are relevant for the company and justify any refusal to implement suggestions, preferably with detailed and convincing reasons. Furthermore, customers stand to gain in 
power by communicating via social media with the company (Bieber and Lamla 2005). In blogs, forums, or social networks, they can collectively demand reforms and rule changes. Such cumulative feedback (Waldman and Bowen 1998) from numerous customers forces organizations to negotiate with customers in more areas than ever before. We sense that the problems illustrated in our cases and the new challenges these companies experienced are only part of a greater whole.

We assume that the main reason for the emergence of the negative side effects of consumer feedback via web 2.0 observed above lies in the fact that companies have difficulties understanding "working consumers" as internet users with their own expectations and standards of participation. In several domains, the special characteristics of the new consumer culture in web 2.0 differ from the "working customer" culture, which emerged in the self-service context. In the following discussion, the differences between self-service applications and internet use shall be explicated. Four relevant characteristics are addressed in the following order: (1) the strategic value of integrating customers, (2) the reasons for consumers' participation, (3) control issues, and (4) cost issues.

(1) The original concept of "working customer" describes how companies voluntarily integrate customers as active participants in the production of services and goods. Practices of "shifting a wide array of previously internal capacities and functions onto their own customers..." (Kleemann et al. 2008, p. 8) were planned systematically. Individual, non-public feedback was integrated in internal business processes as a welcome supplement to conventional quality assurance. In contrast, the wide diffusion of web 2.0 applications among an increasing number of enterprises indicates that companies are under heavy pressure to utilize new communication channels in response to intensified challenges of competitiveness and that they are doing so in a less strategic fashion. Companies can take advantage of the web to go to where the customers are, since web 2.0 allows a penetration into the customer's private sphere. But by making web 2.0 a part of internal business processes, enterprises also allow their internal business processes to be penetrated by "working customers."

The potential problems associated with these entrepreneurial activities are based on the fact that web 2.0 allows anyone to contribute online. For example, internet users can leave positive and negative feedback about the company whenever and wherever they want. The generally recommended strategy for avoiding uncontrolled customer movement online is to show presence on all channels (Leisenberg 2007). The company should become part of the online community of the target group and contribute to discussions of company products and other company-related topics. It is also thought important to monitor relevant communities over the long-term and to intervene if necessary. Bender (2008) also recommends creating a more controlled platform for a continuous dialogue with customers by directing the target group to the company's own internet-platform. There, customer attachment to the company can be strengthened. Yet, if companies follow any 
of these recommendations, they also open their organizational boundaries for customer input and become vulnerable to the problems noted above. Thus, it must be emphasized that if the company depends in part on online sales or if managers maintain an interactive internet presence for any reason, there are no easy answers or best business practices regarding the appropriate scope of customer integration.

(2) If we focus on internet users, the motives of participation are different from those of customers in a conventional sense. Conventional customers' participation takes place in the context of the physical constraints of self-service environments. These constraints allow customers little choice but to contribute actively in order to receive goods and services from companies. Focusing on the collaborative activities of internet users that arise in connection with non-commercial projects such as the Wikipedia or open source software, Hanekop and Wittke $(2008,2009)$ have illustrated that one important characteristic of this new consumer role is the voluntary nature of participation. Users decide how, when, and what they want to contribute. One can assume that in the commercial sphere, giving feedback to companies over the internet is also mainly voluntary; they spend time expressing feedback without being pressured or compelled. Further research is needed to better understand consumers' motives, as financial compensation is rarely paid for consumer work of any kind. It can be deduced theoretically that the participative elements on which web 2.0 is based are spilling over into corporate practices. Since internet users actively use the internet anyway as a communicating and consuming platform, the barriers to giving feedback have been lowered. However, this obviously voluntary participation of "working consumers" can lead to unintended and problematic side effects associated with a certain loss of control for company management.

(3) At the time when consumers became co-workers, customer integration remained basically under the control of the commercial enterprise. When companies begin operating in a web 2.0 environment, however, they have to expose the internal workings of the value chain to public input and can thus experience a loss of control in several areas. Most especially, this has an impact on existing consumercompany relations because consumers gain more power. As part of the "primary activities" of value adding, we can identify new qualities of consumer participation in organizational operations, marketing, and services. But through "support activities," internet users also become involved in R\&D work more than usually intended.

In reference to organizational operations, the case study of designenlassen.de shows impressively how companies can lose their autonomy over basic decisions and internal rule changes. This is rooted in the fact that internet users can easily demand organizational changes via social media. Enterprises have to avoid disappointing users by implementing at least some of their consumers' suggestions for improvement. Also, collective demands of internet users can become so compelling that enterprises are forced to make internal changes that may not even be 
profitable in the near future. Finally, companies have to put up with the state of being permanently beta (Neff and Stark 2002; O'Reilly 2005). Internet-based feedback is no longer an explicit request of the company - the feedback diffuses into the company more or less automatically. Companies receive customer input all the time and through an incredible variety of channels. What this means for businesses in the long-term needs to be analyzed in greater detail.

The largest apparent loss of control can be identified in the field of marketing. It is central to our discussion that the behaviors discussed above occurred in public sphere of web 2.0. Disappointed and annoyed customers can create new and destructive risks of viral marketing (Rayport 1996; Ferguson 2008; Morrissey 2009; Breazeale 2009). It is easier than ever to distribute negative experiences via social media channels (Kranz et al. 2009), and enterprises do not control these channels. A blemished image and an insufficient intensity of recommendations can lead to a decreased number of new customers.

Internet users as customers make demands regarding service before, during, and after using or purchasing products and are doing so more than ever. This was seen in both mass customizer examples discussed above. With public entries in social networks, blogs and forums, customers vehemently demanded explanations for delayed delivery time, bad products, and bad service. The new type of customer also expects information that companies would not generate on their own. They want to know, for example, the exact status of their ordered product in the production process. Imprecise information (such as "in process") is often unsatisfactory. Such "new" customers also demand transparency regarding delivery status and expect status updates via the internet. Companies open to social media seem to want to meet customers' need for knowledge of internal procedures. Furthermore, feedback generated through social media is different from conventional complaints via telephone, the postal system, or electronic mail. Critical remarks used to be a linear communication between customer and company, where detailed explanations were neither expected nor given. In web 2.0, however, feedback becomes public and everyone can read about negative experiences with companies' products and services. Explanations are expected to be given online using the same communication channel used to voice the complaint. Explanations are expected to be immediate and personal (Colwell 2010; Boy and Rieke 2010; Thiele et al. 2010). The new customer seems to be less patient. However, a new relationship between providers and customers is emerging in the context of service activities. The relationship is flatter than before, with decreased hierarchy and more transparency.

Finally, consumers' public feedback regarding product characteristics is not always beneficial. Internet-based critique forces the company to communicate R\&D issues more openly. Requests for product improvement must be followed up on more quickly and with a higher sophistication of overall response; deficits have to be explained and future actions have to be communicated on the internet. Here, too, a higher transparency is de rigueur. Thus, it is beyond question that generating feed- 
back through social media can also have negative impacts on the customer relationship. Customers who are dissatisfied because a company ignored their feedback can easily move to another supplier.

In sum, consumers take over tasks in ways that are obviously not intended by the company. Thus, the "working consumer" is no longer just an exploited internet user. Internet users interfere in internal business processes with demands and special expectations. Companies have to deal with a new and rebellious consumer character.

(4) Looking at the theoretical approach of "working consumer", the assumption was made that "fulfilling functions and providing capacities in the value creation process [is] usually for free" (Kleemann et al. 2008, p. 8). But if the loss of control (intended or not) one can expect from activating internet users in web 2.0 is taken into account, there are indeed direct and indirect costs for companies. The skills possessed by the "working consumer" are no longer automatically "valuable economic assets" (Kleemann et al. 2008, p. 9). Operating in social media itself can also have a negative impact on the relationship to consumers. If individuals distribute negative feedback in the public sphere of web 2.0, the company's online reputation may suffer, and consequently, the company's potential customer base may shrink. Companies must constantly invest resources to maintain and improve their online reputation (Leisenberg 2009; Lazkani 2009; Colwell 2010; Rice 2010) and to receive widespread positive attention. Acting in the internet means not only retrieving customer data from relevant sources, it also means making an intensive communication effort. Self-intensifying feedback loops with negative emergence effects require an immediate reaction. Thus, feedback sources must be continuously identified and monitored; intervention may be necessary at times. This point becomes more critical when we consider that consumer feedback is not always generated using the company's resources or on its pages. Companies have to search for relevant content in various ranking portals, blogs, and forums. Users also expect the company to react positively to suggestions for improvement, whether this be explaining why their ideas cannot become realized or actually making suggested changes in organizational rules, products, or services. Both options are costly in terms of time and money. In their work on open source software development, Hanekop and Wittke (2008) also emphasize the importance of taking users' voluntary contributions explicitly into account in strategic cost calculations. Like MeyerGossner (2008) pointed out, a problem arises when using social media as a feedback channel. A large amount of feedback requires a large capacity in human resources to evaluate it. However, as a rule, customer service budgets have not increased proportionally to the requirements created by companies' web 2.0 presence.

The risks associated with doing business in the new consumer culture have not been considered adequately. Of course, web 2.0 can be seen as a good opportunity to gain important and useful input for product quality assurance or service im- 
provement, but operating in web 2.0 leads to several problems that arise from a new kind of customer-company relationship. At any rate, companies that rely on internet commerce will hardly be able to avoid these problems in the future, as empirical studies indicate that for many of these companies, the proportion of consumers who use the internet in a sophisticated manner is continually increasing. Strictly speaking, the results in this paper hold only for our case studies, but the new prevalence of social media in all economic sectors and its increased use by consumers probably means that other companies and other kinds of companies will face the phenomena we observed some way or another. In web 2.0, traditional target groups are dissolving and individual behaviors are forming a new marketing base (Bender 2008). Companies and researchers should become aware of the fact that internet users do not behave and "work" like conventional customers.

\section{Conclusion}

To face the typical problems caused by the steady qualitative change of consumer characteristics, companies have to react with commensurate business standards and practices. Thus, it can be assumed that a new type of company will emerge. The fact that companies so often make mistakes in their web 2.0 communications suggests that companies either have not noticed the change of consumer culture, do not want to face the challenges it presents, or do not take it seriously enough. We might suppose that negotiations take place within companies about adequate standards for reacting to different online situations, but the conventional customer is still the predominant focus of planning and strategy. Consequently, inadequate forms of interaction with the new type of internet customer can serve to aggravate or bring out the negative side effects that are already inherent in web 2.0 customer integration. Reichwald and Piller (2006) indicate that a company's ability to integrate customer knowledge in its entrepreneurial value chain should be embedded in management training, organization, and infrastructure as a matter of routine. But apart from gaining customer input proactively, companies operating in web 2.0 have to develop and implement permanent organizational resources and practices in order to harness consumers who are adept internet users.

Organizational innovation in response to web 2.0 users means a potential loss of organizational control. The new risks caused by using web 2.0 for gaining feedback from internet users cannot be solved merely by better implementation of conventional customer integration methods. For most companies, an internet presence apparently is still considered to be a kind of adjunct to existing organizational operations. They do not see the inevitable necessity of adapting internal structures as a consequence of internet success. Until now, many companies are not communicating in appropriate ways because the web 2.0 logic has not been internalized. We assume that most companies know how social media works and have learned how to integrate this new field of activity into their operations appro- 
priately, but for many, "being web 2.0 " is superficially articulated. Companies set up a blog, but write nothing. They have a Facebook like page, but do not react to consumers' comments. They have a feedback area in their own website's forum, but have no possibility of implementing suggestions for improvement. There seems to be a serious attempt to integrate consumers, but only as long as the dictates of web 2.0 culture can be ignored. Companies have to become aware of the fact that it is not just about being present and being seen in the internet. Successful presence in web 2.0 demands action in two senses. First, a new level of informing, communicating, helping, and negotiating with consumers is necessary. Second, all domains of the value chain have to be reconceptualized in terms of their role for communication and customer service. Further research is needed to understand how common forms of organizational control remain functional for companies acting in the internet. All in all, companies should be warned against simply "experimenting" with web 2.0; once a company is present in the internet, it must follow an elaborated strategy to avoid negative side effects.

At this point we want to emphasize again that operating in the internet is no longer just another option, especially for companies serving a target group which is obviously active in web 2.0. If the enterprise does not start to act in the internet, customers will start to communicate negatively about the company using webbased technologies, independently from organizational control. There is evidence to suggest that an increasing number of entrepreneurs are orienting their business strategies towards web-based activities, as they feel communication with customers over the internet as necessary for maintaining competitiveness. If a company possesses neither know-how nor money to take over communication tasks internally, outsourcing these tasks to an external service provider specialized in social media management can be an affordable alternative (Piller 2000). Such "intermediaries" can take over the dialog with consumers, but further research is needed regarding what this means for companies' authenticity in web 2.0. We assume that as long as the company has not internalized web 2.0 culture, outsourcing this business area to specialists will lead in the end to additional problems caused by just pretending to "be web 2.0."

The practices expected by academic theorists regarding web 2.0 as a source for consumer input differ from actual business practices because theorists often focus only on methods of customer integration. The fact that web 2.0 feedback affects every aspect of an organization is too often overlooked. Successfully dealing with the new qualities of consumer feedback requires adapting a company's entire organizational structure. This fact should be reflected also in academic discussions.

At the very least, it should be emphasized that many companies should make the management of feedback through social media a major field of operations. In this context, it should never be forgotten that social media users are a very special, but growing, target group. They have their own preferences, wishes, and needs. This group is likely to differ in many ways from those who do not use social media 
as a communications channel, for whom conventional market research methods and complaint management are appropriate.

\section{References:}

Alby, T. (2008). Web 2.0. Konzepte, Anwendungen, Technologien. 3rd edition, München: Hanser.

Ashkenas, R.; Ulrich, D., Jick, T. and Kerr, S. (1995). The Boandaryless Organization. Breaking the Chains of Organizational Structure. San Francisco: Jossey-Bass.

Beißwenger, M. and Storrer, A. (eds) (2005). Chat-Kommunikation in Beruf, Bildung und Medien. Konzepte, Werkzenge, Anwendungsfelder. Stuttgart: Ibidem.

Bender, G. (2008). “Kundengewinnung- und Bindung im Web 2.0.” In: Hass, B. H., Walsh, G. and Kilian, T., pp. 173-190.

Bieber, C. and Lamla, J. (2005). "Das Netz der Konsumenten Innovationschancen der Verbraucherbewegung im Internet.” In: Forschungsjournal Neue Soriale Bewegungen 18(4): 65-77.

Bieber, C., Eifert, M., Gross, Th. and Lamla, J. (eds) (2009). Soziale Netze in der digitalen Welt. Das Internet zwischen egalitärer Teilhabe und ökonomischer Macht. Frankfurt a.M., New York: Campus.

Birgit Blättel-Mink, B. and Hellmann, K-U. (eds) (2009). Prosumer Revisited. Zur Aktualität einer Debatte. Wiesbaden: VS Verlag.

Boy, B. and Rieke, N. (2010). Das Prinzip Offenheit - oder haben wir wirklich die Wahl? Retrieved from http://iblogforbrands.blogspot.com/2010/08/dasprinzip-offenheit.html (accessed 11/08/2010).

Breazeale, M. (2009). "Word of mouse.” In: International Journal of Market Research 51(3): 297-318.

Bruseberg, A. and McDonagh-Philp, D. (2002). "Focus groups to support the industrial/product designer: a review based on current literature and designers' feedback.” In: Applied Ergonomics 33(1): 27-38.

Calder, B. J. (1977). "Focus groups and the nature of qualitative marketing research.” In: Journal of Marketing Research 14(3): 353-364.

Colwell, T. (2010). "Protecting Your Online Reputation - an Exercise in Restraint." In: Greater Games Industry Catalog13: 21.

Crystal, D. (2006). Language and the Internet. 2nd edition, Cambridge: Cambridge University Press.

Ebersbach, A., Glaser, M. and Weigl, R. (2008). Social Web. Konstanz: UVK.

Ferguson, R. (2008). "Word of mouth and viral marketing: taking the temperature of the hottest trends in marketing.' In: Journal of Consumer Marketing 25(3): 179182. 
Habscheid, St.,Holly, W.,Kleemann, F., Matuschek, I. andVoß, G. G. (eds) (2006). Über Geld spricht man. Medienvermittelte Kommunikationsarbeit und Arbeitskommunikation im Bank.geschäft. Wiesbaden: VS Verlag.

Hanekop, H. and Wittke, V. (2008). "Die neue Rolle der Anwender in internetbasierten Innovationsprozessen.” In: AIS-Studien 1(1): 7-28.

Hanekop, H. and Wittke, V. (2009). "Kollaboration der Prosumenten. Die vernachlässigte Dimension des Prosuming-Konzepts.” In: Blättel-Mink, B. and Hellmann, K.-U., 96-113.

Harnoncourt, M., Holzhauser, A., Seethaler, U. and Meinl, P. (2005). "Referenzierbarkeit als Schlüssel zum effizienten Chat." In: Beißwenger, M. and Storrer, A., 160-179.

Hass, B. H., Walsh, G. and Kilian, T. (eds) (2008). Web 2.0. Neue Perspektiven für Marketing und Medien. Berlin, Heidelberg: Springer-Verlag.

Kaplan, A. M. and Haenlein, M. (2010). "Users of the world, unite! The challenges and opportunities of social media." In: Business Horizons. 53(1): 59-68.

Kleemann, F., Rieder, K. and Voß, G. G. (2008). "Un(der)paid Innovators: The Commercial Utilization of Consumer Work through Crowdsourcing." In: Science \& Technology Studies 4(1): 5-26.

Knorr, E. (2003). “The Year of Web Services.” In: CIO: Fast Forward 2010. The Fate of I.T., 1 January, 90.

Kranz, J., Janello C. and Picot, A. (2009). "Die Rolle von Web 2.0-Prinzipien im Innovationsprozess." In: IM - Die Fachzeitschrift für Information Management und Consulting 24(2): 39-47.

Lazkani, N. (2009). “Managing Your Online Reputation.” In: Response 18(1): 53.

Leisenberg, M. (2007). Web 2.0: Soziale Prozesse bringen Geld. Retrieved from http://www.computerwoche.de/management/it-strategie/591442/ (accessed 01/07/2010).

Leisenberg, M. (2009). Digitale Reputation in Web 2.0 und Sozialen Netzen. Chancen und Risiken des modernen Internet erkennen. Retrieved from http://leisenberg.blogg.de/ eintrag.php?id=81 (accessed 05/07/2010).

McQuarrie, E.F. and McIntyre, S.H. (1986). "Focus groups and the development of new products by technologically driven companies: some guidelines." In: Journal of Product Innovation Management 3(1): 40-47.

Meyer-Gossner, M. (2008). Kundenfeedback in der Internetwelt - präventiv gedacht. Retrieved from http://www.thestrategyweb.com/kundenfeedback-inder-internetwelt-praventiv-gedacht (accessed 02/07/2010)

Morrissey, B. (2009). “Who's in Charge of Social media?” In: Sales \& Marketing Management 161(6): 34. 
Münker, St. (2009). Emergenz digitaler Öffentlichkeiten. Die sozialen Medien im Web 2.0. Frankfurt a.M.: Suhrkamp.

Neff, G. and Stark, D. (2002). Permanently Beta: Responsive Organization in the Internet Era. Retrieved from http://opensource.mit.edu/papers/neff-stark.pdf (accessed 02/07/2010).

O'Reilly, T. (2005). What Is Web 2.0. Retrieved from http://www.oreillynet.com/pub/a/oreilly/tim/news/2005/09/30/what-isweb-20.html?page $=4$ (accessed 02/07/2010).

Papsdorf, C. (2009). Wie Surfen zu Arbeit wird. Crowdsourcing im Web 2.0. Frankfurt a. M., New York: Campus.

Picot, A. , Reichwald, R. and Wiegand, R. T. (1996). Die grenzenlose Unternehmung. Information, Organisation und Management. Lehrbuch zur Unternehmensfübrung im Informationszeitalter. Wiesbaden: Gabler.

Piller, F. (2000). Mass Customization. Ein wettbewerbsstrategisches Konzept im Informationszeitalter. Wiesbaden: Gabler.

Piller, F. and Müller, M. (2004). "A new marketing approach to mass customisation.” In: International Journal of Computer Integrated Manufacturing 17(7): 583-593.

Piller, F., Moeslein, K. and Stotko, C. (2004). "Does mass customization pay? An economic approach to evaluate customer integration." In: Production Planning \& Control 15(4): 435-444.

Ramsey, R. (2010). "How to handle customer complaints.” In: American Salesman 55(6): 25-30.

Rayport, J. (1996). The Virus of Marketing. Retrieved from http://www.fastcompany.com/magazine/06/virus.html (accessed 04/08/2010).

Reichwald, R. and Piller, F. (2006). Interaktive Wertschöpfung: Open Innovation, Individualisierung und neue Formen der Arbeitsteilung. Wiesbaden: Gabler.

Rice, D. (2010). "Managing Your Reputation in a Viral World.” In: Security Distributing \& Marketing 40(3): 93-100.

Salvador, F., Holan, P. and Piller, F. (2009). "Cracking the Code of Mass Customization.” In: MIT Sloan Management Review 50(3): 71-78.

Schreyögg, G. and Sydow, J. (1997). Managementforschung 7. Gestaltung von Organisationsgrenzen. Berlin, New York: de Gruyter.

Stegbauer, Ch. and Jäckel, M. (eds) (2008). Social Software. Formen der Kooperation in computerbasieten Netzwerken. Wiesbaden: VS Verlag für Sozialwissenschaften.

Thiele, U., Kramer, S. and Frey, C. (2010). Social media und die neue Offenheit. Retrieved from http://www.tagesspiegel.de/wirtschaft/social-media-und-dieneue-offenheit/1867636.html (accessed 11/08/2010). 
Voß, G. G. (1998). "Die Entgrenzung von Arbeit und Arbeitskraft. Eine subjektorientierte Interpretation des Wandels der Arbeit." In: Arbeitsmark.t- und Berufsforschung 31(3): 473-487.

Voß, G. G. (2005). "Die nächste Stufe der Selbstbedienung ist der arbeitende Kunde ...” In: GDI-Impuls, Winter 2005: 56-65.

Voß, G. G. (2006). “Arbeitende Bankkunden.” In: Habscheid, St., Holly, W., Kleemann, F., Matuschek, I. and Voß, G. G., 123-161.

Voß, G. G.and Rieder, K. (2005). Der arbeitende Kunde. Wenn Konsumenten zu unbezablten Mitarbeitern werden. Frankfurt a. M., New York: Campus.

Voß, G. G. and Kleemann, F. (2009). “Arbeitende Kunden im Web 2.0.” In: Bieber, C., Eifert, M., Gross, Th. and Lamla, J., 141-160.

Voß, G. G. and Rieder, K. (Forthcoming 2010). "The Working Customer - an Emerging New Type of Consumer.” In: Journal Psychologie des Alltagshandelns $3(2)$.

Waldman, D. and Bowen, D. (1998). "The acceptability of 360 degree appraisals: A customer-supplier relationship perspective.” In: Human Resource Management 37(2): 117-129.

Zairi, M. (2000). "Managing customer dissatisfaction through effective complaints management systems.” In: The TQM Magazine 12(5): 331-337. 


\title{
Prosuming, or when Customers Turn Collaborators: Coordination and Motivation of Customer Contribution
}

\author{
Birgit Blättel-Mink, Raphael Menez, Dirk Dalichau and \\ Daniel Kahnert ${ }^{1}$
}

\begin{abstract}
This article investigates the phenomenon of increasing integration of customers and users into the organizational creation of value, focusing primarily on the dissolving boundaries between production and consumption. Concepts such as "prosuming", the "working customer", "produsing" and "interactive value creation" have been used to describe this phenomenon. Within the framework of a research project at the Goethe-University Frankfurt/Main, this debate was investigated theoretically as well as empirically in three case studies. The research question is as follows: Why do customers participate in "new types of prosuming" or "interactive value creation" and how are these processes coordinated by the firms? The results show a considerable range of motives and forms of coordination: The customers' primary motives to voluntarily assume tasks and activities were both intrinsic and extrinsic in nature. The organizational models identified range from strategies of rationalization to prosuming as a basic business model to the collaborative and interactive value creation between the company and the web-community.
\end{abstract}

\footnotetext{
${ }^{1}$ We are very grateful to Angela Weil who translated this article with high professionalism and a lot of patience!
} 


\section{Introduction}

Today, according to a prominent sociological hypotheses, significant changes in the relationship between work and consumption are taking place. While in the industrialized society the line between production and consumption was clearly defined, now the phenomenon of the "working customer" dissolves this boundary: Companies are systematically diverting to consumers activities and organizational tasks previously performed internally. At the same time, consumers increasingly perform productive activities which provide tangible benefits to other participants in the market and which prove to be a real contribution to the added value of the companies (Kleemann, Voß and Rieder 2008). The Internet and Web 2.0 also contribute to new options for the inclusion of users in the production process and to extending the reach of the co-produced goods and services (Hanekop and Wittke 2008). This development, often described as do-it-yourself, prosuming, coproduction or McDonaldization, is now surpassed by the phenomenon of crowdsourcing, in which companies "...delegate previously internally completed tasks to outsiders in the form of open calls for submission, on web-based platforms. for the production or use of a product" (Kleemann, Voß and Rieder 2008:29).

Relevant questions in this context, which so far have rarely been investigated from a sociological perspective, are the following: What are the reasons for companies to increasingly transfer value-creating activities to customers, what are the motives of the customers to work voluntarily and without payment for a company, and what options do companies use to coordinate and control the integration of the customer?

Within the framework of a research project at the Goethe-University in Frankfurt/Main ${ }^{2}$, current phenomena from prosuming to crowdsourcing have been both theoretically and empirically investigated, and the following research questions were developed: Why do customers participate in "new types of prosuming" or in "interactive value creation" and how are these processes coordinated by the firms? The theoretical context of the research project is the approach derived from theories of the sociology of work concerning the "working customer" (Voß and Rieder 2005), the sociological view of consumption discussing "prosuming" (Toffler 1980, Blättel-Mink and Hellmann 2010) and the "new type of prosuming" (Hanekop and Wittke 2008), the economic model of "interactive value creation" (Reichwald and Piller 2009), and the theoretical concepts of "crowdsourcing" (Howe 2006) and "produsing" (Bruns 2009) both of which originated from the research on Web 2.0 issues. At the centre of the empirical research are three companies: Deutsche Bahn AG, the Swedish furniture company IKEA and a German developer of computer games, Crytek. This selection offers a differentiated view on the parameters and characteristics of the phenomenon under investigation.

\footnotetext{
2 See also the website of the research project: http://www.gesellschaftswissenschaften.unifrankfurt.de/index.pl/prosuming.
} 
Both the perspective of the customer or user and the perspective of the company are analyzed. Methods range from content analysis of relevant texts to semistructured expert interviews with representatives of the companies to standardized written surveys of customers and users.

The theoretical and empirical aspects of the integration of customers and users in the process of value creation are explored in the section immediately following. Then the research question is presented and the methodology explained, followed by the results of the three case studies, with main emphasis on Crytek. In the end, a critical evaluation of the research findings is given.

1. Theoretical considerations for understanding the phenomenon of customer integration into the value creation process

The sociology of work considers consumption as primarily being an area in which labor-power is reproduced. Work and consumption occurred in two separated social spheres. G. Günther Voß and Kerstin Rieder (2005) start their analysis with the following conclusion " $\ldots$ there are dramatic changes in the societal form and function of private consumption, the societal relationship between productive work within a company and the active utilization of goods outside of the producing organization" (Voß and Rieder 2005:14). They relate such changes to the fact that companies are increasingly and systematically outsourcing previously internally provided tasks to their customers and the fact that consumers are increasingly providing services that used to be provided by the companies. The "buying customer", formerly a consumer of finished products, turns into a "working customer" who not only plays the role of a consumer but also acts as an uncompensated worker for the companies, by adopting the role of a co-producer. "....its main characteristic is its expanded productivity - based on active services - which in many cases is explicitly controlled and used by the company" (Voß and Rieder 2005:16). The authors assume that particularly the companies' rationalization efforts are a primary reason for the extensive inclusion of the customers.

Since the advent of the Web 2.0 phenomenon, Alvin W. Toffler's (1980) concept of the "prosumer", who is at the same time producer and consumer, has been gaining new recognition (see the articles in Blättel-Mink and Hellmann 2010). Toffler anticipated that the spheres of consumption and production, which had been structurally distinct since the industrial revolution, would move closer together again in the Third Wave (the Service Society). The so-called prosumer economy bridges the historical gap between consumption and production and is divided into two sectors. Sector A involves the concept of "production for use": " $[\ldots]$ unpaid work done directly by people for themselves, their families, or their communities" (Toffler 1980:266)., Whereas sector B stands for the concept of "production for exchange": "[...] the production of goods or services for sale or swap through the exchange network or market" (Toffler 1980:266). According to Toffler, sector B 
was dominant during the second wave. Then, however, a shift takes place in the third wave, since more activity is moved from sector B (market) to sector A (prosumption). Toffler also anticipated the spread of self-help groups, the do-ityourself movement or the spread of self-service in grocery stores. He points to the rise of new technologies that enable these developments: "In this system the prosumer, who dominated in first wave societies, is brought back into the center of economic action - but on the third wave, high-technology basis" (Toffler 1980:275).

An extended analysis of Toffler's concept was presented by Kai-Uwe Hellmann (2010). For him, prosumption takes place whenever "...a contribution is provided without which the production process would have remained unfinished in the development of a product or service that is predominantly meant for personal use and thereby gains its practical value independently of whether the service must be paid for or not" (Hellmann 2010:36). In this definition, he makes a distinction between the "production for exchange" and the personal use of the service, as well as distinguishing "active consumption" from a process of production that cannot be completed without a contribution provided by the prosumer.

Heidi Hanekop, Andres Tasch and Volker Wittke (2001) introduce a further development of Toffler's prosumer concept, the "new type of prosumer". According to them, this new type resembles (in competencies and tasks) forms of professional knowledge work ${ }^{3}$. Therefore this can be related to discussions about the dissolving boundaries of work in the fields of industrial sociology and sociology of work. In other publications on collaborative web-based production and innovation processes (Hanekop and Wittke 2008 and 2010) the authors describe a new quality of prosuming and co-production which differs from Toffler's concept. The typical characteristics of co-production are radicalized when self-service is used online, even though the co-producing customers are not physically on the company's premises nor within its domain, but instead enter it from home or any other place that has Internet access. The new online forms of co-production take on a new quality through mass cooperation among users and effectively go beyond the private domain, as seen in Wikipedia and open source software (OSS)" (Hanekop and Wittke 2010:101). On the one hand, they agree with Toffler's conclusion that "production for use", which is not marketable, is constitutive for prosuming. On the other hand, they show that collaborative processes of value creation through active work and by personal initiative can take place outside of marketable modes of "production for exchange".

Ralf Reichwald and Frank Piller presented an economic approach of "interactive value creation" in 2006. They conceptualize the relationship between customers and companies as a win-win situation and stress the factor of voluntarism, as well as the involved actors' competence for interaction. The point of departure for

\footnotetext{
3 Toffler considers personal initiative or do-it-yourself to be "manual work".
} 
the analysis is the identification of two central problems within the conventional arrangement of value creation: First, the customer is seen by the company as a "passive receiver of value" and his or her 'average' needs are analyzed using market research. Second, the "problem of searching locally" clearly confines the capabilities of the company to innovate, because only known solutions and approaches can be applied. In order to clarify these two problems, the authors introduce the concepts "needs information" and "solution information". "... Needs information relates to the needs and preferences of the customers or users: This can be information on explicit as well as latent needs [...].Solution information is (technical) knowledge on how to solve problems or fulfill needs through special product specifications or with a service" (Reichwald and Piller 2009:47). According to the authors, both are important input factors for the companies. While needs information assures higher effectiveness during the value creation value process, because it allows the fulfillment of the customers desires, solution information focuses on efficiency in the creation of value, because new solutions can be developed faster and more economically.

The approach of interactive value creation stresses the voluntarism and reciprocity of the relationship between customer and company. The authors consider this concept to be an extension of the classic economic models: "This supplements the two classic forms of coordination (hierarchy and market) by adding a third alternative: the self-selection and self-organization of tasks by (highly) specialized actors, who are mainly motivated by their own usage of the cooperatively accomplished achievements, as well as a multitude of other social, intrinsic and extrinsic motives" (Piller, Reichwald and Ihl 2007:91).

Reichwald and Piller distinguish two other constitutive phenomena within the interactive value creation: "open innovation" 4 and "mass customization". The first "... describes all activities that take place between the manufacturing company and its external partners that are based on the innovation process and thus target the development of new products for a larger circle of consumers. Open innovation provides new methods and approaches to better access information on needs and problem solving and to increase the effectiveness and efficiency of the innovation process" (Reichwald and Piller 2009:53). Open innovation offers an open space for solutions ${ }^{5}$ that is extended and modified collectively together with external partners. On the other hand, mass customization “... is the cooperation between companies and customers that is concerned with the value creation activities dur-

\footnotetext{
4 Reichwald and Piller reference the research of Eric von Hippel (von Hippel 2005; Baldwin and von Hippel 2009; Harhoff, Henkel and von Hippel 2003). Henry Chesbrough (2003) takes a slightly different perspective on open innovation: In his approach, open innovation is mainly understood as a flexible and open handling of different business models, while including the companies' external partners.

5 The authors define solution space as the " $\ldots$ sum of all solutions that a company is able to offer at the moment, on the basis of its existing product architecture and the pertinent production and distribution processes" (Reichwald and Piller 2009:53).
} 
ing the operational production process and is also aimed at the development of individualized products for the consumers. The goal is to gain access to needs information by integrating the customers and in doing so being able to better fulfill the specific desires of individual consumers within a heterogeneous market" (ibid.).

Axel Bruns (2009) investigates the impact of Web 2.0. He argues that the web enables novel forms of cooperation and collaboration between users of certain products and services. The division between customer and company can be overcome because web users creating collaborative content are independent of any organizational connection to a company and their work has little in common with traditional forms of production. Instead of using the term "production," Bruns suggests the term "produsage" and for the actors, the producing web users, the term "produser": "The creation of common content takes place in a well networked participative environment. Produsers don't participate in a conventional form of content production, they participate in the produsage of content: a collaborative and continuous development and expansion of existing content, focused on quality improvements" (Bruns 2010:199). Thus, the formerly clearly defined roles of producer and consumer break down because produsers are, according to Bruns, active editors and users at the same time and therefore, they assume the "... role of a hybrid user/producer where both forms of contribution are inseparably intertwined with each other" (ibid.).

Along with the rejection of the concept of production in this context, for Bruns, the idea is that products created in this way are not traditional products to be traded as tangible goods on the market. He calls them unfinished artifacts accessible free of charge to anyone. The typical example of a prodused artifact is the free online encyclopedia Wikipedia: an ever unfinished artifact in a state of constant change. In produsing, crowds of networked users contribute to the process of content creation, very much in contrast to the process of industrial production, in which an individual producer or production teams create a product. Within a produsing community the roles of individual users can change as well. The focus of their contribution can shift within a given project, it can shift to other projects entirely or the users can increase or decrease their influence on the community at will. The status of a produser in the community depends on the resources and competencies contributed by him or her, most importantly knowledge, skills and the amount of time given to the project. Accordingly, Bruns describes the rank and order in a community as a changeable heterarchy or as an ad-hoc-meritocracy (Bruns 2010:201). The question of ownership in the context of produsing is not entirely resolved. In most cases, a prodused artifact will be freely available under a "creative commons" license ${ }^{6}$. This type of license can permit further alterations to

\footnotetext{
6 "Creative Commons licenses are several copyright licenses that allow the distribution of copyrighted works. The licenses differ by several combinations that condition the terms of distribution. They were initially released on December 16, 2002 by Creative Commons, a U.S. non-profit corporation founded in 2001.” (http://en.wikipedia.org/wiki/Creative_Commons_licenses)
} 
the product and non-commercial use. The motivation factor for individuals to join a produsing community and to be active in one is not the expectation of monetary rewards, it is - next to the original benefit of using the artifact - primarily the recognition in the community. Communities frequently offer merit scores that document individual accomplishments and make them recognizable to others (Bruns: 2007:4).

Yet communal produsing and commercial activities are not mutually exclusive because the commercial viability of a project can have a decisive influence on the long-term stability of such a project. Therefore, Bruns describes the value chain in the context of produsing as networked communal processes that have a multitude of input and output (Bruns 2009).

\section{Research question and methodological design}

The above description of the theoretical approaches that have been decisively determining the discussion of the changes in consumption, production and innovation, shows the following: The bandwidth and perspectives of the discussed approaches may be heterogeneous, however they come to an agreement in their diagnosis that there has been a dissolution of previous boundaries and the allocation of roles within the social relation of consumption, production and innovation.

Following this diagnosis, two questions are particularly of interest that have rarely been researched from a sociological perspective and that make up the core of this project: 1 . Why do customers engage in the creation of value without gaining financial reimbursement, and 2 . How do companies coordinate the involvement of the customers?

One of the goals of this research project was to describe the process of the increase in prosuming, which is marked by the fact that, first of all, there is more "work" done by the customers or users and second, that the companies boundaries are broadened by the increased use of technology such as the Internet. Therefore, companies that cover the whole bandwidth, from rationalizing to collaboration, are empirically interesting cases.

A first case encompasses companies that practice the outsourcing of services that were formerly performed internally by the company to the customers, as a result of a rationalization process. Deutsche Bahn AG, for example, asks its customers to do more and more work during ticket buying, from the basic service orientation at the counter to automated ticket machines to online ticket buying. A second case encompasses companies that have always relied on their customers collaboration - if only in offline areas - such as IKEA, by applying the possibilities of new information and communication technologies to intensify the cooperation of their customers. This is visible in the increasing introduction of self check out cashiers. Lastly companies are of interest that cooperate with user communities rather than customers. These users produce products that are initially concretized 
and further developed by produsage. For this example the computer gaming manufacturer Crytek was chosen, which turns users into "modders" who can bring in their own ideas and modify games as they please.

This project's specific research question is: Why do customers take part in processes such as "new types of prosuming" and "interactive value creation" and how are these processes coordinated by the firms? To find an answer to these questions the three above mentioned companies were analyzed from both customer and company perspectives. For this research project, six student work groups were given the task of studying the empirical phenomena in depth, specifying the research questions for their case and developing an appropriate theoretical framework. Subsequently, a methodological design was developed which provided a basis for the case studies.

The following chapter describes the results of the surveys.

\section{Deutsche Bahn and IKEA}

\section{Deutsche Bahn AG: Rationalization and the work of customers}

Deutsche Bahn was chosen as a company of interest on the one hand because the company presents itself as a customer-oriented service provider with a high concern for its customers' input; on the other hand because it has increasingly been eliminating service features and has instead - in the course of economization measures - been placing more emphasis on the work of its customers. This has become especially evident in ticket buying. The standard ticket buying procedure no longer takes place at the ticket counter but has shifted to sales at automated ticket machines and online ticketing. Therefore, the survey closely examined ticket buying behavior. In addition, six semi-structured expert interviews were conducted with Deutsche Bahn employees who had knowledge in the field of online sales to explore the company's coordination of the customers' work.

The survey's findings ${ }^{7}$ at Deutsche Bahn clearly show distinct tendencies. On the one hand, customers strongly value the possibilities the Internet or web gives them in order to search for information and buy tickets online, however at the same time the conventional distribution and information channels are not ignored. A factor analysis revealed a service factor that represents the answering behavior of a group of customers that still value conventional delivery of services. It can be determined nevertheless that a large proportion of Deutsche Bahn's customers are prepared to turn into working customers because they regard participation as being easy and convenient, whereas another proportion of customers still request assistance and service and are not engaged in this development and therefore will re-

\footnotetext{
7 The data collection was conducted in May 2010; the questionnaire was available online for two weeks. Within this period, 936 respondents completed the questionnaires $(\mathrm{N}=936)$.
} 
main merely buying customers. The motivation of the respondents identified as working customers is not intrinsic. They do not participate because they enjoy the task itself, but because they hope to save time and expect to gain more independence from external factors such as business hours, long lines at the service counter or reliability of the information provided by Deutsche Bahn's service employees. The tasks that are outsourced to Deutsche Bahn's customers in particular involve highly standardized procedures that do not leave much room for distinct ideas and creative capacities.

The interviews with Deutsche Bahn's employees demonstrate that Deutsche Bahn does not apply systematic customer interface management. Deutsche Bahn coordinates the involvement of customer participation through highly standardized gateways, such as the online ticketing interface, the automated ticket machines or online contact forms. Although further customer information is collected and partially processed, the most rudimentary deliberate and strategic actions are only taken by the customer advisory committee. It is this advisory committee that gives specific recommendations, formulates them and passes them on. In all, it is not possible to conclude that Deutsche Bahn conducts customer inclusion and value creation based on the division of labor in the sense of interactive value creation. The possibilities of creating value by strategically using the customers creative capacities and knowledge has not gained much significance yet. The customer is seen as the receiver of services, rather than as a partner in the process of value creation. Conventional means such as market research are trusted and are used to collect information from and about customers. Nevertheless - and this points towards a prosumptive future at Deutsche Bahn AG - an organizational unit is being restructured in order to improve the processing of customer information in the future: "In principle we are establishing the whole issue of further development at the moment: What information do we get from the customers? Yes, as a team we are relatively new here. Yes, one colleague who was here before the restructuring is still in this department. All of the others are new. In principle we are establishing the whole thing to the point where we are able to say, yes, what information do we receive from the customers and how do we pass it on" (DB 2).

\section{IKEA: Prosuming as business model and possibilities for its expansion}

A look at IKEA offers a typical example of a company using the classic (manual, offline-based) forms of prosumption. The company has distinct elements of a doit-yourself concept: In most cases, shopping at IKEA means selecting products without the help of a salesperson or any kind of assistance, and as of recently, in certain IKEA locations items have to be paid for at the self check-out stations. The question in the IKEA analysis was: How do customers use, and how are they motivated to use, new forms of collaboration? Therefore the analysis focused on self check-out stations as a new paying concept in addition to the classical cashieroperated checkout stations. 
Both the people who had already used the self check-out stations and those who had not were asked to describe their attitude towards this new method of payment ${ }^{8}$. The results show very clearly that the involvement of customers is viewed as self-evident and a natural everyday occurrence, both by consumers at IKEA and by the company. The customers are involved in different contexts at IKEA: they are do-it-yourself prosumers during the transportation and assembly of furniture in their homes, working customers in regard to their involvement at the furniture store and in certain situations also a new type of prosumers, when using the scan-it-yourself checkout, which requires more mental engagement. Customers especially view these new types of prosumption with a certain degree of scepticism, but they are reaching some acceptance and at least are utilized. It is not surprising to discover that users of new forms of involvement see such novelties in a more positive light than non-users, who are much more sceptical. In addition, there are groups of customers who evaluate new forms of customer involvement not only in the subjective light of advantages or disadvantages for themselves but question them in a general social context. They are concerned about the consequences for IKEA's employees. "New type prosumers" are motivated by their perception of increased self-directedness by actively contributing as well as by the "discovery of something new" and the experience of "fun".

Otherwise, the integration of customers at IKEA seems to be taken for granted and there is no need for additional coordination on the side of the company to further motivate the customers, as long as it is an involvement typical of IKEA. The subject is not explicitly addressed, as the involvement of the customers is always implicitly contextualized as the norm in the analyzed company communication materials. The topic of collaboration, prosuming or working customership is raised on a side note, usually in the context of additional services or as an extension of the various possibilities a visit at IKEA has to offer to its customers. According to the company's communication, work done by their customers is described as something beneficial to the customer on three dimensions: experience, variety and cost-benefits. The material shows that the dimension of variety is considered to be the variety of possibilities. Even completely new tasks such as self checkout do not need any special motivational offers, as long as they stay in line with the core business of IKEA. Only in areas outside of the core business, such as marketing activities like a photo event in which customers take pictures of their personal home environment and supply the images to IKEA in order to acquire an authentic and accurate idea of how IKEA furniture would look in the home of the customer, does the need for focused coordination arise in order to motivate customers to cooperate.

\footnotetext{
8 The field research on the customer perspective was carried out analogously to the other two case studies: a standardized online survey with a return of 361 completed questionnaires distributed via online forums about furnishing and decorating, and in part by using a mailing list of students.
} 


\section{Crytek: Interactive value creation and collaboration of the modder community}

The Crytek company, located in Frankfurt, is one of the largest German developers of computer games. In international comparison, Crytek is considered to be one of the most innovative companies in the sector. The company was founded 1999 in Coburg (Germany) and has today about 600 employees distributed internationally in five developing studios and two distribution centers. Games developed by the company are all categorized as first-person-shooter ${ }^{9}$ (Far Cry, Crysis and Crysis2) and have earned multiple international prizes. "Cryengine" is considered to be very powerful and flexible developer software that is licensed by other companies for various applications such as for the development of architectural simulations with sophisticated graphics (Kanning 2010).

In the context of the present research project, Crytek is considered to be paradigmatic for a company that is a pioneer in applying the web-based collaboration of customers and users. The business model of Crytek is based on the process of interactive value creation together with external actors. In particular customers are being integrated in all processes of quality control, product adjustment, development and innovation. A flat hierarchy and the particular importance of the coordination of customer interface systems are central features of Crytek. The open boundaries of the company not only facilitate the exchange of information, knowledge and ideas, they also allow the fast recruitment and incorporation of external experts into the structure of the company. Crytek also offers the platform for two major web-based communities which together have about 110,000 active members (www.mycrisis.com and www.crymod.com) ${ }^{10}$. The platform also cooperates with numerous external fan-based communities.

The research project focuses on the interaction between Crytek and the modding community, investigating two research questions: 1 . Why would gamers voluntarily contribute as modders to the development of computer games without pay? 2. How does Crytek coordinate the exchange between the community and especially with the modders? The approach of the interactive value creation described by Reichwald and Piller (2009) is used to develop the concept of interaction and coordination between the company and the modders. This theoretical perspective is particularly useful to identify the information on the side of the

\footnotetext{
9 "First-person shooter (FPS) is a video game genre which centers the gameplay around gun and projectile weapon-based combat through the first person perspective; i.e., the player experiences the action through the eyes of a protagonist. Generally speaking, the first-person shooter shares common traits with other shooter games, which in turn fall under the heading "action game". From the genre's inception, advanced 3D or pseudo-3D graphics elements have challenged hardware development, and multiplayer gaming has been integral." http://en.wikipedia.org/wiki/First_person_shooter

${ }^{10}$ Exact figures on the distribution of the members in both communities are not available. The major proportion of registered users are at mycrisis.com, while crymod.com as a pure modding portal is mostly frequented by game modders and has far fewer members.
} 
modders concerning needs and solutions relevant to the company and to analyze the integration of such solutions into its value chain. The working hypothesis has been that the openness of the product and the open organization structure enables a collaborative value creation between the company and the modders. The concept of the "produser" by Bruns (2008) is applied to understand the work of the modders as the process of "produsing". The modder as a produser is producer, distributor and consumer at the same time. He or she is not generating finished products but artifacts of content that remain continuously unfinished and undergo an almost evolutionary development. The basic hypothesis has been that modders are above all intrinsically motivated to mod and distribute their mods over the Internet.

The research method is as follows: 1. an online survey with a standardized questionnaire was administered at crymod.com, targeting modders. In all, 195 respondents completed the questionnaire; 2. A case study was conducted at Crytek with five semi-structured interviews with experts: two community mangers, a project manager, a game designer and a public relation manager.

\section{First insights}

The web-based collaboration between Crytek and their customers and users differentiates between three types of target markets, where each is approached and later integrated in a different way: The "casual gamers" constitute the largest group of 'normal' computer game players. They are the classic paying customers and are approached through conventional marketing strategies using editorials in pertinent magazines and/or the use of social networks such as Facebook and Twitter. "Hardcore gamers" have been involved in the company for many years, have formed a loyal fan community, know all the Crytek games inside out, because they play them multiple times, each time under different conditions (e.g. different levels, different equipment, single or multiplayer modus). The latter group of customers is particularly important for quality control as well as feedback and has their own separate community on the mycrisis.com platform. Finally, the "modders" are gamers that have the special status of distinguished experts with special qualifications that enable them to modify the games. They are able to modify the software in such a way that the flow of the game, the graphics or individual elements of the game are changed. Such modifications, called "mods", are then distributed to the gamers and made available at no cost over the web (Jeppesen 2004; Postigo 2007; Sotamaa 2007; Behr 2008). Crytek offers this target group an exclusive platform on crymod.com. There, the modders can not only develop their mods and make them available to the community of gamers, the platform is also used to coordinate and facilitate the entire exchange among the modders themselves, between the modders and the company as well as between the entire international modding community. In addition, Crytek supplies special tools to the modders that allow to 
modify individual games. Such Software Development Kits (SDK) ${ }^{11}$ are essentially a light version of the tools that the developers employed at Crytek are using to program and design the games (see figure 1).

\section{Crytek: Community and Toolkits}

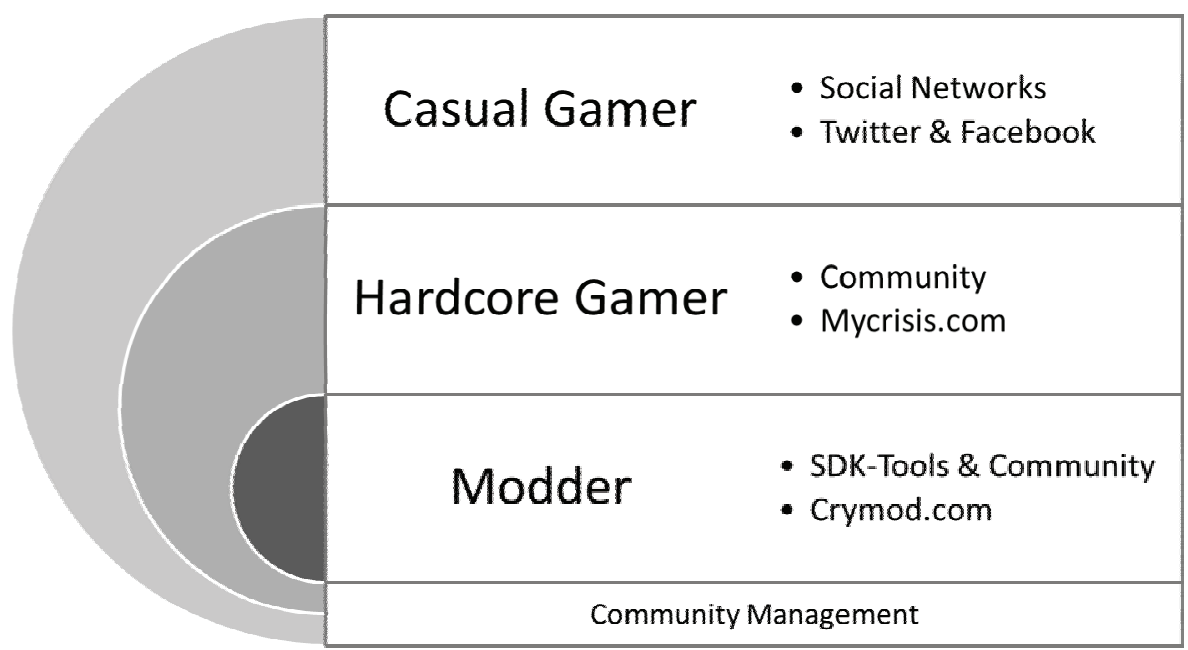

Figure 1: $\quad$ Crytek-related communities and toolkits

\section{Customer perspective}

All of the modders responding to the survey are male. 61 percent are between 15 and 19 years old ${ }^{12}$, many are still attending school (47 percent), 30 percent have a high school diploma. 77 percent of the responding modders come from countries other than Germany. 42 percent live in Europe, 24 percent in North America. Interviewees from the semi-structured interview sessions described the multicultural make up of the modding community and the problems stemming from language barriers: "Sometimes we have issues with the language-barrier. Not everyone from our community speaks English as a first, second or third language. So we have to try and facilitate that as well. We have a lot of Turkish guys on the forums, Americans, French, Germans, Spanish guys, some of them are from Afghanistan, someone from Iraq and a couple of Chinese guys. So it really is multicultural." (Cry 2)

\footnotetext{
11 A software development kit (SDK or "devkit") is typically a set of development tools that allows the creation of applications for a certain software package, software framework, hardware platform, computer system, video game console, operating system, or similar platform. http://en.wikipedia.org/wiki/Software_Development_Kit

12 The youngest of the modders at crymod.com is now 12 years old but started modding two years ago. Because of his unusually young age and because of his special talent, he is already a well known in the community.
} 
Concerning the question as to why modders agree to contribute voluntarily to the improvements, development or remodeling of the computer games and make the modifications available to the community free of charge, it has been observed that three types of motives played a major role for the responding modders: Figure 2 shows that intrinsic, extrinsic and social motivation are estimated almost equally on a rather high level. ${ }^{13}$

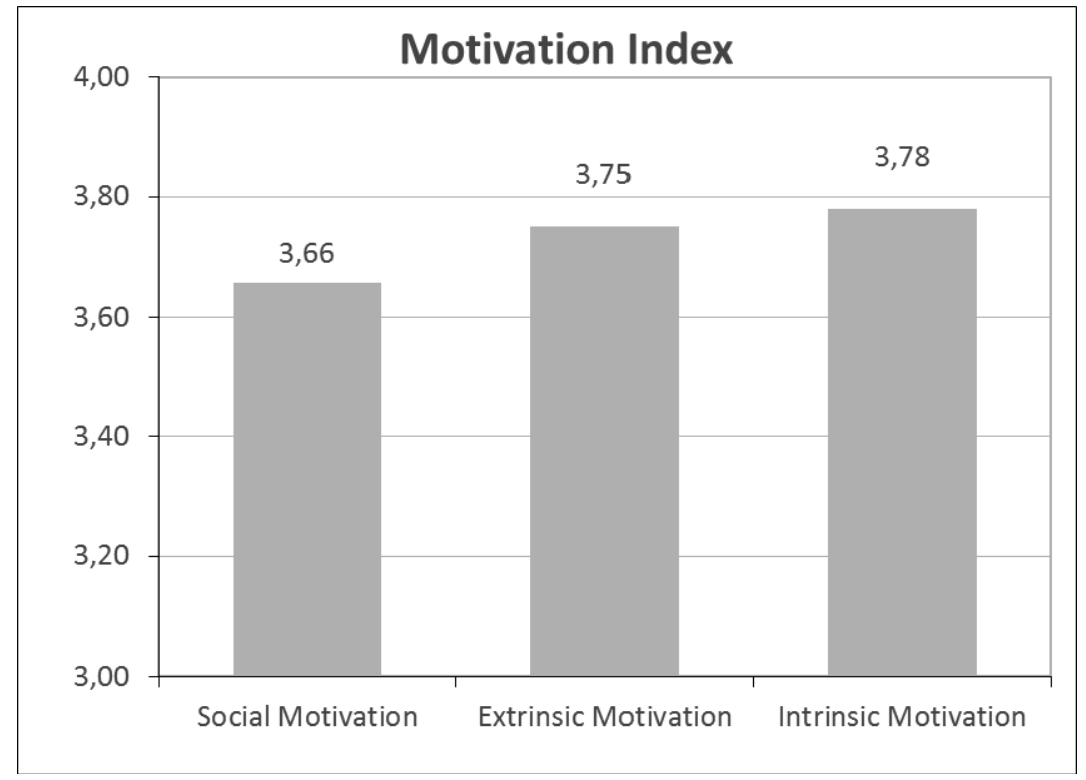

Figure 2: $\quad$ Motivation Index

The reason for investigating social motives was to analyze the importance of the role of the community. Modding is similar to open-source projects, because it takes place as long term projects in teams, where individual tasks are partitioned in a modular way and meritocratic structures develop. Accordingly, the responding modders indicated that helping each other in the community was the most important issue: to receive help from others (87.4 percent) and to help other modders (77 percent); followed by the possibility to pursue interesting discussions (80 percent), to communicate with other modders (72 percent) or to exchange information about technical aspects of the mods (68 percent). The "fun" factor (76 percent) is another very important reason to engage in the community. Less important to the respondents is the possibility to establish friendships with others or to discuss personal issues with other members of the community.

\footnotetext{
13 The motivation index was generated on the basis of 13 to 16 items, explored with a scale of five. Tests of reliability of the indices showed a high Cronbachs Alpha of 0.741 for intrinsic motives, 0.834 for extrinsic motives and 0.842 for social motives.
} 
When asked what their reason for modding is and what type of meaning modding had for them, the respondents mentioned primarily intrinsic motives, namely incentives born out of the activity itself: Creativity ( 93 percent) and creative design (91 percent), the experience of achievement (90 percent), mastery of a challenge (85 percent) and the possibility of self-fulfillment (74 percent). Less important aspects were intrinsic motives such as passing one's time, escapism and flow.

However, extrinsic motives for modding were mentioned as well. Almost 70 percent of the respondents agreed with the statement that they plan to apply their modding capabilities in their professional career. The respondents also want to use their modding experience to increase their technical know how and abilities (90 percent). In response to the question of which type of competencies are most enhanced by modding, the respondents primarily mentioned aspects of teambuilding. The items reaching the highest level of agreement were: learning to accept criticism (85 percent), to be able to voice constructive criticism (81 percent), the ability to work in teams (81 percent) and to increase one's sense of responsibility (75 percent)

The results allow a surprising conclusion: The responding modders who perform their modding activity in their free time do so not only do because modding is an end in itself. They do so with the intention to improve their social and technical competence in order to apply the acquired skills in a professional context at a later time. ${ }^{14}$ For many modders, direct full-time employment at Crytek seems to be a very desirable option, as two respondents expressed ${ }^{15}$ : "I am able to learn more on modding / programming, and may even get a future job at Crytek or other great developers." and "I want to work for Crytek in the future. Learning their tools in and out seems like the best way to accomplish this."

\section{Company perspective}

Indeed, the semi-structured interviews with selected experts at Crytek supported the fact that the modders' career aspirations would not remain dreams, but rather, they represent a quite realistic career path. Recruiting personnel from the community of modders is common practice at Crytek - presently, about 30 to 40 former members of the modding community hold positions at Crytek: "..that we frequently get people from the modding community has the simple reason that they do such a good job, they are so professional, that we say: 'They are good enough'. We should not waste such talent and therefore, we take them on. Meanwhile, we have about 30 or 40 people from the modding com-

\footnotetext{
${ }^{14}$ Initial multivariate analyses point in this direction: An explorative factor analysis to structure the data identified six factors with a total explained variance of 70 percent. The largest factors are loading on performance (leadership, teamwork, sense of responsibility and discipline) as well as on technical competence (editing, image processing, removal of bugs).

${ }^{15}$ Open response to the question: "Why did you decide to join the Crymod community?"
} 
munity, of course, accumulated after all those years, starting with Far Cry and so on and now they work at Crytek worldwide, in all our studios" (Cry1).

The clear advantage for Crytek is the fact that the modders are already trained even though they have not worked in the company yet and have acquired their competencies and abilities independently through the community: "It's a natural byproduct of running a site such as Crymod.com. It benefits us and it benefits them, when we have guys sitting on our forum who have been using our product for 3-4 years. A lot of the times it is beneficial for us, it saves us time training people up on our engine. It is very beneficial for us to get these guys on board, as soon as possible. They really have a good idea of what our engine does, what Crytek, is, what our games are. These guys really understand our community and our products inside and out" (Cry2).

\section{Crytek: Collaboration with Modders}

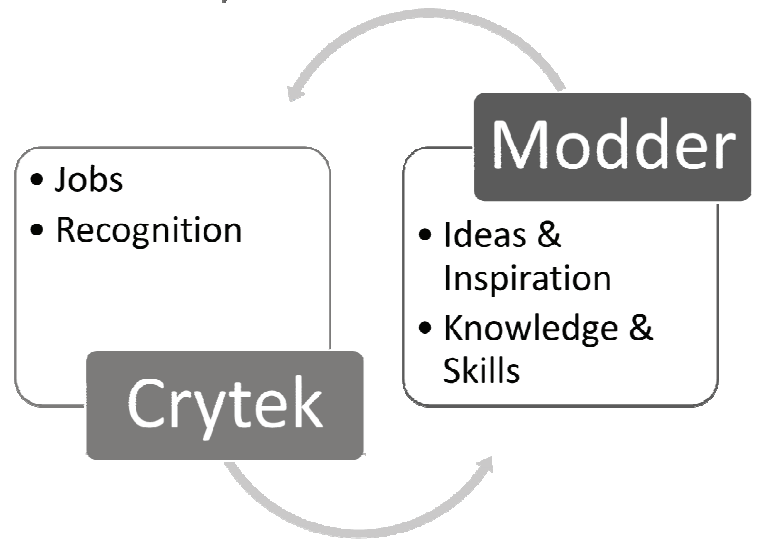

Figure 3: $\quad$ Collaboration between Crytek and the modders

The idea of creating a modding portal at Crytek came up during the development of the first game, Far Cry. It was an idea born out of hardship, because game development took up all the resources and Crytek no longer had the capacity to make the most out of their game engine. Therefore, input from the "wisdom of the crowds" (Surowiecki 2004) was appreciated. "But somehow, we had the feeling that we should be doing something in the direction of modding, because even at this early time, we had such a powerful engine and we knew we could bring out so much more with this. We don't have the time to do that, because we are working on FarCry but we can give the tools and all that stuff to the community and see what they come up with... and then we realized: Wow; this is really unbelievable, the type of stuff that people are able to produce" (Cry1).

Now, how can Crytek profit from its modding community? As the expert interviews reveal, Crytek employees benefit particularly from all the suggestions and ideas the modding community provides. Direct copying or a one-to-one takeover of an artefact created by a modder however, is not acceptable - instead the modder in question will be recruited and integrated into the team: “...but copying directly, no, 
something like that would never happen. If anything, we would hire the person. If someone were to create the mod of the century right now and it would be the best idea ever available in a game, I believe, this person would here faster than be could [blink]" (Cry3).

In the interview the game designer explains the reasons why direct copying is not an option. It is related to his work ethic: “...one-to-one takeover is not possible because there is always the problem that one wants to achieve something. I would feel very uneasy, if I were to copy something from somebody else, well, because it would simply not be mine. For me, personally that would not work and I certainly know quite a few people who think the same way, because, you know, many want to show off, want to prove themselves and they want to be able to put their name on something" (Cry3).

Instead, there are many ways in which something can be developed together with the community: be it a patch or bug fix that is developed cooperatively, the exchange of ideas and further developments at community meetings or competitions and challenges that are issued by Crytek to solve particular problems or to implement certain ideas. "...for example, we developed a patch for FarCry together with the community. That means we got the most talented artists from the community together and said "Ok, this and that is our wish-list. Do you feel like working with us on this and then publishing the complete community patch?" And that was the first collaboration of Crytek and the community for such a general patch" (Cry1).

It was apparent during the interviews that the experts' identification with the community was quite high and that there was a sense of connectedness and mutual esteem on both sides: "And if you talk directly with the people, you can see immediately how strong the emotions are, how they are all hot for the whole thing and this is absolutely great for us, just watching, because without them this entire community would not work. Really, it is that simple...the fan-sites and so on are, all these people are so unbelievably important and that's why we try and invite then as often as possible and start such events" (Cry1).

This connectedness is not only celebrated at certain events, but is part of everyday life in the Crytek community. Every Crytek employee has a forum account and can communicate with the users and modders in the different communities. Some employees even switch roles, become free-time modders and join a modding team after work. One of these modding teams received the award for "Mod of the year 2009"16. "That was truly sensational! We had hoped for it, we had wished for it, but when it really happened it was awesome. ModDB is the No. 1 modding site for the whole of the modding scene and we had been nominated! I say "we" because this is our community and we feel part of it. ... Later on we recruited two of the modders. They simply were that good. So we said: "Join us and work for us" (Cry1).

16 In 2009 both the "Editor's Choice" and the "Gamer's Choice" awards went to the Crysis-Mod

"MechWarrior: Living Legends" (http://www.mechlivinglegends.net). 
In order to keep the interaction between Crytek and the community working as fast and as smoothly as possible, Crytek engages so-called community managers, who take on the position of gatekeepers and are often recruited directly from the community. Community managers see themselves as speakers for the community within the company and as a link between the company and the active web-users. Because of the differences between the target markets of the various Crytekcommunities, the type of work of the community managers is also different for each of them: "As far as crymod.com goes, we're quite a lot keen in the way that they almost motivate themselves. I mean we tried to make sure that we offer them all of the tools, that they require and facilitate everything that they want to do, but I mean pretty much that whole website is run by people that are entbusiastic about creating games and creating their work, so the imput from our side is actually fairly minimal in terms of keeping them going, because they love doing it. So we do try to offer at least competitions to give them a kind of award and a thank-you for being there and for doing it all, but for the most part they're self-sustaining. Mycrisis.com on the other hand is pretty much where people go for the latest information and to meet other gamers and to do things like that. So from our side keeping people interested in that site is a lot more work, because we need to include lots and lots of news-updates ...". (Cry4)

In contrast to the impact of the gaming community, the impact of the modding community for Crytek is based on the fact that this is where the true hard core of self-motivated and very competent users is located. This type of user has the status of a highly specialized expert and on a social level identifies strongly with the company. So much so, that the company can eliminate certain common market risks when incorporating external knowledge or recruiting external experts by using the route over the community.

\section{Crytek: Collaboration with customers}

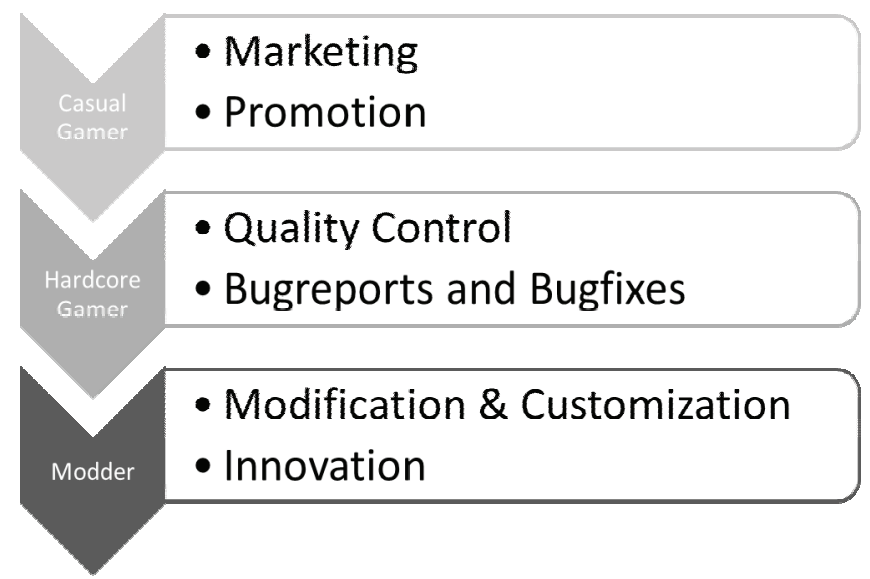

Figure 4: Levels of Collaboration with the customers 


\section{Results for the Crytek case}

The part of the project concerning Crytek has discovered a new species of customers: the modders, self-motivated and often sharing the work on modifications of computer games in highly complex team structures, be it by providing changes to the game concept, the game design or the game construction. Just as described in the theoretical concept of Bruns, modders can be understood as produsers who combine several roles and generate artifacts of content in a hybrid process between production, distribution and consumption. Here, modders have the status of experts and for companies such as Crytek they can transmit information concerning their needs as well as the solution to those needs. Because the average gamer also provides information on his or her needs, modders are particularly valued for their ability to develop new ideas or applications using the tools provided by Crytek in a new and creative way and thereby extending the solution space offered by the Cryengine. The relationship between Crytek and the modders has been described as one of interactive value creation. Interactive, because the company and the members of the community collaborate in developing modifications on existing products and innovations using the help of Web 2.0 technology and SDK tools. This has an effect on the creation of value of Crytek, since the company receives information from the community about the needs and problems as well as information concerning the solution to those needs and problems. Therefore, the scope of possible solutions provided by the Cryengine can continuously be extended. An additional result concerns the recruitment of personnel. Modders active in the community are extrinsically motivated in regard to their professional aspirations and through modding, they acquire important skills, especially technical and social competencies. These competencies match the requirements of skills and abilities of the workforce at Crytek perfectly. Thus, Crytek not only benefits from the ideas of the modders, they also follow the strategy to recruit talent from the community and integrate them into the team in order to profit from their expert knowledge and creativity.

\section{Conclusion}

The phenomenon of customer or user involvement in the value creation of companies is central to this research project. The review of the existing literature revealed clear distinctions between the materiality of the phenomenon, its specifications, its evaluation and its varying foci. The original sociological approach of the "working customer" predicts a rise in the companies' dominance over the customers, as well as an increasing economization and capitalistic takeover of the private realm. In contrast, researchers investigating innovation and the internet assume there will be a loss of relevance of the private company as an institution and an increase in relevance of collaborative community building. The economists cited here - and also some sociologists studying consumption - take up an intermediate 
position between these two extremes: They assume that companies as well as customers or user communities will be able to benefit from each other and will create a win-win situation for all participants.

The current state of research leaves questions regarding the companies' coordination of these processes and the motivation of the customers unanswered. The research team used the multitude of these approaches constructively by posing the following research question: Why do customers participate in processes of "new types of prosuming" or in "interactive value creation" and how are these processes coordinated by the firms?

Three cases were chosen to serve as examples for the diversity of the phenomena: Deutsche Bahn AG, whose main product is a service that was formerly carried out without collaboration or the working customer, has started to rely on it within the past few years: offline at the ticket machine, online or by mobile phone. IKEA is a company whose business model is based on prosuming and the working customer. Furthermore, the technical possibilities allow the customer to carry more and more of the work load. The newest example for this development are the scan-it-yourself checkouts. Lastly, Crytek is a very successful developer of computer games that relies on collaboration and systematically integrates customers and users into the processes of quality control, product modification, product development and innovation. In order to answer the research question, the inquiry was adapted to the three case studies and an appropriate theoretical approach was chosen for each. In all cases the dependent variable was a "new type of prosuming" which is web-based and involves a (quantitative and qualitative) increase in collaboration in contrast to former concepts of prosumption.

In the case of Deutsche Bahn AG the results showed that not only a large group of customers use the internet to buy tickets, it is also very frequently used to search for information before traveling. Both sides agree that the "interactivity" factor of the customers' involvement in value creation is limited. The representatives at the company's customer interfaces are very selective in the handling of the customer information and the impression arises that the company's strategies are based more on the monitoring of customers with the intention to maximize profits, rather than being based on interactive collaboration.

For the analysis of IKEA the customers" "collaboration" is so deeply anchored in the company's business model and self-concept that it is fully taken for granted and is no longer questioned by either side. At IKEA prosumption has been institutionalized. Only when trying to involve the customers in "new types of prosumption" does the company have to persuade the customers to participate. The customers are generally motivated by self-determination and fun, as well as by monetary benefits.

For Crytek the intrinsic (creativity), extrinsic (impact on career aspirations), but also social (recognition by the community, fun in the community) motives are relevant to the modders. The analysis of the company perspective shows how im- 
portant the modders' knowledge is for the development of the games - and therefore to the company's success. The company's objective is to actively support modders and eventually hire them as employees. Looking at the interaction between Crytek and its customers you notice that both sides have a good fit of needs and solutions based on a high level of commitment on both sides. As such Crytek is looked at as an open, innovative company with fluid boundaries to its external community. This fluidity is maintained purposefully and is part of the company's operating strategy.

All in all, the customers in the cases discussed generally appreciate their involvement in the process of value creation, rather than disapprove of this development. Only in the case of the Deutsche Bahn does there seem to be a dissonance between the customers' and the company's perspective, which most likely is caused by the fact that the customers' willingness to collaborate is not adequately considered by the Deutsche Bahn. In the case of the two other companies there seems to be a general consensus in regard to customer concerns and the capitalist logic of the companies' activities. Combinations of the three types of motives for collaboration become evident in each case study, depending however on the kind of need information and solution information that are looked for by the particular company, as well as on the collaboration space that is offered. Given a huge space for working together, as is the case with Crytek, broad collaboration can succeed. It can be fun to enjoy a service, but it is even more fun to be creative. Receiving social and material recognition can establish a certain kind of commitment to the company.

Collaborative practices show up as a rich field for future research: Living in an age in which individuals show an increasing willingness to offer their skills to companies without a financial reimbursement - but are still full of personal motivation - seems to become a regular pattern with considerable reach. In terms of the theoretical approaches it can be said that they have all been validated within their specific context. Nevertheless, in the future theoretical approaches need to be developed that allow for a better understanding of the reciprocity of the relationship between customers and companies.

\section{References}

Baldwin, C. Y. and Eric von Hippel. (2009). "Modeling a Paradigm Shift: From Producer Innovation to User and Open Collaborative Innovation." Ín: MIT Sloan School of Management Working Paper No. 4764-09. Cambridge: MIT.

Behr, K.-M. (2008). "Kreative Spiel(weiter)entwicklung. Modding als Sonderform des Umgangs mit Computerspielen.” In: Quandt, T., Wimmer, J. and Jens Wolling. Die Computerspieler: Studien zur Nutzung von Computergames. Wiesbaden: VS Verlag, pp. 193-207. 
Blättel-Mink, B. and Kai-Uwe Hellmann. (2010) (eds.). Prosumer Revisited: Zur Aktualität einer Debatte. Wiesbaden: VS Verlag für Sozialwissenschaften.

Bruns, A. (2007). The Future Is User-Led: The Path towards Widespread Produsage. Paper presented at Perth DAC conference, Perth, Western Australia, 15.-18. Sep. 2007.

Bruns, A. (2008). Blogs, Wikipedia, Second Life, and Beyond: From Production to Produsage. New York: Peter Lang Publishing.

Bruns, A. (2009). “Anyone Can Edit: Vom Nutzer zum Produtzer.” In: kommunikation@gesellschaft10.

http://www.sowiport.de/tomcat/journals/text/K.G/10/B3_2009_Bruns.pdf.

Bruns, A. (2010). "Vom Prosumenten zum Produtzer." In: Blättel-Mink, B. and Kai-Uwe Hellmann (eds.), Prosumer Revisited: Zur Aktualität einer Debatte. Wiesbaden: VS Verlag für Sozialwissenschaften, pp. 191-206.

Bryman, A. (2004). The Disneyization of Society. London: Sage Publications Ltd.

Chesbrough, H. (2003). Open Innovation: The New Imperative for Creating and Profiting from Technology. Harvard Business School Press.

Hanekop, H. and Volker Wittke. (2008). "Die neue Rolle der Anwender in internetbasierten Innovationsprozessen.” In: AIS-Studien, 1(1): pp. 7-28.

Hanekop, H. and Volker Wittke. (2010). "Kollaboration der Prosumenten. Die vernachlässigte Dimension des Prosuming-Konzepts.” In: Blättel-Mink, B. and Kai-Uwe Hellmann (eds.), Prosumer Revisited. Zur Aktualität einer Debatte. Wiesbaden: VS Verlag für Sozialwissenschaften, pp. 96-113.

Hanekop, H., Tasch, A. and Volker Wittke. (2001). "New Economy und Dienstleistungsqualität: Verschiebung der Produzenten- und Konsumentenrolle bei digitalen Dienstleistungen." In: SOFI-Mitteilungen 29/2001: pp. 73-91. Online-Document http://webdoc.sub.gwdg.de/edoc/le/sofi/2001_29/hanekop-wittke.pdf.

Harhoff, D., Henkel, J. and Eric von Hippel. (2003). Profiting From Voluntary Information Spillovers: How Users Benefit by Freely Revealing Their Innovations. http://userinnovation.mit.edu/papers/3.pdf.

Hellmann, K-U. (2010). "Prosumer Revisited: Zur Aktualität einer Debatte. Eine Einführung.” In: Blättel-Mink, B. and Kai-Uwe Hellmann (eds.), Prosumer Revisited. Zur Aktualität einer Debatte. Wiesbaden: VS Verlag für Sozialwissenschaften, pp. 13-48.

Howe, J. (2006). “The Rise of Crowdsourcing.” In: Wired, June 2006. http://www.wired.com/wired/archive/14.06/crowds.html.

Jeppesen, L. B. (2004). "Profiting From Innovative User Communities: How Firms Organize the Production of User Modifications in the Computer Games Industry.” In: København Center for Strategic Management and Globalization. 
http://research.cbs.dk/da/publications/profiting-from-innovative-usercommunities(6ea9f480-c020-11db-9769-000ea68e967b).html.

Kanning, T. (2010). "Spieleentwickler Crytek. Die intelligentesten Aliens kommen aus Fechenheim." In: $F A Z$ vom 01.09.2010.

http://www.faz.net/s/RubBEFA4EA6A59441D98AC2EC17C392932A/Doc $\sim$ E2A27075D84884CF8BFE388A63208F8F6 ATpl Ecommon Scontent.ht $\mathrm{ml}$ (abgerufen am 22.11.10).

Kleemann, F., Voß, G. G. and Kerstin Rieder. (2008). "Crowdsourcing und der Arbeitende Konsument." In: Arbeits- und Industriesoziologische Studien, 1(1): pp. 29-44.

Luhmann, N. (1964). Funktionen und Folgen formaler Organisation. Berlin: Duncker \& Humblot.

Piller, F., Reichwald, R. and Christopher Ihl. (2007). "Interaktive Wertschöpfung Produktion nach Open-Source-Prinzipien." In Open Source Jahrbuch 2007, pp. 87-102.

Postigo, H. (2007). "Of Mods and Modders. Chasing Down the Value of FanBased Digital Game Modifications.” In: Games and Culture 2(4): 300-313.

Reichwald R., Ihl, C., and Sascha Seifert. (2004). "Kundenbeteiligung an unternehmerischen Innovationsvorhaben. Psychologische Determinanten der Innovationsentscheidung." In: Arbeitsbericht Nr. 40 (Juni 2004) des Lehrstuhls für Betriebswirtschaftslehre - Information, Organisation und Management der Technischen Universität München.

Reichwald, R. amd Frank Piller. (2009). Interaktive Wertschöpfung: Open Innovation, Individualisierung und neue Formen der Arbeitsteilung. 2., komplett überarbeitete und aktualisierte Auflage. Wiesbaden: Gabler.

Sotamaa, O. (2007). “On Modder Labour, Commodification of Play, and Mod Competitions." In: First Monday 12/9:

http://www.uic.edu/htbin/cgiwrap/bin/ojs/index.php/fm/article/view/2006 /1881.

Steinecke, A. (2000). "Tourismus und neue Konsumkultur: Orientierungen Schauplätze - Werthaltungen.” In: Steinecke, A., Erlebnis- und Konsumwelten. München et al.: Oldenbourg.

Surowiecki, J. (2004). The Wisdom of Crowds: Why the Many Are Smarter Than the Few and How Collective Wisdom Shapes Business, Economies, Societies and Nations. New York: Doubleday.

Tacke, V. (1997). "Systemrationalisierung an ihren Grenzen Organisationsgrenzen und Funktionen von Grenzstellen in Wirtschaftsorganisationen.” In: Schreyögg, G. and Jörg Sydow (eds.), Managementforschung 7. Gestaltung von Organisationsgrenzen. Berlin: de Gruyter, pp. $2-44$. 
Toffler, A. (1980). The Third Wave. New York: Morrow.

von Hippel, E. (2005). Democratizing Innovation. MIT Press.

http://web.mit.edu/evhippel/www/-democ1.htm.

Voß, G. G. and Kerstin Rieder. (2005). Der arbeitende Kunde. Wenn Konsumenten ₹u unbezablten Mitarbeitern werden. Frankfurt: Campus. 


\title{
Role Confusion in Open Innovation Intermediary Arenas
}

\author{
Tobias Fredberg ${ }^{1}$, Maria Elmquist, Susanne Ollila and Anna Yström
}

\begin{abstract}
Intermediaries have become an increasingly important part of innovation collaboration arrangements such as open innovation. Much attention has been given to structural arrangements for open innovation, but less interest has been given to how people experience the participation in open innovation work. This chapter is based on a longitudinal case study of SAFER, an open innovation intermediary arena for research on traffic and vehicle safety. It investigates how participants in this arena experience their situation as they spend time on things typically "outside" their tasks in their home organizations. The study provides insight into the tensions and confusion that the participants experience in their work, as they constantly need to renegotiate their positions both within their home organizations, and in the relation to the intermediary arena and the other organizations.
\end{abstract}

1 Corresponding author (tobias.fredberg@chalmers.se) 


\section{Introduction}

As $R \& D$ and innovation processes are increasingly opened up to external parties, they are consonantly associated with increasing levels of collaboration. Initiatives by large companies such as Procter\&Gamble, for example, are seen as success stories in the use of external sources to innovate (Dodgson, Gann and Salter 2006; Huston and Sakkab 2006a).

New actors such as innovation intermediaries (Chesbrough 2006) have developed, functioning as marketplaces for ideas, talent and technologies. The important role of innovation intermediaries has been stressed in several recent publications (Klerkx and Leeuwis 2008; Lichtenthaler and Ernst 2008a; 2008b; Maria, Marko and Mikk, 2010; Sieg, Wallin and von Krogh 2010). As pointed out by Howells (2006) there is a range of intermediation functions. Innovation intermediaries have been described in the literature as bridgers (Bessant and Rush 1995; McEvily and Zaheer 1999), brokers (Hargadon and Sutton 1997; Provan and Human 1999) and as third parties (Mantel and Rosegger 1987). In this chapter, we focus on another distinct form of intermediary, which we call an intermediary arena: an organization that gathers competing and complementary companies within a field of expertise, and provides an arena for them to collaborate on at the same time as it negotiates their common goals.

In general, research on the human aspects of open innovation work is scarce. Our interest in this chapter therefore is to focus on the people who take part in open innovation work. Specifically, we investigate the dual role as experienced when people work in an open innovation intermediary arena while remaining employed by their home organization, with the expectation that they give their best efforts working at "the border zone" between their employer and other organizations.

To explore this dual role in open innovation work we examine the case of SAFER, an intermediary arena for research on vehicle and traffic safety, located in Gothenburg, Sweden. SAFER not only facilitates the innovation process of its partner firms by bringing them together but also has proprietary objectives. More than just a marketplace, it is also a physical place for innovation work across organizational boundaries. SAFER connects 170 people from 22 organizations to jointly conduct world-leading research and create breakthrough innovations. An important aspect of this collaboration is that the organizations working together in SAFER come from various fields, and include competitors, suppliers/customers, government institutions and pure research institutes.

Our results show that people experience confusion in their roles and that there are tensions in four specific areas. We argue that these tensions are unavoidable in open innovation in general, and in an intermediary arena in particular, but that they can also be a source of creativity if managed properly. 


\section{Theoretical Background}

As Piller, Ihl and Vossen point out in the opening chapter, open innovation has many faces. We see it as an umbrella term for collaboration between a firm and outside partners in many different parts of the innovation process. Innovation intermediaries typically enable collaboration between organizations and numerous individual experts (Chesbrough 2006). Other innovation intermediaries focus on connecting companies that want to innovate together, in what are called codevelopment partnerships (Chesbrough and Schwartz 2007). Chiaromonte (2006) argues that the difference between open innovation and traditional outsourcing of innovative capacity is that in the former, the outside partners are seen not as suppliers but as peers. The general focus seems to be on structural components or methods. There is very little written about the experiences of the people participating in these activities. Indeed, in a series of recent literature reviews on open innovation (Eklöf 2010; Elmquist, Fredberg and Ollila 2009; Fredberg, Elmquist and Ollila 2008; Giannopoulou 2009), it was found that most papers and books referring to "open innovation" concern the phenomenon itself (e.g. Chesbrough 2004; Chiaromonte 2006; Gassmann and Reepmeyer 2005; West and Gallagher 2006), commercialization issues (e.g. Lichtenthaler 2007; Lichtenthaler 2008), regional clusters (e.g. Belussi, Sammarra and Sedita 2008; Teirlinck and Spithoven 2008), organizational boundaries (e.g. Jacobides and Billinger 2006) or tools and technologies for open innovation (Dodgson et al. 2006; Huston and Sakkab 2006b; Piller and Walcher 2006; Tao and Magnotta 2006). The most recent literature also looks increasingly at the communities that drawn on when firms turn to open innovation (Bessant 2008; Dahlander and Wallin 2006; Füller, Matzler, and Hoppe 2008).

Literature reviews (Eklöf, 2010; Elmquist et al. 2009; Fredberg et al. 2008; Giannopoulou 2009) show that very few articles focus on issues of organization and leadership in open innovation work, and even fewer on the people involved. We did not find a single article focusing on role or identity confusion, and the only article published under "open innovation" that directly concerns the situation of or motivation factors for people participating in open innovation is Leimeister et al 2009, which theorizes about motives and incentives involved in the use of Internet-based tools for open innovation practices. One of the few related papers in the innovation literature focuses on the management of trust in innovation work (Davenport, Davies, and Grimes 1999), but does not focus on the collaborative aspects.

This chapter explores how people experience their dual roles when working in an intermediary arena. In role theory, it is assumed that the acquisition of role is a formal, sequential, staged process of socialization into an occupational or societal position. Two main perspectives, both focusing on role as a function, are distinguished: a constructionist perspective and an open systems perspective. From a constructionist perspective, roles perform a crucial function in the establishment of all institutionalized conduct (Berger and Luckmann 1967). Roles are considered an 
ongoing process of social construction that depends upon the interplay between a fairly predictable, static social order, and the creative actions of actors (Blumer 1969). Here, roles are conceptualized as different social 'masks' that actors may choose to adopt in their ongoing constructions of both self and society (Strauss 1969). From an open systems perspective, Katz and Kahn (1966) define role in terms of role expectations, sent role, received role and role behaviour. Enacting a role is considered a continuous cycle of sending, receiving and responding to behavioural expectations that are used to evaluate the actions of the individual occupying a specific role (Callero 1994; Stets and Burke 2000).

Working in an open innovation intermediary arena, together with actors from various fields and organizations, implies that individuals have at least two roles: one connected to the employer and one to the intermediary arena. What can we learn about open innovation work by acknowledging these dual roles and the struggles that they imply?

\section{Case and Method}

SAFER is an open innovation intermediary arena that connects 22 partners from academia, industry and government authorities that cooperate in the design of future vehicle and traffic safety systems. The organizations involved are both large actors (such as AB Volvo, Scania and Autoliv) and smaller technology organizations. The explicit vision of SAFER is "to enable Sweden to reach world leading competitiveness and to provide new countermeasures to considerably reduce both the number of traffic accidents and the number of fatalities and serious injuries" (SAFER (https://www.chalmers.se/safer/EN/about) 2010). The participating organizations have jointly agreed on the goal of increasing the transaction volume of project money in SAFER twenty-fold within ten years.

Innovation activities at SAFER are organized around four research areas: PreCrash, Crash, Post-crash and Traffic Safety Analysis, led by four research leaders (each with an attached expert reference group) who supervise and coordinate the research projects in each area. The research is multi-disciplinary in that it encompasses many different areas, from vehicle dynamics and communication technologies to bio-mechanics and human behaviour. Issues of intellectual property rights are regulated through major agreements between the participating organizations. SAFER typically engages in research in very early stages, and in the development of processes and methods, for example for simulating traffic situations and field operational tests or evaluating severe accidents. The knowledge generated in SAFER is then used separately by the companies in their respective new product development projects.

SAFER has a board of nine members, mainly from industry. The board is responsible for the overall strategy, monitors the project portfolio, decides when and whether projects are started, may request project initiation in areas not covered by 
present project portfolio, and appoints the director. Operations are led by a management group appointed by the board, consisting of the director, an information officer and the four research leaders (see above). The director is chairman of the management group, which prepares board meetings, supports the board in project portfolio management and supervises research programs and project development.

In May 2010, about 170 people were involved in projects at SAFER, while still employed by their respective organizations. Only four people work full-time for SAFER (the director and three administrative staff members). Thus almost all of the people participating in SAFER have their organizational and functional base elsewhere. In terms of their identities and careers, they belong to the partner organizations. Although the partner organizations have all expressed the absolute importance of the innovation work at SAFER and have committed resources to help the intermediary arena flourish, SAFER is not an alternative employer and does not provide the participating persons with the kind of management attention that they get in their home organization.

\section{Research approach, data collection and analysis}

The research project for this paper was set up as a joint endeavour between SAFER and the research team. Researchers and the management jointly formulated the research questions in accordance to a collaborative research approach (Shani, Mohrman, Pasmore, Stymne and Adler 2007). The study started in 2008 and is scheduled to continue for five years. Our research is exploratory and aims at creating a better understanding of how best to manage collaborative innovation work. A case study approach (Yin 1994) was chosen because the intention is not to test existing theory, but to contribute to the emerging knowledge of open innovation management in practice.

Several studies are included in the design of the research project in order to get several perspectives on how SAFER operates. The first is a longitudinal interview study with the centre director, where interviews are performed on a regular basis (one interview each month). The second is an interview study of four of the partner organizations (Volvo Cars, SAAB Automobiles, Volvo Trucks and Autoliv). A third study maps the stakeholder perspective of SAFER to investigate the various reasons for joining SAFER. A fourth study has focused on one of the projects in the project portfolio with the focus on understanding how the collaboration takes place in practice. A fifth study interviewed 27 people from 20 of the participating organizations about their work at SAFER. Furthermore, several workshops have been held on the themes of identity building, creative climate and office layout, and norms for open innovation. A total of 64 interviews have been conducted and 9 workshops have been held as of this writing (September 20 2010).

Data were analyzed thematically using a systematic combining approach (Dubois and Gadde 2002) and software for qualitative analysis (NVivo). Emerging 
results have been validated through discussions with actors within SAFER. Primary data collection was complemented with the analysis of internal documentation at SAFER.

\section{Tensions Experienced at SAFER}

In this chapter we look at how people at SAFER experience their work. In a thematic analysis of the empirical data from SAFER, four areas of tension were identified and have tentatively been labelled (1) Career, (2) Loyalty, (3) Trust and (4) Knowledge sharing. These tensions influence the work of the participating individuals, and create insecurity in their everyday decisions on where to put their best effort: in SAFER activities or in the home organizations. At SAFER, activities include working in joint projects and participating in joint seminars and conferences as well as co-creating the open innovation milieu. The actions of individuals ultimately determine how well SAFER functions as an intermediary arena. Some reports from the people interviewed are presented below as illustrations of each tension area.

\section{Career tensions}

All parties involved in SAFER have engaged to have employees spend a substantial amount of time in SAFER activities; the time commitment, however, varies among the 22 partners. The agreement assumes that the innovation collaboration only works if enough people actively participate. It is not clear, however, how the career paths of the participating organizations acknowledge participation in SAFER activities, since these are "outside" the regular organization, as expressed in the following quote:

"This project is new to me. Normally I lead research projects and that is tied to my work as an Assistant Professor. This [project] is new and a bit scary since I cannot see that I can leverage it in my research role, in my work towards becoming Associate Professor." (Participant from a university)

At the same time, it is evident to the participants that the engagement level from the partaking organisations is crucial to making SAFER work:

"It is part of our strategy to contribute to the building of collaborations like SAFER. So it would be really bad if our people did not feel that it is worth something. But I kind of wonder if anyone has used their engagement in SAFER as part of their salary negotiations." (Participant from a research institute)

A few people argue that their engagement in SAFER has been positive for their careers. They state that SAFER has provided them with new experiences and insights into research projects as well as new contacts in other organizations: 
"The network is fantastic. Other than that, I cannot claim that what we have reported back to [the home organization] has benefited me in my career. On the other hand, I have not suffered from it, either." (Participant from a partner company)

The general tendency among the respondents is to express a willingness towards and appreciation of the work in the intermediary arena, while feeling insecure about whether and how they will be rewarded for their work.

\section{Loyalty tensions}

Some of the respondents see their connection to SAFER as participating in and contributing to something bigger than their own organization:

"Because then you put on your SAFER hat and want to support the core values of SAFER, for example about competence and sharing of knowledge, and to strengthen the Swedish industry. Then you get to be bigger than only your own organization." (Participant from a partner company)

In practice this implies that the partner organizations need to manage the tensions between what they want SAFER to achieve and what they want to achieve in their home organizations:

"In the projects that I am involved in, I try to push towards not focusing on innovations. Rather I try consciously to keep them focused on methods. Because [my home organization] does not make money on methods. It is not our core business." (Participant from a partner company)

This divided loyalty also means that it is sometimes difficult for the participants to know whether they are to credit SAFER or the home organization for important results from their work - it is not always easy to know where results have originated.

\section{Trust tensions}

Another interesting aspect is that SAFER enables organizations to meet and collaborate that otherwise would have had difficulties in finding such opportunities. As expressed by a university interviewee:

"I now understand that [the participating companies] see this as an opportunity to work with each other, to go to SAFER. It is somehow a legitimate way to collaborate... Sometimes I see that they walk away and discuss by the coffee machine when I am not around. And now I understand that it is their only chance to talk in a legitimate way." (Participant from a university)

It is evident that some collaboration partners are more interesting than others. Choosing the partners within each project is therefore an essential activity that seldom is openly discussed: 
"It is like poker... the fewer we are the easier it is to put forward [ideas]. It has to do with who the parties are...we have pre-discussions at least in the areas we feel are really important and if we really want something to happen then we can see some kind of preparing bebind the scenes before meetings and we propose a more or less finished proposal." (Participant from a partner company)

This process of gathering the preferred constellation of partners can also mean that some partners are invited to participate in a project that they feel is less interesting because the right people are not involved. One member from a partner company described how they might then refuse to participate:

"It is complicated to do this kind of collaboration. We have examples of projects that we think are interesting, but the partners that want to work in the project makes the project less interesting. We do not want to do projects with certain partners, because then we don't really know where the IP created in the project will end up. So in fact sometimes we do not join a project due to wrong constellation..." (Participant from a partner company)

The mating dance that goes on to form project groups within SAFER is a sign of the different levels of trust that the partner organizations seem to have in one another, and of the tension in knowing whom to trust, although the basic premises of SAFER's existence is mutual trust, as stated in the signed agreements between the organizations.

\section{Knowledge-sharing tensions}

Within SAFER, the partners are involved in an exchange of knowledge and ideas. The assumption is that if everyone gives, everyone gains. This easily becomes a source of tension for the people in the projects:

"It is almost like a secret-service activity, you have to exchange a little. You give some and you get some. As long as you get more than you give and don't reveal anything concrete and seriously secret." (Participant from a partner company)

The tensions become a practical issue as some partner organizations, for example the research institutes, are less of a threat and are therefore more attractive as speaking partners.

'It is not like everyone says hush, hush, don't tell him or her about [corporate secrets]. It is rather so that someone sits down with you and tells you Volvo-specific information, and then someone else tells you Autoliv-related information, because the Volvo participant is not allowed to bear it." (Participant from a partner company)

A third dimension of the tension around knowledge sharing is connected to how the various partner organisations experience their position in relation to the others. As some are larger, some more specialized, the relationship in a project can be asymmetrical, which makes mutual knowledge sharing problematic: 
"For us as experts in the field, it is sometimes very hard to understand why we should join some projects. That would mainly be a case of us teaching the others, and I don't see the point of that." (Participant from a partner company)

Other interviewees report that some organizations join projects not mainly to contribute, but to understand their own competitive positions in relation to others and to then guard that position as knowledge development progresses.

\section{The tensions experienced in SAFER}

The analysis suggests that the tensions share the same dual nature. They all consist of a pull towards participation in the open innovation intermediary arena and a pull away from participation due to their affiliation with the home organization. The four tensions identified influence the work of the individuals that participate in SAFER and create insecurity in the everyday decisions on where to put their best efforts: in SAFER activities or in the home organizations. These individual choices ultimately determine how well SAFER functions.

The first tension relates to the career of the individual. As evaluations are made by the home organization it is often unclear to the individual whether and how the work at SAFER will benefit the career in the home organization. This can become a self-fulfilling prophecy - if they do not believe that they will be credited for the work, they do not put in their best effort, and the quality of the collaboration suffers. The second tension relates to loyalty. Although the individuals feel that they are contributing to something bigger than their own organization, they are often uncertain of how to balance the tradeoff between benefiting the home organization and SAFER, for example when it comes to allocating resources and crediting SAFER or the home organization for results. Third, there is a tension related to trust. Respondents from participating organisations argued that SAFER constitutes a more or less neutral arena for them to meet and work together in, to some extent neutralizing competition. However, the individuals constantly need to consider to what degree they can trust the other companies and exchange sensitive information, for instance on product plans, as is sometimes required in designing the projects. The level of trust is strongly connected to the expectations that these individuals have on the possible outcomes of SAFER. Finally, there is a tension related to knowledge sharing in SAFER, where individuals need to decide how much of their expertise they should share with the others - it has to be enough to design pertinent projects, while at the same time they want to keep any potential knowledge advantage. Also, motivations differ; some want to contribute to the generation of overall knowledge, while others are more careful with what they share and see their task rather as collecting information. 


\section{Discussion: Role Confusion in Open Innovation Intermediary Arenas}

Our aim in this chapter is to discuss the dual role that people experience working in an open innovation intermediary arena as they remain employed by their home (partner) organization, while at the same time are expected to give their best in an intermediary arena, which is by definition at the boundary between the home organization and other organizations. It seems perfectly clear to the participants that they share a collective responsibility to make SAFER succeed. Simply expressed: without the 22 partner organizations and the 170 participants, SAFER would not exist. The challenge is that SAFER is something "other" than their main responsibility in their home organization. We found tensions in four different areas, as summarized in Figure 1 below.
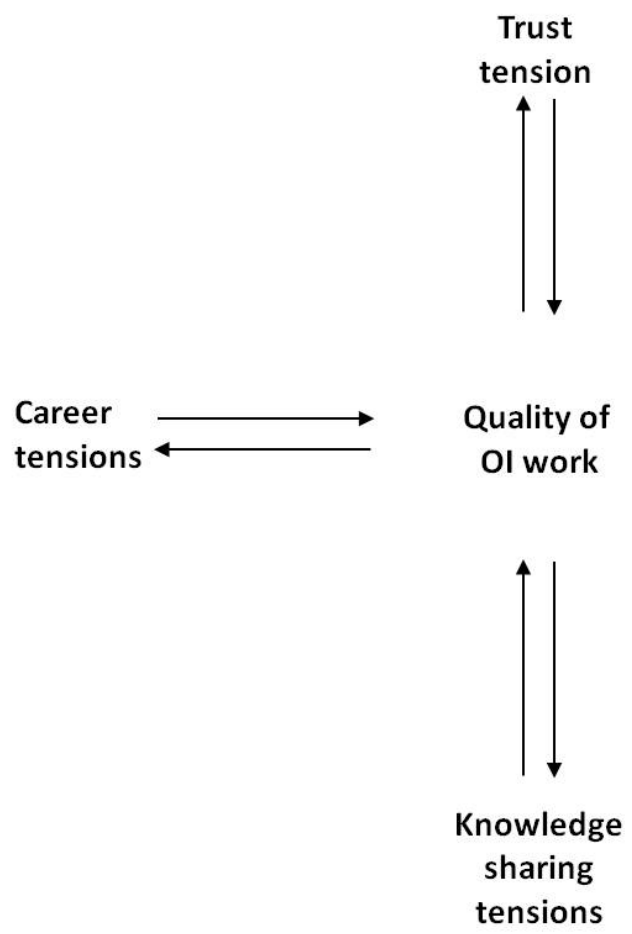

Figure 1. Tensions for people working in an open innovation intermediary arena

The analysis suggests that the tensions described share the same dual nature as that of the work itself. They all consist of a pull towards participation in the open innovation intermediary arena and a pull away from participation due their affiliation with the home organization. In our reviews of all literature published under "open innovation," (Eklöf 2010; Elmquist et al. 2009; Fredberg et al. 2008; Giannopoulou 
2009), we were unable to find any in-depth analysis of the situations for people taking part in open innovation work. Although there is some literature referring to contests (e.g. Piller and Walcher 2006), and the rewards paid to solvers by the open innovation intermediary Innocentive (Lakhani and Jeppesen 2007; Sieg et al. 2010), the tensions experienced by the people taking part in open innovation work have not been previously analyzed. This chapter presents some initial findings of what these tensions are. One way to understand how these tensions develop is to apply role theory. It seems that the roles of the participating persons are continuously constructed and re-constructed as they move between the home organization and the work in the open innovation intermediary arena. Their decisions, which deeply affect the effectiveness and efficiency of the intermediary arena, are made depending on whether they are acting based on their home organisation role or on their SAFER role. This means that merely partaking in the open innovation intermediary arena both creates the relationships to others through joint knowledge creation (Verona, Prandelli and Sawhney 2006), and organizes the process by which the participants shape their roles. The continuous cycle of sending, receiving and responding to expectations - of the others in the intermediary arena and of the home organizations - shapes the roles at the same time as it creates tensions and confusion (Callero 1994; Stets and Burke 2000).

To provide an environment that invites people to participate to their full potential, management at both the partner organizations and the intermediary arena should consider the four tensions that come with open innovation work. However, we speculate that it is not necessarily beneficial to eliminate these tensions. The work in an open innovation intermediary arena builds on the constant changing of perspectives, and of the people entering and leaving the innovation process. Eliminating the tensions would imply the creation of stable roles. This would reduce the dynamics of the setting, which would most likely reduce the productive outcomes of the intermediary arena. However, the tensions should be acknowledged and addressed, to reduce the confusion experienced by the participating individuals so that they focus less on the tensions. We conclude with the following suggestions for the management of both the intermediary arena and the partner organizations:

- Ensure that some intermediary arena activities also benefit the career at the home organization

- Clarify that contributions to the strengthening of the intermediary arena also strengthen the participating organizations

- Encourage people to spend time on social activities both at the intermediary arena and participating organizations, to build trust.

- Provide people with opportunities to create new relationships and expand their network in order to support knowledge sharing. 


\section{Acknowledgements}

The authors greatly appreciate a major research grant from Vinnova that is funding the study. Maria Elmquist is grateful to the Tom Hedelius and Jan Wallander Foundation for generous research support.

\section{References}

Belussi, F., Sammarra, A. and Sedita, S. R. (2008). "Managing long distance and localized learning in the Emilia Romagna life science cluster." In: European Planning Studies 16(5): 665-692.

Berger, P. L. and Luckmann, T. (1967). The Social Construction of Reality: A Treatise in the Sociology of Knowledge. New York: Anchor.

Bessant, J. (2008). "Dealing with discontinuous innovation: The European experience.” In: International Journal of Technology Management 42(1-2): 36-50.

Bessant, J. and Rush, H. (1995). "Building bridges for innovation: the role of consultants in technology transfer." In: Research Policy 24(1): 97-114.

Blumer, H. (1969). Symbolic Interactionism. Englewood Cliffs: Prentice Hall.

Callero, P. L. (1994). "From role-play to role-using: Understanding Role as Resource.” In: Social Psychology Quarterly 57(228-243).

Chesbrough, H. W. 2004. "Managing open innovation.” In: Research-Technology Management 47(1): 23-26.

Chesbrough, H. W. (2006). "Open Innovation: A new paradigm for understanding industrial innovation.” In: H. W. Chesbrough, W. Vanhaverbeke and J. West (Eds.), Open innovation: Researching a new paradigm. Oxford: Oxford University Press, 1-12.

Chesbrough, H. W. and Schwartz, K. (2007). "Innovating business models with co-development partnerships.” In: Research-Technology Management 50(1): 55-59.

Chiaromonte, F. (2006). "Open innovation through alliances and partnership: theory and practice.” In: International Journal of Technology Management 33(2-3): 111-114.

Dahlander, L. and Wallin, M. W. (2006). "A man on the inside: Unlocking communities as complementary assets.” In: Research Policy 35(8 SPEC. ISS.): 1243-1259.

Davenport, S., Davies, J. and Grimes, C. (1999). "Collaborative research programmes: building trust from difference." In: Technovation 19(1): 31-40.

Dodgson, M., Gann, D. and Salter, A. (2006). "The role of technology in the shift towards open innovation: the case of Procter and Gamble.” In: R $\approx D$ Management 36(3): 333-346. 
Dubois, A. and Gadde, L.-E. (2002). "Systematic combining: an abductive approach to case research.” In: Journal of Business Research 55(7): 553-560.

Eklöf, A. (2010): Open innovation in practice - A literature review of recent contributions and empirical research on open innovation. Chalmers University of Technology, Gothenburg.

Elmquist, M., Fredberg, T. and Ollila, S. (2009). "Exploring the field of open innovation: a review of research publications and expert opinions." In: European Journal of Innovation Management 12(3): 326-345.

Fredberg, T., Elmquist, M. and Ollila, S. (2008). Managing Open Innovation: Present Findings and Future Directions. Stockholm Vinnova VR 2008:02.

Füller, J., Matzler, K. and Hoppe, M. (2008). "Brand Community Members as a Source of Innovation.” In: Journal of Product Innovation Management 25(6): 608619.

Gassmann, O. and Reepmeyer, G. (2005). “Organizing Pharmaceutical Innovation: From Science-based Knowledge Creators to Drug-oriented Knowledge Brokers." In: Creativity and Innovation Management 14(3): 233-245.

Giannopoulou, E. (2009). Exploring the Concept of Open Innovation: An illustration of the recent literature, the changes in the research trends and the managerial implications of "openness". Chalmers University of Technology, Gothenburg.

Hargadon, A. and Sutton, R. I. (1997). "Technology Brokering and Innovation in a Product Development Firm.” In: Administrative Science Quarterly 42: 716-749.

Huston, L., and Sakkab, N. (2006a). "Connect and develop: Inside Procter and Gamble's new model for innovation.” In: Harvard Business Review 84(3): 58.

Huston, L., and Sakkab, N. /2006b). "Connect and develop: Inside Procter and Gamble's new model for innovation.” In: Harvard Business Review 84(3): 58-67.

Jacobides, M. G. and Billinger, S. (2006). "Designing the boundaries of the firm: From "make, buy, or ally" to the dynamic benefits of vertical architecture." In: Organization Science 17(2): 249-261.

Katz, D. and Kahn, R. L. (1966). The Social Psychology of Organizations. New York: Wiley.

Klerkx, L. and Leeuwis, C. (2008). "Balancing multiple interests: Embedding innovation intermediation in the agricultural knowledge infrastructure." In: Technovation 28(6): 364.

Lakhani, K. and Jeppesen, L. B. (2007). "Getting Unusual Suspects to Solve RandD Puzzles.” In: Harvard Business Review 85(5): 30-32.

Lichtenthaler, U. (2007). "Hierarchical strategies and strategic fit in the keep-or-sell decision." In: Management Decision 45(3): 340-359. 
Lichtenthaler, U. (2008). "Externally commercializing technology assets: An examination of different process stages." In: Journal of Business Venturing 23(4): 445-464.

Lichtenthaler, U. and Ernst, H. (2008a). "Innovation Intermediaries: Why Internet Marketplaces for Technology Have Not Yet Met the Expectations.” In: Creativity and Innovation Management 17(1): 14.

Lichtenthaler, U. and Ernst, H. (2008b). "Intermediary Services in the Markets for Technology: Organizational Antecedents and Performance Consequences." In: Organization Studies 29(7): 1003.

Mantel, S. and Rosegger, G. (1987). "The Role of Third Parties in the Diffusion of Innovations: A Survey.” In: R. Rothwell and J. Bessant (Eds.), Innovation: Adaptation and Growth. Amsterdam: Elsevier Science Publishers, pp. 123-134.

Maria, A., Marko, M. and Mikko, A. (2010). "Motivating and supporting collaboration in open innovation." In: European Journal of Innovation Management 13(1): 100.

McEvily, B. and Zaheer, A. (1999). "Bridging Ties: A Source of Firm Heterogeneity in Competitive Capabilities." In: Strategic Management Journal 20(12): 1133-1156.

Piller, F. T. and Walcher, D. (2006). "Toolkits for idea competitions: a novel method to integrate users in new product development." In: R \&D Management 36(3): 307-318.

Provan, K. G. and Human, S. E. (1999). "Organisational learning and the role of the network broker in small-firm manufacturing networks." In: A. Grandori (Ed.). Interfirm Networks: Organisation and Industrial Competitiveness. London: Routledge.

SAFER. 2010. Research for traffic and vehicle safety, Vol. 2010. Gothenburg: Chalmers University, https://www.chalmers.se/safer/EN/about, accessed Feb 11, 2010.

Shani, A. B. R., Mohrman, S., Pasmore, W. A., Stymne, B. A. and Adler, N. (2007). Handbook of Collaborative Management Research. New York: Sage.

Sieg, J., Wallin, M. and von Krogh, G. (2010). "Managerial challenges in open innovation: a study of innovation intermediation in the chemical industry." In: R\&D Management 40(3): 281.

Stets, J. E. and Burke, P. J. (2000). "Identity Theory and Social Identity Theory." In: Social Psychology Quarterly 63(3): 224-237.

Strauss, A. (1969). Mirrors and Masks: The Search for Identity. Glencoe: Free Press.

Tao, J. and Magnotta, V. (2006). "How air products and chemicals identifies and accelerates.” In: Research Technology Management 49(5): 12-18. 
Teirlinck, P. and Spithoven, A. (2008). "The spatial organization of innovation: Open innovation, external knowledge relations and urban structure." In: Regional Studies 42(5): 689-704.

Verona, G., Prandelli, E. and Sawhney, M. (2006). "Innovation and Virtual Environments: Towards Virtual Knowledge Brokers.” In: Organization Studies 27(6): 765-788.

West, J. and Gallagher, S. (2006). "Challenges of open innovation: the paradox of firm investment in open-source software.” In: R\&D Management 36(3): 319331.

Yin, R. K. (1994). Case Study Research: Design and Methods. Newbury Park, CA: Sage. 



\section{List of Contributors}

Birgit Blättel-Mink is a professor of sociology of industry and organization in the Department of Social Sciences at the University of Frankfurt. She studied in Mannheim, obtained her Ph.D. in Heidelberg and her habilitation in Stuttgart. Among other things, she has been a guest researcher at University College Cork, Ireland. Her main research foci are socio-economics of innovation, sustainable development, research in higher education, and sociology as a profession.

Dirk Dalichau studied sociology at the University of Frankfurt and is currently doing his doctorate on standardized working and consumption conditions in themed consumption settings. He is a scientific assistant in the accompanying social-scientific research on the Rhein-Main "Electromobility Model Region." In that context he develops and holds so-called prosumption workshops to involve customers in the process of innovation. He has worked in a research project on sustainable effects of used goods and the involvement of prosumption in the market of used goods.

Christian Damsgaard Jensen holds an M.Sc. in computer science from the University of Copenhagen, a Ph.D. in computer science from University of Grenoble and an M.A. from Trinity College Dublin. He is an Associate professor at the Department of Informatics and Mathematical Modelling at the Technical University of Denmark, where he teaches and conducts research in the area of security in open distributed systems. For the past 10 years, he has focused on trust-based methods and technologies to secure collaboration among entities in open distributed systems.

Niva Elkin-Koren is the dean of the University of Haifa Faculty of Law and the founding director of the Haifa Center for Law \& Technology. She received her LL.B. from Tel Aviv University Faculty of Law in 1989, her LL.M. from Harvard Law School in 1991, and her S.J.D. from Stanford Law School in 1995. Her research focuses on the legal institutions that facilitate private and public control over the production and dissemination of information. She has written and spoken extensively about the privatization of information policy, copyright law and democratic theory; the effects of cyberspace on the economic analysis of law; liability of information intermediaries; the regulation of search engines, and legal strategies for enhancing the public domain. 
Maria Elmquist is an associate professor at Chalmers University of Technology. Her current academic research is mainly focused on the management of innovation, $\mathrm{R} \& \mathrm{D}$, design activities and strategic change. Ongoing research includes projects on the development of innovative capabilities and the management of open innovation. Her research has appeared in journals such as Research Policy, R\&D Management and Creativity and Innovation Management.

Tobias Fredberg is an associate professor at Chalmers University of Technology. His research interest is in organizational renewal and its connection with innovation management and strategic change, and specifically in practices to involve and engage customers and employees in renewal processes. His recent research has appeared in journals such as the Harvard Business Review, the International Journal of Technology Management, and Long Range Planning.

Heidemarie Hanekop is a senior researcher at the Sociological Research Institute and the Department of Sociology at the University of Göttingen. She studied sociology and informatics in Göttingen. She began as a research assistant in the Department of Communication at the University of Göttingen in 1983, since 1986 she has been at the Sociological Research Institute Göttingen. Currently she is also at the Department of Sociology and a member of the Göttingen Centre for Digital Humanities at the University of Göttingen. For 15 years her research has focused on the interplay of social change and technological development, in particular in the fields of new media, mobile telecommunication and the Internet.

Sabine Hornung is a researcher on the "consumers@work" project and doctoral candidate in sociology at Chemnitz University of Technology. Her research interests are customer integration in business processes, entrepreneurship and social media.

Christoph Ihl has been an assistant professor in the TIM research group at RWTH Aachen University since October 2008. He graduated from TU Berlin and UBC Vancouver with a master's degree in engineering and business administration. He holds a Ph.D. from TU Munich for his dissertation on marketing and consumer behavior in the context of mass customized products. At the TIM group in Aachen, he coordinates the "Open Innovation Readiness" research initiative. His research focus here is on how firms should organize and leverage their internal capabilities to benefit from external knowledge sources, in general or through specific channels like innovation contests or broadcast search.

Audun Jøsang is a professor of informatics at the University of Oslo and an expert in trust management and information security. He joined Oslo University and the UNIK graduate center in March 2008 and moved to the Oslo University Department of Informatics in 2011. Prior to that he was Associate Professor at QUT, 
research leader of the Security Unit at DSTC in Brisbane, and worked in the telecommunications industry for Alcatel in Belgium and for Telenor in Norway. He was also Associate Professor at the Norwegian University of Science and Technology (NTNU). He has a master's degree in Information Security from Royal Holloway College, University of London, and a Ph.D. from NTNU in Norway.

Daniel Kahnert is a sociologist at the University of Frankfurt. He is currently doing his doctorate on the effects of open innovation on employees and organizational structure. His research fields and interests include open and user innovation and research on organizations. Recently he has been part of a research team in a project on integration of user innovation in different types of organizations.

Frank Kleemann is a lecturer in the Department of Sociology at the Chemnitz University of Technology and currently a visiting professor at the University of Frankfurt. His research activities are focused on structural changes in the social organization of work; the impact of information technologies on work and the private sphere; work-life balance issues; interactive service and communication work, and knowledge work.

Raphael Menez is a research fellow at the Institute for Social and Political Analysis, Department of Social Sciences at the University of Frankfurt. He studied sociology and political science at the Universities of Hanover and Stuttgart. He was a research assistant at the Center for Technology Assessment in BadenWürttemberg, the Institute of Social Science at the University of Stuttgart and the Institute of Political Science at the University of Tübingen. His research fields and interests include open and user innovation, prosuming, and organization science.

Susanne Ollila is an assistant professor at the Chalmers University of Technology. Her research interest is in organizational behavior, innovation management and knowledge sharing. She has published her recent research in journals such as Creativity and Innovation Management and the Journal of Knowledge Management.

Frank T. Piller is a professor of management and director of the Technology \& Innovation Management Group of RWTH Aachen University. He also is an Executive Faculty Member of the MIT Smart Customization Group at the MIT Design Lab, Massachusetts Institute of Technology. Before taking up his current position in Aachen, he worked at the MIT Sloan School of Management (2004-2007) and has been an associate professor of management at the Department of Information, Organization and Management at TUM Business School (1999-2004). At TUM, he founded and directed the "Customer-driven Value Creation" research group. During sabbaticals in 2001 and 2004, he worked as a visiting professor at the Hong Kong University of Science and Technology. 
Christian Stegbauer is currently a lecturer in sociology at the University of Frankfurt. He is the speaker for the Sociological Network Analysis section of the German Sociological Association (DFG). Research interests: Investigating the fundamentals of sociology with the aid of network analysis; communications sociology and cultural sociology.

G. Günter Voß is a full professor of Industrial Sociology and the Sociology of Technology at the Chemnitz University of Technology. His research activities are focused on the historical development of work and modern capitalism with special emphasis on subjectivity and the labor force, including work-life balance issues and the relationship between production and consumption.

Alexander Vossen has been a research associate and Ph.D. student at the RWTH Aachen University TIM Research Group since January 2009. He graduated in business administration from RWTH Aachen University in 2008. In his Ph.D. thesis he examines firm-hosted idea contests with external participants. He focuses in particular on contest design factors and their impact on the motives and behavior of specific participants.

Volker Wittke is a full professor of Sociology at the University of Göttingen and director of the Department of Sociology and president of the Sociological Research Institute Göttingen (SOFI). He is a member of the board of the Göttingen Centre for Digital Humanities at the University of Göttingen and of the board of the Sociology of Labor and Industry section of the German Sociological Association (DGS). His research focuses on globalization and the governance of global value chains, science and innovation, in particular on Internet-based innovation and production processes.

Anna Yström is a Ph.D. student at the Chalmers University of Technology. Her research topic is creativity related to collaborative, inter-organizational environments, one example of such being open innovation, and she also has an interest in design management research. Her research is forthcoming in the Journal of Technology Management \& Innovation. She has presented her research at conferences such as the International Product Development Conference, the Academy of Management Annual Meeting and the International Conference on Intellectual Capital, Knowledge Management \& Organisational Learning. 
T he Internet has enabled new forms of large-scale collaboration. Voluntary contributions by large numbers of users and co-producers lead to new forms of production and innovation, as seen in Wikipedia, open source software development, in social networks or on user-generated content platforms as well as in many firm-driven Web 2.0 services. Large-scale collaboration on the Internet is an intriguing phenomenon for scholarly debate because it challenges well established insights into the governance of economic action, the sources of innovation, the possibilities of collective action and the social, legal and technical preconditions for successful collaboration. Although contributions to the debate from various disciplines and fine-grained empirical studies already exist, there still is a lack of an interdisciplinary approach.

This book provides interdisciplinary contributions addressing questions on new innovation and production processes on the Internet, their preconditions and further prospects. It brings together the sociological perspective on the governance of collaborative production and innovation, the perspective of innovation management on open innovation, customer co-creation and open intermediary arenas, the legal perspective on social production and the perspective of computer sciences on trust and reputation management systems for Wikipedia and other online communities. It includes a social network analysis of the cooperation in Wikipedia, as well as empirical studies on the "working consumers in Web 2.0" and on motivation and coordination of "prosumers" in different firm-driven scenarios.

\section{SOFI}

Soziologisches Forschungsinstitut Göttingen an der Georg-August-Universität 